Reactor Engineering

Division

ANL/RE-97/2

Reactor Engineering

Division

Reactor Engineering

Division

Reactor Engineering

Division

Reactor Engineering

Division

Reactor Engineering

Thermophysical Properties of Uranium Dioxide

Division

Reactor Engineering

Division

Reactor Engineering

by J. K. Fink and M. C. Petri

Reactor Engineering

Division

Reactor Engineering

Division

Reactor Engineering

Division

Reactor Engineering

Division

Reactor Engineering

Division

RECEIVED

Reactor Engineering

Division

APR 221997

OSTI

Reactor Engineering

Division

Reactor Engineering

Division

Reactor Engineering

Division

Reactor Engineering

Division

Reactor Engineering

Division

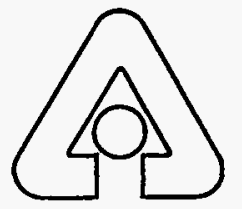

Argonne National Laboratory, Argonne, Illinois 60439

operated by The University of Chicago

for the United States Department of Energy under Contract W-31-109-Eng-38

Reactor Engineering

Division

Reactor Engineering

Division

Reactor Engineering

Division 
Argonne National Laboratory, with facilities in the states of Illinois and Idaho, is owned by the United States government, and operated by The University of Chicago under the provisions of a contract with the Department of Energy.

\section{DISCLAIMER}

This report was prepared as an account of work sponsored by an agency of the United States Government. Neither the United States Government nor any agency thereof, nor any of their employees, makes any warranty, express or implied, or assumes any legal liability or responsibility for the accuracy, completeness, or usefulness of any information, apparatus, product, or process disclosed, or represents that its use would not infringe privately owned rights. Reference herein to any specific commercial product, process, or service by trade name, trademark, manufacturer, or otherwise, does not necessarily constitute or imply its endorsement, recommendation, or favoring by the United States Government or any agency thereof. The views and opinions of authors expressed herein do not necessarily state or reflect those of the United States Government or any agency thereof.

Reproduced from the best available copy.

Available to DOE and DOE contractors from the

Office of Scientific and Technical Information

P.O. Box 62

Oak Ridge, TN 37831

Prices available from (423) 576-8401

Available to the public from the

National Technical Information Service

U.S. Department of Commerce

5285 Port Royal Road

Springfield, VA 22161 
Reactor Engineering Division

Argonne National Laboratory

9700 South Cass Avenue

Argonne, Illinois 60439

\section{THERMOPHYSICAL PROPERTIES OF URANIUM DIOXIDE}

VERSION 0 FOR PEER REVIEW

by

J. K. Fink and M. C. Petri

February 1997

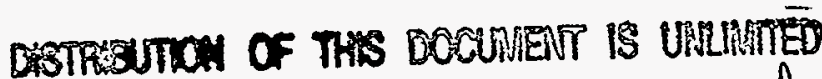
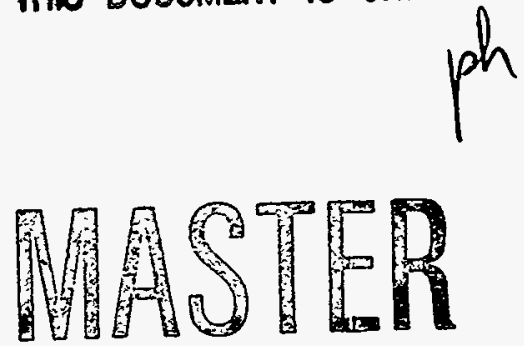


\section{DISCLAMMIER}

Portions of this document may be illegible in electronic image products. Images are produced from the best available original document. 


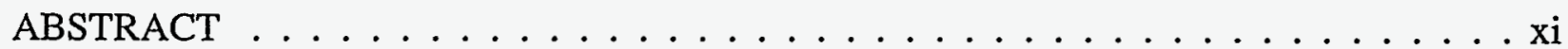

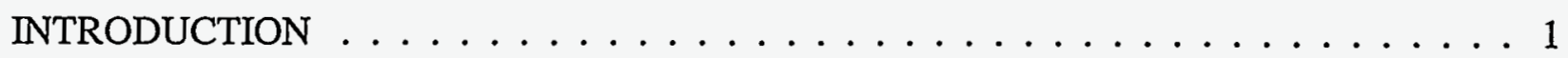

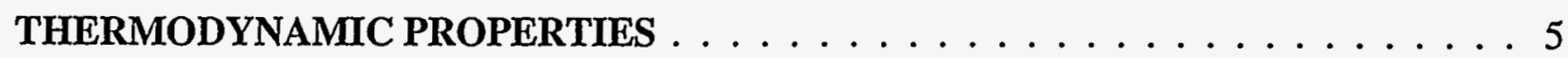

1. ENTHALPY AND HEAT CAPACITY OF URANIUM DIOXIDE . . . . . . . . . 5

.1 .1 ENTHALPY AND HEAT CAPACITY OF SOLID UO $\mathrm{UO}_{2} \ldots \ldots \ldots$

Summary and Recommended Equations $\ldots \ldots \ldots \ldots \ldots$

Uncertainties . . . . . . . . . . . . . . 7

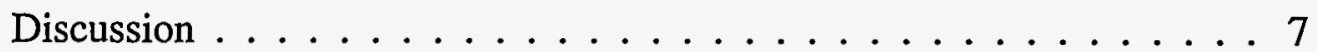

References . . . . . . . . . . . . . . 14

1.2 ENTHALPY AND HEAT CAPACITY OF LIQUD $\mathrm{UO}_{2} \ldots \ldots \ldots$

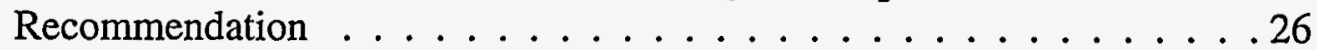

Uncertainties . . . . . . . . . . . . . . . 27

Discussion . . . . . . . . . . . . . . . . . . . .

References . . . . . . . . . . . . . . . . . 39

2. MELTING POINT OF URANIUM DIOXIDE . . . . . . . . . . . . . 51

Recommendation . . . . . . . . . . . . . . 51

Discussion of Recommendation and Effects of Burnup . . . . . . . . .51

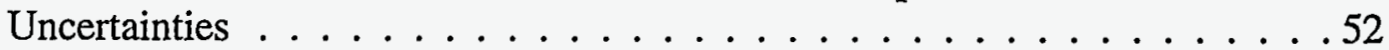

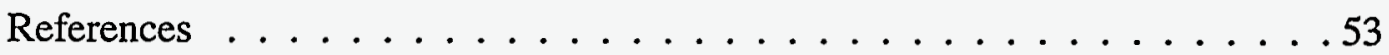

3. ENTHALPY OF FUSION OF URANIUM DIOXIDE . . . . . . . . . . . . 54

Recommendation . . . . . . . . . . . . . . . . 54

Discussion of Recommendation . . . . . . . . . . . . . . .54

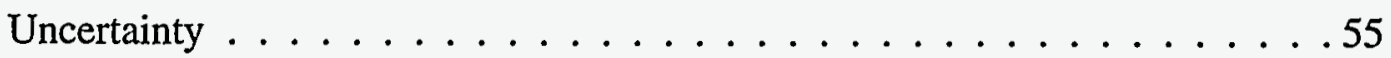

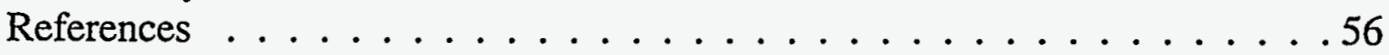

4. THERMAL EXPANSION AND DENSITY OF URANIUM DIOXDE $\ldots \ldots \ldots 57$

4.1 THERMAL EXPANSION OF SOLID UO $\mathrm{UO}_{2} \ldots \ldots \ldots \ldots \ldots . \ldots . \ldots . \ldots$

Summary and Recommended Equations $\ldots \ldots \ldots \ldots 7$

Uncertainties . . . . . . . . . . . . . . . . . . 58

Discussion of Recommended Equations for $\mathrm{UO}_{2} \ldots \ldots$. . . . . . 59

Comparison of $\mathrm{UO}_{2}$ Recommendation with Previous

Recommendations . . . . . . . . . . . . 60

Discussion of Hyperstoichiometric Uranium Dioxide $\left(\mathrm{UO}_{2+\times}\right) \ldots \ldots 61$

References . . . . . . . . . . . . . . . . 62 


\section{TABLE OF CONTENTS}

(contd)

Page

4.2 DENSITY OF SOLID $\mathrm{UO}_{2} \ldots \ldots \ldots \ldots \ldots \ldots$

Recommended Equations . . . . . . . . . . . . . . 74

Uncertainties . . . . . . . . . . . . . . . . . . . . . . . . . . . . . . . . .

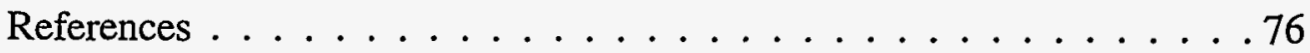

4.3 THERMAL EXPANSION COEFFICIENT OF LIQUID UO $\mathrm{UO}_{2} \ldots \ldots$

Recommended Equations . . . . . . . . . . . . . . . . . . 79

Uncertainties . . . . . . . . . . . . . . . . . . . . . . . . . . . . . . . . . . . . . .

Discussion of the Recommended Equation . . . . . . . . . . . . . . . . . . . .

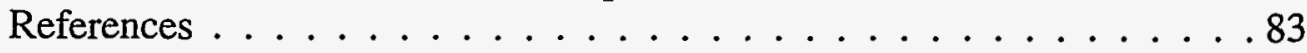

4.4 DENSITY OF LIQUID $\mathrm{UO}_{2} \ldots \ldots \ldots \ldots \ldots \ldots$

Recommended Equation . . . . . . . . . . . . . . . . . . . . . . . . . . . . . .

Uncertainties . . . . . . . . . . . . . . . . . . . . . . . . . . . . . . . . . . . . .

Discussion of Recommended Equation . . . . . . . . . . . . . . . . . . . . .

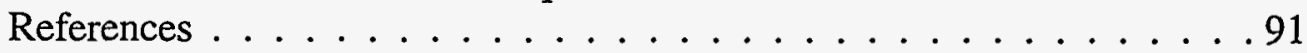

4.5 DENSTTY AND THERMAL EXPANSION RELATIONS . . . . . . . . . . 96

5. SURFACE TENSION AND SURFACE ENERGY OF

URANIUM DIOXIDE . . . . . . . . . . . . . . . . . . . . . . . . . . . . . . . . . . . . . . . . . . .

Summary and Recommendation . . . . . . . . . . . . . . . . . . . . . . . . . . . . . . . .

Uncertainties . . . . . . . . . . . . . . . . . 100

Discussion . . . . . . . . . . . . . . . . 101

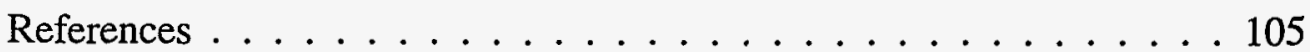

6. VAPOR PRESSURE OF URANIUM DIOXIDE . . . . . . . . . . . . . . 110

Summary of Recommendations . . . . . . . . . . . . . . . . . . . . . . . . . . . . . . .

Uncertainties . . . . . . . . . . . . . . . . 111

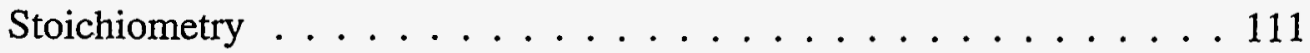

Discussion: Vapor Pressure over Liquid $\mathrm{UO}_{2} \ldots \ldots \ldots 11$

Discussion: Vapor Pressure over Solid $\mathrm{UO}_{2} \ldots \ldots . \ldots 116$

References ....................... . . 119 


\section{TABLE OF CONTENTS}

(contd)

$\underline{\text { Page }}$

TRANSPORT PROPERTIES $\ldots \ldots \ldots \ldots$. . . . . . . . . . . . 133

7. THERMAL CONDUCTIVITY AND DIFFUSIVITY OF URANIUM DIOXIDE . . 133

7.1 THERMAL CONDUCTIVITY OF SOLID UO $\mathrm{O}_{2} \ldots \ldots \ldots \ldots \ldots$

Summary and Recommended Equation . . . . . . . . . . . . 133

Uncertainties . . . . . . . . . . . . . . . . . . . 133

Discussion of Recommendation . . . . . . . . . . . . . . . . 134

Comparison with Recommendation . . . . . . . . . . . . 137

Effect of Porosity . . . . . . . . . . . . . . . . . . 139

References . . . . . . . . . . . . . . . . . . . . 142

7.2 THERMAL CONDUCTIVITY AND DIFFUSIVITY OF LIQUID UO $\mathrm{O}_{2} \ldots 150$

Preliminary Recommendation . . . . . . . . . . . . . . . 150

Experiments . . . . . . . . . . . . . . 150

Discussion . . . . . . . . . . . . . . . 154

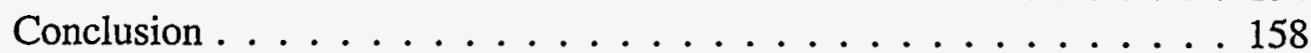

Uncertainty . . . . . . . . . . . . . . . 158

References . . . . . . . . . . . . . . . . . . . 159

8. VISCOSITY OF LIQUID URANIUM DIOXIDE . . . . . . . . . . . . . . 163

Summary and Recommendation . . . . . . . . . . . . . . . 163

Uncertainties . . . . . . . . . . . . . . . . . . . 163

Discussion . . . . . . . . . . . . . . . 163

References . . . . . . . . . . . . . . . . 165

9. EMISSIVITY AND OPTICAL CONSTANTS OF URANIUM DIOXIDE . . . . . 169

Summary of Recommendations . . . . . . . . . . . . . . . 169

Uncertainties . . . . . . . . . . . . . . . . . . . . 170

Discussion . . . . . . . . . . . . . . . . 170

References . . . . . . . . . . . . . . . . 174

ACKNOWLEDGMENTS . . . . . . . . . . . . . . . . . 181 


\section{LIST OF FIGURES}

$\underline{\text { Page }}$

Figure No.

1. $\quad 1.1 .1$ Enthalpy of Solid $\mathrm{UO}_{2} \ldots \ldots \ldots \ldots$

1.1.2 Recommended Heat Capacity of Solid $\mathrm{UO}_{2}$ with Uncertainties . . . . . . . 19

1.1.3 Heat Capacity of Solid $\mathrm{UO}_{2}$ Calculated by Ronchi and Hyland . . . . . . . . 20

1.1.4 Comparison of Equations for the Heat Capacity of Solid $\mathrm{UO}_{2} \ldots \ldots . . .21$

1.1.5 Comparison of Equations for the Enthalpy of Solid $\mathrm{UO}_{2} \ldots \ldots . \ldots 22$

1.1.6 $\mathrm{UO}_{2}$ Enthalpy Data Deviations from the MATPRO Equation . . . . . . . . 23

1.1.7 Enthalpy Data Deviations from the Equations of Harding et al. . . . . . . . 24

1.1.8 $\mathrm{UO}_{2}$ Enthalpy Data Deviations from Equations of Fink et al. . . . . . . . . 25

1.2.1 Recommended Values for the Enthalpy of Liquid $\mathrm{UO}_{2} \ldots \ldots$. . . . . . 43

1.2.2 Liquid $\mathrm{UO}_{2}$ Heat Capacity . . . . . . . . . . . . . . . . . 44

1.2.3 Fit of the Enthalpy of Liquid $\mathrm{UO}_{2}$ by Linear Equation of Rand et al. . . . . .45

1.2.4 Liquid $\mathrm{UO}_{2}$ Heat Capacity Measurements of Ronchi et al. . . . . . . . . . 46

1.2 .5 Liquid Density of $\mathrm{UO}_{2} \ldots \ldots \ldots \ldots \ldots$

1.2.6 Comparison of Equations for the Enthalpy of Liquid $\mathrm{UO}_{2} \ldots \ldots . \ldots$

1.2.7 Comparison of Equations for the Heat Capacity of Liquid $\mathrm{UO}_{2} \ldots$. . . . . . 49

1.2 .8 Liquid $\mathrm{UO}_{2}$ Heat Capacity . . . . . . . . . . . . . . . . . . . . . .

4. $\quad 4.1 .1$ Recommended $\mathrm{UO}_{2}$ Linear Thermal Expansion, $\Delta \mathrm{L} / \mathrm{L}_{273} \ldots \ldots 6$

4.1.2 $\mathrm{UO}_{2}$ Instantaneous Linear Thermal Expansion Coefficient . . . . . . . . 67

4.1.3 Recommended $\mathrm{UO}_{2}$ Thermal Expansion Compared with

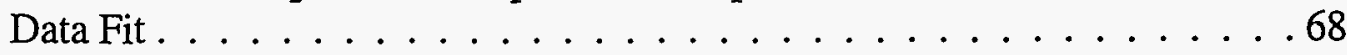

4.1.4 Deviations of $\mathrm{UO}_{2}$ Linear Thermal Expansion Data from Recommendation ...................669

4.1.5 Comparison of $\mathrm{UO}_{2}$ Thermal Expansion Eqs. of Martin and of Momin et al. . . . . . . . . . . . . . . . . . . 70

4.1.6 Comparison of Recommended $\mathrm{UO}_{2}$ Thermal Expansion with Previous Recommendation and Data of Christensen, Conway, and Hutchings . . . . 71 


\section{LIST OF FIGURES}

(contd)

Page

4.1.7 Comparison of Recommended $\mathrm{UO}_{2}$ Linear Thermal Expansion Coefficient of Martin with Previous Recommendation . . . . . . . . . . 72

4.1.8 $\mathrm{UO}_{2+\mathrm{x}}$ Thermal Expansion Data Compared with Recommendation . . . . . . 73

4.2.1 Density of Solid $\mathrm{UO}_{2} \ldots \ldots \ldots \ldots \ldots$. . . . . . . . . . . .

4.3.1 Coefficient of Thermal Expansion for Liquid $\mathrm{UO}_{2} \ldots \ldots \ldots$. . . . . 85

4.3.2 Deviations from (U,Pu) $\mathrm{O}_{2}$ Liquid Thermal Expansion of Breitung \& Reil . . . . . . . . . . . . . . . . 86

4.4.1 Liquid Density of $\mathrm{UO}_{2} \ldots \ldots \ldots$. . . . . . . . . . . 93

4.4.2 Liquid Density of $\mathrm{UO}_{2} \ldots \ldots$. . . . . . . . . . . . . . . . . 94

4.4.3 Deviations from $(\mathrm{U}, \mathrm{Pu}) \mathrm{O}_{2}$ Liquid Density Eq. of Breitung \& Reil . . . . . 95

5. $\quad 5.1$ Comparison of Published Data on Surface Energy of Solid $\mathrm{UO}_{2} \ldots \ldots$

5.2 Corrections by Hall et al. to $\mathrm{UO}_{2}$ Surface Energy Data . . . . . . . . . . . 108

5.3 Surface Energy of Solid $\mathrm{UO}_{2}$ of Hall et al. and Corrected Data . . . . . . . 109

6. $\quad 6.1$ Total Vapor Pressure Over Liquid $\mathrm{UO}_{2} \ldots \ldots \ldots \ldots$

6.2 Vapor Pressure Over Solid $\mathrm{UO}_{2} \ldots \ldots \ldots \ldots \ldots$

6.3 Comparison of Liquid $\mathrm{UO}_{2}$ Heat Capacity Data and Equations _ . . . . . 129

6.4 Total Vapor Pressure Over Liquid UO $U_{2} \ldots \ldots \ldots$

$6.5 \quad$ Vapor Pressure Over Solid $\mathrm{UO}_{2} \ldots \ldots \ldots \ldots \ldots$

6.6 Vapor Pressure Over $\mathrm{UO}_{2}$ at Solid/Liquid Interface $\ldots \ldots \ldots \ldots$

7. 7.1.1 Recommended Thermal Conductivity of Solid $\mathrm{UO}_{2}$ with Uncertainties . . . 146

7.1.2 Comparison of Equations for the Thermal Conductivity of Solid $\mathrm{UO}_{2} \ldots \ldots \ldots \ldots \ldots \ldots \ldots$

7.1.3 Deviations from $\mathrm{UO}_{2}$ Thermal Conductivity Eq. of Harding \& Martin . . . . . . . . . . . . . . . . . . . . . . 148

7.1 .4 Thermal Conductivity of $\mathrm{UO}_{2} \ldots \ldots \ldots \ldots$ 


\section{LIST OF FIGURES}

(contd)

Page

$7.2 .1 \mathrm{UO}_{2}$ Thermal Diffusivity . . . . . . . . . . . . . . . . . . 161

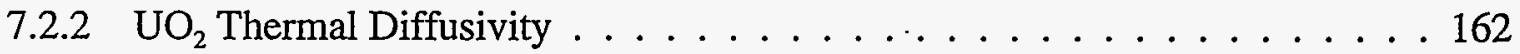

8. $\quad 8.1 \quad$ Viscosity of Liquid $\mathrm{UO}_{2} \ldots \ldots \ldots \ldots$

8.2 Viscosity of Liquid $\mathrm{UO}_{2} \ldots \ldots \ldots \ldots$

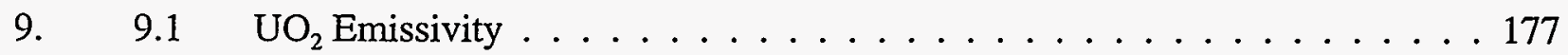

9.2 Average Refractive Index of $\mathrm{UO}_{2} \ldots \ldots \ldots \ldots \ldots$

9.3 Average Refractive Index of $\mathrm{UO}_{2}$ from Measurements of Bober et al. . . . 179

9.4 Average $\mathrm{UO}_{2}$ Absorption Coefficient from Measurements of

Bober et al. . . . . . . . . . . . . . . . . . . . 180 


\section{LIST OF TABLES}

$\underline{\text { Page }}$

1. $\quad 1.1 .1$ Enthalpy and Heat Capacity of $\mathrm{UO}_{2}$ per mole of $\mathrm{UO}_{2} \ldots \ldots \ldots$

1.1.2 Enthalpy and Heat Capacity of $\mathrm{UO}_{2}$ per $\mathrm{kg}$ of $\mathrm{UO}_{2} \ldots \ldots \ldots \ldots$

1.2.1 Enthalpy and Heat Capacity of Liquid $\mathrm{UO}_{2}$ per mole of $\mathrm{UO}_{2} \ldots \ldots$. . . 41

1.2.2 Enthalpy and Heat Capacity of Liquid $\mathrm{UO}_{2}$ per $\mathrm{kg}$ of $\mathrm{UO}_{2} \ldots \ldots \ldots$

4. $\quad 4.1 .1$ Recommended Linear Thermal Expansion of $\mathrm{UO}_{2} \ldots \ldots \ldots 4$

4.1.2 Recommended Volumetric Thermal Expansion of $\mathrm{UO}_{2} \ldots \ldots \ldots$

4.2.1 Density of Solid Uranium Dioxide . . . . . . . . . . . . . . . 77

4.3.1 Density and Volumetric Thermal Expansion Coefficient for Liquid $\mathrm{UO}_{2} \ldots \ldots \ldots \ldots \ldots \ldots$

4.4.1 Density of Liquid $\mathrm{UO}_{2} \ldots \ldots \ldots . \ldots \ldots 2$

5. 5.1 Measurements of the Surface Tension of Liquid $\mathrm{UO}_{2}$ at the Melting Point $\ldots \ldots \ldots \ldots \ldots \ldots \ldots$

6. 6.1 Total Vapor Pressure Over Liquid $\mathrm{UO}_{2} \ldots \ldots \ldots$

6.2 Vapor Pressure Over Solid $\mathrm{UO}_{2}$ Calculated from Equations of Ackermann et al. and of Tetenbaum and Hunt . . . . . . . . . 124

$6.3 \quad$ Vapor Pressure Measurements Over Liquid $\mathrm{UO}_{2} \ldots \ldots \ldots$

6.4 Measurements of the Vapor Pressure of $\mathrm{UO}_{2}$ at $2150 \mathrm{~K} \ldots \ldots \ldots$

7. 7.1.1 Recommended Thermal Conductivity of Theoretically Dense $\mathrm{UO}_{2} \ldots \ldots 145$

7.2.1 Thermal Conductivity of Liquid $\mathrm{UO}_{2}$ from Measurements of Thermal Diffusivity and Thermal Conductivity . . . . . . . . 151

7.2.2 Thermal Diffusivity of Liquid $\mathrm{UO}_{2}$ from Measurements of Thermal Diffusivity and Thermal Conductivity . . . . . . . 156

8. 8.1. Viscosity of Liquid Uranium Dioxide . . . . . . . . . . . . 166

9. 9.1 Normal Spectral Emissivity of Premelted $\mathrm{UO}_{2}$ at $\lambda=630 \mathrm{~nm} \ldots \ldots \ldots$

9.2 Normal Spectral Emissivity of Liquid $\mathrm{UO}_{2}$ at $\lambda=630 \mathrm{~nm} \ldots \ldots$ 


\title{
THERMOPHYSICAL PROPERTIES OF URANIUM DIOXIDE \\ VERSION 0 FOR PEER REVIEW
}

by

J. K. Fink and M. C. Petri

\begin{abstract}
Data on thermophysical properties of solid and liquid $\mathrm{UO}_{2}$ have been reviewed and critically assessed to obtain consistent thermophysical property recommendations for inclusion in the International Nuclear Safety Center Database on the World Wide Web (http://www.insc.anl.gov.). Thermodynamic properties that have been assessed are enthalpy, heat capacity, melting point, enthalpy of fusion, thermal expansion, density, surface tension, and vapor pressure. Transport properties that have been assessed are thermal conductivity, thermal diffusivity, viscosity, and emissivity. Summaries of the recommendations with uncertainties and detailed assessments for each property are included in this report and in the International Nuclear Safety Center Database for peer review. The assessments includes a review of the experiments and data, an examination of previous recommendations, the basis for selecting recommendations, a determination of uncertainties, and a comparison of recommendations with data and with previous recommendations.' New data and research that have led to new recommendations include thermal expansion and density measurements of solid and liquid $\mathrm{UO}_{2}$, derivation of physically-based equations for the thermal conductivity of solid $\mathrm{UO}_{2}$, measurements of the heat capacity of liquid $\mathrm{UO}_{2}$, and measurements and analysis of the thermal conductivity of liquid $\mathrm{UO}_{2}$.
\end{abstract}




\section{INTRODUCTION}

\section{BACKGROUND ON THE INSC DATABASE}

The International Nuclear Safety Center (INSC) has been established at Argonne National Laboratory to promote continuing improvement in nuclear safety and nuclear technology through collaboration in research, analyses, and development and through the open exchange of nuclear safety information. As an integral part of the INSC, the International Nuclear Safety Center Database has been established to provide an open exchange of safety data, tools, and information needed for reactor safety analyses and to support plant safety evaluation activities. Information in the database is maintained with the Oracle Relational Database Management System. An Internet interface provides international interactive access to the INSC Database via standard World Wide Web browsers. The INSC Database is located on the World Wide Web at http://www.insc.anl.gov.

Information that is being added to the INSC Database includes:

(1) thermophysical and mechanical properties of reactor materials for safety analyses;

(2) plant-specific operating, and design data;

(3) bibliography of available safety evaluations and risk assessments;

(4) documentation on computer codes, analysis methods, and input data for codes;

(5) network links to other information sources and databases.

\section{MATERIAL PROPERTIES INCLUDED IN THE INSC DATABASE}

One role of the INSC Database is to provide recommended thermophysical and mechanical property data of water reactor materials for normal operation, accident, and severe accident conditions. Materials that have been identified for inclusion in the database are:

Fuel: $\quad \mathrm{UO}_{2}, \mathrm{UO}_{2}-\mathrm{PuO}_{2}, \mathrm{UO}_{2}-\mathrm{Gd}_{2} \mathrm{O}_{3}$, Irradiated $\mathrm{UO}_{2}$, SIMFUEL, $\left(\mathrm{UO}_{2} / \mathrm{PuO}_{2}\right)-\mathrm{ThO}_{2}$, $\mathrm{PuO}_{2}-\mathrm{ZrO}_{2}$, and $\operatorname{Cermet}\left(\mathrm{UO}_{2}-\mathrm{Zr}\right)$;

Cladding: Zirconium alloys (Zircaloy-2, Zircaloy-4), $\mathrm{Zr}-\mathrm{Nb}$ alloys $(\mathrm{Zr}-1 \% \mathrm{Nb}, \mathrm{Zr}-2.5 \% \mathrm{Nb}$, $\mathrm{Zr}-3 \% \mathrm{Nb})$;

Absorbers: Ag-In-Cd, $\mathrm{B}_{4} \mathrm{C}$; 
Structural Materials: $\quad$ LWR vessel materials (e.g. stainless steels),

VVER vessel materials,

HWR pressure tube materials $(\mathrm{Zr}-2.5 \% \mathrm{Nb})$,

HWR calandria tube materials (Zircaloy-2),

steam generator materials (Inconels);

Liquid Mixtures: $\quad$ combinations of $\mathrm{UO}_{2}, \mathrm{Zr}, \mathrm{ZrO}_{2}$, stainless steel, absorber materials, concrete Concrete: limestone/common sand, siliceous, limestone.

Properties identified for inclusion in the database are most thermodynamic, transport, and mechanical properties. However, not all properties would be included for each material. Selection would be based on need for reactor safety calculations and risk assessments. Possible properties are listed below:

Thermodynamic Properties:

enthalpy,

heat capacity,

density,

thermal expansion,

solidus/liquidus and/or melting point,

enthalpy of fusion,

vapor pressure,

boiling point,

enthalpy of vaporization,

surface tension, and

phase diagram information for mixtures.

Transport Properties:

thermal conductivity,

thermal diffusivity,

viscosity, 
emissivity, and

electrical conductivity.

Mechanical Properties:

Young's modulus,

shear modulus,

Poisson's ratio,

flow stress,

yield strength,

tensile strength,

creep strength, and

biaxial creep rupture strength.

A survey of material property needs of analysts and experimenters doing reactor safety research at Argonne National Laboratory has been used to rank the material properties for inclusion in the INSC database. This ranking has set the order of assessment. Selected thermodynamic and transport properties of $\mathrm{UO}_{2}$ were ranked the highest.

\section{CRITICAL ASSESSMENT AND PEER REVIEW PROCESS}

The material property recommendations in the INSC database are based on the following critical assessment of the material property data and peer review process:

(1) collection and critical assessment of all available property data;

(2) recommendation of equations (which requires assessment of existing recommendations and, when appropriate, development of new equations by fitting data);

(3) comparison of recommendations with previous recommendations;

(4) determination of the uncertainties in recommended equations from errors in fitting the data, uncertainties in the data, and uncertainties in the theory used to fit the data;

(5) inclusion of recommendations in the database for peer review (version 0 );

(6) international peer review of recommendations;

(7) iteration of steps 2 through 6 until a consensus is reached;

(8) inclusion of peer reviewed recommendation in the database (version 1). 
As new data or new theories relevant to any material property in the database become available, the critical assessment and peer review process, outlined above, will be repeated so that the recommendations in the database remain current.

For the $\mathrm{UO}_{2}$ thermophysical properties, critical assessments through step 5 (given above) have been completed. These assessments and recommendations are ready for peer review. They are available in the INSC database and have been documented in this report to facilitate the peer review process. All information relevant to each material property has been included under each material property in the INSC database and in each subsection of this report so that the reviewer or user needs only read the subsection for the property being reviewed. All tables and graphs given in this report are available in the INSC Database. The graphs in the INSC Database are in color for ease of identification of data and curves. Peer review comments may be sent to the main author of this report by mail or by electronic mail at the electronic mail address given at the bottom of each page in the material property section of this report.

\section{REPORT ORGANIZATION}

This report has been organized by thermophysical property. Thermodynamic properties of solid and liquid $\mathrm{UO}_{2}$ are given in the first six sections. These sections cover enthalpy and heat capacity, melting point, enthalpy of fusion, thermal expansion and density, surface tension, and vapor pressure. Transport properties are given in the last three sections. Section 7 includes solid and liquid thermal conductivity and thermal diffusivity. Section 8 covers liquid viscosity. Section 9 covers emissivity and optical constants. When appropriate, sections are subdivided into solid and liquid properties. The section on thermal expansion and density is divided into five subsections that cover solid thermal expansion, solid density, liquid thermal expansion, liquid density, and thermodynamic relations between density and thermal expansion. The subsections for each property include a summary with recommended equation, uncertainties in the recommendation, recommended property values tabulated as a function of temperature (when appropriate), a graph of the recommendation with uncertainties, a detailed discussion of the assessment and recommendation, and a list of references. The summary is given first so that users of the INSC database not interested in the details of the assessment will be able to locate property data quickly. 


\section{THERMODYNAMIC PROPERTIES}

\section{ENTHALPY AND HEAT CAPACITY OF URANIUM DIOXIDE \\ 1.1 ENTHALPY AND HEAT CAPACITY OF SOLID UO $\mathrm{UO}_{2}$}

Summary and Recommended Equations

Recommended equations for the enthalpy and heat capacity of solid $\mathrm{UO}_{2}$ are from the assessment by Fink et al. ${ }^{1-3}$ of the experimental enthalpy data ${ }^{4-10}$ from 483 to $3112 \mathrm{~K}$ and the heat capacity data ${ }^{11-16}$ from 5 to $1006 \mathrm{~K}$ and from the assessment by Harding et al. ${ }^{17} \mathrm{The}^{\mathrm{UO}} \mathrm{O}_{2}$ phase transition at $2670 \mathrm{~K}$, included in these equations, has been confirmed by high-temperature neutron diffraction and scattering experiments reported by Hutchings et al. ${ }^{18-19}$ and by thermal analysis of $\mathrm{UO}_{2 \pm \mathrm{x}}$ cooling curves from 2300 to $3000 \mathrm{~K}$ by Hiernaut et al. ${ }^{20}$ Thermal analysis of cooling curves for stoichiometric $\mathrm{UO}_{2.00}$ indicated a second order $\lambda$-transition peak at $2670 \mathrm{~K}$. Cooling curves of substoichiometric uranium dioxide $\left(\mathrm{UO}_{2-\mathrm{x}}\right)$ indicated a first order $\lambda$-transition whose temperature varied with stoichiometry while no transition was observed in cooling curves of $\mathrm{UO}_{2+\mathrm{x}}$.

The equations of Fink et al. for the enthalpy of $\mathrm{UO}_{2}$ relative to the enthalpy at $298.15 \mathrm{~K}$ are For $298.15 \mathrm{~K} \leq \mathrm{T} \leq 2670 \mathrm{~K}$,

$$
\begin{aligned}
H(T)-H(298.15 K)= & C_{1} \theta\left[\left(e^{\theta / T}-1\right)^{-1}-\left(e^{\theta / 298.15}-1\right)^{-1}\right] \\
& +C_{2}\left[T^{2}-(298.15)^{2}\right] \\
& +C_{3} k\left(T e^{-E_{d} / k T}-298.15 e^{-E_{d} / k 298.15}\right)
\end{aligned}
$$

where

$$
\begin{aligned}
& \theta=516.12 \mathrm{~K}, \\
& \mathrm{C}_{1}=78.215 \mathrm{~J} \cdot \mathrm{mol}^{-1} \cdot \mathrm{K}^{-1}, \\
& \mathrm{C}_{2}=3.8609 \times 10^{-3} \mathrm{~J} \cdot \mathrm{mol}^{-1} \cdot \mathrm{K}^{-2}, \\
& \mathrm{C}_{3}=3.4250 \times 10^{8} \mathrm{~J} \cdot \mathrm{mol}^{-1} \cdot \mathrm{eV}^{-1}, \\
& \mathrm{E}_{\mathrm{a}}=1.9105 \mathrm{eV}, \\
& \mathrm{k}=8.6144 \times 10^{-5} \mathrm{eV} \cdot \mathrm{K}^{-1} \text {, is the Boltzmann constant, } \\
& \mathrm{T} \text { is in } \mathrm{K} \text {, and the enthalpy increment is in } \mathrm{J} \cdot \mathrm{mol}^{-1} \text {. }
\end{aligned}
$$


For $2670 \mathrm{~K} \leq \mathrm{T} \leq 3120 \mathrm{~K}$,

$$
H(T)-H(298.15 K)=167.04 T-218342 .
$$

where $\mathrm{T}$ is in $\mathrm{K}$ and the enthalpy increment is in $\mathrm{J} \cdot \mathrm{mol}^{-1}$.

The heat capacity of solid $\mathrm{UO}_{2}$ is well represented by the temperature derivative of the equations for the enthalpy increments because, for solid $\mathrm{UO}_{2}$, the other thermodynamic contributions to the heat capacity are small. ${ }^{1-2}$ The equations of Fink et al. for the heat capacity of $\mathrm{UO}_{2}$ are as follows:

For $298.15 \mathrm{~K} \leq \mathrm{T}<2670 \mathrm{~K}$,

$$
C_{P}=\frac{C_{1} \theta^{2} e^{\theta / T}}{T^{2}\left(e^{\theta / T}-1\right)^{2}}+2 C_{2} T+C_{3} k e^{-E_{d} k T}\left(1+\frac{E_{a}}{k T}\right)
$$

where the symbols are defined above for Eq. (1), $\mathrm{T}$ is in $\mathrm{K}$, and $\mathrm{C}_{\mathrm{P}}$ is in $\mathrm{J} \cdot \mathrm{mol}^{-1} \cdot \mathrm{K}^{-1}$.

For $2670 \mathrm{~K}<\mathrm{T} \leq 3120 \mathrm{~K}$,

$$
C_{p}=167.04 \mathrm{~J} \cdot \mathrm{mol}^{-1} \cdot \mathrm{K}^{-1}
$$

Values for enthalpy in $\mathrm{J} \cdot \mathrm{mol}^{-1}$ and heat capacity in $\mathrm{J} \cdot \mathrm{mol}^{-1} \cdot \mathrm{K}^{-1}$ calculated from these equations are tabulated as a function of temperature in Table 1.1.1. Tabulated values for enthalpy in $\mathrm{J} \mathrm{kg}^{-1}$ and heat capacity in $\mathrm{J} \cdot \mathrm{kg}^{-1} \cdot \mathrm{K}^{-1}$ are given in Table 1.1.2. Figure 1.1.1 compares the enthalpy increments from these equations with the experimental data. ${ }^{4-6}$ Recommended values for the heat capacity with uncertainties are shown in Figure 1.1.2.

The polynomial equations for the enthalpy and heat capacity of solid $\mathrm{UO}_{2}$ given by Harding et al. ${ }^{17}$ fit the data with about the same standard deviations, except at low temperatures. Thus, the equations given by Harding et al. ${ }^{17}$ are suggested as reasonable alternatives to the recommended equations of Fink et al. because of the simpler mathematical form of the equations by Harding et al. The following equations are given by Harding et al. for the enthalpy increment in $\mathrm{J} \cdot \mathrm{mol}^{-1}$ : 
For $298.15 \mathrm{~K} \leq \mathrm{T} \leq 2670 \mathrm{~K}$,

$$
\begin{aligned}
H(T)-H(298 K)= & -22528+201296 \tau+138884 \tau^{2}+5498.6 \tau^{3} \\
& -329758 \tau^{4}+322837 \tau^{5}+186.3 \tau^{-1}
\end{aligned}
$$

where $\tau$ is the reduced temperature defined as $\tau=T / T_{m}$ and $T_{m}$ is the melting point, $3120 \mathrm{~K}$. For $2670<\mathrm{T}<3120 \mathrm{~K}$,

$$
H(T)-H(298 K)=521159 \tau-220041 .
$$

where $\tau$ is the reduced temperature and the enthalpy increment $\mathrm{H}(\mathrm{T})-\mathrm{H}(298 \mathrm{~K})$ is in $\cdot \mathrm{mol}^{-1}$.

The recent analysis by Ronchi and Hyland ${ }^{21}$ of heat capacity data from 1000 to $3.000 \mathrm{~K}$ provides the best physically based analysis available, but the complexity of the functional forms for the contributions of each physical process as a function of temperature makes it unsuitable for numerous repetitive calculations required in computer codes used in reactor safety analyses.

\section{Uncertainties}

The uncertainty in the recommended enthalpy increments is $1 \%$ from $298.15 \mathrm{~K}$ to the melting point at $3120 \mathrm{~K}$. The heat capacity uncertainty is $2 \%$ from 298.15 to $2000 \mathrm{~K} ; 5 \%$ from $2600 \mathrm{~K}$ to near the phase transition. From 2000 to $2600 \mathrm{~K}$, the uncertainty increases linearly. The recommended equations are discontinuous at the $2670 \mathrm{~K} \lambda$ - phase transition. Because no attempt has been made to calculate the heat capacity peak at this transition, as was done in the detailed analysis by by Ronchi and Hyland, ${ }^{21}$ the heat capacity equations and uncertainties are not valid for temperatures close to the $\lambda$-phase transition. The heat capacity uncertainty above the transition is $8 \%$.

\section{Discussion}

No new analysis of the experimental data has been done for this assessment. The recommendations are based on assessments of existing equations, comparisons with available data, and recent theoretical considerations. In addition to the experimental data ${ }^{4-16}$ on which the existing equations are based, new experimental data ${ }^{18-20}$ confirm the existence of the phase transition first suggested by Bredig 22 at $0.8 \mathrm{~T}_{\mathrm{m}}$ and adopted in the equations of Fink et al. and of Harding et al. 
Experimental Data - Fink et al. ${ }^{2-3}$ reviewed the experimental enthalpy and heat capacity data available prior to 1980 . Their comparison of the available enthalpy data showed that the data of Hein and Flagella ${ }^{6}$ (from 1174 to $3112 \mathrm{~K}$ ) are in good agreement with that of Leibowitz, Mishler and Chasanov $^{4}$ (from 2561 to $3088 \mathrm{~K}$ ) and with the data of Fredrickson and Chasanov ${ }^{5}$ (from 674 to $1436 \mathrm{~K})$. Data given by Hein, Sjodahl and $\mathrm{Szwarz}^{7}$ is identical with that reported by Hein and Flagella. ${ }^{6}$ Data reported by Conway and $\mathrm{Hein}^{8}$ in 1965 are preliminary results of the data published in 1968. The 1947 measurements by Moore and Kelley (from 483 to $1464 \mathrm{~K}$ ) do not agree well with the data of Fredrickson and Chasanov. ${ }^{5}$ The data of Ogard and Leary (from 1339 to $2306 \mathrm{~K}$ ) do not agree well with the data of Hein and Flagella ${ }^{6}$ or that of Fredrickson and Chasanov. ${ }^{5}$

The heat capacity data of Hunzicker and Westrum ${ }^{12}$ ( 5 to $346 \mathrm{~K}$ ) and that of Gronvold et al. $^{11}$ (304-1006 K) are in good agreement in the temperature range of overlap. However, between 500 and $800 \mathrm{~K}$, the data of Gronvold et al. ${ }^{11}$ are high because of contamination of the sample by $\mathrm{U}_{4} \mathrm{O}_{9}$. The heat capacity data of Affortit and Marcon ${ }^{15}$ and of Affortit ${ }^{16}$ clearly disagree with other data. Data of Popov et al. ${ }^{13}$ ( 433 to $876 \mathrm{~K}$ ) are consistently high. Data of Engel ${ }^{14}$ (300 to $1000 \mathrm{~K}$ ) appear to have a systematic error because they differ from other data by a normalization factor.

The recent high-temperature thermal analysis of cooling curves of $\mathrm{UO}_{2 \pm \mathrm{x}}$ by Hiernaut et al. ${ }^{20}$ have shown the existence of a solid phase transition in stoichiometric $\mathrm{UO}_{2.00}$ and in $\mathrm{UO}_{2-\mathrm{x}}$ and provided heat capacity data in the vicinity of this transition. The high-temperature laser pulseheating experiments by Ronchi et al. ${ }^{23}$ to determine the heat capacity of liquid $\mathrm{UO}_{2}$ to $8000 \mathrm{~K}$ included measurements of the solid at the melting point. Ronchi ${ }^{24}$ reports $640 \mathrm{~J} \cdot \mathrm{kg}^{-1} \cdot \mathrm{K}^{-1}$ as the heat capacity of the solid for the experimental point nearest the solidus. In their analysis of the heat capacity data of solid and liquid $\mathrm{UO}_{2}$, Ronchi and Hyland ${ }^{21}$ estimated an $8 \%$ error in the heat capacity data above the $2670 \mathrm{~K}$ solid phase transition.

Hiernaut et al. ${ }^{20}$ found that the transition temperature in nominally stoichiometric $\mathrm{UO}_{2.00}$ is $2670 \pm 30 \mathrm{~K}$, which is coincident with the transition temperature proposed by Bredig ${ }^{22}$ but higher than the $2610 \mathrm{~K}$ value proposed by Ralph and Hyland. ${ }^{25}$ The scatter in their data was approximately twice the precision of the temperature measurement. The transition was identified as a first-order phase transition from cooling curves in the temperature range of 2300 to $3000 \mathrm{~K}$. However, when the sample was initially heated above its melting point, no transition appeared, even in subsequent 
heatings of the sample to submelting temperatures. They found that for substoichiometric urania $\left(\mathrm{UO}_{2-\mathrm{x}}\right)$ the transition temperature increased with increasing $\mathrm{x}$ (i.e., reduction of the sample in a $3 \%$ hydrogen atmosphere) and the cooling curves exhibit undercooling indicative of a first-order transition. No transition was detected in $\mathrm{UO}_{2+\mathrm{x}}$.

Heirnaut et al. ${ }^{20}$ found that the phase transition in stoichiometric $\mathrm{UO}_{2.00}$ was consistent with that in stoichiometric non-actinide fluorites (e.g., $\mathrm{SrCl}_{2}$ ), where the high-temperature phase is established rapidly but continuously. They modeled the $\lambda$-like phase transition in $\mathrm{UO}_{2.00}$ as a second-order transition involving oxygen Frenkel disorder. Their model is consistent with the second-order $\lambda$ transition in $\mathrm{UO}_{2.00}$ converting to a first-order phase transition in $\mathrm{UO}_{2-\mathrm{x}}$. Although no transition was detected in $\mathrm{UO}_{2+\mathrm{x}}$, their model is consistent with a second-order transition that decreases with increasing $x$ from $T=2670 \mathrm{~K}$ at $\mathrm{x}=0$ to cross the $\mathrm{U}_{4} \mathrm{O}_{9}$ phase boundary near $973 \mathrm{~K}$, where a diffuse order-disorder transition is observed in the $\mathrm{U}_{4} \mathrm{O}_{9}$ oxygen sublattice. They suggested that the second-order $\lambda$ transition in $\mathrm{UO}_{2.00}$ is the stoichiometric counterpart of the interstitial superlattice transition in $\mathrm{U}_{4} \mathrm{O}_{9}$. Heirnaut et $\mathrm{al}^{20}$ stated that they did not experimentally observe a transition in $\mathrm{UO}_{2+\mathrm{x}}$ because, according to their model, the transition rapidly decreases in peak height and increases in peak width with $\mathrm{x}$. Based on their experimental results and their model, Heirnaut et al. ${ }^{19}$ have modified the U-O phase diagram to include these transitions.

High-temperature neutron diffraction, coherent diffuse, and inelastic scattering experiments on $\mathrm{UO}_{2}$ and $\mathrm{ThO}_{2}$ at temperatures from 293 to $2930 \mathrm{~K}$ reported by Hutchings et al. ${ }^{18-19}$ provide direct evidence for thermally induced Frenkel oxygen lattice disorder at temperatures above approximately $2000 \mathrm{~K}$. The disorder has been identified as dynamic Frenkel type similar to that in halide fluorites with a Frenkel pair formation energy of $4.6 \pm 0.5 \mathrm{eV}$. Hutchings ${ }^{18}$ suggested that the high oxygen vacancy concentrations and their mobility at high temperatures may be related to the observed high creep rate ${ }^{26}$ and softening or plasticity of $\mathrm{UO}_{2}$ above $2500 \mathrm{~K}$. He also reported that inelastic magnetic scattering on lowest magnetic energy levels of $\mathrm{U}^{4+}$ indicate that excitation of these levels makes a significant contribution to the heat capacity in $\mathrm{UO}_{2}$.

Theory and Equations - An excellent discussion of the current theoretical understanding of the contributions to the heat capacity of $\mathrm{UO}_{2}$ is given by Ronchi and Hyland. ${ }^{21}$ The dominant 
contributions in each of four temperature intervals for the solid discussed in detail by Ronchi and Hyland are summarized below.

(1) From room temperature to $1000 \mathrm{~K}$, the increase in heat capacity is governed by the harmonic lattice vibrations, which may be approximated by a Debye model. By $1000 \mathrm{~K}$, this contribution becomes constant. A smaller contribution is provided by thermal excitation of localized electrons of $\mathrm{U}^{4+}(5 \mathrm{f})^{2}$ in the crystal field levels. This crystal field contribution is proportional to $\mathrm{T}$ at low temperatures, but becomes temperature independent at high temperatures where the concentration of $U^{4+}$ decreases as the concentrations of $U^{3+}$ and $\mathrm{U}^{5+}$ increase.

(2) From 1000 to $1500 \mathrm{~K}$, the heat capacity increases because of increases in the anharmonicity of the lattice vibrations as evidenced in the thermal expansion. This contribution has been previously referred to as the thermal expansion or dilation contribution.

(3) From 1500 to $2670 \mathrm{~K}$, the increase in heat capacity is due to formation of lattice and electronic defects. The peak in the heat capacity at $2670 \mathrm{~K}$ ( $85.6 \%$ of the melting point) has been attributed to Frenkel defects both from theoretical considerations ${ }^{21}$ and neutron scattering measurements of the oxygen defect concentration as a function of temperature as discussed by Hutchings. ${ }^{18}$ A similar discontinuity and anion behavior was observed for $\mathrm{ThO}_{2} \cdot{ }^{18,19}$ Harding et al. ${ }^{17}$ commented that, because no excess enthalpy is evident in $\mathrm{ThO}_{2}$ below the corresponding transition, it is reasonable to suggest that the increase in $\mathrm{UO}_{2}$ below the phase transition is due to coupling between electronic disorder and Frenkel disorder. Ronchi et al. ${ }^{21}$ pointed out that the increase in the electrical conductivity in this temperature interval indicates a contribution from electronic defects, but the small polaron contribution from electron-hole interactions is minor compared to contributions due to Frenkel defects.

(4) Above the phase transition temperature, the peak of the heat capacity drops sharply due to rapid saturation of the defect concentration. From $2700 \mathrm{~K}$ to the melting point, Schottky defects become important.

The $\mathrm{UO}_{2}$ heat capacity calculations of Ronchi and Hyland ${ }^{21}$ from $1000 \mathrm{~K}$ to the melting point have a sound theoretical basis and provide good agreement with the high-temperature heat capacity data. They are the only available calculations that include a calculation of the peak in the jkfink@anl.gov 
heat capacity. Figure 1.1.3 shows heat capacities calculated by Ronchi and Hyland, ${ }^{21}$ experimental data (shown in their graph ${ }^{21}$ ), and their tabulated smoothed experimental data. The experimental data shown in their graph was obtained from differentiation of enthalpy data below the phase transition, the measurements of Hiernaut et al. ${ }^{20}$ in the vicinity of the $\lambda$-transition peak, and the measurements by Ronchi et al. ${ }^{23}$ just below the solidus. The values of the heat capacity calculated from Eqs. (3) and (4) of Fink et al. have been included in Figure 1.1.3 for comparison.

Although the calculations of Ronchi and Hyland ${ }^{21}$ are the best theoretical description of the temperature dependence of the heat capacity of $\mathrm{UO}_{2}$, their complexity limits their usefulness for the repetitive calculations required by reactor safety computer codes. Consequently, other existing equations have been examined. Figure 1.1.4 shows the heat capacities determined by the Kerrisk and Clifton $^{27}$ equation recommended by MATPRO ${ }^{28}$ for the entire temperature range, the equations of Fink et al. ${ }^{1-3}$ and of Harding et al., ${ }^{17}$ and the assessed experimental data as given by Ronchi and Hyland. ${ }^{21}$ Note that Kerrisk and Clifton limited their equation to the temperature range of 298 to $1500 \mathrm{~K}$. Its uise for the entire temperature range, as suggested in MATPRO, is not recommended because this equation does not include a phase transition at $2670 \mathrm{~K}$. Figure 1.1.4 shows that the heat capacity equation given in MATPRO deviates significantly from experimental data above $2670 \mathrm{~K}$. Although the enthalpy increments calculated from the equations given in these three assessments do not appear to differ significantly, as shown in Figure 1.1.5, examination of their deviations from the experimental data shows differences. Figures 1.1.6 through 1.1.8 show the percent deviations of the equations given by MATPRO, ${ }^{28}$ Harding et al., ${ }^{17}$ and Fink et al. ${ }^{1-3}$ from the experimental enthalpy data. $^{4-6}$ The deviations of the MATPRO-recommended Kerrisk and Clifton equation (Figure 1.1.6) appear to be systematic both below and above $2670 \mathrm{~K}$. Equations of Fink et al. and of Harding et al. have similar deviations. The chi-square deviations of the data from these equations are 56 for MATPRO, 25 for Harding et al., and 20 for Fink et al.

Phase transitions have been included in both the assessments of Fink et al. and of Harding et al. Their enthalpy equations above the phase transition [Eqs. (2) and (6) shown above] give values that agree within $1 \%$ and the difference in their heat capacities above $2670 \mathrm{~K}$ is not statistically significant. The heat capacities of Harding et al. do not differ significantly from those of Fink et al. except at low temperatures. Both agree well with the calculations of Ronchi and Hyland below the 
phase transition. The polynomial equation given by Harding et al., Eq. (5), contains seven parameters, whereas Eq. (1) of Fink et al. contains five parameters but only four of them are free. One of the parameters in Eq. (1) is set by the constraint that the heat capacity at $298.15 \mathrm{~K}$ equals the heat capacity measured by Huntzicker and Westrum, ${ }^{12} 63.60 \mathrm{~J} \cdot \mathrm{mol}^{-1} \cdot \mathrm{K}^{-1}$. The form of equation used by Fink et al. constrains the enthalpy increment at $298.15 \mathrm{~K}$ to zero. The equation of Harding et al. gives a zero enthalpy increment at $298 \mathrm{~K}$ but gives $66.21 \mathrm{~J} \cdot \mathrm{mol}^{-1} \cdot \mathrm{K}^{-1}$ for the heat capacity at $298.15 \mathrm{~K}$. This value is high relative to the experimental data by $4 \%$. The equations of Fink et al. have been recommended because of their better fit to the enthalpy data $\left(X^{2}=20\right)$ with the use of fewer parameters. However, the 7-term polynomial and linear equations given by Harding et al. fit the available data almost as well $\left(\mathrm{X}^{2}=25\right)$, except for low temperature heat capacities, and provide a simpler analytical form for programming.

The forms of equations selected by Kerrisk and $\mathrm{Clifton}^{27}$ and used by Rand et al. ${ }^{29}$ and Fink et al. ${ }^{1-3}$ to describe the enthalpy data below the $2670 \mathrm{~K}$ phase transition include terms that have traditionally been identified with contributions to the enthalpy and heat capacity from different physical processes. The first term in Eq. (1) approximate the harmonic lattice contribution, the second term accounts for the anharmonicity of the lattice as given by dilation, and the last term gives an anomalous contribution due to defects. The recent neutron diffraction and scattering experiments ${ }^{18-19}$ have shown that the phase transition at $2670 \mathrm{~K}$ arises from Frenkel defects, and calculations by Ronchi and Hyland ${ }^{21}$ show that contributions to the heat capacity due to Frenkel defects are much larger than the electronic small-polaron contribution. The mathematical form of the third term selected by Fink et al. is more appropriate for describing electronic defects than Frenkel defects. Frenkel defects are more appropriately described by a term of the form used by Rand et al. ${ }^{29}$ and by Kerrisk and Clifton, ${ }^{27}$ which is $\mathrm{C} \mathrm{e}^{-\mathrm{E} / \mathrm{kT}}$. Although the equations of Rand et al. ${ }^{29}$ had been considered in the assessment by Fink et al., they chose the form used in Eq. (1) because it provided a better fit to the available data. ${ }^{1-2}$ Browning et al..$^{30}$ have commented that the ability to calculate the magnitude of each contribution to the enthalpy from physical principles, as was done by Ronchi and Hyland, ${ }^{21}$ makes analysis of the enthalpy data based on fitting procedures used by Fink et al. and Rand et al. obsolete. They also stated that attribution of the terms of equations used by Rand et al. and by Fink et al. to any physical process is only a rough 
approximation because these equations do not account for all physical processes and, therefore, the fitting procedure gives values for parameters in these equations that differ from the known physical values. For example, the Debye and Einstein temperatures of $\mathrm{UO}_{2}$ are well known and different from the values obtained in such a fitting procedure. However, Browning et al. concurred that the best fit to the experimental data below $2500 \mathrm{~K}$ is obtained with equations of the form used by Rand et al. and by Fink et al. These forms of equations provide a better fit to the experimental data than do fits using polynomials. 


\section{REFERENCES}

1. J. K. Fink, Enthalpy and Heat Capacity of the Actinide Oxides, Int. J. Thermophys. 3(2), $165-200$ (1982).

2. J. K. Fink, M. G. Chasanov, and L. Leibowitz, Thermophysical Properties of Uranium Dioxide, J. Nucl. Mater. 102, 17-25 (1981); also as ANL Report ANL-CEN-RSD-80-3, Argonne National Laboratory (April 1981).

3. J. K. Fink, M. G. Chasanov, and L. Leibowitz, Enthalpy and Heat Capacity of Solid $\mathrm{UO}_{2}$, ANL Report ANL-CEN-RSD-81-2, Argonne National Laboratory (May 1981).

4. L. Leibowitz, L. W. Mishler, and M. G. Chasanov, J. Nucl. Mater. 29, 356 (1969).

5. D. R. Fredrickson and M. G. Chasanov, J. Chem. Thermodynamics 2, 263 (1970).

6. R. A. Hein and P. N. Flagella, Enthalpy Measurements of $\mathrm{UO}_{2}$ and Tungsten to $3260 \mathrm{~K}, \mathrm{GE}$ Report GEMP-578, General Electric, February 16, 1968.

7. R. A. Hein, L. A. Sjodahl, and R. Szwarc, J. Nucl. Mater. 25, 99 (1968).

8. J. B. Conway and R. A. Hein, J. Nucl. Mater. 15, 149 (1965).

9. G. E. Moore and K. K. Kelly, J. Am. Chem. Soc. 69, 2105 (1947).

10. A. E. Ogard and J. A. Leary, High-Temperature Heat Content and Heat Capacity of Uranium Dioxide and Uranium Dioxide-Plutonium Dioxide Solid Solutions, in Thermodynamics of Nuclear Materials 1967, IAEA, Vienna, p. 651 (1969).

11. F. Gronvold, N. J. Kvseth, A. Sveen, and J. Tichy', J. Chem. Thermo. 2, 665 (1970).

12. J. J. Hunzicker and E. F. Westrum, J. Chem. Thermo. 3, 61 (1971).

13. M. M. Popov, G. L. Gal'chenko, and M. D. Seniv, Zh. Neorg. Khim. 3, 1734 (1958); [Trans. J. Inorg. Chem., USSR 3, 18 (1958)].

14. T. K. Engel, J. Nucl. Mater. 31, 211 (1969).

15. C. Affortit and J. Marcon, Rev. Int. Hautes Temp. et Refract. 7, 236 (1970).

16. C. Affortit, High Temp.-High Pressures 1, 27-33 (1969). 
17. J. H. Harding, D. G. Martin, and P. E. Potter, Thermophysical and Thermochemical Properties of Fast Reactor Materials, Commission of the European Communities Report EUR 12402 EN (1989).

18. M. T. Hutchings, High-Temperature Studies of $\mathrm{UO}_{2}$ and $\mathrm{ThO}_{2}$ Using Neutron Scattering Techniques, J. Chem. Soc. Faraday Trans. II 83, 1083-1103 (1987).

19. M. T. Hutchings, K. Clausen, M. H. Dicken, W. Hayes, J. K. Kjems, P. G. Schnabel, and C. Smith, J. Phys. C 17, 3903 (1984).

20. J. P. Hiernaut, G. J. Hyland, and C. Ronchi, Premelting Transition in Uranium Dioxide, Int. J. Thermophys. 14(2), 259-283 (1993).

21. C. Ronchi and G. J. Hyland, Analysis of Recent Measurements of the Heat Capacity of Uranium Dioxide, J. of Allys and Compounds 213/214 159-168 (1994).

22. M. A. Bredig, L'Etude des Transformations Crystalline a Hautes Temperatures, Proceedings of a Conference held in Odeillo, France, 1971 (CNRS, Paris, 1972), p. 183

23. C. Ronchi, J. P. Hiernaut, R. Selfslag, and G. J. Hyland, Laboratory Measurement of the Heat Capacity of Urania up to 8000 K: I. Experiment, Nucl. Sci. and Eng. 113, 1-19 (1993).

24. C. Ronchi, J. Phys. On the Thermal Conductivity and Diffusivity of Solid and Liquid Uranium Dioxide, Condens. Mater. 6, L561-L567 (1994).

25. J. Ralph and G. J. Hyland, Empirical Confirmation of a Bredig Transition in $\mathrm{UO}_{2}$, J. Nucl. Mater. 132, 76 (1985).

26. L. Leibowitz, J. K. Fink, and O. D. Slagle, Phase Transitions, Creep, and Fission Gas Behavior in Actinide Oxides, J. Nucl. Mater. 116, 324-325 (1983).

27. J. F. Kerrisk and D. G. Clifton, Smoothed Values of the Enthalpy and Heat Capacity of $\mathrm{UO}_{2}$, Nucl. Technol. 16, 531 (1972).

28. J. K. Horhorst, editor, SCADAP/RELAP5/MOD2 Code Manual Vol. 4: MATPRO - a Library of Materials Properties for Light-Water-Reactor Accident Analysis, NUREG/CR-5273 (1990).

29. M. H. Rand, R. J. Ackermann, F. Gronvold, F. L. Oetting, A. Pattoret, The Thermodynamic Properties of the Urania Phase, Rev. Int. Hautes Temp. Refract. 15, 355-365 (1978).

30. P. Browning, G. J. Hyland, and J. Ralph, The Origin of the Specific Heat Anomaly in Solid Urania, High Temp.-High Pressures 15, 169-178 (1983). 
Table 1.1.1 Enthalpy and Heat Capacity of $\mathrm{UO}_{2}$ per mole of $\mathrm{UO}_{2}$

\begin{tabular}{|c|c|c|}
\hline Temperature & $\begin{array}{c}\text { Enthalpy } \\
\mathbf{H}(\mathbf{T})-\mathbf{H}(\mathbf{2 9 8 . 1 5} \mathbf{K}) \\
\mathbf{k J / m o l}\end{array}$ & $\begin{array}{c}\text { Heat Capacity } \\
\mathbf{\mathbf { C } _ { \mathbf { P } }} \\
\mathbf{J} / \mathbf{\text { mol }} \mathbf{)}\end{array}$ \\
\hline $\mathbf{K}$ & 0.00 & 63.60 \\
398.15 & 0.12 & 63.79 \\
400 & 6.91 & 71.30 \\
500 & 14.27 & 75.49 \\
\hline 600 & 21.96 & 78.20 \\
700 & 29.89 & 80.17 \\
800 & 37.98 & 81.74 \\
900 & 46.22 & 83.06 \\
1000 & 54.59 & 84.22 \\
\hline 1100 & 63.07 & 85.29 \\
1200 & 71.65 & 86.29 \\
1300 & 80.32 & 87.26 \\
1400 & 89.10 & 88.21 \\
1500 & 97.97 & 89.21 \\
\hline 1600 & 106.94 & 90.31 \\
1700 & 116.04 & 91.64 \\
1800 & 125.28 & 93.33 \\
1900 & 134.72 & 95.59 \\
2000 & 144.43 & 98.68 \\
\hline 2100 & 154.49 & 102.88 \\
2200 & 165.05 & 108.53 \\
2300 & 176.26 & 116.03 \\
2400 & 188.33 & 125.75 \\
2500 & 201.50 & 138.13 \\
\hline 2600 & 216.06 & 153.56 \\
2670 & 227.25 & 166.39 \\
\hline 2670 & 227.65 & 167.04 \\
2700 & 232.67 & 167.04 \\
2800 & 249.37 & 167.04 \\
2900 & 266.07 & 167.04 \\
3000 & 282.78 & 167.04 \\
\hline 3100 & 299.48 & 167.04 \\
3120 & 302.82 & 167.04 \\
\hline & & \\
\hline & & \\
\hline
\end{tabular}


Table 1.1.2 Enthalpy and Heat Capacity of $\mathrm{UO}_{2}$ per $\mathrm{kg}$ of $\mathrm{UO}_{2}$

\begin{tabular}{|c|c|c|}
\hline Temperature & $\begin{array}{c}\text { Enthalpy } \\
\text { H(T)-H(298.15 K) } \\
\text { kJ/kg }\end{array}$ & $\begin{array}{c}\text { Heat Capacity } \\
\mathbf{C}_{\mathbf{P}} \\
\text { J/(kg K) }\end{array}$ \\
\hline K & 0.00 & 235.55 \\
308.15 & 0.44 & 236.27 \\
400 & 25.61 & 264.07 \\
500 & 52.85 & 279.58 \\
\hline 600 & 81.34 & 289.63 \\
700 & 110.69 & 296.93 \\
800 & 140.68 & 302.72 \\
900 & 171.20 & 307.62 \\
1000 & 202.18 & 311.94 \\
\hline 1100 & 233.58 & 315.89 \\
1200 & 265.35 & 319.60 \\
1300 & 297.49 & 323.17 \\
1400 & 329.99 & 326.71 \\
1500 & 362.84 & 330.40 \\
\hline 1600 & 396.08 & 334.50 \\
1700 & 429.77 & 339.40 \\
1800 & 464.01 & 345.68 \\
1900 & 498.97 & 354.05 \\
2000 & 534.92 & 365.47 \\
\hline 2100 & 572.20 & 381.02 \\
2200 & 611.30 & 401.98 \\
2300 & 652.82 & 429.73 \\
2400 & 697.52 & 465.76 \\
2500 & 746.30 & 511.58 \\
\hline 2600 & 800.22 & 568.72 \\
2670 & 841.65 & 616.27 \\
\hline 2670 & 843.17 & 618.67 \\
2700 & 861.73 & 618.67 \\
2800 & 923.59 & 618.67 \\
2900 & 985.46 & 618.67 \\
3000 & 1047.33 & 618.67 \\
\hline 3100 & 1109.19 & 618.67 \\
3120 & 1121.57 & 618.67 \\
\hline
\end{tabular}


Figure 1.1.1 Enthalpy of Solid $\mathrm{UO}_{2}$

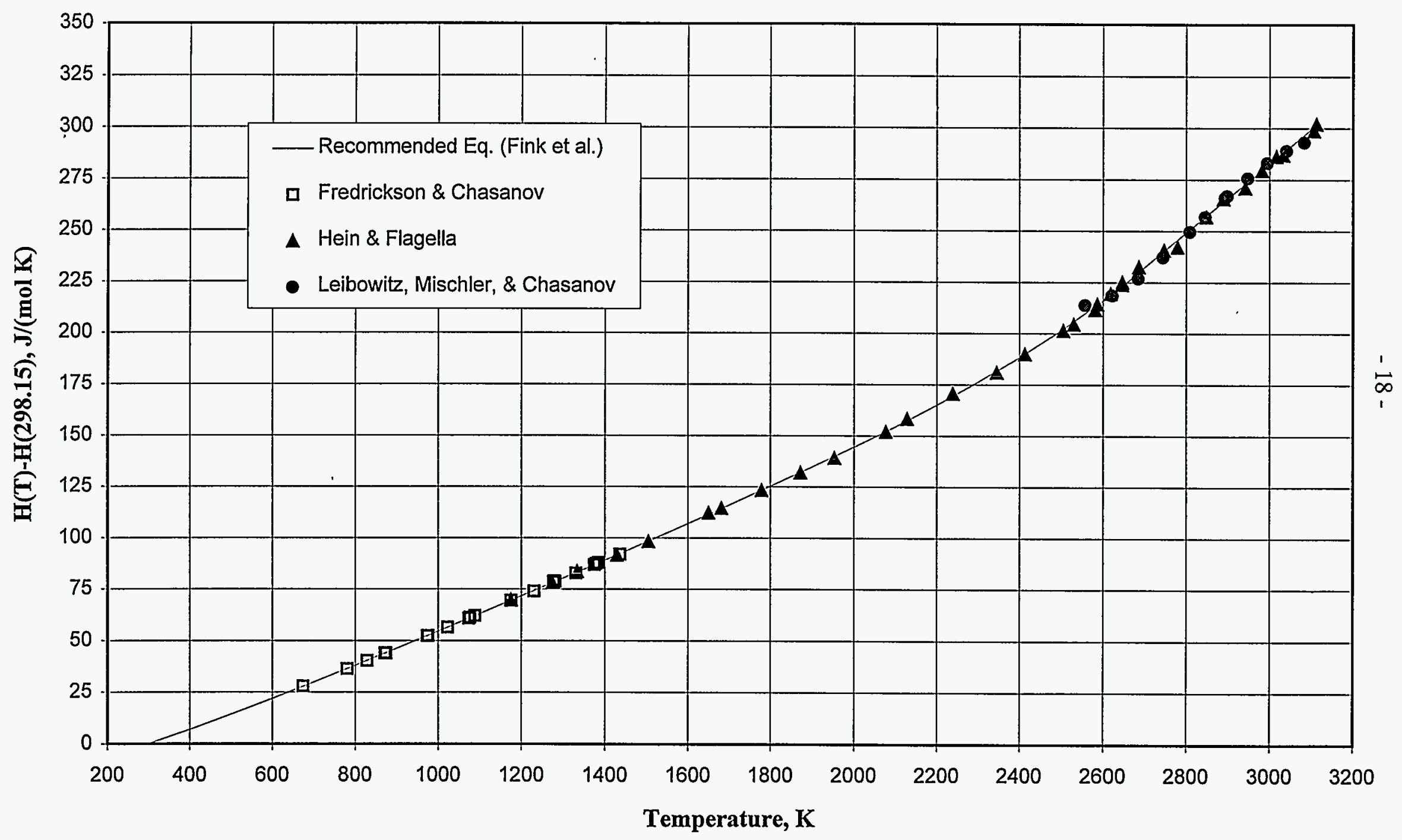




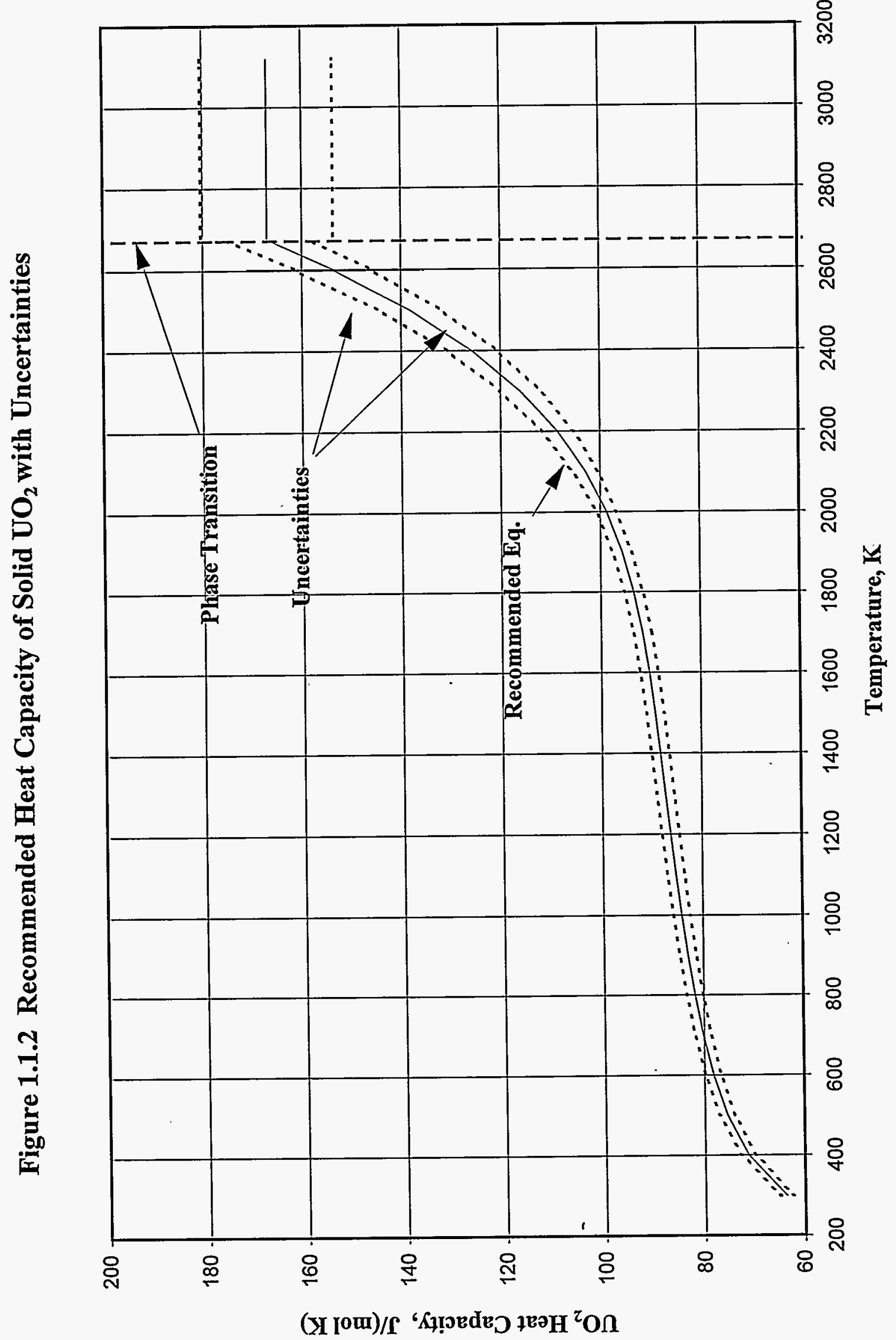




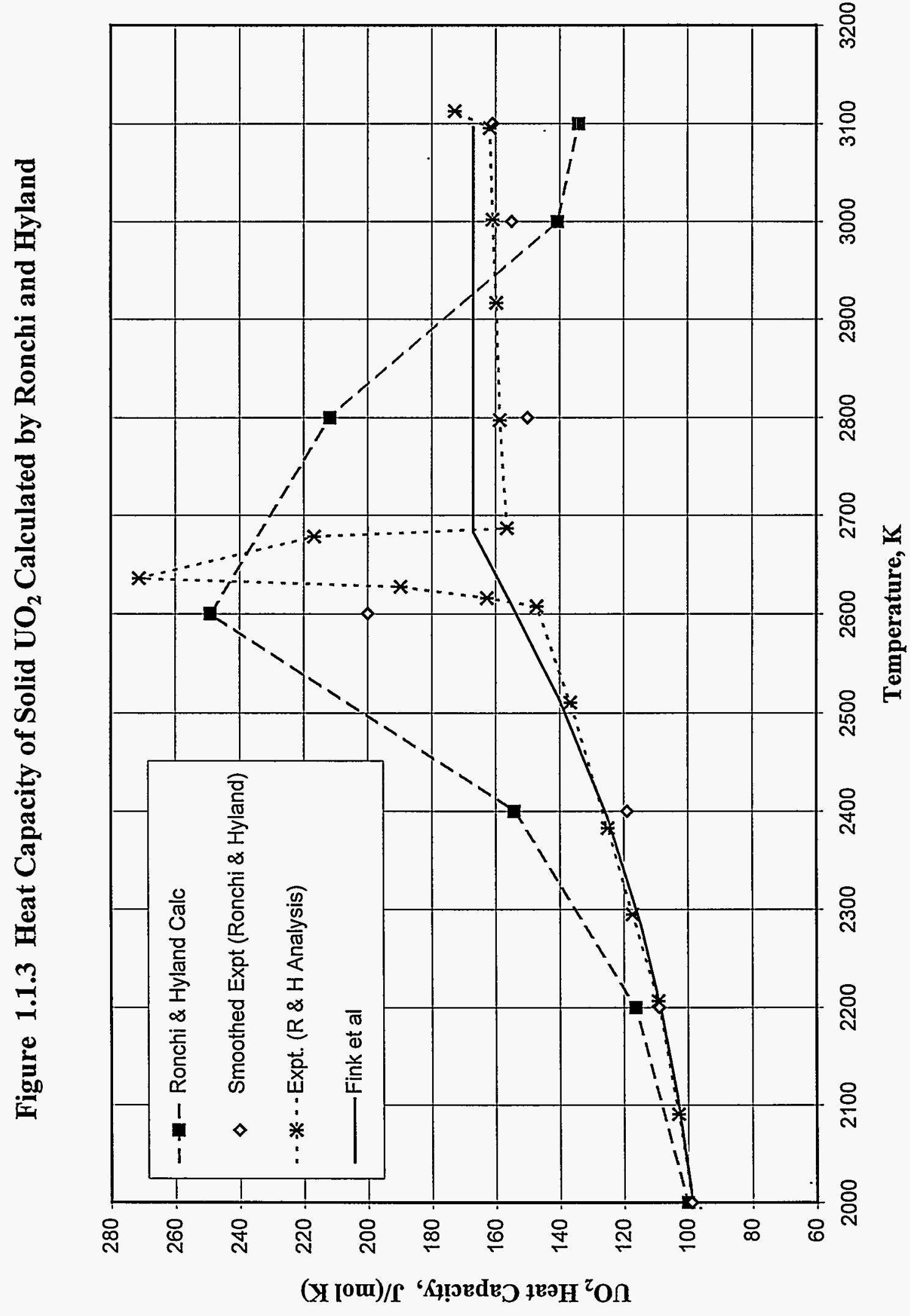


Figure 1.1.4 Comparison of Equations for the Heat Capacity of Solid $\mathrm{UO}_{2}$

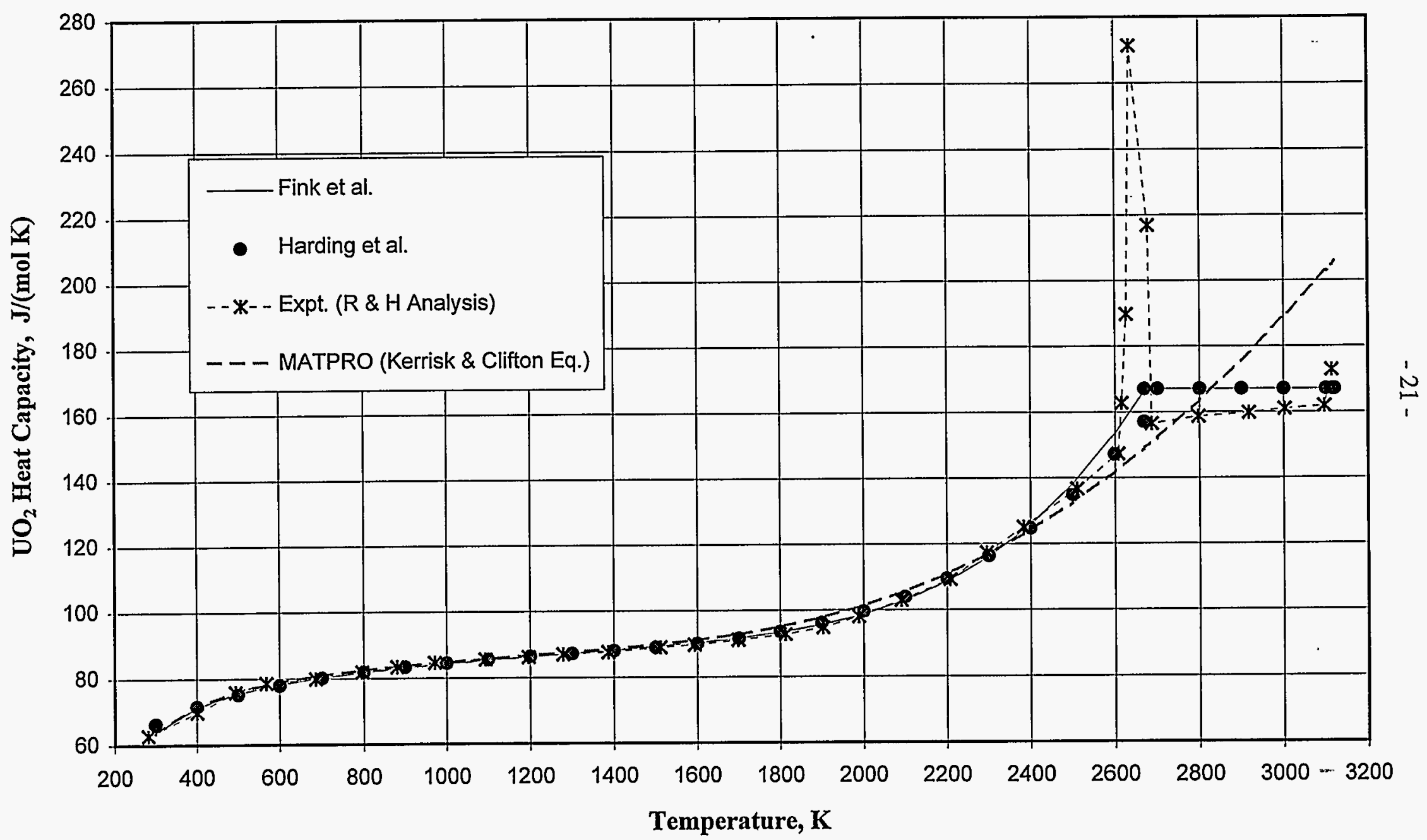


娄

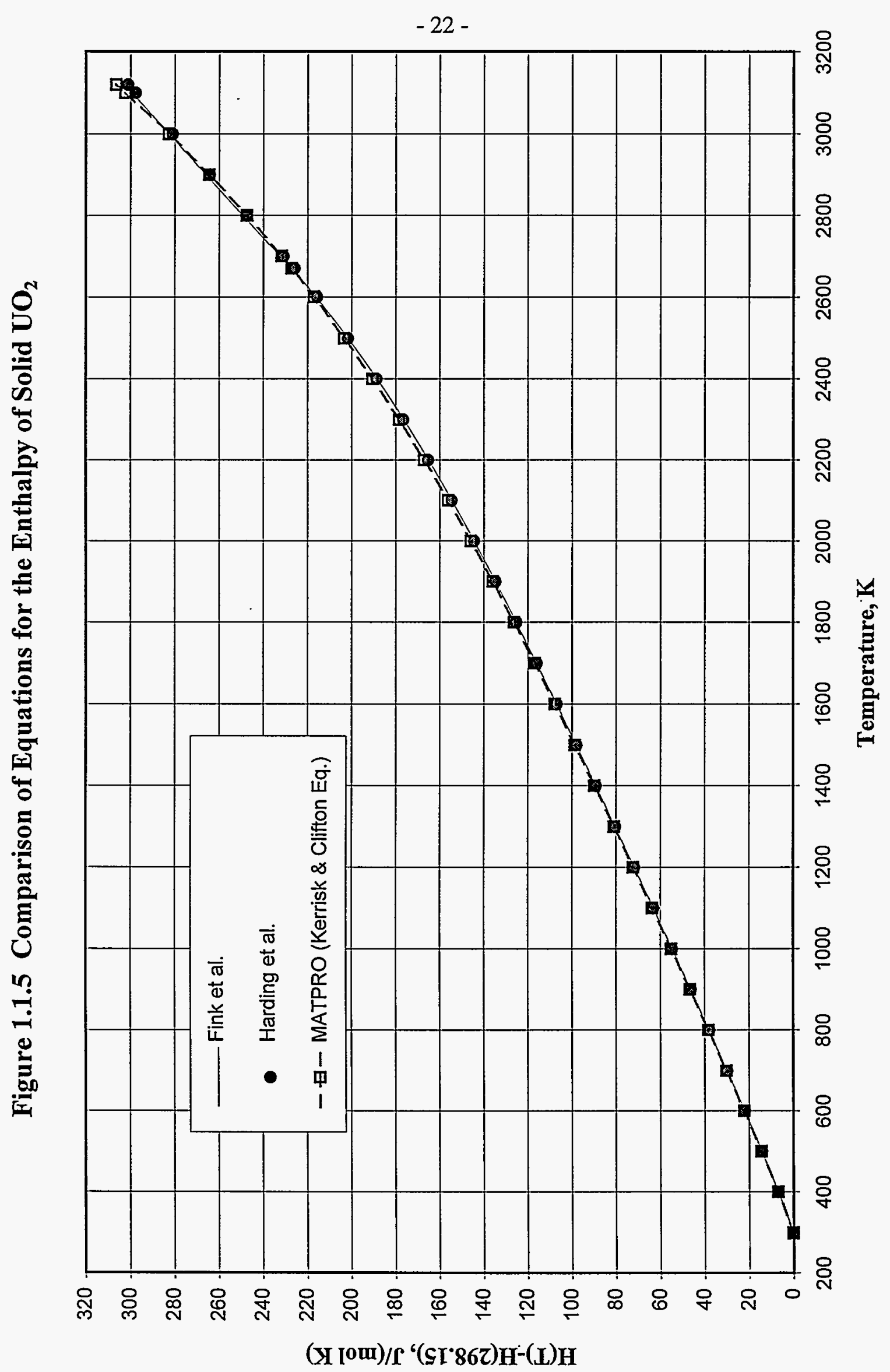

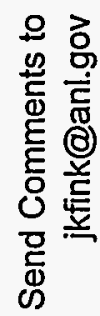

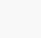




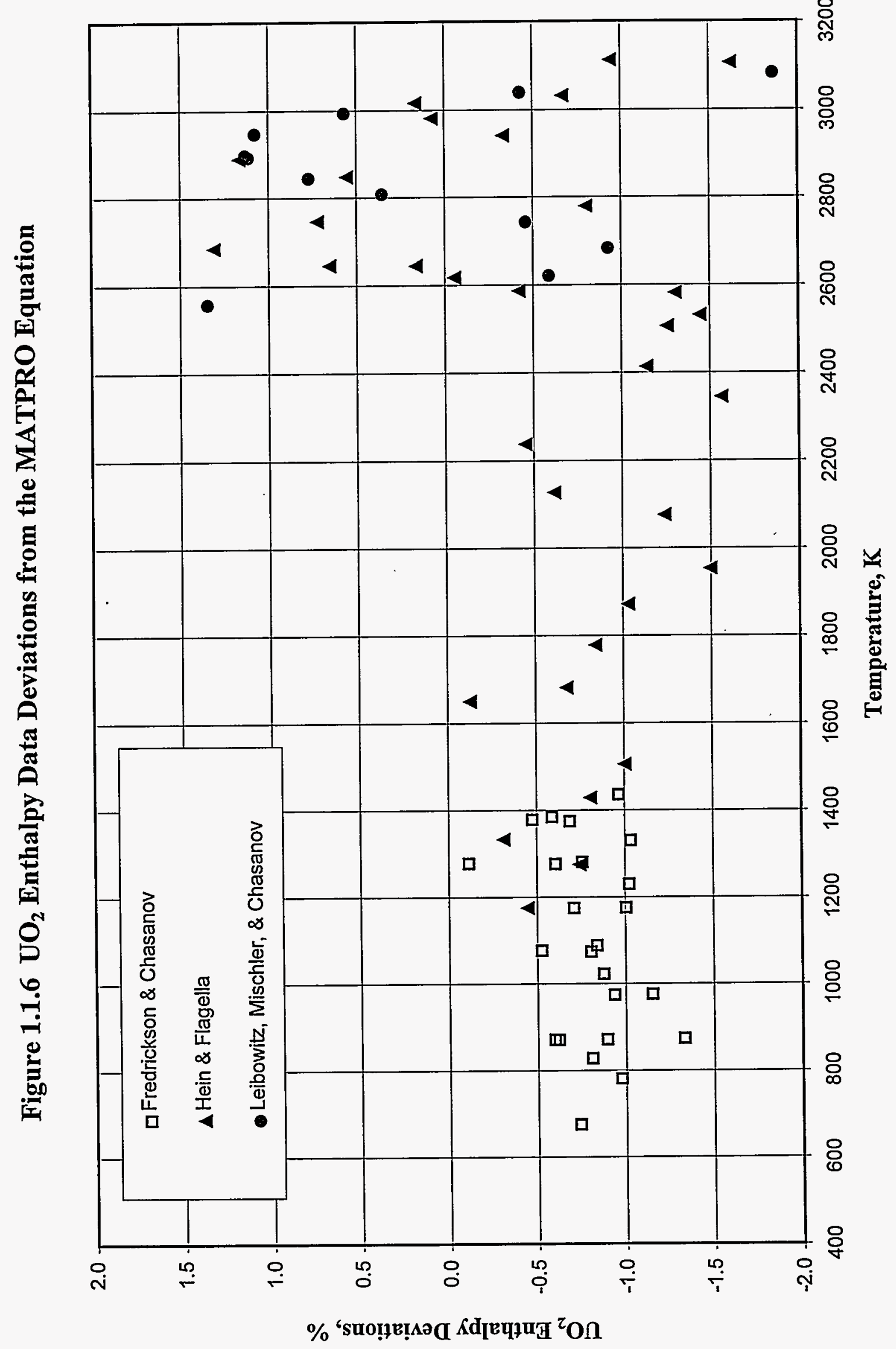

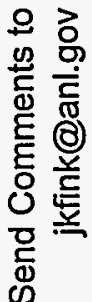

 
Figure 1.1.7 Enthalpy Data Deviations from the Equations of Harding et al.

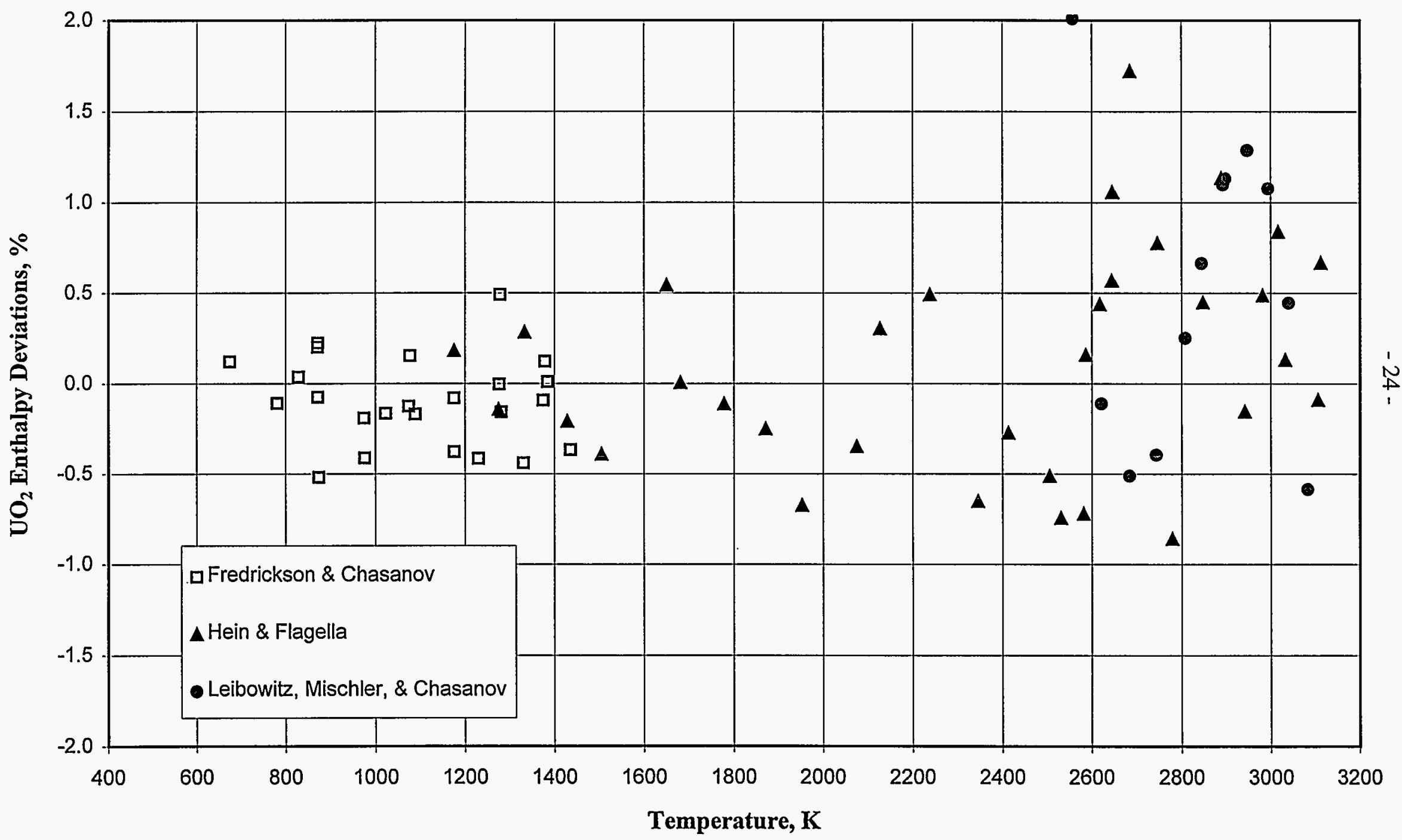




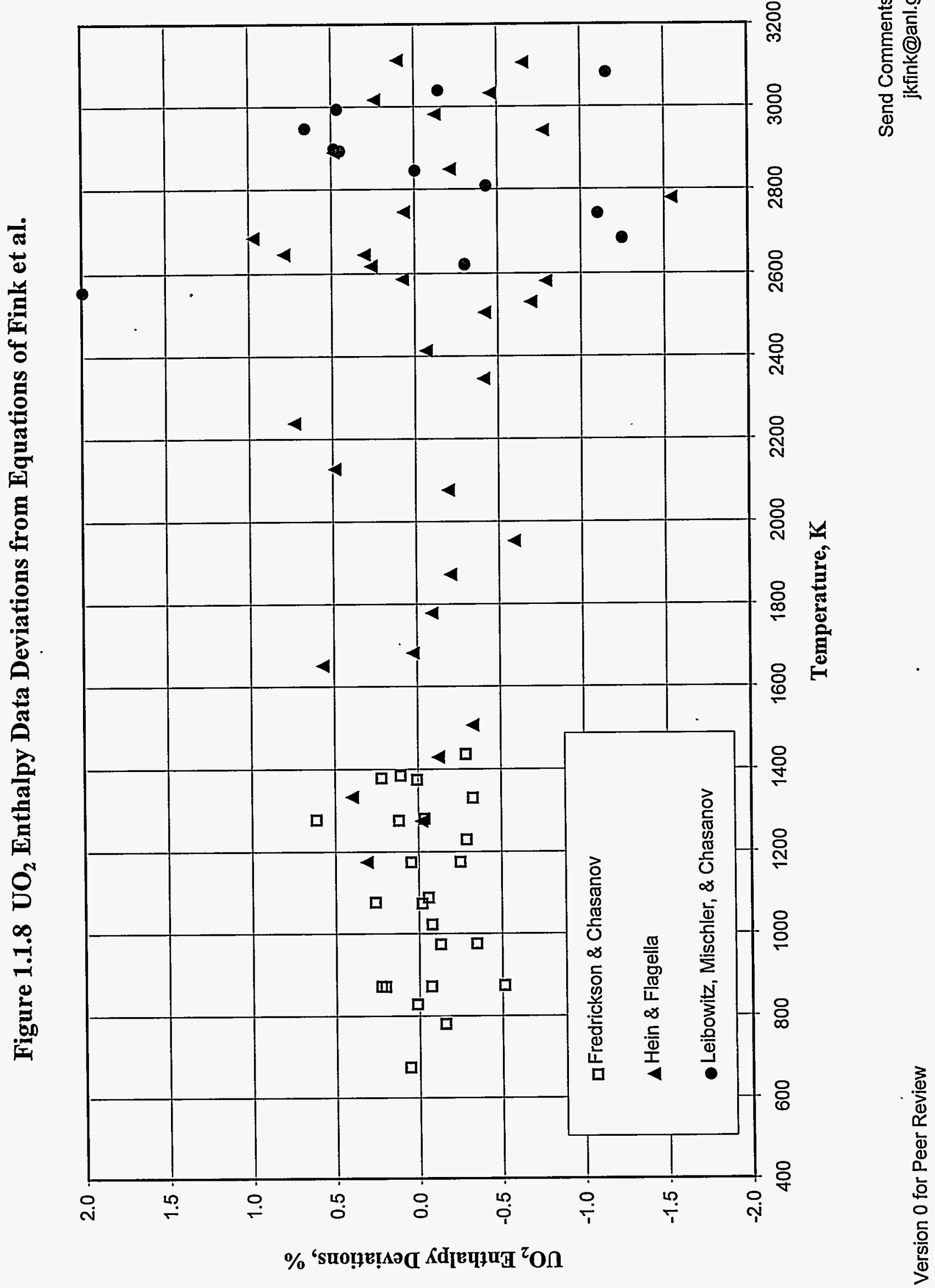




\subsection{ENTHALPY AND HEAT CAPACITY OF LIQUID UO \\ Recommendation}

The recommended equations for the enthalpy and heat capacity of liquid $\mathrm{UO}_{2}$ are a least squares fit to the combined enthalpy data of Leibowitz et al. ${ }^{1}(3173-3523 \mathrm{~K})$ and of Hein and Flagella ${ }^{2}(3123-3260 \mathrm{~K})$ and the heat capacity data of Ronchi et al. ${ }^{3}(3100-4500 \mathrm{~K})$. The data were weighted according to their uncertainties. Although measurements were made by Ronchi et al. to $8000 \mathrm{~K}$, the data fit was limited to the temperature range 3100 to $4500 \mathrm{~K}$ because the range of interest for reactor safety calculations is from the melting point $(3120 \mathrm{~K})$ to $4500 \mathrm{~K}$ and the uncertainties in the determined heat capacities increase significantly with temperature above $4500 \mathrm{~K}$.

For the temperature range 3120 to $4500 \mathrm{~K}$, the recommended equation for the enthalpy increment of liquid $\mathrm{UO}_{2}$ in $\mathrm{J} \mathrm{mol}^{-1}$ is:

$$
H(T)-H(298.15 K)=8.0383 \times 10^{5}-8.4199 \times 10^{-2} T-\frac{1.3288 \times 10^{9}}{T}
$$

The heat capacity at constant pressure is the temperature derivative of the enthalpy. For 3120 to $4500 \mathrm{~K}$, the recommended equation for the heat capacity, $C_{P}$, in $\mathrm{J} \mathrm{mol}^{-1} \mathrm{~K}^{-1}$ is:

$$
C_{P}=-8.4199 \times 10^{-2}+\frac{1.3288 \times 10^{9}}{T^{2}}
$$

In Eqs.(1) and (2), the temperature, $T$, is in $\mathrm{K}$. Recommended values of the enthalpy increment in $\mathrm{J} \mathrm{mol}^{-1}$ and the heat capacity in $\mathrm{J} \mathrm{mol}^{-1} \mathrm{~K}^{-1}$ are tabulated in Table 1.2.1 and shown in Figures 1.2.1 and 1.2.2.

The recommended equations for the enthalpy increment in $\mathrm{J} \mathrm{kg}^{-1}$ and the heat capacity at constant pressure in $\mathrm{J} \mathrm{kg}^{-1} \mathrm{~K}^{-1}$ are

$$
H(T)-H(298.15 K)=2.9768 \times 10^{6}-0.31182 T-\frac{4.9211 \times 10^{9}}{T} .
$$

and 


$$
C_{P}=-0.31182+\frac{4.9211 \times 10^{9}}{T^{2}}
$$

where temperature, $T$, is in $\mathrm{K}$. Table 1.2 .2 gives values for the enthalpy increment in $\mathrm{J} \mathrm{kg}^{-1}$ and the heat capacity in $\mathrm{J} \mathrm{kg}^{-1} \mathrm{~K}^{-1}$.

\section{Uncertainties}

The uncertainty in the recommended values for the enthalpy of liquid $\mathrm{UO}_{2}$ is $2 \%$ from 3120 to $3500 \mathrm{~K}$ and $10 \%$ in the extrapolated range from 3500 through $4500 \mathrm{~K}$. The recommended values for the heat capacity of liquid $\mathrm{UO}_{2}$ have larger uncertainties. From 3120 through $3400 \mathrm{~K}$, the uncertainty is $10 \%$. The uncertainty increases linearly from $10 \%$ at $3400 \mathrm{~K}$ to $25 \%$ at $4500 \mathrm{~K}$. Uncertainties have been included in Figures 1.2.1 and 1.2.2.

\section{Discussion}

Enthalpy Experiments - Both Leibowitz et al. ${ }^{1}$ and Hein and Flagella ${ }^{2}$ used drop calorimetry to measure the enthalpy increments of molten $\mathrm{UO}_{2}$ encapsulated in tungsten. Leibowitz et al. made six measurements from 3173 to $3523 \mathrm{~K}$; Hein and Flagella made six measurements in the temperature range from 3123 to $3264 \mathrm{~K}$ but the datum at $3124 \mathrm{~K}$ was low relative to other data and discarded by Hein and Flagella. These two sets of data are in excellent agreement even though the samples differed in stoichiometry. The sample of Hein and Flagella had an $\mathrm{O} / \mathrm{M}=2.003 \pm 0.003$ at the start of the measurements and an $\mathrm{O} / \mathrm{M}=2.000 \pm 0.003$ at the end of the experiments, whereas the sample of Leibowitz et al. had an $\mathrm{O} / \mathrm{M}=2.015$ at the start and an $\mathrm{O} / \mathrm{M}=1.98$ at the end of the experiments. Although the change in $\mathrm{O} / \mathrm{M}$ was greater in the experiments of Leibowitz et al. than in those of Hein and Flagella, the range in $\mathrm{O} / \mathrm{M}$ is well within the range expected for variations of $\mathrm{O} / \mathrm{M}$ in reactor fuel. The greater variation in the $\mathrm{O} / \mathrm{M}$ in the experiments of Leibowitz et al. is most likely due to reduction from tungsten at high temperatures $(-3500 \mathrm{~K})$ because the effect of tungsten would increase as the melting point of tungsten $(3685 \mathrm{~K})$ is approached. Four of the six measurements of Leibowitz et al. were above the highest temperature measured by Hein and Flagella. Rand et al. ${ }^{4}$ fit the data of Leibowitz et al. ${ }^{1}$ and of Hein and Flagella ${ }^{2}$ to a linear equation: 


$$
H(T)-H(298.15 K)=130.95 T-3091
$$

where the enthalpy increment is in $\mathrm{J} \mathrm{mol}^{-1}$ and temperature $(T)$ is in $\mathrm{K}$. This equation fits the data with a standard deviation of $0.41 \%$. This equation has been recommended for the enthalpy of liquid $\mathrm{UO}_{2}$ by Fink et al. ${ }^{5}$ and by Harding, Martin, and Potter. ${ }^{6}$ The data of Leibowitz et al. ${ }^{1}$ and of Hein and Flagella ${ }^{2}$ and the linear equation of Rand et al. ${ }^{4}$ are shown in Figure 1.2.3.

Heat Capacity Experiments - The heat capacity of molten $\mathrm{UO}_{2}$ has been determined by Ronchi et al. ${ }^{3}$ from the analysis of cooling curves of 0.5 - to 1-mm-diameter $\mathrm{UO}_{2}$ microspheres heated to $3100-8000 \mathrm{~K}$ by four tetrahedrally oriented Nd:YAG lasers. The sintered $\mathrm{UO}_{2}$ microspheres were suspended on a tungsten needle in an inert atmosphere autoclave at pressures up to $1000 \mathrm{bar}(100 \mathrm{MPa})$. Analysis of the experiments was based on an energy balance of the rate of input energy and the enthalpy increase of the sample. The determination of the heat capacity is based on the measurement of the sample surface-temperature history during heating and cooling. Since, in most cases, the laser-energy deposition rate cannot be assessed with precision, the cooling branch of the curve is used preferentially. ${ }^{7}$ Consequently, these difficult experiments required accurate (1) measurements of the sample temperature during and after laser pulse heating, (2) evaluation of energy loss rates, and (3) determination of the heat transport in the sample.

The experimenters took great care to minimize measurement errors as much as possible and to assess all energy losses. In an effort to reduce the errors due to optical absorption by the vapor surrounding the sample, ${ }^{8}$ temperatures were measured using a six-wavelength optical pyrometer. Melting experiments of oxides and refractory metals, including tungsten, indicated that the accuracy of the temperature measurement was within $\pm 10 \mathrm{~K}$. Measurements of the freezing temperature of $\mathrm{UO}_{2}$ on various samples indicated that it was in the interval $3070 \pm 20 \mathrm{~K}$ for samples heated in an inert atmosphere with up to 0.1 bar $(0.01 \mathrm{MPa})$ of oxygen. Higher melting temperatures ( $3140 \pm$ $20 \mathrm{~K}$ ) were obtained for samples in an inert atmosphere without oxygen. This trend is consistent with the effect of change of $\mathrm{O} / \mathrm{U}$ ratio on the melting temperature. The melting point of stoichiometric $\mathrm{UO}_{2}$ is $3120 \pm 30 \mathrm{~K}$. This value, recommended by Rand et al. ${ }^{4}$ from their analysis of fourteen experimental studies (over a period of 20 years), has been accepted internationally. 
Although Ronchi et al. ${ }^{3}$ cited accurate measurements of lower values ${ }^{9}$ ( $3075 \pm 30 \mathrm{~K}$ ), Adamson et al. ${ }^{10}$ found in their examination of melting behavior of $\mathrm{UO}_{2}$ and $(\mathrm{U}, \mathrm{Pu}) \mathrm{O}_{2}$ as a function of stoichiometry and irradiation that these measurements used a V-filament method, which yields consistently low melting temperatures. The V-filament method is a measurement on uncontained samples supported on a tungsten needle analogous to the method used for heat capacity measurements by Ronchi et al. ${ }^{3}$ Adamson et al. ${ }^{10}$ stated that in the V-filament method pronounced compositional changes occur in the small uncontained samples as a result of rapid incongruent vaporization and in some cases interactions involving oxygen exchange between either the atmosphere or the tungsten support. These changes lead to surface emissivity changes which cause an error in the temperature measurement. Ronchi et al. did not determine the stoichiometry of the microspheres before or after the heat capacity measurements because of the small size of the samples. They commented that oxidation to stoichiometries of $\mathrm{O} / \mathrm{U} \approx 2.03$ cannot be excluded, but no evidence in the formation of $\mathrm{U}_{4} \mathrm{O}_{9}$ was observed in $\mathrm{x}$-ray analysis. Although increases in stoichiometry may have occurred during heating at high pressure in an atmosphere of an inert gas plus oxygen, reductions could have occurred from heating in contact with tungsten in an inert atmosphere. Diffusion of tungsten from the supporting needle into the $\mathrm{UO}_{2}$ was observed above $3000 \mathrm{~K}$. The thickness of the $\mathrm{UO}_{2} /$ tungsten interaction region was a function of the pulse time. For a $20 \mathrm{~ms}$ pulse creating central melting, the chemical interaction only affected a 10 to $20 \mu \mathrm{m}$ region near the tungsten needle and was, therefore, negligible. With repeated pulses, the tungsten precipitates migrated to the outer surface of the microsphere.

Heat losses taken into account during the pulse included radiation losses, evaporation losses, and convective losses. The experimenters observed that the plasma that surrounded their samples was significantly affected by laser excitation (inverse bremsstrahlung and photoeffects). Because the vapor partial pressure of liquid $\mathrm{UO}_{2}$ is high and evaporation of atoms presented a serious experimental complication, the experiments had to be done under high pressures to prevent significant vaporization and mass loss. The type and pressure of the gas in the autoclave was selected based on the equation of state of Fischer ${ }^{11}$ to reduce losses from vaporization to $<1 \%$ of the radiative losses. Heat losses due to heat conduction and convection in the buffer gas were 
determined from similar experiments using tungsten, which has a well-known heat capacity. Convective losses were dominant up to $4000 \mathrm{~K}$.

In analysis of the experiments, Ronchi et al. used an iterative numerical method to find the unique heat capacity $C_{p}(T)$ that satisfies at any time the heat transport equation with the measured temperature boundary conditions and the one-dimensional unsteady energy conservation equation:

$$
\frac{d H}{d t}=\int_{0}^{r_{0}} 4 \pi r^{2} \rho(T) C_{P}(T) \frac{\partial T(r)}{\partial t} d r=\text { losses }
$$

where $H$ is the enthalpy, $\rho(T)$ is the density as a function of temperature, $C_{P}(T)$ is the heat capacity at constant pressure as a function of temperature, $T$ is the temperature, $t$ is the time, and $r_{0}$ is the radius of the $\mathrm{UO}_{2}$ microsphere. The losses in Eq.(6) are defined by the following boundary condition:

For $r=r_{\mathrm{o}}$ and $t>0$,

$$
-k \frac{\partial T}{\partial r}=\epsilon \sigma\left(T_{S}^{4}-T_{A}^{4}\right)+D\left(T_{S}-T_{A}\right)-\phi_{L}(t)
$$

where

$k=$ thermal conductivity of the sphere,

$T_{S}=$ sphere surface temperature,

$T_{A}=$ ambient temperature,

$\sigma=$ Stefan-Boltzmann constant,

$\epsilon=$ total hemispherical emissivity,

$r_{0}=$ outer radius of the sphere,

$D=$ coefficient of convective and conductive heat losses to the environment,

and $\phi_{L}=$ laser energy flux deposited onto the surface.

The quality of the experiments and selection of analyzed pulses was based on post-test metallographic examination of the microsphere to determine the integrity of the zone beneath the 
measured area. Because severe cracking and large voids influenced temperature measurements, data from samples with defects in the vicinity of the measured area were discarded. Of 120 laser shots, only 20 were considered of sufficient quality for data analysis. Figure 1.2.4 shows the heat capacity data and uncertainties from Ronchi et al. The data were extracted from Figure 14 of Reference 3 because the experimenters did not tabulate their data. The points designated as "Ronchi (Not Used)" in the legend of Figure 1.2.4 indicate data that the experimenters considered to be in error and were discarded in their data analysis. They fit their data to the equation:

$$
\begin{aligned}
C_{P}= & 277+\frac{1.1 \times 10^{7}}{T^{2}} \exp \left(\frac{15500 \pm 1000}{T}\right) \\
& +\frac{1.0 \times 10^{12}}{T^{2}} \exp \left(-\frac{35500 \pm 4000}{T}\right)
\end{aligned}
$$

where $T$ is the temperature in $\mathrm{K}$ and $C_{P}$ is the heat capacity in $\mathrm{J} \mathrm{kg}^{-1} \mathrm{~K}^{-1}$. Heat capacities calculated with this equation are shown in Figure 1.2.4 as the curve labeled "RHSH Eq."

The experimenters commented ${ }^{3}$ that the accuracy of the heat capacities obtained from their data analysis depended on the spherical symmetry and the precision of the physical properties used in the analysis. The data reduction and analysis by Ronchi et al. ${ }^{3}$ assumed spherical symmetry of the heat pulse, spherical symmetry of the temperature distribution in the microsphere, and maintenance of the spherical shape of the microsphere throughout the measurement. Because the surface temperature was measured on only a small area of the sample, the analysis is only viable if this temperature can be assumed to be homogeneous and if the internal temperature field can be considered spherically symmetric. ${ }^{7}$ Although the experimenters commented that post-test examination of their samples showed that the melting front was approximately circular, it is not clear from the paper that all the necessary spherical symmetries were always maintained throughout the measurements. Peak surface temperatures of 3100 to $7850 \mathrm{~K}$ were achieved using input laser powers of 40 to $500 \mathrm{MW} / \mathrm{m}^{2}$ with pulse durations ranging from 153 to $10 \mathrm{~ms}$. The experimenters commented that the pulse duration was limited because the liquid adhered to the supporting tungsten needle for only a few tens of milliseconds before dropping. It is not clear how long the spherical 
symmetry of the liquid was maintained because the liquid drop must deform prior to dropping from the needle in tens of milliseconds. The plume of hot gas around the sample during the laser heating, shown in photographs in Figure 6 of Reference 3 and Figure 4 of Reference 7, was not spherical. It is not clear if this departure from spherical symmetry was due to (1) gas flow in the autoclave, (2) nonspherical energy input and heat transfer, (3) change in the sample shape from that of a sphere, or some combination of these mechanisms.

Because the reliability of the calculated heat capacities depends on the accuracy of the physical properties used in the data analysis, the equations used for thermal conductivity and density have been compared with literature recommendations. Ronchi et al ${ }^{3}$ calculated the density of solid $\mathrm{UO}_{2}$ from

$$
\rho^{S}(T)=10970\left[1+2.04 \times 10^{-5}(T-273)+8.7 \times 10^{-9}(T-273)^{2}\right]^{-1}
$$

where density $\rho^{S}$ is in $\mathrm{kg} \mathrm{m}^{-3}$ and $T$ is in $\mathrm{K}$. Densities calculated with this equation agree within $2 \%$ with values recommended in the recent assessment by Martin. ${ }^{12}$ The thermal conductivity of solid $\mathrm{UO}_{2}$ in $\mathrm{W} \mathrm{m}^{-1} \mathrm{~K}^{-1}$ was obtained from the equation of Hyland: ${ }^{13}$

$$
k(T)=(2.3 \pm 0.4)+\frac{2.25 \times 10^{5}}{T} \exp \left(-\frac{12410}{T}\right)
$$

where $T$ is in $\mathrm{K}$. Values calculated with this equation agree within $8 \%$ with the values recently recommended by Harding and Martin. ${ }^{14}$ Both are in good agreement with the available data.

Ronchi et al. ${ }^{3}$ calculated the liquid density of $\mathrm{UO}_{2}$ from their least-squares fit to the data of Christensen ${ }^{15}$ and Drotning: ${ }^{16}$

$$
\rho^{L}(T)=10970\left[1+9.30 \times 10^{-5}(T-273)\right]^{-1}
$$

where density is in $\mathrm{kg} \mathrm{m}^{-3}$ and $T$ is in $\mathrm{K}$. The form selected for this equation is the same as that for the solid density. Values calculated with this equation differ significantly from those obtained from the equation recommended by Drotning and the recent equation of Breitung and Reil, ${ }^{17}$ which is 
based on in-reactor measurements of the density and thermal expansion from the melting point to $8000 \mathrm{~K}$. The equation of Breitung and Reil ${ }^{17}$ is

$$
\rho^{L}=8860-0.9285(T-3120)
$$

where density $\left(\rho^{L}\right)$ is in $\mathrm{kg} \mathrm{m}^{-3}$ and $T$ is in $\mathrm{K}$. Densities obtained from the equation by Breitung and Reil are in good agreement with values recommended by Drotning (within $1.2 \%$ from 3120 to $7600 \mathrm{~K}$ ), and within $2.5 \%$ of the densities recommended from the melting point to $7600 \mathrm{~K}$ in an independent assessment by Harding, Martin, and Potter. ${ }^{6}$ In Figure 1.2.5, densities calculated with the equation given by Ronchi et al. $^{3}$ are compared with the experimental data of Drotning and of Christensen, and with the equation recommended by Breitung and Reil. Densities calculated with the equation used by Ronchi et al. show a systematic deviation compared to densities calculated from the equation of Breitung and Reil. They deviate by $-2 \%$ at the melting point, $+4 \%$ at $4500 \mathrm{~K},+16 \%$ at $6000 \mathrm{~K}$, and $+40 \%$ at $7600 \mathrm{~K}$. Although the analytical form of equation selected by Ronchi et al. gives decreasing densities with increasing temperature, the densities do not decrease as fast as in the linear equations recommended by Breitung and Reil and by Christensen. Fischer ${ }^{11}$ commented that the linear decrease with temperature of the liquid density is well established by existing experiments and the only physical reason for the liquid density to deviate from a straight line is due to the approach of the critical point where the deviation is more negative. The critical temperature and density given by Fischer ${ }^{11}$ are respectively $10600 \mathrm{~K}$ and $1560 \mathrm{~kg} \mathrm{~m}^{-3}$. The possibility exists that the density equation used by Ronchi et al. includes the increase of density with pressure since experiments at higher temperatures were performed at high pressure. However, Ronchi et al. made no mention of including the effects of pressure in their equation for the liquid density. They simply stated that the data of Drotning and of Christensen were fit to Eq. (11). Breitung and Reil have commented that along the saturation line the change in density due to increasing pressure is much smaller than the change in density due to thermal expansion. ${ }^{17}$ Even at $8000 \mathrm{~K}$, the correction of density for saturation pressure is only a few percent, ${ }^{17}$ so the effects of pressure can be ignored. Thus, it is unclear why the equation given by Ronchi et al. $^{3}$ for the liquid density or $\mathrm{UO}_{2}$ deviates 
so greatly from the expected liquid density behavior and recommended densities at high temperatures.

For the thermal conductivity of liquid $\mathrm{UO}_{2}$, Ronchi et al. used $2.5 \mathrm{~W} \mathrm{~m}^{-1} \mathrm{~K}^{-1}$, which is the value obtained just above the melting point in recent measurements by $\operatorname{Tasman}^{18}$ at the Institute for Transuranium Elements. This value is in agreement with the average value of $2.2 \mathrm{~W} \mathrm{~m}^{-1} \mathrm{~K}^{-1}$ previously obtained by Tasman et al. ${ }^{19}$ for the temperature range $3103-3473 \mathrm{~K}$. In these earlier measurements, a thermal conductivity of $2.4 \mathrm{~W} \mathrm{~m}^{-1} \mathrm{~K}^{-1}$ was obtained in an experiment in which the maximum top center temperature of the moiten pool was $3473 \mathrm{~K}$. In addition to the thermal conductivity measurements of Tasman et al. ${ }^{18,19} \mathrm{UO}_{2}$ thermal diffusivity measurements were made by Kim et al. ${ }^{20}$ from 3187 to $3310 \mathrm{~K}$ and by Otter and Damien ${ }^{21}$ in the temperature range of 3133 to $3273 \mathrm{~K}$. The available experimental data on the thermal diffusivity and thermal conductivity ${ }^{19}$ of $\mathrm{UO}_{2}$ were reassessed in 1985 by Fink and Leibowitz, ${ }^{22}$ who recommended $5.6 \mathrm{~W} \mathrm{~m}^{-1} \mathrm{~K}^{-1}$ for the thermal conductivity from the melting point to $3500 \mathrm{~K}$. In this reassessment, Fink and Leibowitz used $131 \mathrm{~J} \mathrm{~mol}^{-1} \mathrm{~K}^{-1}\left(485 \mathrm{~J} \mathrm{~kg}^{-1} \mathrm{~K}^{-1}\right.$ ), the constant heat capacity given by the enthalpy equation of Rand et al. ${ }^{4}$ If the heat capacities given by Ronchi et al. had been used in the reassessment, lower thermal conductivity values ( 3.3 to $5.8 \mathrm{~W} \mathrm{~m}^{-1} \mathrm{~K}^{-1}$ ) would have been obtained in the assessment of these data. Ronchi et al. commented that the existence of a systematic error in the experimental measurements of Tasman cannot be excluded. At low temperatures, their calculated heat capacity is approximately inversely proportional to the thermal conductivity. Thus, selection of a higher thermal conductivity in this low temperature region would give lower heat capacities.

Ronchi et al. have assumed a constant thermal conductivity based on the assumption that thermal conductivity of liquids obey the Lorenz rule and are therefore only a weak function of temperature. Because no temperature dependence was evident in any of the thermal diffusivity data and no information is available on variation of thermal conductivity with temperature from the

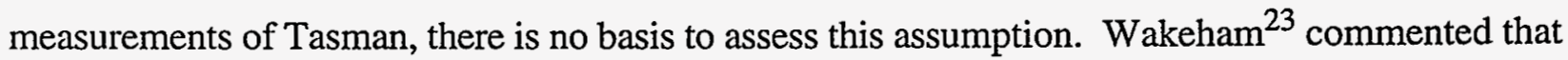
the thermal conductivities of a number of liquids at high pressure are stronger functions of density change with pressure than functions of temperature. In their analysis, Ronchi et al. did not consider the effects of changes in pressure on the thermal conductivity, although the high temperature 
measurements were done at pressures on the order of $100 \mathrm{MPa}(1000 \mathrm{bar})$. Wakeham ${ }^{23}$ found that for pressure variations from 0.1 to $700 \mathrm{MPa}$, the reduced thermal conductivity decreased as a function of increasing reduced molar volume (inverse reduced density).

Relationship Between Enthalpy and Heat Capacity Measurements, $C_{P}$ and $C_{\sigma}$ - The enthalpy measurements by Leibowitz et al. ${ }^{1}$ and by Hein and Flagella ${ }^{2}$ were performed on encapsulated samples so that the liquid was maintained in equilibrium with a small amount of vapor, giving the enthalpy along the saturation curve. The temperature derivative of these enthalpies is the heat capacity along the saturation curve, $C_{\sigma}$, which is related to the heat capacity at constant pressure, $C_{P}$, by

$$
\left(\frac{\partial H}{\partial T}\right)_{\sigma}=C_{\sigma}=C_{P}-\frac{\left(T \alpha_{P}-1\right)}{\rho}\left(\frac{\partial P}{\partial T}\right)_{\sigma}
$$

where $P$ is the vapor pressure, $\rho$ is the density, $\alpha_{P}$ is the instantaneous thermal expansion coefficient, $T$ is the temperature, and the subscript $\sigma$ designates the saturation curve. For most liquids, the difference between $C_{P}$ and $C_{\sigma}$ is not significant at temperatures below $75 \%$ of the critical temperature. Recent vapor pressure measurements by Breitung and Reil ${ }^{17}$ and equation-of-state calculations by Fischer ${ }^{11}$ indicate that the critical temperature for $\mathrm{UO}_{2}$ is $10600 \mathrm{~K}$. Thus, differences between $C_{P}$ and $C_{\sigma}$ are not significant below $7950 \mathrm{~K}$. So for the temperature range of the $\mathrm{UO}_{2}$ enthalpy data, the temperature derivative of the equation that fits the enthalpy measurements may be considered as the heat capacity at constant pressure.

The heat capacity measurements of Ronchi et al. were not done at constant pressure because measurements at constant pressure would have resulted in complete vaporization of the sample as the temperature was increased. Ronchi et al. used the saturated and total pressures from the equation of state of Fischer ${ }^{11}$ to determine the pressure needed to prevent large losses from vaporization. However, the extent of pressure increase beyond the saturation pressure is not clear from the description of the experiment. In the analysis of Ronchi et al. and in the analysis below, the heat capacities reported by Ronchi et al. are assumed to be equivalent to $C_{P}$. 
Combined Analysis of Enthalpy and Heat Capacity Data - Ronchi et al. ${ }^{3}$ stated that the enthalpy data of Hein and Flagella and of Leibowitz et al. are consistent with their Equation 20, which will subsequently be referred to as "RHSH Eq. 20":

$$
C_{P}(T)=277+\frac{(2370 \pm 290)}{(T / 1000)^{2}}
$$

where heat capacity is in $\mathrm{J} \mathrm{kg}^{-1} \mathrm{~K}^{-1}$ and temperature is in $\mathrm{K}$. The first term of this equation is the Neumann-Kropp heat capacity value for a harmonic triatomic lattice $(9 \mathrm{R})$ which was fixed so that the only free parameter in the fitting procedure was the coefficient for the second term. They fit their heat capacity data from 3200 to $4500 \mathrm{~K}$ to an equation of the same form allowing both parameters to vary, giving their Equation 21, which will be referred to as "RHSH Eq. 21":

$$
C_{P}(T)=67.7+\frac{(3831 \pm 300)}{(T / 1000)^{2}}
$$

where heat capacity is in $\mathrm{J} \mathrm{kg}^{-1} \mathrm{~K}^{-1}$ and temperature is in $\mathrm{K}$. A graph of this fit has been included in Figure 1.2.4 for comparison with the fit given by Ronchi et al. for the entire temperature range 3100 to $8000 \mathrm{~K}$.

A weighted combined fit has been performed for the enthalpy data of Leibowitz et al. ${ }^{1}$ from 3173 to $3523 \mathrm{~K}$ and of Hein and Flagella ${ }^{2}$ from 3123 to $3260 \mathrm{~K}$ and the heat capacity data of Ronchi et al. ${ }^{3}$ from 3100 to $4500 \mathrm{~K}$. Only the heat capacities at or below $4500 \mathrm{~K}$ have been included in this combined analysis because:

1. above $4500 \mathrm{~K}$, the deviations of the densities used by Ronchi et al. increases above $4 \%$ from accepted liquid densities;

2. at higher temperatures, the pressure in the autoclave was increased significantly to prevent sample vaporization;

3. at $4500 \mathrm{~K}$ and above, oxygen was added to the gas in an attempt to control the change in sample stoichiometry arising from vaporization, so greater uncertainty exists in the stoichiometry of the sample and in the temperature measurements; 
4. as the temperature increases, sample loss due to laser ablation and ionization effects from the laser heating become more pronounced;

5. data above $4500 \mathrm{~K}$ are not needed for light water nuclear reactor severe accident analysis because higher temperatures are unlikely in these accident scenarios.

The form of the equation for the heat capacity used in this combined analysis is that suggested by Ronchi et al. in their data analysis in this temperature range. A weighted chi-squared minimization was used to determine the coefficients with the constraint that the enthalpy increment at the accepted melting point $(3120 \mathrm{~K})$ equals that given by the enthalpy equation of Rand et al. ${ }^{4}$ This constraint provides consistency with the accepted heats of fusion at the accepted melting point. The data have been weighted by the inverse of their uncertainties. Because the enthalpy data are in excellent agreement in the two independent experiments, 1,2 which used standard techniques with calibration standards, and the stoichiometry change in these enthalpy experiments were within the variation for reactor fuel, these data were considered to be of higher quality than the heat capacity data. The uncertainty in the enthalpy data has been estimated as $2 \%$. Ronchi et al. stated that the uncertainty in the heat capacity data is on the order of 15 to $20 \%$ from 3000 to $5000 \mathrm{~K}$. A $15 \%$ uncertainty has been assumed for the heat capacity data. Thus, the enthalpy chi-squared has been weighted by a factor of 50 relative to the heat capacity chi-squared in the combined chi-squared minimization.

Equations (1) and (2) are, respectively, the enthalpy and heat capacity equations obtained from this weighted chi-squared minimization. In Figure 1.2.6, this weighted fit to enthalpy and heat capacity data is compared with the enthalpy data, the linear equation of Rand et al., the RHSH Eq. 20 , and the enthalpies obtained by Ronchi et al. from fitting the heat capacity data from the melting point to $8000 \mathrm{~K}$ adjusted to a melting point of $3120 \mathrm{~K}$ and the enthalpy increment of Rand et al. (labeled "RHSH rel 3120"). This weighted equation fits the data to within $0.6 \%$ except for the data at and above $3475 \mathrm{~K}$ which are fit to $1.6 \%$. The greater deviation for the higher temperature data is acceptable because the stoichiometry variation detected by Leibowitz et al. most likely occurred during these high temperature measurements. 
In Figure 1.2.7, the heat capacity data of Ronchi et al. from the melting point to $4500 \mathrm{~K}$ are plotted as a function of the square of the inverse temperature. Included for comparison with the data are the constant heat capacity of Rand et al., RHSH Eq. 20 (which fits the enthalpy data with one free parameter), RHSH Eq. 21 (which fits the heat capacity data with two free parameters), the fit by Ronchi et al. to all the heat capacity data (labeled "RHSH"), and the recommended weighted combined fit to the enthalpy and heat capacity data. This combined fit is much better than the fit to the enthalpy data alone (RHSH Eq. 20) and fits the data as well as the fit given by Ronchi et al. to the heat capacity data for the entire temperature range.

Figure 1.2.8 shows the heat capacity data with the error bars given by Ronchi et al., the fit by Ronchi et al. to data up to $4500 \mathrm{~K}$ (RHSH Eq. 21), the fit by Ronchi et al. to the heat capacities for the entire temperature range (RHSH), and the weighted combined fit to the enthalpy and heat capacities. The combined fit is within the error bars of most of the heat capacity data. Data with error bars that do not intersect this combined fit are also not well represented by the RHSH Eq. 21, indicating that they are not consistent with other heat capacity data in this temperature range. Deviations of the data from the combined fit are within the estimated uncertainty shown in Figure 1.2.2 except for isolated data near $3370 \mathrm{~K}, 3700 \mathrm{~K}$, and $4370 \mathrm{~K}$. 


\section{REFERENCES}

1. L. Leibowitz, M. G. Chasanov, L. W. Mishler, and D. F. Fischer, Enthalpy of Liquid Uranium Dioxide to 3500 K, J. Nucl. Mater. 39 115-116 (1971).

2. R. A. Hein and P. N. Flagella, Enthalpy Measurements of $\mathrm{UO}_{2}$ and Tungsten to $3260 \mathrm{~K}$, General Electric Report GEMP-578 (February 16, 1968).

3. C. Ronchi, J. P. Hiernaut, R. Selfslag, and G. J. Hyland, Laboratory Measurement of the Heat Capacity of Urania up to $8000 \mathrm{~K}$ : I. Experiment, Nuclear Science and Engineering 113, $1-19$ (1993).

4. M. H. Rand, R. J. Ackermann, F. Gronvold, F. L. Oetting, A. Pattoret, The Thermodynamic Properties of the Urania Phase, Rev. Int. Hautes Temp. Refract. 15, 355-365 (1978).

5. J. K. Fink, M. G. Chasanov, and L. Leibowitz, Thermophysical Properties of Uranium Dioxide, J. Nucl. Mater. 102, 17-25 (1981); also as ANL Report ANL-CEN-RSD-80-3, Argonne National Laboratory (April 1981).

6. J. H. Harding, D. G. Martin, and P. E. Potter, Thermophysical and Thermochemical Properties of Fast Reactor Materials, Commission of the European Communities Report EUR 12402 EN (1989).

7. J. P. Hiernaut, and C. Ronchi, Calorimetric Measurements with Acoustic Levitation in HighTemperature Heating Experiments with Pulsed Laser Beams, High Temps-High Pressures 21, 119-130 (1989).

8. C. Ronchi, R, Beukers, H. Heinz, J. P. Hiernaut, and R. Selfslag, Graphite Melting Under Laser Pulse Heating, Int. J. Thermophys. 13 (1) 107-129 (1992).

9. J. L. Bates, Proc. IAEA Symp. Thermodynamics, Vienna, July 22-27 1965, Vol. II, p. 73, International Atomic Energy Agency, Vienna (1966); as referenced by C. Ronchi, J. P. Hiernaut, R. Selfslag, and G. J. Hyland, Laboratory Measurement of the Heat Capacity of Urania up to 8000 K: I. Experiment, Nuclear Science and Engineering 113, 1-19 (1993).

10. M. G. Adamson, E. A. Aitken, and R. W. Caputi, Experimental and Thermodynamic Evaluation of the Melting Behavior of Irradiated Oxide Fuels, J. Nucl. Mater. 130, 349-365 (1985).

11. E. A. Fischer, Evaluation of the Urania Equation of State Based on Recent Vapour Pressure Measurements, Kernforschungszentrum Karlsruhe GmbH Report KfK 4084 (September 1987); Nuclear Science and Engineering 101, 97-116 (1989). 
12. D. G. Martin, The Thermal Expansion of Solid $U_{2}$ and $(U, P u)$ Mixed Oxides - A Review and Recommendations, J. Nucl. Mater. 152, 94-101 (1988).

13. G. J. Hyland, Thermal Conductivity of Solid $\mathrm{UO}_{2}:$ Critique and Recommendation, J. Nucl. Mater. 113, 125-132 (1983).

14. J. H. Harding and D. G. Martin, A Recommendation for the Thermal Conductivity of $U_{2}$, J. Nucl. Mater. 166, 223-226 (1989).

15. J. A. Christensen, Thermal Expansion and Change in Volume of Uranium Dioxide on Melting, J. Am. Ceram. Soc. 46, 607-608 (1963).

16. W. D. Drotning, Thermal Expansion of Molten Uranium Dioxide, Proceedings of the Eighth Symp. On Thermophysical Properties, Gaithersburg, Maryland, June 15-18, 1981, J. V. Sengers, Ed., ASME, New York, Vol. II, pp 245-249 (1981).

17. W. Breitung and K. O. Reil, The Density and Compressibility of Liquid (U,Pu)-Mixed Oxide, Nuclear Science and Engineering 105, 205-217 (1990).

18. H. A. Tasman, Thermal Conductivity of Liquid $\mathrm{UO}_{2}$, Commission of the European Communities Joint Research Centre Annual Report TUAR88, Karlsruhe, Germany EUR12385 , p. 80 (1989), as referenced by C. Ronchi in On the Thermal Conductivity and Diffusivity of Solid and Liquid Uranium Dioxide, J. Phys. Condens. Matter 6, L561-L567 (1994).

19. H. A. Tasman, D. Pel, J. Richter, and H. E. Schmidt, Measurement of the Thermal Conductivity of Liquid $\mathrm{UO}_{2}$, High Temp.-High Pressures 15, 419-431 (1983).

20. C. S. Kim, R. A. Haley, J. Fischer, M. G. Chasanov, and L. Leibowitz, Measurement of Thermal Diffusivity of Molten $\mathrm{UO}_{2}$, Proc. Seventh Symp. On Thermophysical Properties, A. Cezairliyan, Ed., ASME, New York, p. 338-343 (1977).

21. C. Otter and D. Damien, Mesure de la Diffusivite Thermique de $\mathrm{UO}_{2}$ Fondu, High Temp.-High Pressures 16, 1-6 (1984).

22. J. K. Fink and L. Leibowitz, An Analysis of Measurements of the Thermal Conductivity of Liquid Urania, High Temp.-High Pressures 17, 17-26 (1985).

23. W. A. Wakeham, Thermal Conductivity of Liquids Under Pressure, High Temp.-High Pressures 21, 249-259 (1989). 
Table 1.2.1 Enthalpy and Heat Capacity of Liquid $\mathrm{UO}_{2}$ per mole of $\mathrm{UO}_{2}$

\begin{tabular}{|c|c|c|}
\hline \begin{tabular}{|c|} 
Temperature \\
$\mathbf{K}$
\end{tabular} & $\begin{array}{c}\text { Enthalpy } \\
H(T)-H(298.15 \mathrm{~K}) \\
\mathrm{kJ} \mathrm{mol}^{-1}\end{array}$ & $\begin{array}{c}\text { Heat Capacity } \\
C_{P} \\
\mathrm{~J} \mathrm{~mol}^{-1} \mathrm{~K}^{-1} \\
\end{array}$ \\
\hline $\begin{array}{l}3120 \\
3150 \\
3200 \\
3250 \\
\end{array}$ & $\begin{array}{l}378 \\
382 \\
388 \\
395 \\
\end{array}$ & $\begin{array}{r}136 \\
134 \\
130 \\
126 \\
\end{array}$ \\
\hline $\begin{array}{l}3300 \\
3350 \\
3400 \\
3450 \\
3500 \\
\end{array}$ & $\begin{array}{l}401 \\
407 \\
413 \\
418 \\
424\end{array}$ & $\begin{array}{l}122 \\
118 \\
115 \\
112 \\
108 \\
\end{array}$ \\
\hline $\begin{array}{l}3550 \\
3600 \\
3650 \\
3700 \\
3750\end{array}$ & $\begin{array}{l}429 \\
434 \\
439 \\
444 \\
449\end{array}$ & $\begin{array}{c}105 \\
102 \\
100 \\
97.0 \\
94.4\end{array}$ \\
\hline $\begin{array}{r}3800 \\
3850 \\
3900 \\
3950 \\
4000 \\
\end{array}$ & $\begin{array}{l}454 \\
458 \\
463 \\
467 \\
471\end{array}$ & $\begin{array}{l}91.9 \\
89.6 \\
87.3 \\
85.1 \\
83.0 \\
\end{array}$ \\
\hline $\begin{array}{l}4050 \\
4100 \\
4150 \\
4200 \\
4250\end{array}$ & $\begin{array}{l}475 \\
479 \\
483 \\
487 \\
491\end{array}$ & $\begin{array}{l}80.9 \\
79.0 \\
77.1 \\
75.2 \\
73.5 \\
\end{array}$ \\
\hline $\begin{array}{l}4300 \\
4350 \\
4400 \\
4450 \\
4500 \\
\end{array}$ & $\begin{array}{l}494 \\
498 \\
501 \\
505 \\
508 \\
\end{array}$ & $\begin{array}{l}71.8 \\
70.1 \\
68.6 \\
67.0 \\
65.5 \\
\end{array}$ \\
\hline
\end{tabular}


Table 1.2.2 Enthalpy and Heat Capacity of Liquid $\mathrm{UO}_{2}$ per $\mathrm{kg}$ of $\mathrm{UO}_{2}$

\begin{tabular}{|c|c|c|}
\hline $\begin{array}{c}\text { Temperature } \\
\mathbf{K} \\
\end{array}$ & \begin{tabular}{|c|} 
Enthalpy \\
$H(T)-H(298.15 \mathrm{~K})$ \\
$\mathrm{kJ} \mathrm{mol}^{-1}$ \\
\end{tabular} & $\begin{array}{c}\text { Heat Capacity } \\
C_{P} \\
\mathrm{~J} \mathrm{~mol}^{-1} \mathbf{K}^{-1} \\
\end{array}$ \\
\hline $\begin{array}{l}3120 \\
3150 \\
3200 \\
3250 \\
\end{array}$ & $\begin{array}{l}1399 \\
1414 \\
1438 \\
1462\end{array}$ & $\begin{array}{l}505 \\
496 \\
480 \\
466 \\
\end{array}$ \\
\hline $\begin{array}{l}3300 \\
3350 \\
3400 \\
3450 \\
3500 \\
\end{array}$ & $\begin{array}{l}1485 \\
1507 \\
1528 \\
1549 \\
1570\end{array}$ & $\begin{array}{l}452 \\
438 \\
425 \\
413 \\
401\end{array}$ \\
\hline $\begin{array}{l}3550 \\
3600 \\
3650 \\
3700 \\
3750 \\
\end{array}$ & $\begin{array}{l}1589 \\
1609 \\
1627 \\
1646 \\
1663 \\
\end{array}$ & $\begin{array}{l}390 \\
379 \\
369 \\
359 \\
350\end{array}$ \\
\hline $\begin{array}{l}3800 \\
3850 \\
3900 \\
3950 \\
4000 \\
\end{array}$ & $\begin{array}{l}1681 \\
1697 \\
1714 \\
1730 \\
1745 \\
\end{array}$ & $\begin{array}{l}340 \\
332 \\
323 \\
315 \\
307 \\
\end{array}$ \\
\hline $\begin{array}{l}4050 \\
4100 \\
4150 \\
4200 \\
4250\end{array}$ & $\begin{array}{l}1760 \\
1775 \\
1790 \\
1804 \\
1818 \\
\end{array}$ & $\begin{array}{l}300 \\
292 \\
285 \\
279 \\
272 \\
\end{array}$ \\
\hline $\begin{array}{l}4300 \\
4350 \\
4400 \\
4450 \\
4500 \\
\end{array}$ & $\begin{array}{l}1831 \\
1844 \\
1857 \\
1870 \\
1882 \\
\end{array}$ & $\begin{array}{l}266 \\
260 \\
254 \\
248 \\
243\end{array}$ \\
\hline
\end{tabular}


毫

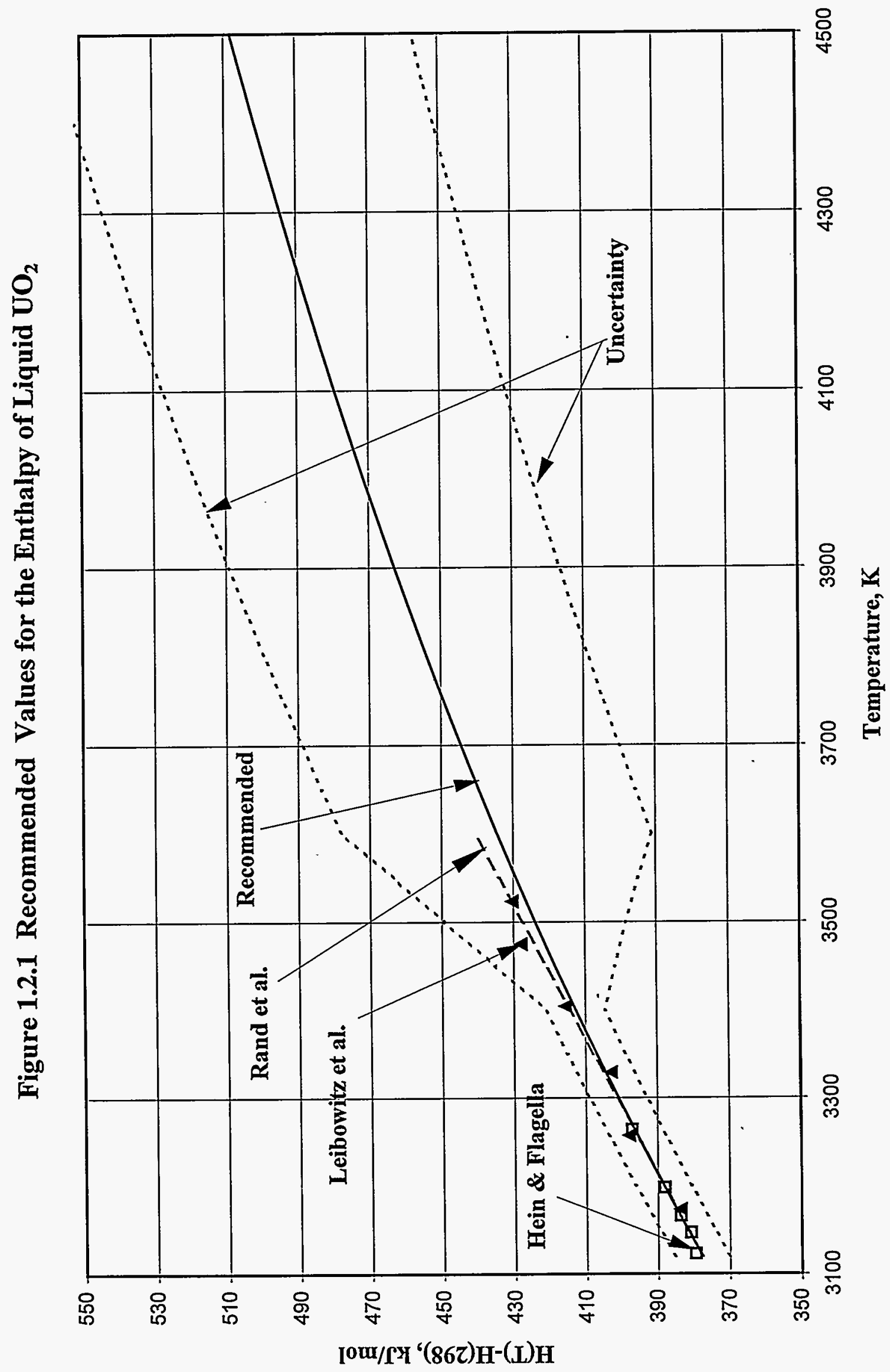

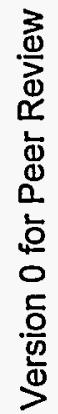




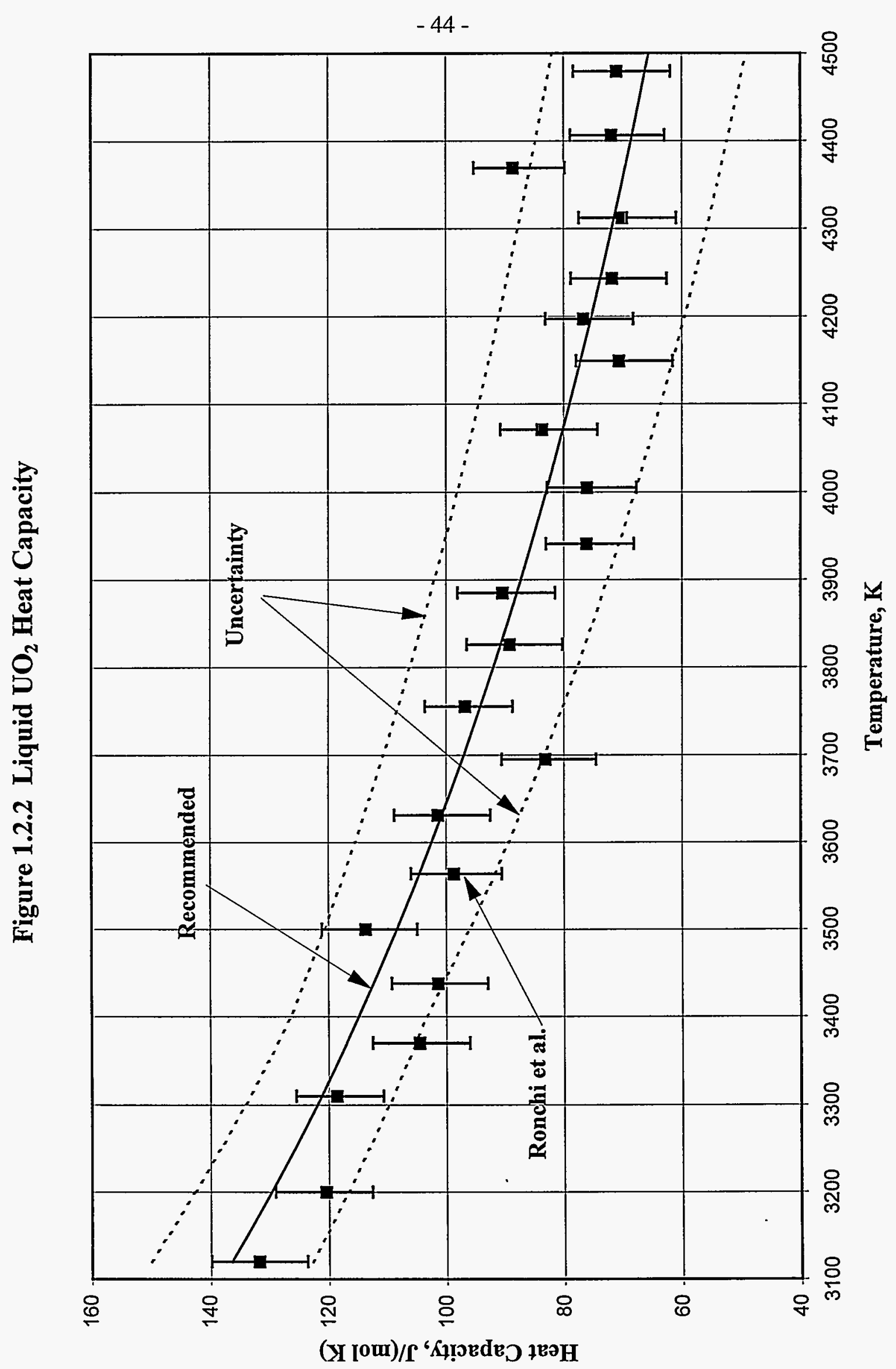

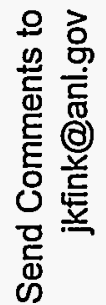


曼

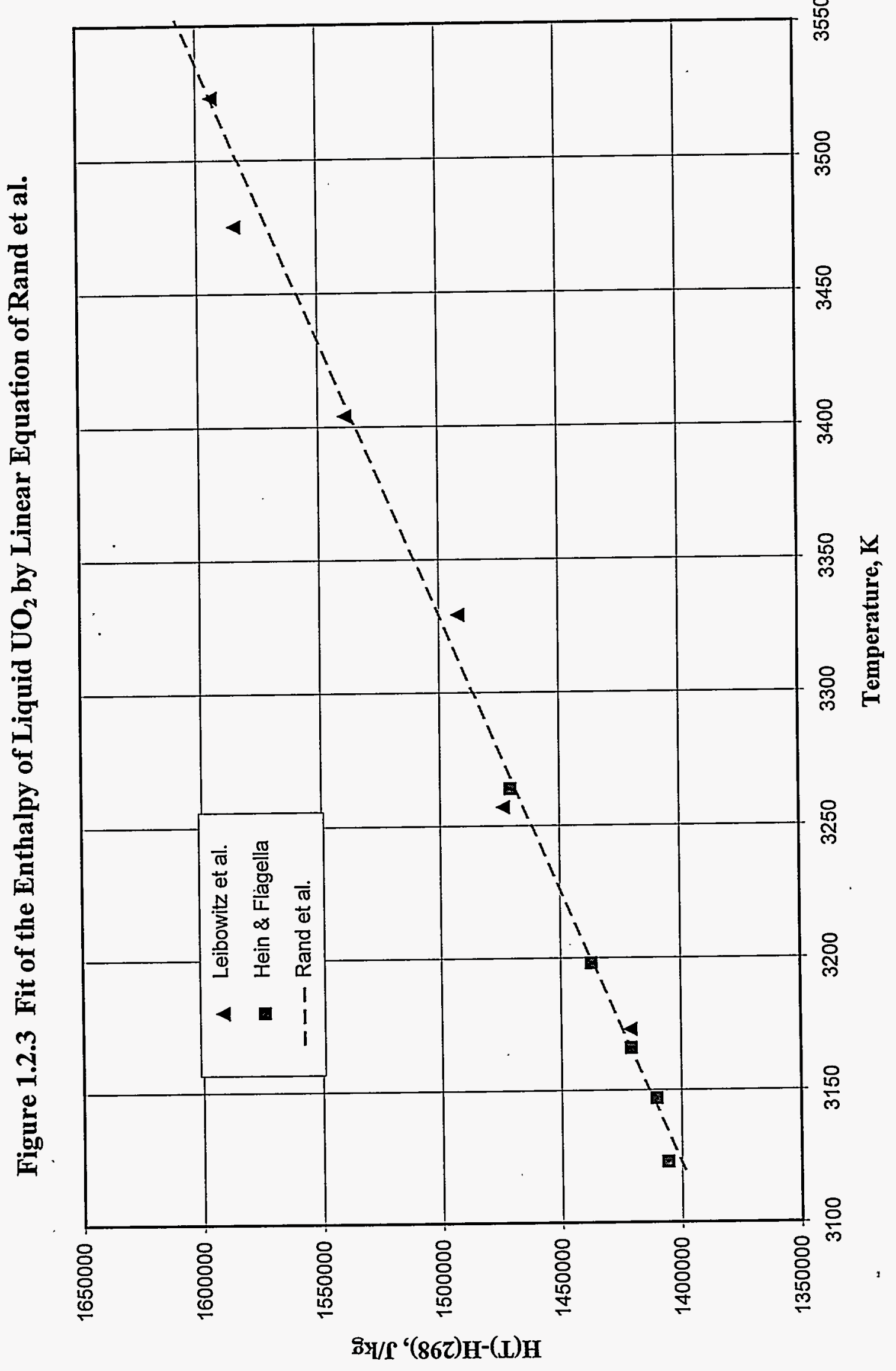


䁶

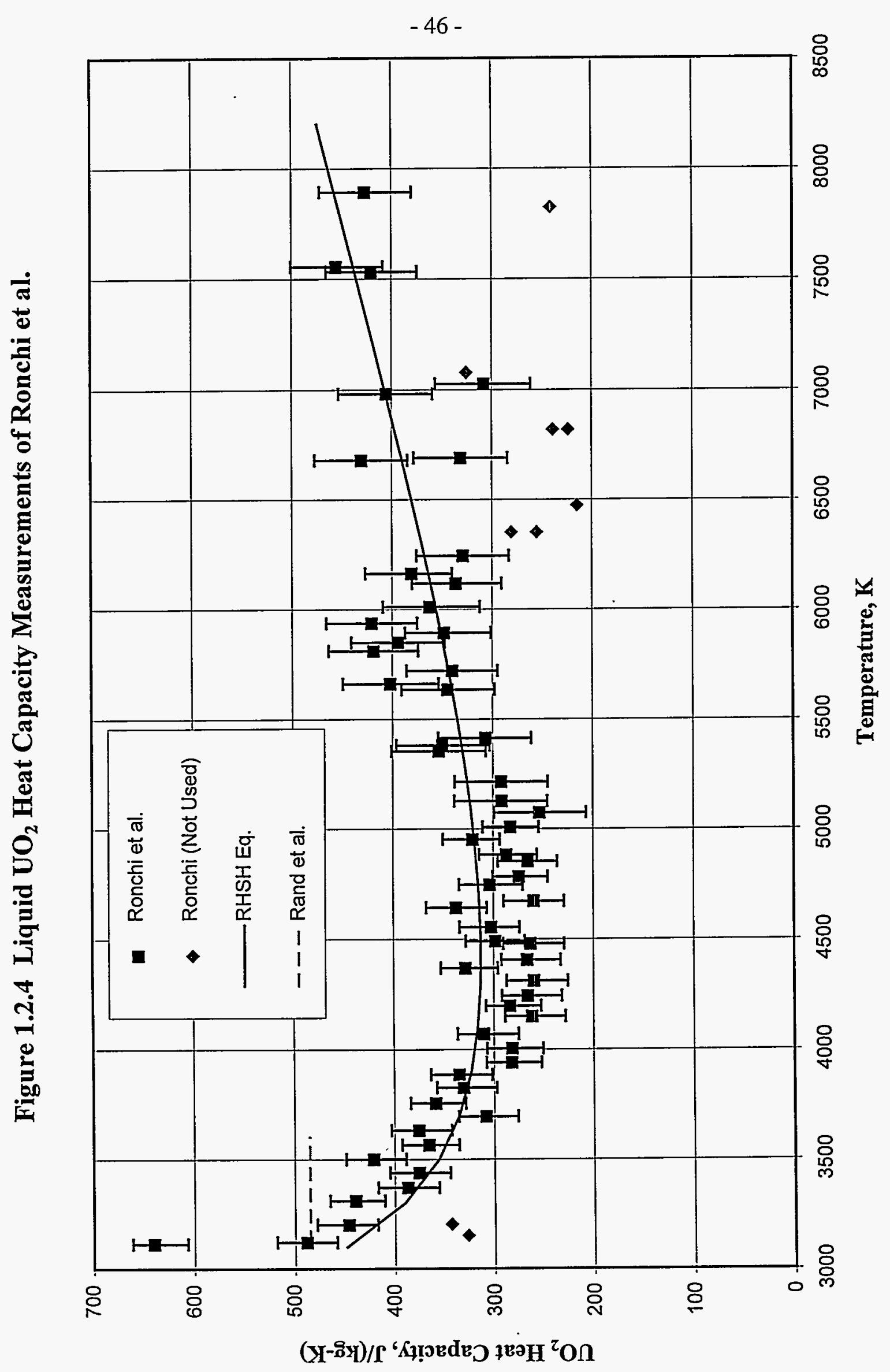

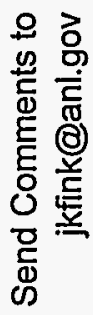




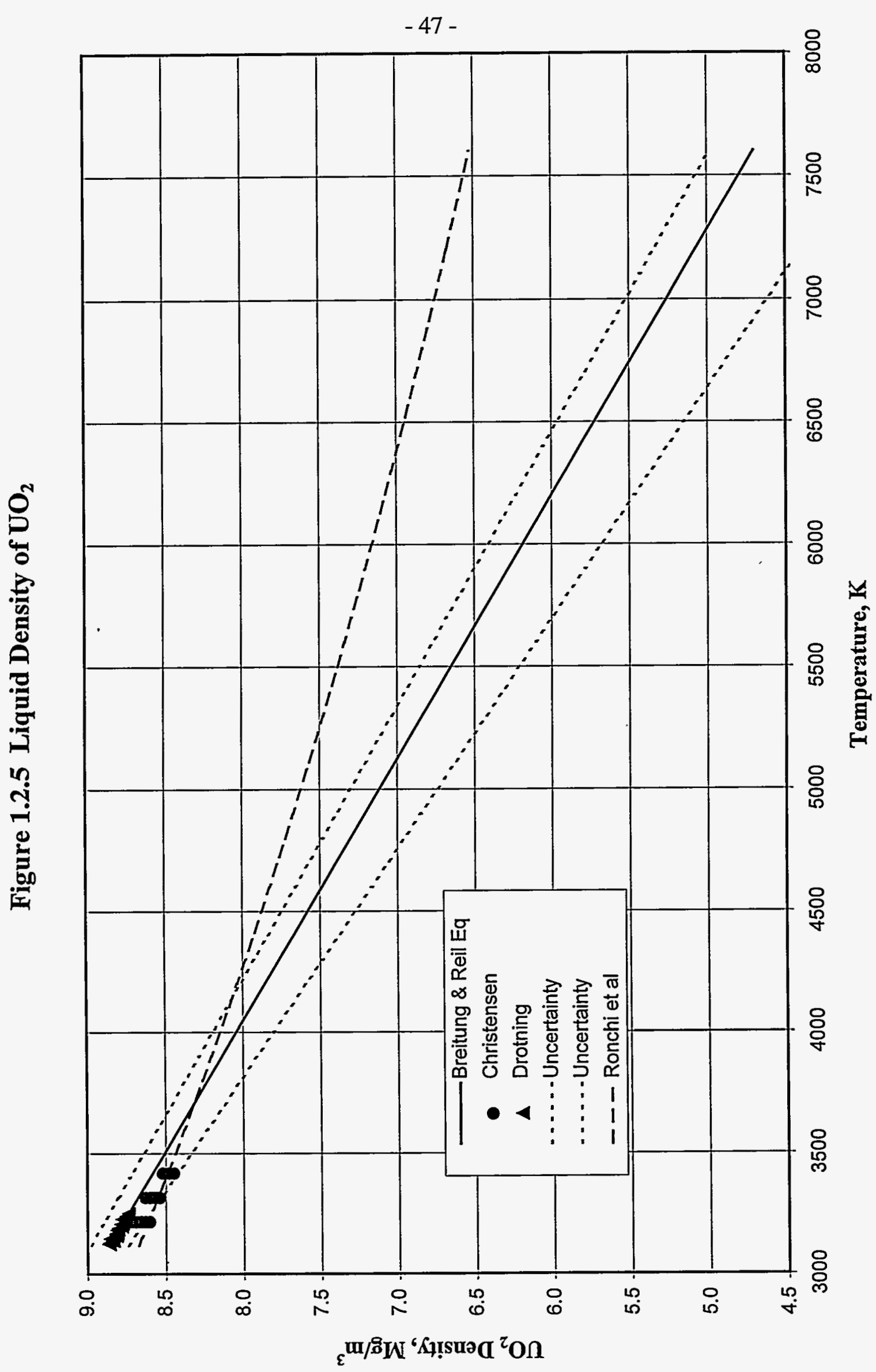

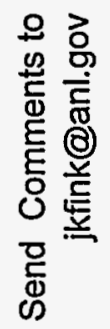

邹 


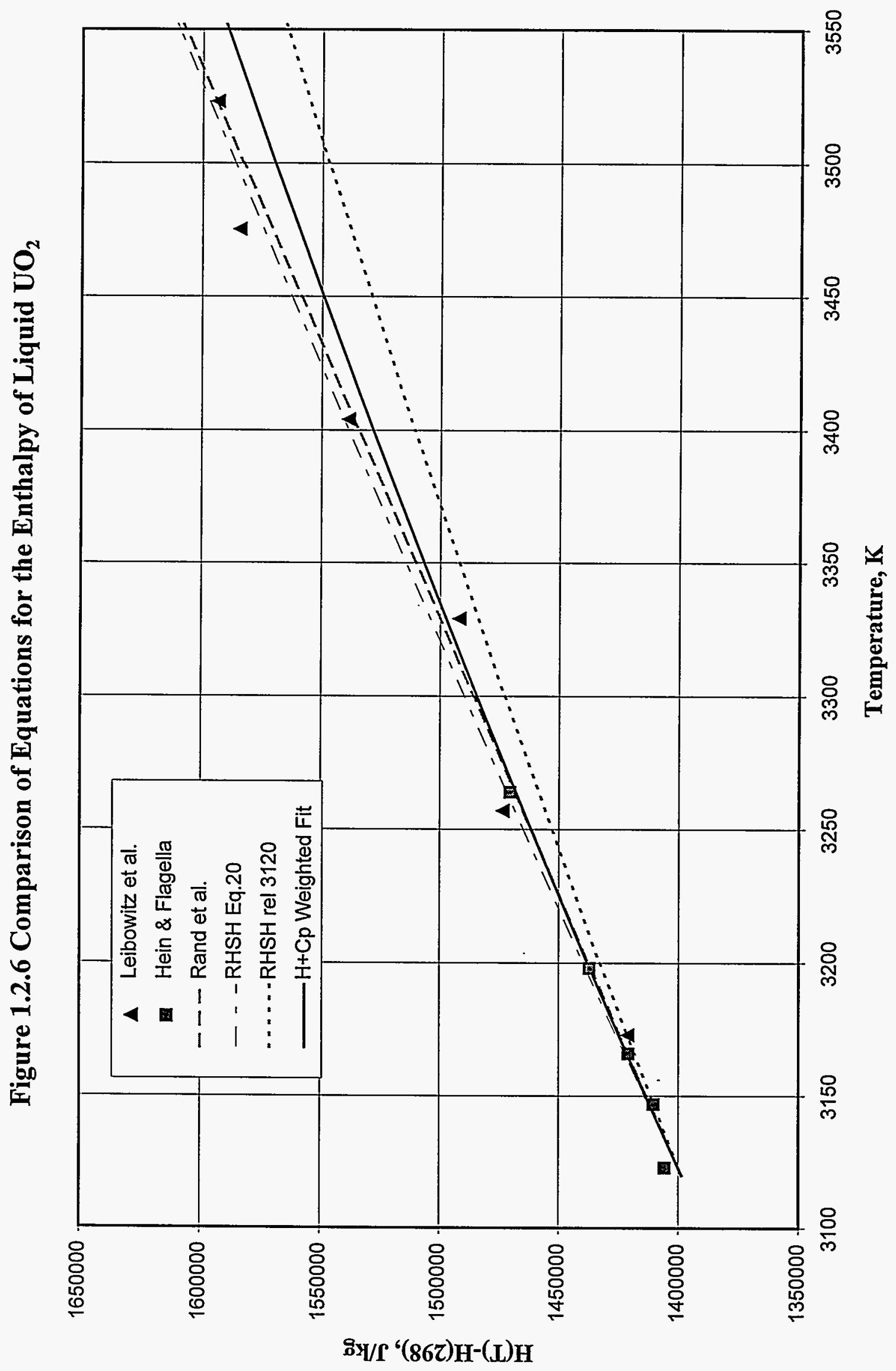

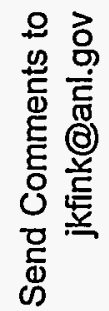

: 
Figure 1.2.7 Comparison of Equations for the Heat Capacity of Liquid $\mathrm{UO}_{2}$

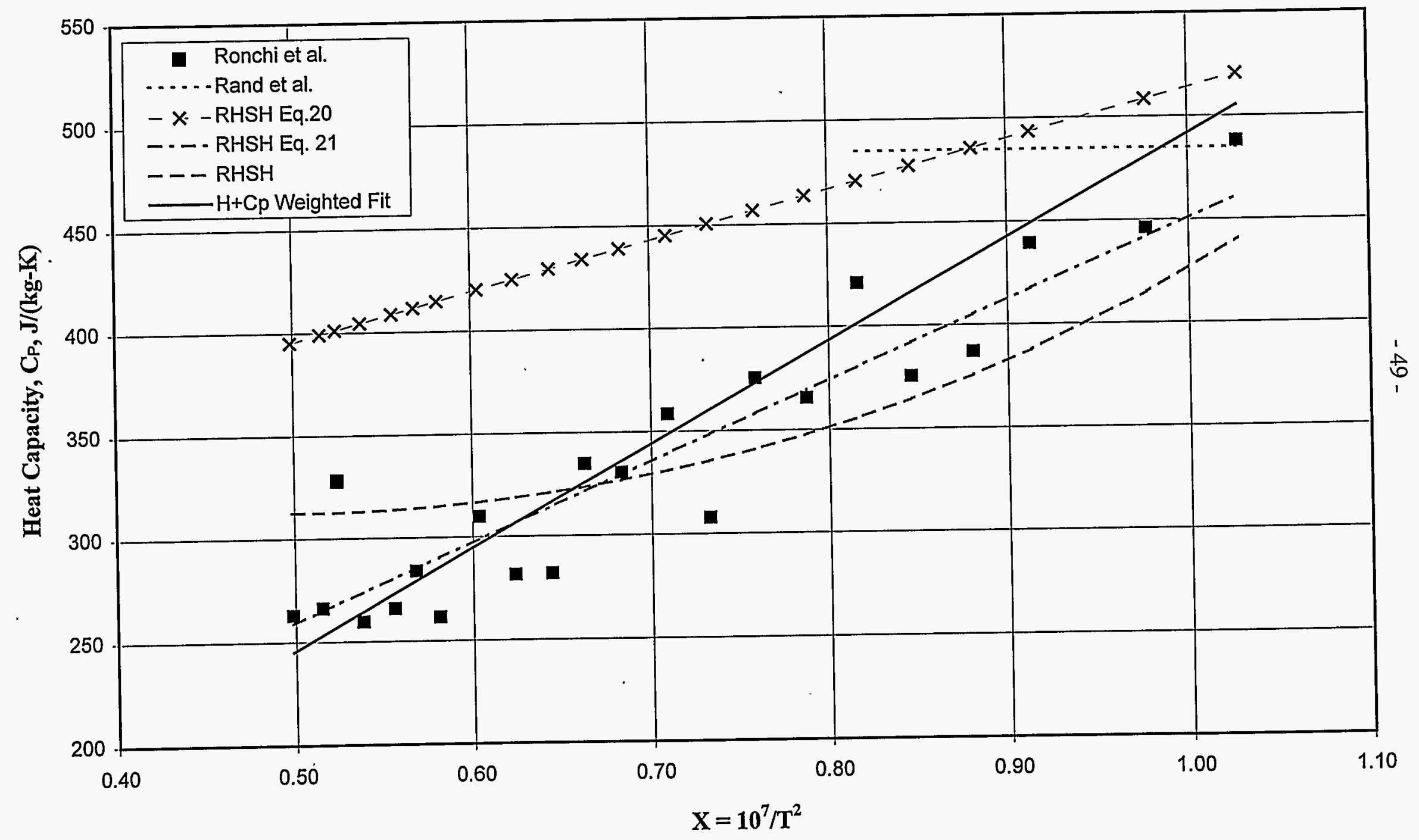

Send Comments to 
Figure 1.2.8 Liquid $\mathrm{UO}_{2}$ Heat Capacity

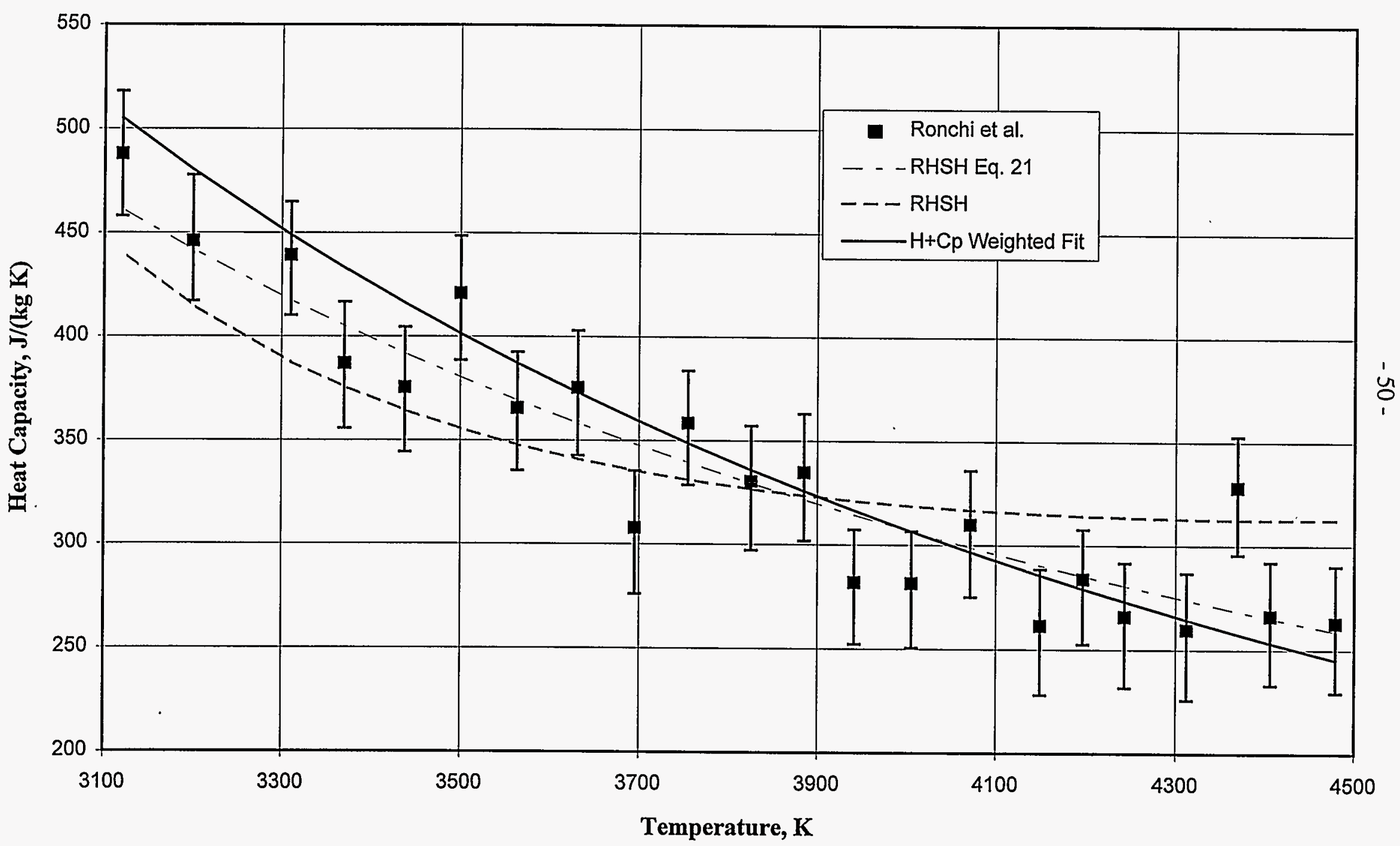




\section{MELTING POINT OF URANIUM DIOXIDE}

\section{Recommendation}

The recommended value for the melting temperature of $\mathrm{UO}_{2.00}$ is:

$$
\mathrm{T}_{\mathrm{m}}=3120 \pm 30 \mathrm{~K}(\text { IPTS }-68 \text { scale })
$$

This value has been recommended by Rand et al. ${ }^{1}$ from their analysis of fourteen experimental studies (over a period of 20 years) of the melting temperature of $\mathrm{UO}_{2}$. This recommendation of Rand et al. has been accepted by international agreement and was recommended in the assessment of $\mathrm{UO}_{2}$ properties by Fink et al. in 1981, 2,3 and by Harding, Martin, and Potter ${ }^{4}$ in their 1989 review of material properties for fast reactor safety.

\section{Discussion of Recommendation and Effects of Burnup}

In their review of experimental measurements on the melting of $\mathrm{UO}_{2}$, Rand et al. noted that the range in the values for the melting temperature decreased with time. Measurements prior to 1965 were reviewed by Hausner. ${ }^{5}$ Measurements since 1965 include measurements by Latta and Fryxell, ${ }^{6}$ Lyon and Baily, ${ }^{7}$ and Bates. ${ }^{8}$ Measurements have been made using a ' $V$ '-filament method and by thermal arrest methods. The latter method is more reliable since the sample is encapsulated and vaporization is not a problem. Of the thermal arrest data, those of Latta and Fryxell appear to be the best. Their value, $3138 \pm 15 \mathrm{~K}$, agrees within experimental errors with the value reported by Lyon and Baily, $3113 \pm 20 \mathrm{~K}$.

In their 1985 review of experimental data on the melting of irradiated oxide fuels, Adamson et al. ${ }^{9}$ commented that the ' $\mathrm{V}$ '-filament method appears to give consistently low melting temperatures when applied to variable-stoichiometry oxides such as $\mathrm{UO}_{2 \pm \mathrm{x}}$ and $(\mathrm{U}, \mathrm{Pu}) \mathrm{O}_{2 \pm \mathrm{x}}$. They attributed the low melting (solidus) temperatures obtained with the ' $V$ '-filament technique, which use small uncontained samples, to pronounced compositional changes that arise from rapid incongruent vaporization and oxygen exchange with the supporting atmosphere ( $\mathrm{Ar}$ or $\mathrm{He}$ ) and/or tungsten support. The compositional changes cause changes in the surface emissivity which lead to measurement errors. Adamson et al. ${ }^{9}$ commented that measurements made by Bates ${ }^{8}$ and by Christensen ${ }^{10,11}$ on unirradiated samples of stoichiometric $\mathrm{UO}_{2}$ gave melting temperatures in the 
range of 3063-3073 $\mathrm{K}$ which are approximately $50 \mathrm{~K}$ lower than its true melting point. The measurements of $\mathrm{Bates}^{8}$ and Christensen ${ }^{10,11}$ on irradiated $\mathrm{UO}_{2}$ gave solidus temperature changes from zero to $+130 \mathrm{~K}$ for low burnup $(\leq 1 \%)$ and $-120 \mathrm{~K}$ for high burnup ( 6 to $11 \%$ ). These data were rejected by Adamson et al. in their assessment because of the unreliability of the ' $\mathrm{V}$ '-filament measurements. Adamson et al. concluded that the effect of burnup on the melting behavior is not large. They developed a model for mixed oxide fuel that predicts variations in the solidus as a function of burnup. For burnups up to $10 \%$, the solidus of $\left(\mathrm{U}_{0.75} \mathrm{Pu}_{0.25} \mathrm{O}_{2}\right)$ is reduced by $22 \mathrm{~K} .^{9}$ In recent experimental measurements of the heat capacity of liquid $\mathrm{UO}_{2}$ using laser heating of a 0.5 to $0.8 \mathrm{~mm}$ diameter $\mathrm{UO}_{2}$ sphere, Ronchi et al. ${ }^{12}$ made several measurements of the freezing temperature of $\mathrm{UO}_{2}$ on different samples. For specimens in an inert gas atmosphere with up to 0.1bar of oxygen, they obtained melting points in the interval $3070 \pm 20 \mathrm{~K}$. Higher melting temperatures $(3140 \pm 20 \mathrm{~K})$ were obtained for samples in an inert gas atmosphere without oxygen. The variation in melting temperature is in accord with the expected lower oxygen to uranium $(O / U)$ ratio in the latter samples. The $\mathrm{O} / \mathrm{U}$ ratio of the samples used in these experiments was not determined but the experimenters cannot exclude a slight oxidation up to $\mathrm{O} / \mathrm{U}=2.03$.

The melting point of $\mathrm{UO}_{2}$ given in MATPRO ${ }^{13}$ is $3113.15 \mathrm{~K}$. This temperature is based on measurements by Brassfield et al. ${ }^{14}$ and the equations for the solidus and liquidus boundaries of the $\mathrm{UO}_{2}-\mathrm{PuO}_{2}$ phase diagram given by Lyon and Baily. ${ }^{7}$ Properties in the MATPRO library are used in the SCDAP/RELAP5 code.

\section{Uncertainties}

The uncertainty in the recommended temperature of $\mathrm{UO}_{2}$ is $\pm 1 \%(1 \sigma)$ The experimental results of Latta and Fryxell ${ }^{6}$ and of Lyon and Baily ${ }^{7}$ are well within this uncertainty. 


\section{REFERENCES}

1. J. K. Fink, M. G. Chasanov, and L. Leibowitz, Properties for Reactor Safety Analysis, ANLCEN-RSD-80-3, Argonne National Laboratory Report (1981).

2. J. K. Fink, M. G. Chasanov, and L. Leibowitz, Thermophysical Properties of Uranium Dioxide, J. Nucl. Mater. 102 17-25 (1981).

3. M. H. Rand, R. J. Ackermann, F. Gronvold, F. L. Oetting, A. Pattoret, Rev. Int. Des Hautes Temperatures et des Refractories 15, 355 (1978).

4. J. H. Harding, D. G. Martin, and P. E. Potter, Thermophysical and Thermochemical Properties of Fast Reactor Materials, " Commission of European Communities Report EUR 12402 (1989).

5. A. Hausner, J. Nucl. Mater. 15, 179 (1965).

6. R. E. Latta and R. E. Fryxell, J. Nucl. Mater. 35, 195 (1970).

7. W. L. Lyon and W. E. Bailey, The Solid-Liquid Phase Diagram for the $\mathrm{UO}_{2}-\mathrm{PuO}_{2}$ System, J. Nucl. Mater. 22, 332 (1967).

8. J. L. Bates, J. Nucl. Mater. 36, 234 (1970).

9. M. G. Adamson, E. A. Aitken, and R. W. Caputi, Experimental and Thermodynamic Evaluation of the Melting Behavior of Irradiated Oxide Fuels, J. Nucl. Mater. 130, 349-365 (1985).

10. J. A. Christensen, R. J. Allio, and A. Biancheria, Trans. American Nuclear Society 7, 390 (1964); also United States Report WCAP-6065 (1965).

11. J. A. Christensen, Irradiation Effects on Uranium Dioxide Melting, United States Report HW69234 (1964).

12. C. Ronchi, J. P. Hiernaut, R. Selfslag, and G. J. Hyland, Laboratory Measuremnt of the Heat Capacity of Urania up to 8000 K: I. Experiment, Nucl. Sci. Eng. 113, 1-19 (1993).

13. J. K. Hohorst (Editor), SCDAP/RELAP5/MOD2 Code Manual, Vol 4: MATPRO- A Library of Materials Properties for Light-Water-Reactor Accident Analysis," Section 2.1 Melting Temperature, NUREG/CR-5273 (1990).

14. H. C. Brassfield et al., Recommended Property and Reactor Kinetics Data for Use in Evaluating a Light-Water-Coolant Reactor Loss-of-Coolant Incident Involving Zircaloy-4 or 304-SS-Clad $\mathrm{UO}_{2}$, GEMP-482 (April 1968). 


\section{ENTHALPY OF FUSION OF URANIUM DIOXIDE}

\section{Recommendation}

The recommended value for the enthalpy of fusion of $\mathrm{UO}_{2.00}$ is:

$$
\Delta \mathrm{H}_{\mathrm{f}}=74.8 \pm 1 \mathrm{~kJ} \mathrm{~mol}^{-1}
$$

or $277.1 \pm 3.7 \mathrm{~kJ} \mathrm{~kg}^{-1}$. The enthalpy of fusion was calculated from the following equations for the enthalpy of solid ${ }^{1,2}$ and of liquid $\mathrm{UO}_{2}$ at the melting point of $3120 \mathrm{~K}$ :

Solid $\mathrm{UO}_{2} ; 2670 \mathrm{~K} \leq \mathrm{T} \leq 3120 \mathrm{~K}$,

$$
H(T)-H(298.15 K)=167.04 T-218342 ;
$$

Liquid $\mathrm{UO}_{2} ; 3120 \mathrm{~K} \leq \mathrm{T} \leq 4500 \mathrm{~K}$,

$$
H(T)-H(298.15 K)=2.64630 \times 10^{6}+41.612 T-\frac{4.2980 \times 10^{9}}{T} ; \quad .
$$

where $\mathrm{T}$ is in $\mathrm{K}$ and enthalpy is in $\mathrm{J} \mathrm{mol}^{-1}$.

\section{Discussion of Recommendation}

Equation (2) for the enthalpy of liquid $\mathrm{UO}_{2}$, is a combined fit of the recent liquid $\mathrm{UO}_{2}$ heat capacity data of Ronchi et al. ${ }^{3}$ and the enthalpy data of Leibowitz et al. ${ }^{4}$ and of Hein and Flagella. ${ }^{5}$ The fit to these data has been constrained to give the same enthalpy of the liquid at the melting point as that obtained from the linear equation of $\mathrm{Rand}^{6}$ for the enthalpy of liquid $\mathrm{UO}_{2}$ :

Liquid $\mathrm{UO}_{2} ; 3120 \mathrm{~K} \leq \mathrm{T} \leq 3550 \mathrm{~K}$,

$$
H(T)-H(298.15 K)=130.95 T-30911 .
$$


The recommended value for the enthalpy of fusion is identical to that recommended by Fink et al. ${ }^{2}$ based on Eq. (1) and Eq. (3). It is consistent with experimental results of enthalpy measurements of Chikalla, ${ }^{7}$ Leibowitz et al., ${ }^{4}$ and Hein and Flagella. ${ }^{5}$ The enthalpy of fusion given in MATPRO ${ }^{8}$ is $274.0 \mathrm{~kJ} \mathrm{~kg}^{-1}$ which is $74.0 \mathrm{~kJ} \mathrm{~mol}^{-1}$.

\section{Uncertainty}

The uncertainty in the recommended enthalpy of fusion of $\mathrm{UO}_{2}$ is $\pm 1 \%(1 \sigma)$. 


\section{REFERENCES}

1. J. K. Fink, Enthalpy and Heat Capacity of the Actinide Oxides, Int. J. Thermophys. 3(2), 165-200 (1982); J. K. Fink, M. G. Chasanov, and L. Leibowitz, Enthalpy and Heat Capacity of Solid $\mathrm{UO}_{2}$, ANL Report ANL-CEN-RSD-81-2, Argonne National Laboratory (May 1981).

2. J. K. Fink, M. G. Chasanov, and L. Leibowitz, Thermophysical Properties of Uranium Dioxide, J. Nucl. Mater. 102, 17-25 (1981); also as ANL Report ANL-CEN-RSD-80-3, Argonne National Laboratory (April 1981).

3. C. Ronchi, J. P. Hiernaut, R. Selfslag, and G. J. Hyland, Laboratory Measurement of the Heat Capacity of Urania up to 8000 K: I. Experiment, Nucl. Sci. Eng. 113, 1-19 (1993).

4. L. Leibowitz, M. G. Chasanov, L. W. Mishler, and D. F. Fischer, J. Nucl. Mater. 39 115-116 (1971).

5. R. A. Hein and P. N. Flagella, Enthalpy Measurements of $\mathrm{UO}_{2}$ and Tungsten to $3260 \mathrm{~K}, \mathrm{GE}$ Report GEMP-578, General Electric, February 16, 1968.

6. M. H. Rand, R. J. Ackermann, F. Gronvold, F. L. Oetting, A. Pattoret, The Thermodynamic Properties of the Urania Phase, Rev. Int. Hautes Temp. Refract. 15, 355-365 (1978).

7. T. D. Chikalla, The Liquidus for the System $\mathrm{UO}_{2}-\mathrm{PuO}_{2}$, General Electric Co. Hanford Atomic Products Operation Report HW-698322 (June 1961).

8. J. K. Horhorst, editor, SCADAP/RELAP5/MOD2 Code Manual Vol. 4: MATPRO - a library of materials properties for light-water reactor accident analysis, EG\&G Idaho Report NUREG/CR-5273 (1990). 


\section{THERMAL EXPANSION OF DENSITY OF URANIUM DIOXIDE}

\subsection{THERMAL EXPANSION OF SOLID UO}

\section{Summary and Recommended Equations}

The recommended equations for the thermal expansion of solid uranium dioxide are from - the 1988 assessment by D. G. Martin ${ }^{1}$ which included the high temperature neutron diffraction data of Hutchings ${ }^{2}$ that were not available to previous assessments. ${ }^{3,4}$ Martin compared data from lattice parameter measurements and macroscopic length changes from 15 references, ${ }^{2,5-18}$ made corrections to macroscopic thermal expansion measurements that exhibited a zero error, and excluded data that did not agree with the common consensus. Martin fit the remaining data to two cubic polynomials.

The recommended equations for the linear thermal expansion of solid $\mathrm{UO}_{2}$ are For $273 \mathrm{~K} \leq \mathrm{T} \leq 923 \mathrm{~K}$,

$$
\begin{aligned}
L=L_{273} & \left(9.9734 \times 10^{-1}+9.802 \times 10^{-6} T-2.705 \times 10^{-10} T^{2}\right. \\
& \left.+4.291 \times 10^{-13} T^{3}\right)
\end{aligned}
$$

For $923 \mathrm{~K} \leq \mathrm{T} \leq 3120 \mathrm{~K}$,

$$
\begin{aligned}
L=L_{273} & \left(9.9672 \times 10^{-1}+1.179 \times 10^{-5} T-2.429 \times 10^{-9} T^{2}\right. \\
& \left.+1.219 \times 10^{-12} T^{3}\right)
\end{aligned}
$$

where $L$ and $L_{273}$ are the lengths at temperatures $T(\mathrm{~K})$ and $273 \mathrm{~K}$, respectively. The fractional change in the linear thermal expansion of $\mathrm{UO}_{2}, \Delta \mathrm{L} / \mathrm{L}_{273}$, expressed as a percent, is shown in Figure 4.1.1 with the uncertainties recommended by Martin given as dotted lines. Recommended values for the fractional change in linear thermal expansion, $\Delta \mathrm{L} / \mathrm{L}_{273}$, are tabulated in Table 4.1.1. Values for the fractional change in volumetric thermal expansion of $\mathrm{UO}_{2}, \Delta \mathrm{V} / \mathrm{V}_{273}$, are given in Table 4.1.2.

From assessment of the available data on hyperstoichiometric uranium dioxide $\left(\mathrm{UO}_{2+\mathrm{x}}\right)$, Martin recommended using these equations for the linear thermal expansion of $\mathrm{UO}_{2+\mathrm{x}}$ for $\mathrm{x}$ in the ranges 0 to 0.13 and 0.23 to 0.25 . 
The recommended equations for the instantaneous linear thermal expansion coefficients, $\alpha_{\mathrm{P}}(\mathrm{l})$, are cubic polynomial approximations ${ }^{1}$ to the exact partial differentials $(1 / \mathrm{L})(\mathrm{dL} / \mathrm{dT})_{\mathrm{P}}$ of Eqs. (1) and (2). These approximations do not differ by more than $0.6 \%$ from the exact differentials over the given temperature range. Martin recommended:

For $273 \mathrm{~K} \leq \mathrm{T} \leq 923 \mathrm{~K}$,

$$
\begin{aligned}
\alpha_{P}(l)= & 9.828 \times 10^{-6}-6.390 \times 10^{-10} T+1.330 \times 10^{-12} T^{2} \\
& +1.757 \times 10^{-17} T^{3}
\end{aligned}
$$

For $923 \mathrm{~K} \leq \mathrm{T} \leq 3120 \mathrm{~K}$,

$$
\begin{aligned}
\alpha_{P}(l)= & 1.1833 \times 10^{-5}-5.013 \times 10^{-9} T+3.756 \times 10^{-12} T^{2} \\
& +6.125 \times 10^{-17} T^{3}
\end{aligned}
$$

where $\alpha_{\mathrm{P}}(l)$ is the coefficient of thermal expansion in $\mathrm{K}^{-1}$. Recommended values of the instantaneous linear thermal expansion coefficient of $\mathrm{UO}_{2}$ are shown in Figure 4.1.2 and tabulated as a function of temperature in Table 4.1.1. Dotted lines in Figure 4.1.2 represent the uncertainties suggested by Martin. Values for the instantaneous volumetric thermal expansion coefficient (the thermodynamic quantity, $\alpha_{\mathrm{p}}$ ) are given in Table 4.1.2. Equations relating the linear and volumetric thermal expansion coefficients and fractional changes in length, volume, and density with temperature are given in the Section 4.5 of this report.

\section{Uncertainties}

Martin gave the uncertainty in the fractional linear expansions $\left(L^{-} / L_{273}-1\right)$ as $\pm 2.6 \times 10^{-4}$ for 293 to $1273 \mathrm{~K}, \pm 4.4 \times 10^{-4}$ for 1273 to $2273 \mathrm{~K}$, and $\pm 7 \times 10^{-4}$ for 2273 to $2929 \mathrm{~K}$. In terms of percents of the linear expansion as a function of temperature, the uncertainties are $105 \%$ at $298 \mathrm{~K}$, $12 \%$ at $500 \mathrm{~K}, 3.6 \%$ at $1000 \mathrm{~K}, 3.4 \%$ at $1500 \mathrm{~K}, 2.2 \%$ at $2000 \mathrm{~K}, 2.3 \%$ at $2500 \mathrm{~K}$, and $1.6 \%$ at $3000 \mathrm{~K}$. 
The corresponding uncertainties in the instantaneous linear thermal expansion, $\alpha_{\mathrm{p}}(l)$, are $\pm 0.11 \times 10^{-6}, \pm 0.22 \times 10^{-6}$, and $\pm 1.1 \times 10^{-6}$ for the temperature ranges 293 to $1273 \mathrm{~K}, 1273$ to $2273 \mathrm{~K}$, and 2273 to $2929 \mathrm{~K}$, respectively.

\section{Discussion of Recommended Equations for $\mathrm{UO}_{2}$}

Martin ${ }^{1}$ reviewed and compared $\mathrm{UO}_{2}$ thermal expansion data from macroscopic length changes, ${ }^{5-13}$ neutron diffraction, ${ }^{2,18}$ and $\mathrm{x}$-ray diffraction measurements ${ }^{17}$ except for the recent $\mathrm{x}$-ray diffraction results by Momin et al. ${ }^{19}$ In his thorough data assessment, Martin examined the macroscopic expansion data for possible zero errors and made corrections to the data of Lambertson and Hanwerk ${ }^{6}$, data of Brett and Russell ${ }^{9}$, and data of Murray and Thackery. ${ }^{10}$ He found good agreement between the data from macroscopic length changes and lattice parameter measurements so that these data could be combined in the final analysis. The good agreement between data from macroscopic measurements by Conway et al. and the lattice parameter measurements of Hutchings ${ }^{2}$ led Martin to conclude that at least up to $2523 \mathrm{~K}$, the contribution to the macroscopic expansion due to Schottky defects is negligible. In formulating equations to represent the linear thermal expansion of $\mathrm{UO}_{2}$, Martin excluded data that did not agree with the common consensus. Data excluded by Martin were data of Bell et al., ${ }^{5}$ data of Christensen, ${ }^{11}$ data of Halden et al., ${ }^{12}$ data above $1871 \mathrm{~K}$ from measurements by Baldock et al., ${ }^{17}$ and data from 1118 to $1200 \mathrm{~K}$ from measurements by Hoch and Momin. ${ }^{15}$ Figure 4.1.3 shows most of the thermal expansion data fit by Martin and his recommended equations, expressed as the percent change in length relative to the length at $273 \mathrm{~K}$, ie. $\left(\Delta \mathrm{L} / \mathrm{L}_{273}, \%\right)$.

Percent deviations of the data from the recommended equations of Martin are shown in Figure 4.1.4. Percent deviations in Figure 4.1.4 are defined as

$$
\operatorname{Deviation}(\%)=\frac{\frac{\Delta L(\text { Data })}{L}-\frac{\Delta L(\text { Martin })}{L}}{\frac{\Delta L(\text { Martin })}{L}} \cdot 100 \%
$$


The uncertainties given by Martin are included in Figure 4.1.4, expressed as percents, for comparison with the deviations of Martin's equations from the analyzed data.

Since this analysis by Martin, ${ }^{1}$ Momin et al. ${ }^{19}$ reported equations for the variation in the lattice parameter from 298 through $1600 \mathrm{~K}$ for $\mathrm{UO}_{2}$ and $\mathrm{UO}_{2}$ doped with fission products. These equations were based on x-ray diffraction measurements. The results by $\mathrm{Momin}$ et al. for $\mathrm{UO}_{2}$, expressed as $\Delta \mathrm{L} / \mathrm{L}_{273}$, are compared with the recommendation of Martin in Figure 4.1.5. Values calculated from the equations of Momin et al. are consistently lower than the recommended values. Deviations, determined in accord with Eq. (5), range from $-24 \%$ at $298 \mathrm{~K}$ to $-0.5 \%$ at $1600 \mathrm{~K}$. Momin et al. reported $0.5469 \mathrm{~nm}$ for the lattice parameter of $\mathrm{UO}_{2}$ at room temperature. This is slightly lower than the $0.54704 \mathrm{~nm}$ value at $293 \mathrm{~K}$ obtained by Gronvold ${ }^{16}$ and the $0.5470 \mathrm{~nm}$ value at $293 \mathrm{~K}$ obtained by Hutchings. ${ }^{2}$ Thus, the results reported by Momin et al. appear to be low relative to other data as well as compared to the recommendation of Martin.

\section{Comparison of $\mathrm{UO}_{2}$ Recommendation with Previous Recommendations}

The 1981 recommendation of Fink, Chasanov, and Leibowitz ${ }^{3}$ and the recommendation of MATPRO ${ }^{4}$ were based on an analysis by Olsen ${ }^{4}$ which used the data of Conway et al. ${ }^{13}$ from 1263 to $2535 \mathrm{~K}$ and that of Christensen ${ }^{11}$ from 1473 to $3073 \mathrm{~K}$. Although the data of Christensen showed much scatter, they were the only data available in 1981 above $2535 \mathrm{~K}$. The recent data of Hutchings ${ }^{2}$ are in much better agreement with that of Conway et al. than the data of Christensen and show that the data of Christensen are not reliable. Figure 4.1.6 compares $\Delta L / L_{273}$ from these three sets of data with the recommended equations of Martin and the 1981 recommendation. Differences are significant at high temperatures where the fits are based on different sets of data. From 2800 through $3120 \mathrm{~K}$, deviations increase from $3 \%$ to $6.5 \%$. These deviations are greater than the uncertainties given by Martin, which are $1.9 \%$ at $2800 \mathrm{~K}$ and $1.5 \%$ at $3120 \mathrm{~K}$. In the temperature range of 500 to $1200 \mathrm{~K}$, deviations between these two recommendations range from $18 \%$ to $5 \%$. These are higher than the uncertainties given by Martin for his recommended values in this temperature range.

The recommended instantaneous linear thermal expansion coefficient given by Martin $^{1}$ is compared in Figure 4.1.7 with the 1981 recommended values. Deviations between these instantaneous linear thermal expansion coefficients are even greater than the deviations between 
the fractional changes in linear thermal expansion $\left(\Delta \mathrm{L} / \mathrm{L}_{273}\right)$ because the linear instantaneous thermal expansion coefficient is the temperature derivative of the linear thermal expansion.

\section{Discussion of Hyperstoichiometric Uranium Dioxide $\left(\mathrm{UO}_{2+\mathrm{x}}\right)$}

Martin has examined the x-ray lattice parameter measurements of $\mathrm{UO}_{2+\mathrm{x}}$ of $\mathrm{Gronvold}^{16}$ for $\mathrm{O} / \mathrm{M}$ ratios of 2.00, 2.10, 2.25, and 2.60; of Roth et al. ${ }^{20}$ for $\mathrm{O} / \mathrm{M}$ ratios of 2.08 and 2.24; of Fergusson et al. ${ }^{21}$ for $\mathrm{O} / \mathrm{M}=2.235$; and the macroscopic expansion studies on $\mathrm{UO}_{2+\mathrm{x}}$ by Murray and Thackery ${ }^{10}$ for $\mathrm{O} / \mathrm{M}=2.00$ and 2.13 and those by Leblanc and Andriessen ${ }^{7}$ for $\mathrm{O} / \mathrm{M}=2.00,2.10$, and 2.21. He made a zero error correction to the data of Murray and Thackery. He excluded the data of Gronvold with an $\mathrm{O} / \mathrm{M}$ ratio of 2.60 on the basis that these data relate to an orthorhombic $\left(\mathrm{U}_{3} \mathrm{O}_{8}\right)$ structure, not a fluorite structure. From comparison of the remaining data to his equations for the thermal expansion of $\mathrm{UO}_{2.00}$, Martin concluded that the thermal expansion of $\mathrm{UO}_{2+\mathrm{x}}$ is the same as that of $\mathrm{UO}_{2.00}$ for $\mathrm{x}$ values of $0-0.13$ and $0.235-0.25$ up to $1520 \mathrm{~K}$. Figure 4.1.8, which compares some of the $\mathrm{UO}_{2+\mathrm{x}}$ data with Martin's recommended percent change in the linear thermal expansion of $\mathrm{UO}_{2.00}$, shows that Martin's conclusion is justified. The data for $\mathrm{UO}_{2+\mathrm{x}}$ are very close to the recommendation for $\mathrm{UO}_{2.00}$ with deviations and scatter similar to that for the $\mathrm{UO}_{2.00}$ thermal expansion data. Because no data for $\mathrm{UO}_{2+\mathrm{x}}$ exist above $1520 \mathrm{~K}$, Martin speculated that his conclusion for thermal expansion at lower temperatures may be extended to the melting point. 


\section{REFERENCES}

1. D. G. Martin, The Thermal Expansion of Solid $U_{2} O_{2}$ and (U,Pu) Mixed Oxides - A Review and Recommendations, J. Nucl. Mater. 152 94-101 (1988).

2. M. T. Hutchings, High-Temperature Studies of $\mathrm{UO}_{2}$ and $\mathrm{ThO}_{2}$ Using Neutron Scattering Techniques, J. Chem. Soc. Faraday Trans. II 83, 1083-1103 (1987).

3. J. K. Fink, M. G. Chasanov, and L. Leibowitz, Thermophysical Properties of Uranium Dioxide, J. Nucl. Mater. 102 17-25 (1981).

4. C. S. Olsen, Fuel Thermal Expansion (FTHEXP) in MATPRO-Version 11: A Handbook of Materials Properties for Use in the Analysis of Light Water Reactor Fuel Rod Behavior, ed. D. R. Hagraman and G. A. Reymann, US Nuclear Regulatory Commission Rep. NUREG/CR-0497 (February 1979); also revision (1981).

5. I. P. Bell and s. M. Makin, R. And D. B. (C), Tech. Note No. 70, Culcheth Laboratories, UK (1954), as referenced by D. G. Martin, The Thermal Expansion of Solid $\mathrm{UO}_{2}$ and (U,Pu) Mixed Oxides - A Reveiw and Recommendations, J. Nucl. Mater. 152 94-101 (1988).

6. W. A. Lambertson and J. H. Hanwerk, The Fabrication and Physical Properties of Urania Bodies, Argonne National Laboratory Report ANL-5053 (1963).

7. J. M. Leblanc and H. Andriessen, EURATOM/USA Report EURAEC-434 (1962).

8. M. D. Burdick and H. S. Parker, J. Am. Ceram. Soc. 39, 181-187 (1956).

9. N. H. Brett and L. E. Russell, The Thermal Expansion of $\mathrm{PuO}_{2}$ and Some Other Actinide Oxides between Room Temperature and $1000^{\circ} \mathrm{C}$, in Plutonium 1960, pp. 397-410, E. Grison, W. B. H. Lord, and R. D. Fowler, eds., Cleaver Hyne Oress Ltd., London (1961).

10. P. Murray and R. W. Thackray, The Thermal Expansion of Sintered $\mathrm{UO}_{2}$, Harwell memo AERE M/M22 (1950).

11. J. A. Christensen, Thermal Expansion and Change in Volume of Uranium Dioxide on Melting, J. Am. Ceram. Soc. 46, 607-608 (1963).

12. F. A. Halden, H. C. Wohlers, and R. H. Reinhart, Thermal Expansion of Uranium Dioxide, Stanford Research Institute Report No. SRI A-6, available from Technical Information Services Oak Ridge National Laboratory Report TID 5722 (1959). 
13. J. B. Conway, R. M. Fincel, and R. A. Hein, The Thermal Expansion and Heat Capacity of $\mathrm{UO}_{2}$ to $2200^{\circ} \mathrm{C}$, Trans. Am. Nucl. Soc. 6, 153 (1963).

14. C. P. Kempter and R. O. Elliot, J. Chem. Phys. 30, 1524 (1959), as referenced by D. G. Martin, The Thermal Expansion of Solid $\mathrm{UO}_{2}$ and $(U, P u)$ Mixed Oxides - A Reveiw and Recommendations, J. Nucl. Mater. 152 94-101 (1988).

15. M. Hoch and A. C. Momin, High Temperature Thermal Expansion of $\mathrm{UO}_{2}$ and $\mathrm{ThO}_{2}$, High Temp.-High Press. 1, 401-407 (1969).

16. F. Gronvold, J. Inorg. Nucl. Chem. 1, 357 (1955).

17. P. J. Baldock, W. E. Spindler, and T. W. Baker, The X-Ray Thermal Expansion of Near Stoichiometric $\mathrm{UO}_{2}$, J. Nucl. Mater. 18 305-313 (1966).

18. A. Albinati, M. J. Cooper, K. D. Rouse, M. W. Thomas, and B. T. M. Willis, Acta Crystallogr. A36, 265 (1980).

19. A. C. Momin, E. B. Miza, and M. D. Mathews, High Temperature X-ray Diffractometric Studies on the Lattice Thermal Expansion Behaviour of $\mathrm{UO}_{2}, \mathrm{ThO}_{2}$, and $\left(\mathrm{U}_{0.2} \mathrm{Th}_{0.8} \mathrm{O}_{2}\right.$ Doped with Fission Product Oxides, J. Nucl. Mater. 185, 308-310 (1991).

20. J. Roth and E. K. Halteman, Nuclear Materials and Equipment Corp. Report NUMEC-23899 (1965).

21. I. F. Ferguson and R. S. Street, Harwell memo AERE M 1192 (1963) as referenced by D. G. Martin, The Thermal Expansion of Solid $\mathrm{UO}_{2}$ and $(\mathrm{U}, \mathrm{Pu})$ Mixed Oxides - A Reveiw and Recommendations, J. Nucl. Mater. 152 94-101 (1988). 
Table 4.1.1 Recommended Linear Thermal Expansion of $\mathrm{UO}_{2}$

\begin{tabular}{|c|c|c|}
\hline Temperature, $\mathbf{K}$ & $\Delta \mathrm{L} / \mathrm{L} \%$ & $\alpha_{\mathrm{p}}(l) \times 10^{6}, \mathrm{~K}^{-1}$ \\
\hline $\begin{array}{l}273 \\
298 \\
300 \\
400 \\
500 \\
\end{array}$ & $\begin{array}{l}0.000 \\
0.025 \\
0.027 \\
0.125 \\
0.223\end{array}$ & $\begin{array}{l}9.74 \\
9.74 \\
9.74 \\
9.76 \\
9.81\end{array}$ \\
\hline $\begin{array}{c}600 \\
700 \\
800 \\
900 \\
1000 \\
\end{array}$ & $\begin{array}{l}0.322 \\
0.422 \\
0.523 \\
0.626 \\
0.730 \\
\end{array}$ & $\begin{array}{c}9.89 \\
9.99 \\
10.12 \\
10.27 \\
10.51\end{array}$ \\
\hline $\begin{array}{l}1100 \\
1200 \\
1300 \\
1400 \\
1500\end{array}$ & $\begin{array}{l}0.837 \\
0.948 \\
1.062 \\
1.181 \\
1.305\end{array}$ & $\begin{array}{l}10.78 \\
11.12 \\
11.53 \\
12.01 \\
12.56\end{array}$ \\
\hline $\begin{array}{l}1600 \\
1700 \\
1800 \\
1900 \\
2000\end{array}$ & $\begin{array}{l}1.436 \\
1.573 \\
1.718 \\
1.871 \\
2.034\end{array}$ & $\begin{array}{l}13.18 \\
13.86 \\
14.62 \\
15.45 \\
16.34\end{array}$ \\
\hline $\begin{array}{l}2100 \\
2200 \\
2273 \\
2273 \\
2300 \\
2400 \\
2500 \\
\end{array}$ & $\begin{array}{l}2.206 \\
2.388 \\
2.528 \\
2.528 \\
2.582 \\
2.788 \\
3.006 \\
\end{array}$ & $\begin{array}{l}17.30 \\
18.33 \\
19.12 \\
19.12 \\
19.43 \\
20.59 \\
21.82\end{array}$ \\
\hline $\begin{array}{l}2600 \\
2670 \\
2670 \\
2700 \\
2800 \\
2900 \\
3000 \\
\end{array}$ & $\begin{array}{l}3.238 \\
3.409 \\
3.409 \\
3.484 \\
3.745 \\
4.021 \\
4.314\end{array}$ & $\begin{array}{l}23.11 \\
24.06 \\
24.06 \\
24.47 \\
25.90 \\
27.39 \\
28.94\end{array}$ \\
\hline $\begin{array}{l}3100 \\
3120\end{array}$ & $\begin{array}{l}4.624 \\
4.688\end{array}$ & $\begin{array}{l}30.56 \\
30.89 \\
\end{array}$ \\
\hline
\end{tabular}


Table 4.1.2 Recommended Volumetric Thermal Expansion of $\mathrm{UO}_{2}$

\begin{tabular}{|c|c|c|}
\hline Temperature, $\mathbf{K}$ & $\Delta \mathrm{V} / \mathrm{V} \%$ & $\alpha_{p} \times 10^{6}, K^{-1}$ \\
\hline $\begin{array}{l}298 \\
300 \\
400 \\
500 \\
\end{array}$ & $\begin{array}{l}0.075 \\
0.080 \\
0.374 \\
0.670 \\
\end{array}$ & $\begin{array}{l}29.22 \\
29.22 \\
29.29 \\
29.44\end{array}$ \\
\hline $\begin{array}{c}600 \\
700 \\
800 \\
900 \\
1000\end{array}$ & $\begin{array}{l}0.969 \\
1.271 \\
1.578 \\
1.891 \\
2.206\end{array}$ & $\begin{array}{l}29.66 \\
29.97 \\
30.35 \\
30.81 \\
31.54\end{array}$ \\
\hline $\begin{array}{l}1100 \\
1200 \\
1300 \\
1400 \\
1500 \\
\end{array}$ & $\begin{array}{l}2.533 \\
2.870 \\
3.220 \\
3.585 \\
3.968 \\
\end{array}$ & $\begin{array}{l}32.35 \\
33.36 \\
34.59 \\
36.03 \\
37.67 \\
\end{array}$ \\
\hline $\begin{array}{l}1600 \\
1700 \\
1800 \\
1900 \\
2000\end{array}$ & $\begin{array}{l}4.370 \\
4.794 \\
5.243 \\
5.720 \\
6.226 \\
\end{array}$ & $\begin{array}{l}39.53 \\
41.59 \\
43.87 \\
46.34 \\
49.02 \\
\end{array}$ \\
\hline $\begin{array}{l}2100 \\
2200 \\
2273 \\
2273 \\
2300 \\
2400 \\
2500 \\
\end{array}$ & $\begin{array}{l}6.764 \\
7.337 \\
7.779 \\
7.779 \\
7.947 \\
8.598 \\
9.292 \\
\end{array}$ & $\begin{array}{l}51.91 \\
54.99 \\
57.37 \\
57.37 \\
58.28 \\
61.77 \\
65.46 \\
\end{array}$ \\
\hline $\begin{array}{l}2600 \\
2670 \\
2670 \\
2700 \\
2800 \\
2900 \\
3000 \\
\end{array}$ & $\begin{array}{l}10.032 \\
10.578 \\
10.578 \\
10.820 \\
11.660 \\
12.556 \\
13.509\end{array}$ & $\begin{array}{l}69.34 \\
72.18 \\
72.18 \\
73.42 \\
77.70 \\
82.17 \\
86.83 \\
\end{array}$ \\
\hline $\begin{array}{l}3100 \\
3120 \\
\end{array}$ & $\begin{array}{l}14.524 \\
14.734 \\
\end{array}$ & $\begin{array}{l}91.69 \\
92.68 \\
\end{array}$ \\
\hline
\end{tabular}


Figure 4.1.1 Recommended $\mathrm{UO}_{2}$ Linear Thermal Expansion, $\Delta \mathrm{L} / \mathrm{L}_{273}$

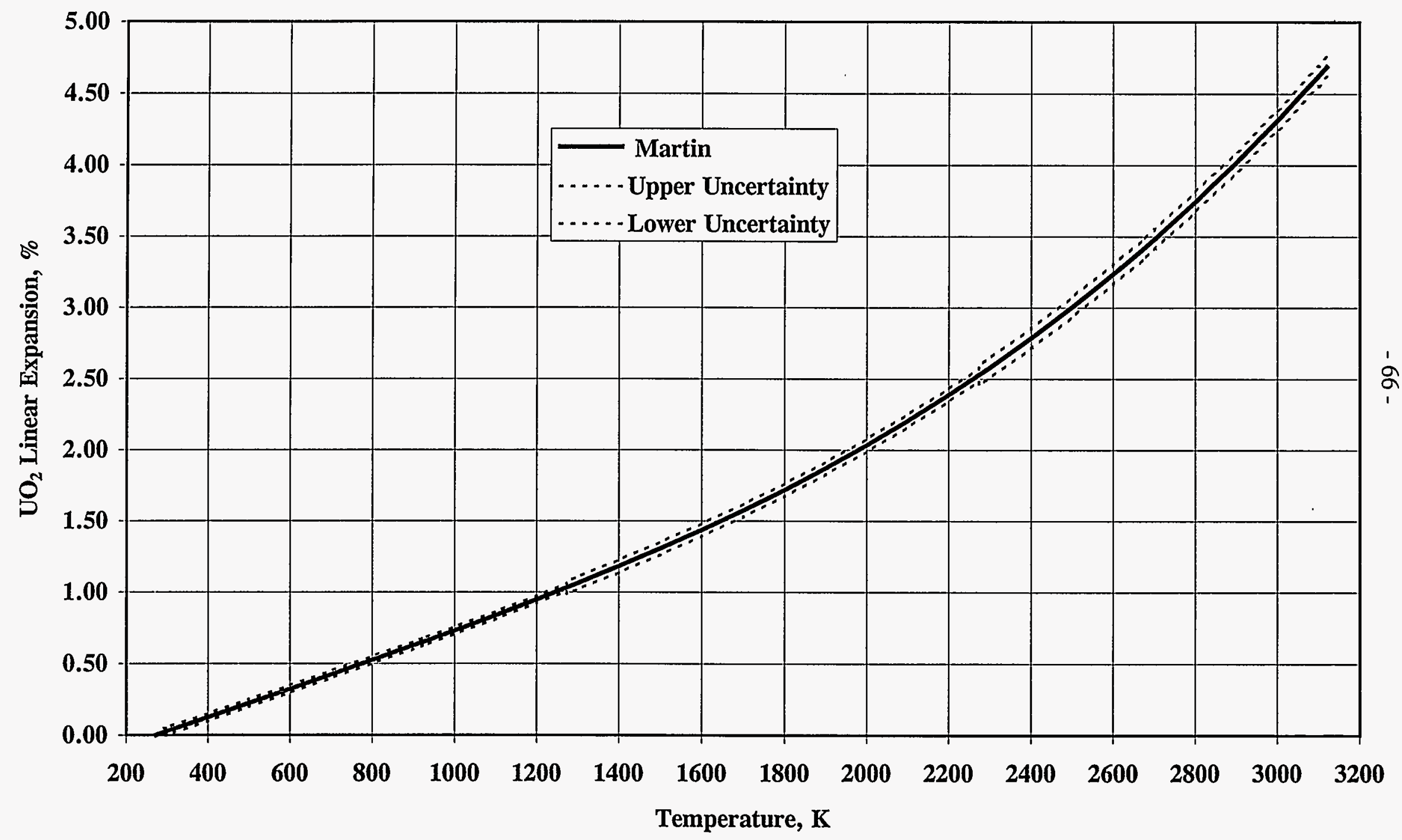




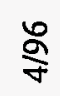

$-67-$
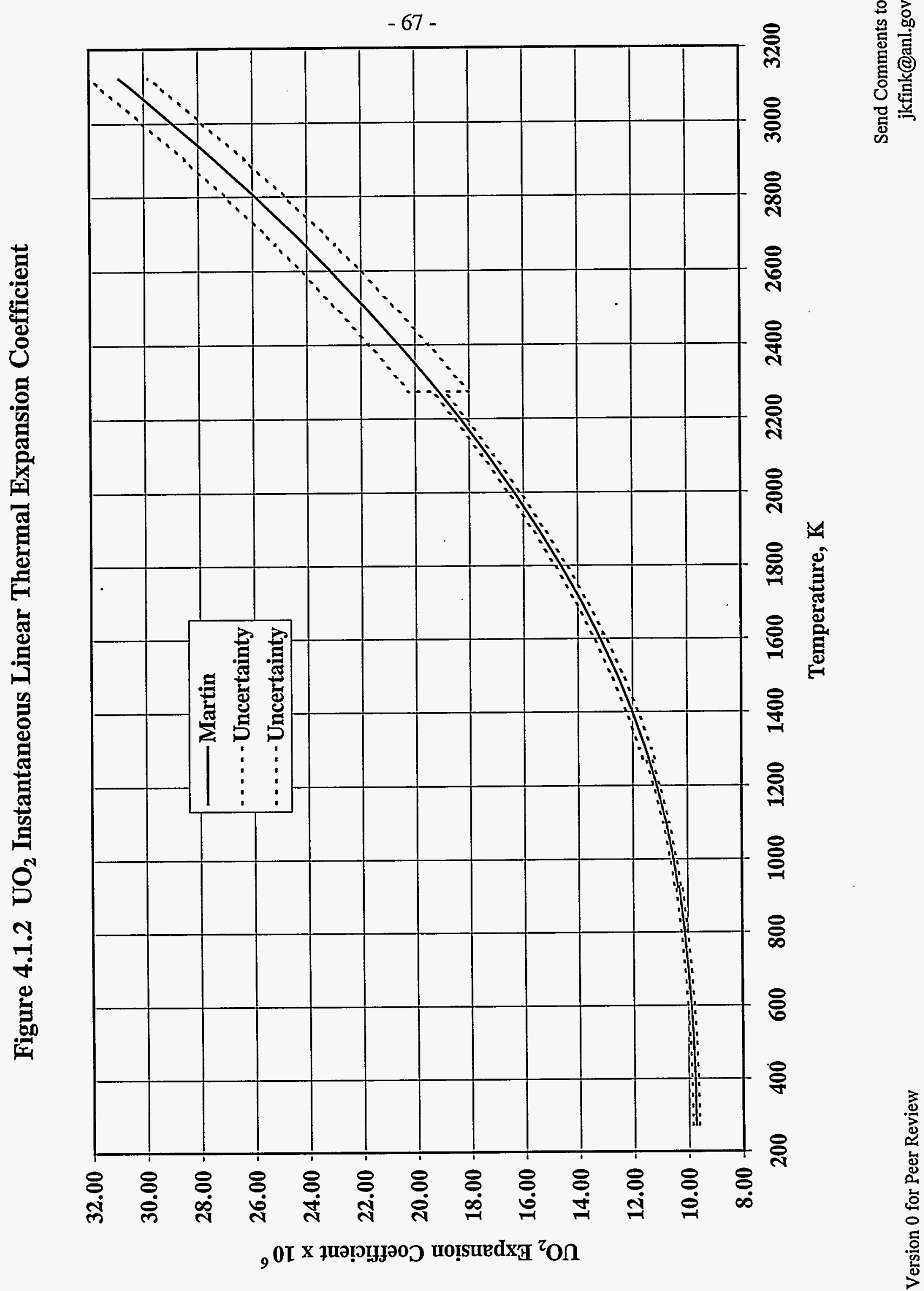
Figure 4.1.3 Recommended $\mathrm{UO}_{2}$ Thermal Expansion Eq. Compared with Data Fit

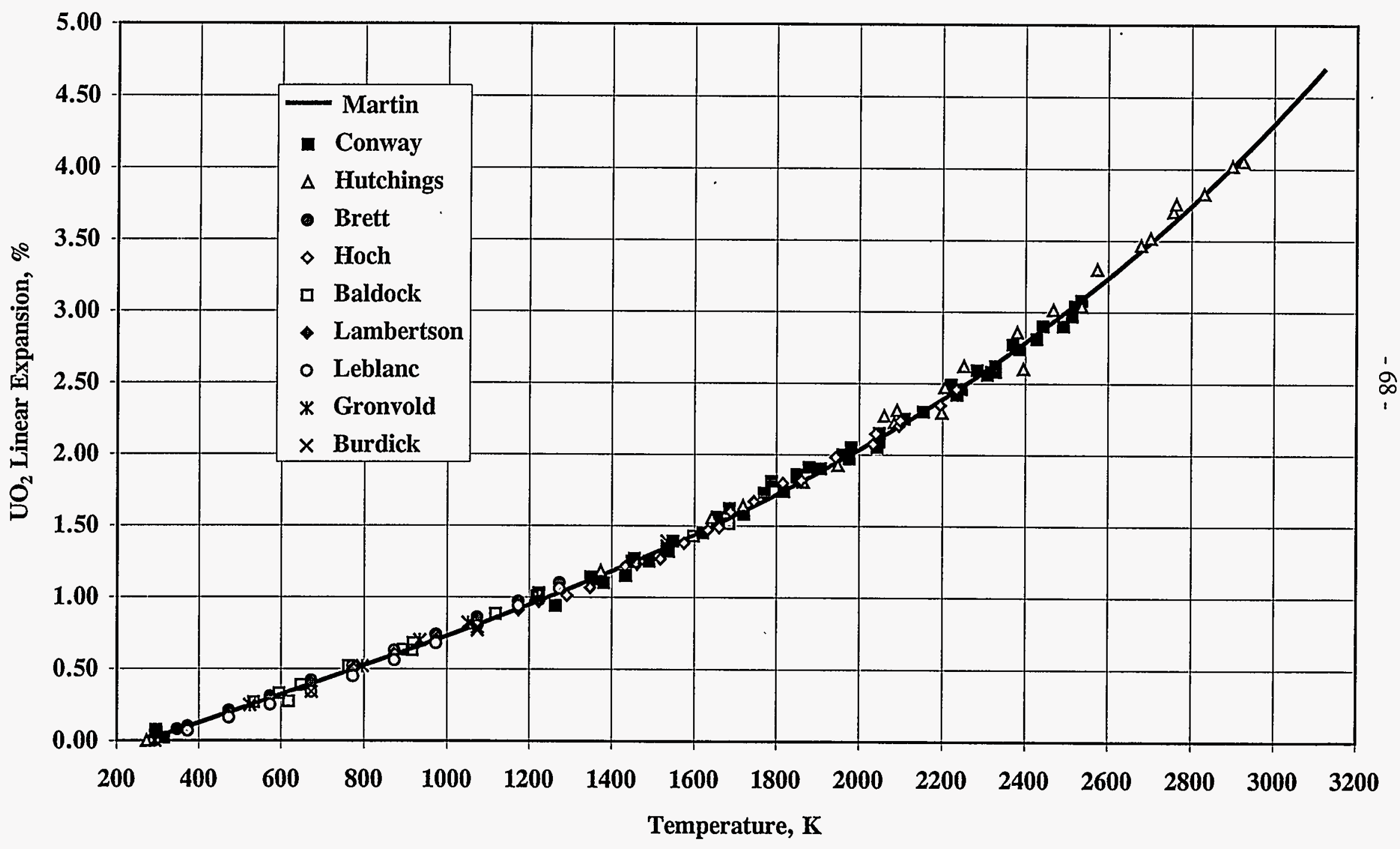




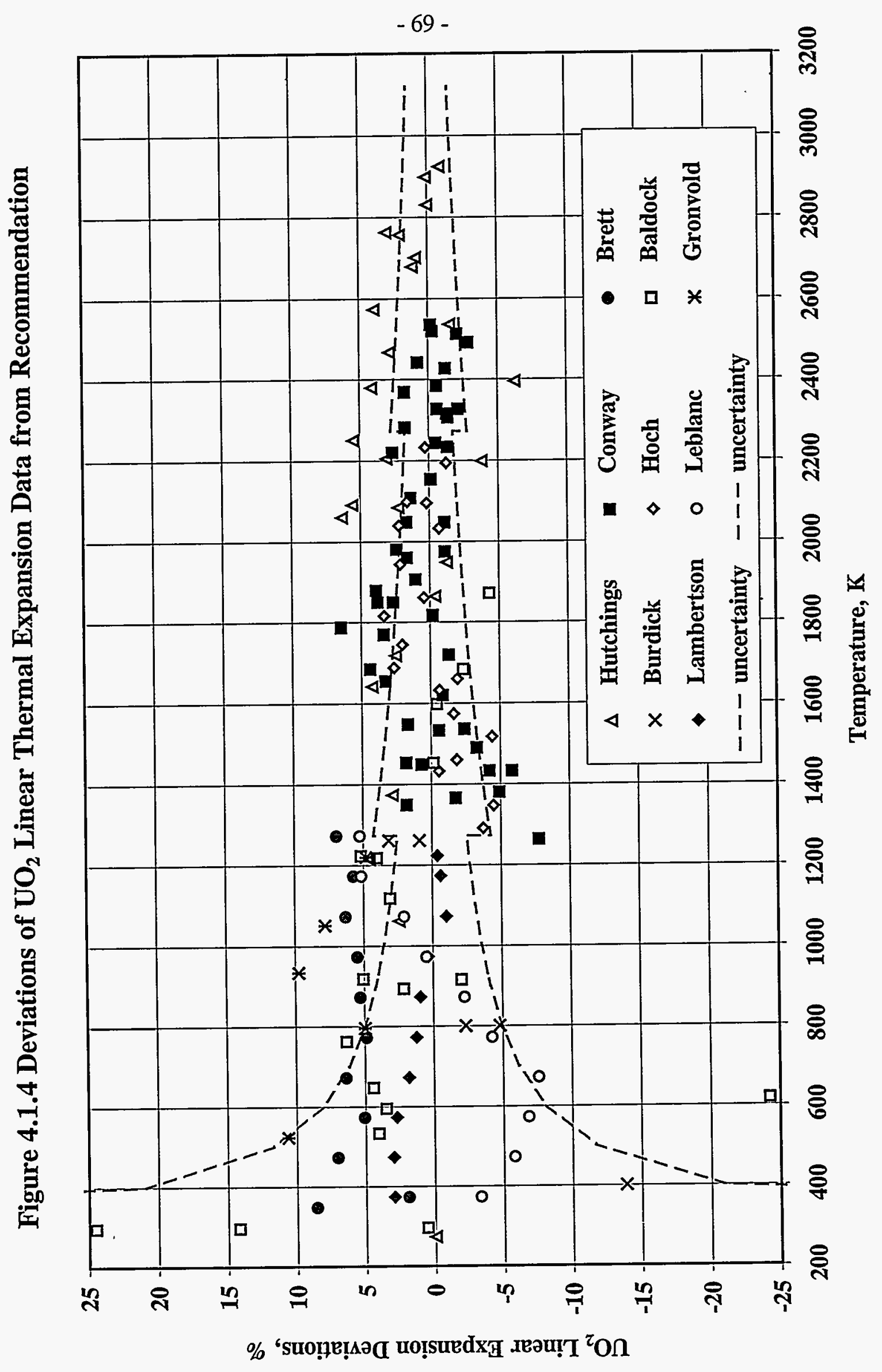


Figure 4.1.5 Comparison of $\mathrm{UO}_{2}$ Thermal Expansion of Martin and of Momin et al.

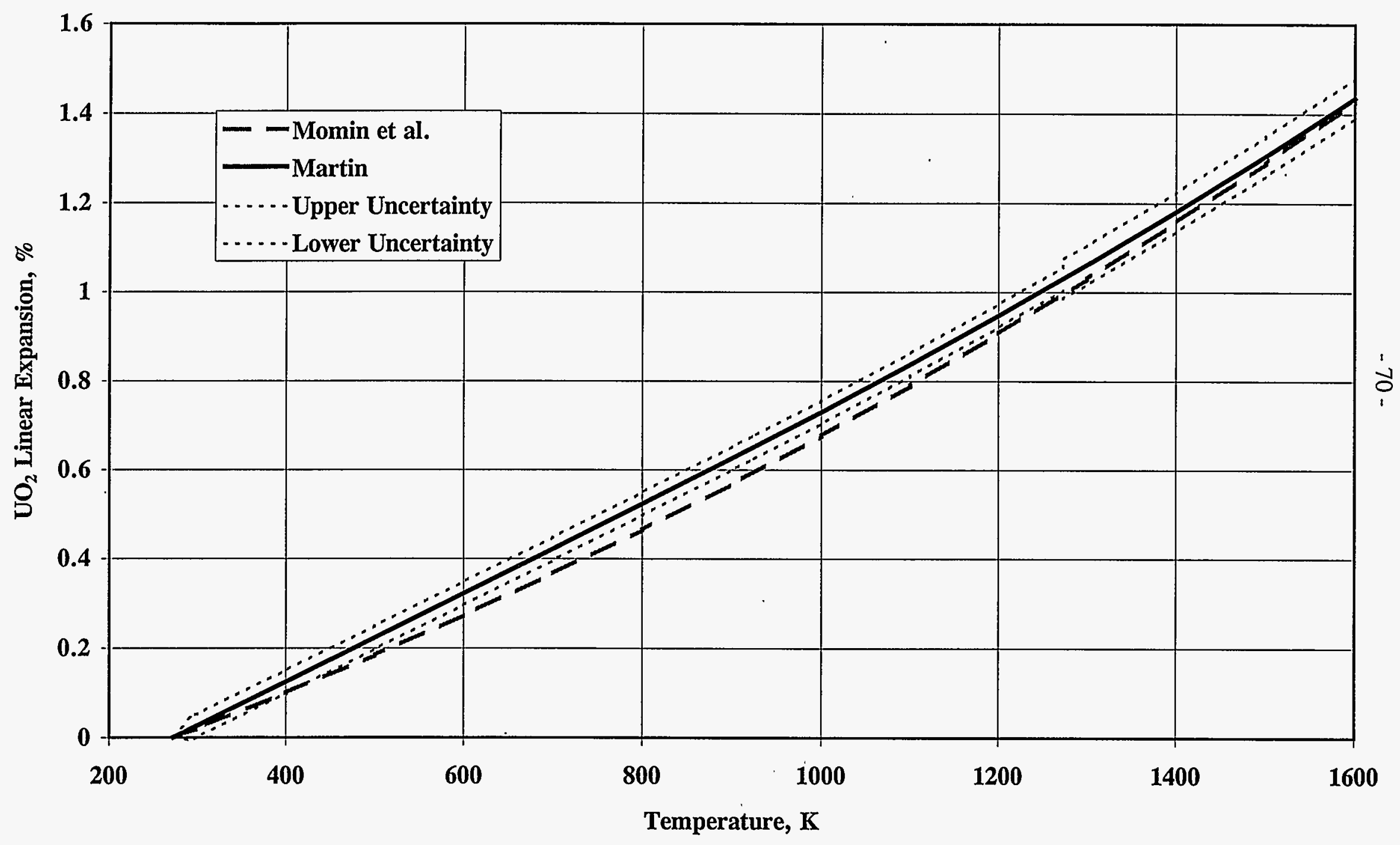


Figure 4.1.6 Comparison of Recommended $\mathrm{UO}_{2}$ Thermal Expansion with Previous Recommendation and Data of Christensen, Conway, and Hutchings

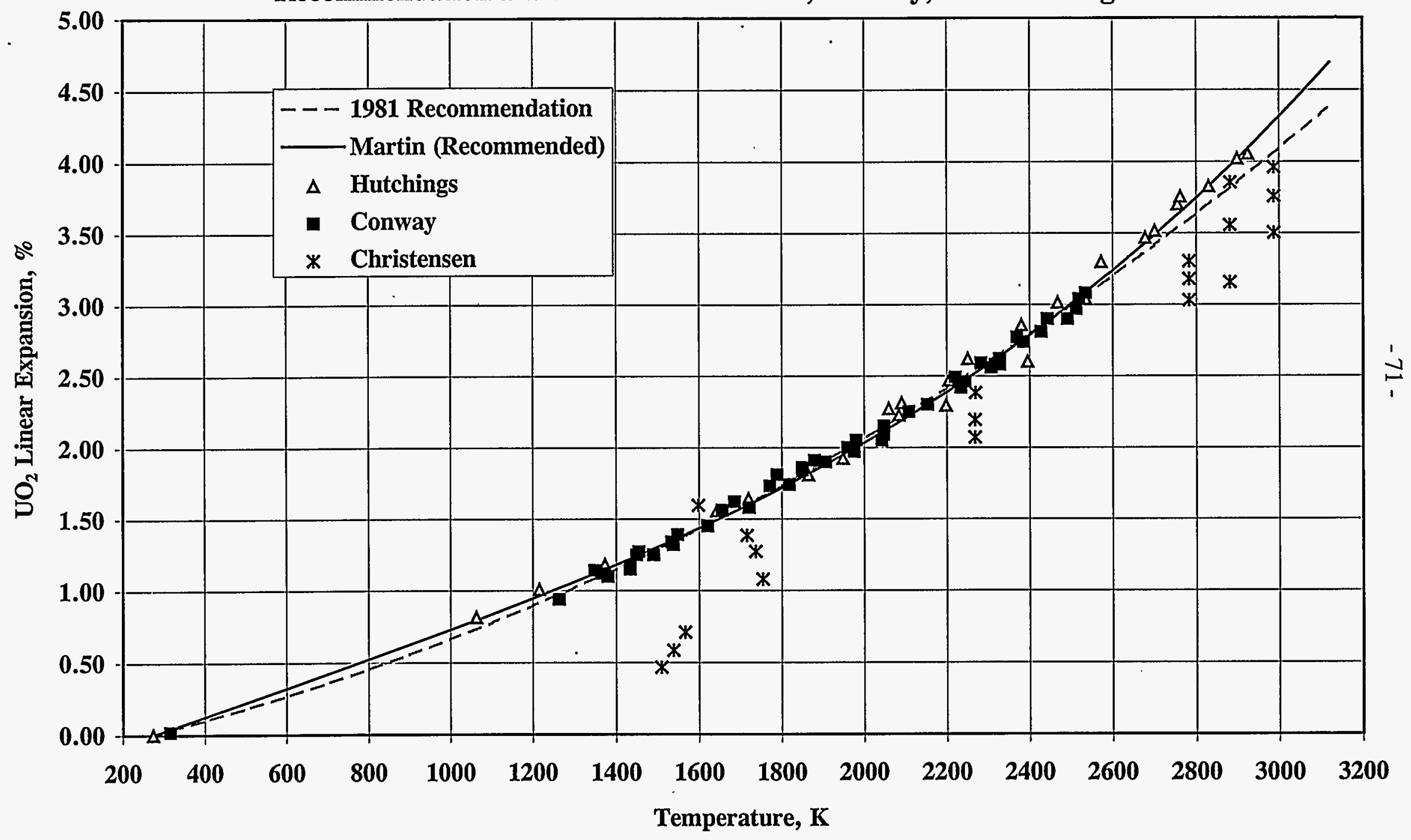


Figure 4.1.7 Comparison of Recommended $\mathrm{UO}_{2}$ Linear Thermal Expansion Coefficient of Martin with Previous Recommendation

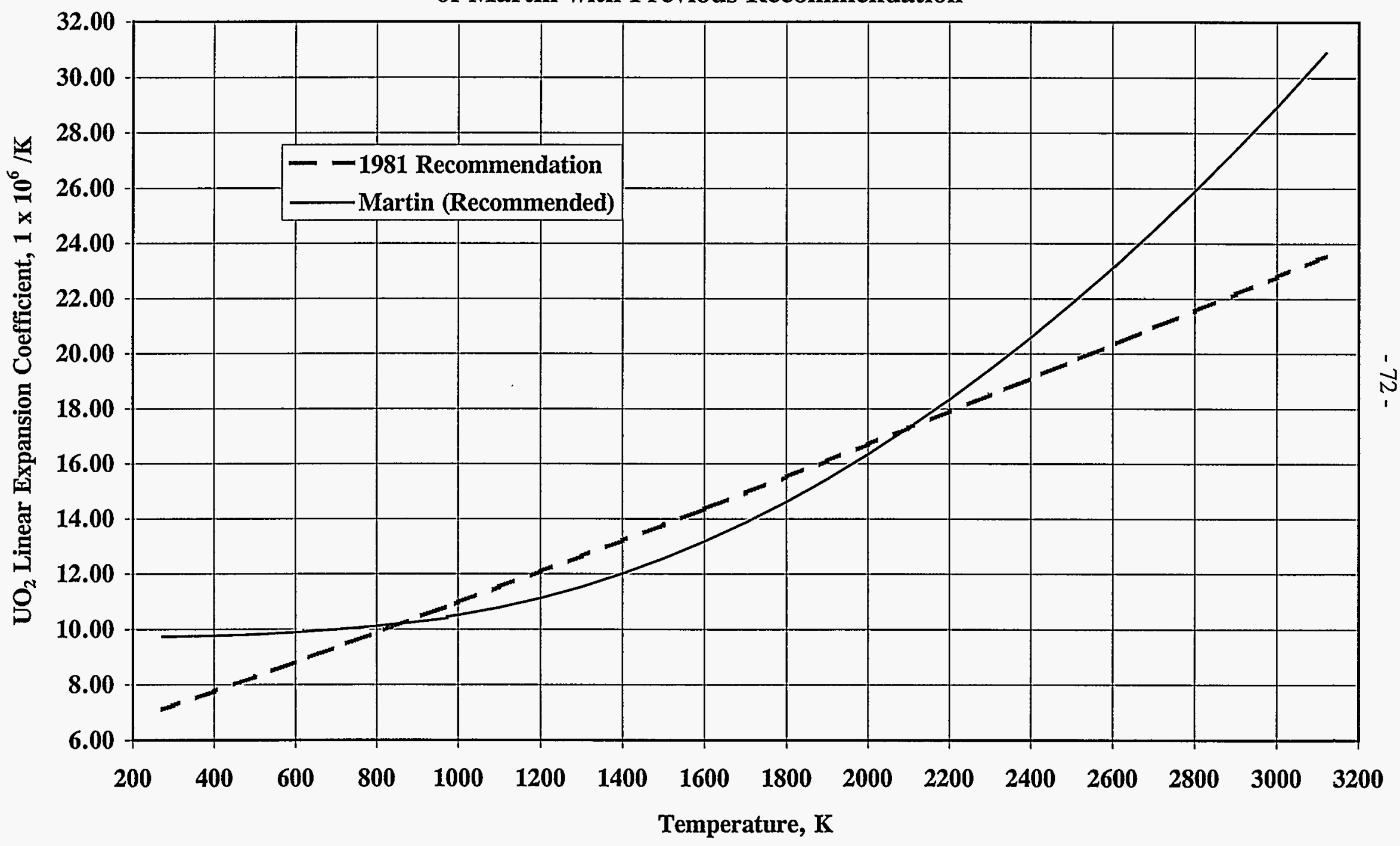


Figure 4.1.8 UO $_{2+\mathrm{X}}$ Thermal Expansion Data Compared with Recommendation

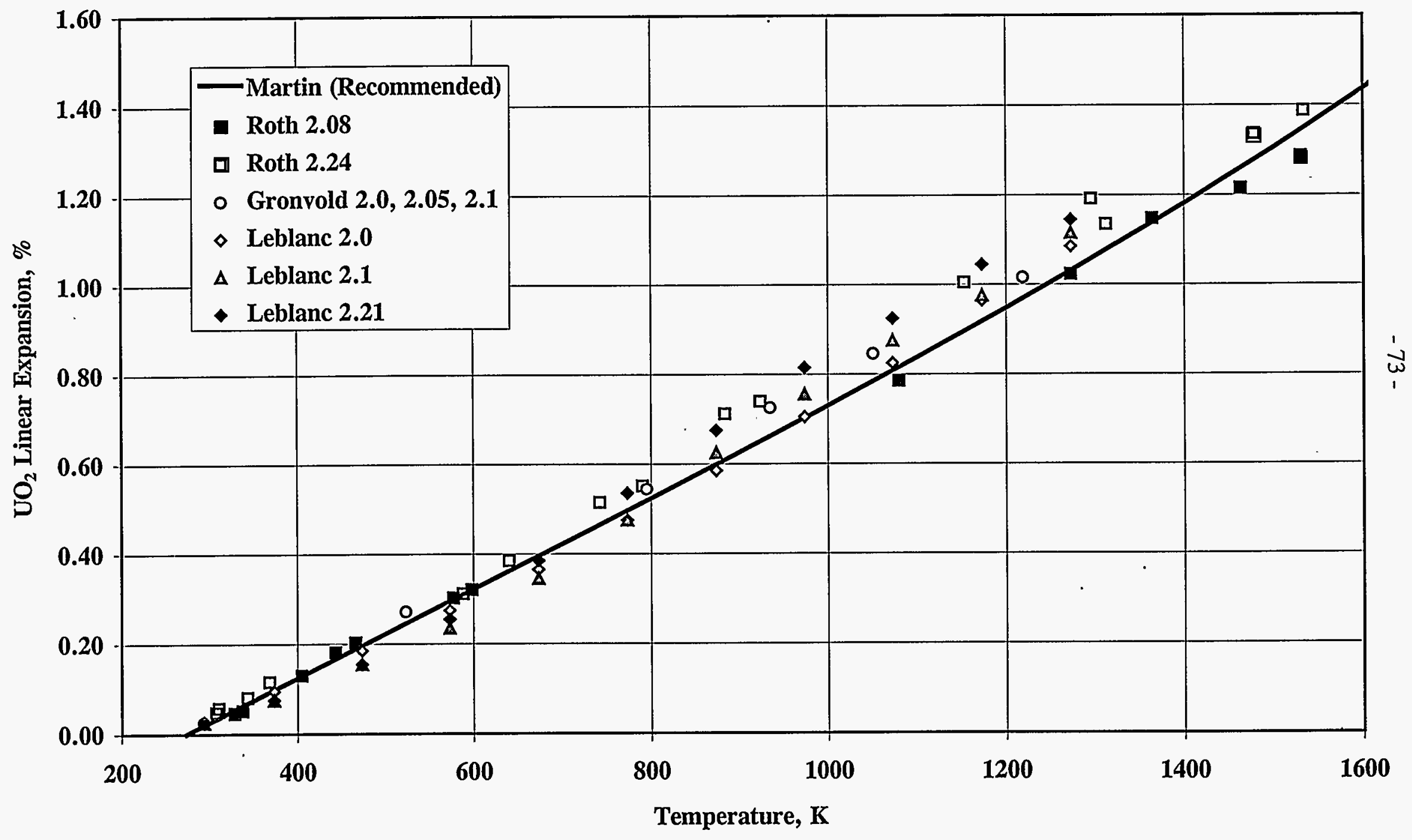




\subsection{DENSITY OF SOLID UO}

\section{Recommended Equations}

The recommended equations for the density of solid uranium dioxide are based on the lattice parameter value of $0.54704 \mathrm{~nm}$ obtained by Gronvold ${ }^{1}$ at $293 \mathrm{~K}$ and the 1988 assessment of thermal expansion by D. G. Martin. ${ }^{2}$ They are in agreement with the 1989 recommendations of Harding, Martin, and Potter. ${ }^{3}$ The lattice parameter of Gronvold is in good agreement with recent measurements by Hutchings. ${ }^{3}$ Assuming the molecular weight of $\mathrm{UO}_{2}$ is 270.03 , this lattice parameter gives a $\mathrm{UO}_{2}$ density at $293 \mathrm{~K}$ of $10.96 \mathrm{Mg} \cdot \mathrm{m}^{-3}$. Applying the thermal expansion recommendation of Martin, the density at $273 \mathrm{~K}$ is $10.963 \mathrm{Mg} \cdot \mathrm{m}^{-3}$.

The density as a function of temperature may be calculated from

$$
\rho(T)=\rho(273)\left(\frac{L(273)}{L(T)}\right)^{3}
$$

where $\rho(273)$ is the density at $273 \mathrm{~K} ; \mathrm{L}(273)$ and $\mathrm{L}(\mathrm{T})$ are the lengths at $273 \mathrm{~K}$ and at temperature $T(K)$, respectively. The ratio of the length at $273 \mathrm{~K}$ to the length at temperature $T(K)$ may be calculated from Martin's equations for the thermal expansion of solid $\mathrm{UO}_{2}$ :

For $273 \mathrm{~K} \leq \mathrm{T} \leq 923 \mathrm{~K}$

$$
\begin{aligned}
L(T)=L(273) & \left(9.9734 \times 10^{-1}+9.802 \times 10^{-6} T-2.705 \times 10^{-10} T^{2}\right. \\
& \left.+4.291 \times 10^{-10} T^{3}\right)
\end{aligned}
$$

For $923 \mathrm{~K} \leq \mathrm{T} \leq 3120 \mathrm{~K}$,

$$
\begin{aligned}
L(T)=L(273) & \left(9.9672 \times 10^{-1}+1.179 \times 10^{-5} T-2.429 \times 10^{-9} T^{2}\right. \\
& \left.+1.219 \times 10^{-12} T^{3}\right)
\end{aligned}
$$


The densities as a function of temperature of solid $\mathrm{UO}_{2}$ are given in Table 4.2.1.

From assessment of the available data on hyperstoichiometric uranium dioxide $\left(\mathrm{UO}_{2+\mathrm{x}}\right)$, Martin recommended using the same equations for the linear thermal expansion of $\mathrm{UO}_{2}$ and of $\mathrm{UO}_{2+\mathrm{x}}$ for $\mathrm{x}$ in the ranges 0 to 0.13 and 0.23 to 0.25 . Therefore, equations (1) through (3) are recommended for the density of $\mathrm{UO}_{2+\mathrm{x}}$ for $\mathrm{x}$ in the ranges 0 to 0.13 and 0.23 to 0.25 .

No data on the effect of burn-up on density or thermal expansion of $\mathrm{UO}_{2}$ are currently available. In the absence of data, equations (1) through (3) are recommended for $\mathrm{UO}_{2}$ during irradiation, in accord with the recommendation of Harding, Martin, and Potter. ${ }^{3}$

\section{$\underline{\text { Uncertainties }}$}

The recommended uncertainty in the density of $\mathrm{UO}_{2}$ is $1 \%$ for the entire temperature range. The uncertainties in the density of $\mathrm{UO}_{2}$ calculated from the thermal expansion uncertainties given by Martin $^{2}$ are less than $1 \%$. The $1 \%$ uncertainty is based on comparison of the recommended density with those of previous recommendations based on different data. Figure 4:2.1 shows the recommended density, the $1 \%$ uncertainty, and the 1981 recommended values ${ }^{5}$ that are based on the thermal expansion values of $\mathrm{Olsen}^{6}$ and a density at $298.15 \mathrm{~K}$ of $10.97 \mathrm{Mg} \cdot \mathrm{m}^{-3}$. 


\section{REFERENCES}

1. F. Gronvold, J. Inorganic and Nucl. Chem. 1 357, (1955).

2. D. G. Martin, The Thermal Expansion of Solid $\mathrm{UO}_{2}$ and $(\mathrm{U}, \mathrm{Pu})$ Mixed Oxides - A Review and Recommendations, J. Nucl. Mater. 152, 94-101 (1988).

3. J. H. Harding, D. G. Martin, and P. E. Potter, Thermophysical and Thermochemical Properties of Fast Reactor Materials, " Commission of European Communities Report EUR 12402 (1989).

4. M. T. Hutchings, High-Temperature Studies of $\mathrm{UO}_{2}$ and $\mathrm{ThO}_{2}$ Using Neutron Scattering Techniques, J. Chem. Soc. Faraday Trans. II 83, 1083-1103 (1987).

5. J. K. Fink, M. G. Chasanov, and L. Leibowitz, Thermophysical Properties of Uranium Dioxide, J. Nucl. Mater. 102 17-25 (1981).

6. C. S. Olsen, Fuel Thermal Expansion (FTHEXP) in MATPRO-Version 11: A Handbook of Materials Properties for Use in the Analysis of Light Water Reactor Fuel Rod Behavior, ed. D. R. Hagraman and G. A. Reymann, US Nuclear Regulatory Commission Rep. NUREG/CR-0497 (February 1979); also revision (1981). 
Table 4.2.1 Density of Solid Uranium Dioxide

\begin{tabular}{|c|c|}
\hline Temperature, $\mathbf{K}$ & Density, $\mathrm{Mg} \cdot \mathrm{m}^{-3}$ \\
\hline $\begin{array}{l}273 \\
298 \\
300 \\
400 \\
500\end{array}$ & $\begin{array}{l}10.96 \\
10.95 \\
10.95 \\
10.92 \\
10.89\end{array}$ \\
\hline $\begin{array}{c}600 \\
700 \\
800 \\
900 \\
1000\end{array}$ & $\begin{array}{l}10.86 \\
10.83 \\
10.79 \\
10.76 \\
10.73\end{array}$ \\
\hline $\begin{array}{l}1100 \\
1200 \\
1300 \\
1400 \\
1500\end{array}$ & $\begin{array}{l}10.69 \\
10.66 \\
10.62 \\
10.58 \\
10.54\end{array}$ \\
\hline $\begin{array}{l}1600 \\
1700 \\
1800 \\
1900 \\
2000\end{array}$ & $\begin{array}{l}10.50 \\
10.46 \\
10.42 \\
10.37 \\
10.32\end{array}$ \\
\hline $\begin{array}{l}2100 \\
2200 \\
2300 \\
2400 \\
2500\end{array}$ & $\begin{array}{l}10.27 \\
10.21 \\
10.16 \\
10.10 \\
10.03\end{array}$ \\
\hline $\begin{array}{l}2600 \\
2700 \\
2800 \\
2900 \\
3000 \\
\end{array}$ & $\begin{array}{l}9.96 \\
9.89 \\
9.82 \\
9.74 \\
9.66 \\
\end{array}$ \\
\hline $\begin{array}{l}3100 \\
3120\end{array}$ & $\begin{array}{l}9.57 \\
9.56\end{array}$ \\
\hline
\end{tabular}


品

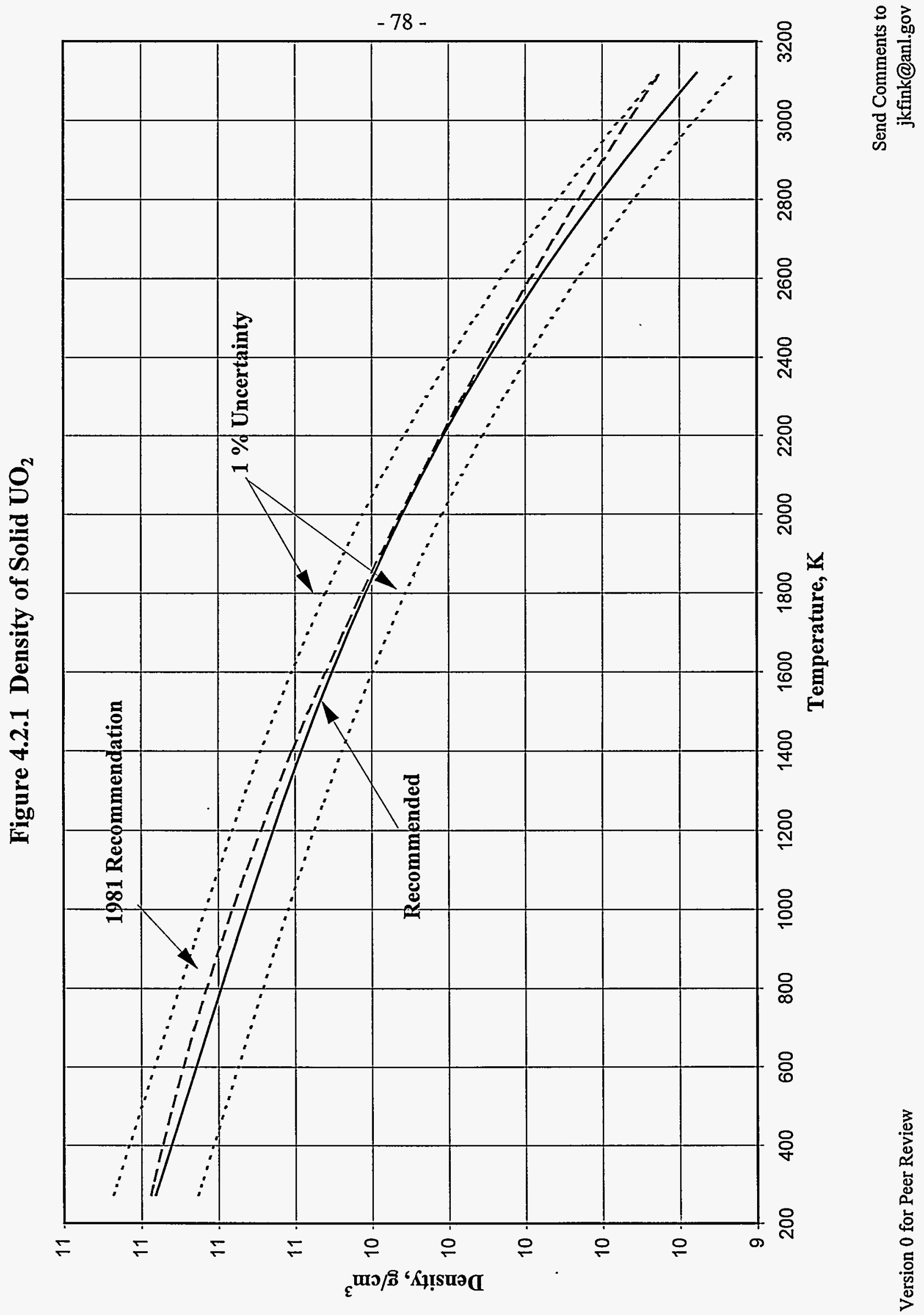




\subsection{THERMAL EXPANSION COEFFICIENT OF LIQUID UO $\mathrm{UO}_{2}$ \\ Recommended Equation}

The recommended equation for the thermal expansion coefficient of liquid uranium dioxide is based on the in-pile effective equation of state measurements of the vapor pressure, density, and isothermal compressibility of liquid $(\mathrm{U}, \mathrm{Pu}) \mathrm{O}_{2}$ by Breitung and Reil. ${ }^{1}$ From these measurements, the density and thermal expansion coefficient as functions of temperature were obtained from the melting point to $7600 \mathrm{~K}$. The equation of Breitung and Reil for the thermal expansion coefficient of $\mathrm{UO}_{2}$ and $(\mathrm{U}, \mathrm{Pu}) \mathrm{O}_{2}$ for mole fractions of $\mathrm{Pu} \leq 0.25$ is in good agreement with the equation for the thermal expansion coefficient of $\mathrm{UO}_{2}$ from experiments by Drotning, ${ }^{2}$ which had been recommended in the 1981 assessment by Fink et al. ${ }^{3,4}$

The recommended equation for the instantaneous volumetric thermal expansion coefficient of $\mathrm{UO}_{2}$ as a function of temperature is

$$
\alpha_{P}=\frac{0.9285}{8860-0.9285(T-3120)}
$$

where the thermal expansion coefficient $\left(\alpha_{\mathrm{P}}\right)$ is in $\mathrm{K}^{-1}$ and temperature $(T)$ is in $\mathrm{K}$. Values for the density and the instantaneous volumetric thermal expansion coefficient of $\mathrm{UO}_{2}$ are given in Table 4.3.1. Figure 4.3.1 shows the recommended values for the instantaneous volumetric thermal expansion coefficient of $\mathrm{UO}_{2}$, the uncertainties determined by Breitung and Reil, ${ }^{1}$ and the instantaneous volumetric thermal expansion coefficients of $\mathrm{UO}_{2}$ calculated from equations of Drotning, ${ }^{2}$ of Christensen, ${ }^{5}$ and of Harding. ${ }^{6}$

\section{Uncertainties}

Breitung and Reil determined experimental uncertainties from the uncertainty in the fuel mass $(\delta \mathrm{m} / \mathrm{m}=10 \%)$, the uncertainty in the test volume $(\delta \mathrm{V} / \mathrm{V}=2.5 \%)$, and the uncertainty in the fuel enthalpy $(\delta h / h=6 \%)$. From these uncertainties, they obtained upper and lower limiting cases which they used to define uncertainties in the parameters in Eq. (1). The liquid density at the melting point, $8860 \mathrm{~kg} \cdot \mathrm{m}^{-3}$, has an uncertainty of $\pm 120 \mathrm{~kg} \cdot \mathrm{m}^{-3}$. The slope of the density, $(d \rho / d T)=0.9285$ $\mathrm{kg} \cdot \mathrm{m}^{-3} \cdot \mathrm{K}^{-1}$, has uncertainties of $+0.036 \mathrm{~kg} \cdot \mathrm{m}^{-3} \cdot \mathrm{K}^{-1}$ and $-0.135 \mathrm{~kg} \cdot \mathrm{m}^{-3} \cdot \mathrm{K}^{-1}$. The upper and lower uncertainty limits calculated using the uncertainties in these parameters are shown in Figure 4.3.1. 
They correspond to uncertainties of

$+10 \%$ and $-12 \%$ at $3120 \mathrm{~K}$;

$+10 \%$ and $-13 \%$ at $3500 \mathrm{~K}$;

$+12 \%$ and $-15 \%$ at $4500 \mathrm{~K}$;

$+13 \%$ and $-17 \%$ at $5500 \mathrm{~K}$;

$+15 \%$ and $-20 \%$ at $6500 \mathrm{~K}$;

$+18 \%$ and $-27 \%$ at $7600 \mathrm{~K}$.

Discussion of the Recommended Equation

Thermodynamic Relations - The instantaneous volumetric thermal expansion coefficient $\left(\alpha_{p}\right)$ is related to the density $(\rho)$ by the thermodynamic relation

$$
\alpha_{P}=-\frac{1}{\rho}\left(\frac{\partial \rho}{\partial T}\right)_{\sigma}+\beta_{T}\left(\frac{\partial P}{\partial T}\right)_{\sigma}
$$

where $\beta_{\mathrm{T}}$ is the isothermal compressibility and $\mathrm{P}$ is the vapor pressure. The subscript $\sigma$ on the partial derivatives indicates that they are along the saturation curve. Breitung and Reil ${ }^{1}$ stated that the magnitude of the second term in Eq. (2) is much smaller than the first term and only contributes a few percent at $8000 \mathrm{~K}$. This is because along the saturation curve, the volume change due to the pressure change is much smaller than the corresponding volume change due to thermal expansion. Thus, for $\mathrm{UO}_{2}$ and $(\mathrm{U}, \mathrm{Pu}) \mathrm{O}_{2}$, the thermal expansion coefficient may be evaluated from the density/ temperature relation using the first term in Eq. (2).

The linear instantaneous thermal expansion coefficient is one third of the instantaneous volumetric thermal expansion coefficient, given by Eq. (1). Equations relating the instantaneous volumetric thermal expansion coefficient and density to other expansion parameters are given in the Section 4.5, "Density and Thermal Expansion Relations."

Comparison with Other Measurements and Assessments - Three experiments have provided . data on the density and thermal expansion of liquid $\mathrm{UO}_{2}$. Breitung and Reil ${ }^{1}$ determined the density of $\mathrm{UO}_{2}$ and $(\mathrm{U}, \mathrm{Pu}) \mathrm{O}_{2}$ from the melting point $(3120 \mathrm{~K})$ to $7600 \mathrm{~K}$ from measurements of the pressure rise of a sealed capsule during a transient in-pile pulse. Their vapor pressure measurements using ultrapure $\mathrm{UO}_{2}$, reactor grade $\mathrm{UO}_{2}$, and reactor grade $(\mathrm{U}, \mathrm{Pu}) \mathrm{O}_{2}$ showed no significant difference for 
the vapor pressures of all three fuel types. Drotning ${ }^{2}$ determined the density of $\mathrm{UO}_{2}$ with $\mathrm{O} / \mathrm{M}$ ratios ranging from 2.01 to 2.04 as a function of temperature using gamma ray attenuation measurements. Christensen measured the thermal expansion of solid and liquid $\mathrm{UO}_{2}$ and the volume change on melting using gamma radiographs to determine the sample dimensions.

The variation of density with temperature from all three measurements is in good agreement. The slope $(d \rho / d T)$ used in the first term of Eq. (2) is

$-0.9285 \mathrm{~kg} \mathrm{~m}^{-3} \mathrm{~K}^{-1} \quad$ (Breitung \& Reil)

$-0.916 \mathrm{~kg} \mathrm{~m}^{-3} \mathrm{~K}^{-1} \quad$ (Drotning)

$-0.918 \mathrm{~kg} \mathrm{~m}^{-3} \mathrm{~K}^{-1} \quad$ (Christensen)

The thermal expansion of Drotning ${ }^{2}$ was recommended in the 1981 assessment by Fink et al. $^{3,4}$ The instantaneous volumetric thermal expansion coefficient calculated from Drotning's density equation using the first term in Eq. (2) is

$$
\alpha_{P}=\frac{0.916}{8860-0.916(T-3120)}
$$

where the thermal expansion coefficient $\left(\alpha_{\mathrm{P}}\right)$ is in $\mathrm{K}^{-1}$ and temperature $(T)$ is in $\mathrm{K}$. Values of thermal expansion calculated with this equation are shown in Figure 4.3.1.

In their 1989 review of the data on density of liquid $\mathrm{UO}_{2}$, Harding, Martin, and Potter ${ }^{6}$ also recommended the change in density with temperature measured by Drotning. However, they recommended $8640 \pm 60 \mathrm{~kg} \cdot \mathrm{m}^{-3}$ for the liquid density at $3120 \mathrm{~K}$. So, the thermal expansion coefficient calculated from the density recommended by Harding et al. using the first term in Eq. (2) is

$$
\alpha_{P}=\frac{0.893}{8640-0.893(T-3120)}
$$

where the volumetric thermal expansion coefficient $\left(\alpha_{\mathrm{P}}\right)$ is in $\mathrm{K}^{-1}$ and temperature $(T)$ is in $\mathrm{K}$. Because both Eq. (3) and Eq. (4) are based on the variation of density with temperature measured 
by Drotning, the values of the thermal expansion coefficient calculated using Eq. (4) are almost identical to those calculated using Eq. (3). Differences are $0.03 \%$ from the melting point to 4800 $\mathrm{K}, 0.04 \%$ from 4900 to $6600 \mathrm{~K}$, and $0.05 \%$ from 6700 to $7600 \mathrm{~K}$.

The instantaneous volumetric thermal expansion coefficient calculated from the liquid density of Christensen and his change of density with temperature is

$$
\alpha_{P}=\frac{0.918}{8740-0.918(T-3120)}
$$

where the thermal expansion coefficient $\left(\alpha_{\mathrm{p}}\right)$ is in $\mathrm{K}^{-1}$ and temperature $(T)$ is in $\mathrm{K}$. Values of the volumetric thermal expansion coefficient determined from the measurements of Christensen have been included in Figure 4.3.1.

Figure 4.3.2 shows the deviations of the recommended thermal expansion coefficients of Breitung and Reil from the thermal expansion coefficients determined from measurements of Christensen ${ }^{5}$ and of Drotning. ${ }^{2}$ Percent deviations in Figure 4.3.2 are defined as

$$
\operatorname{Deviation}(\%)=\frac{\alpha_{P}(E q)-\alpha_{p}(\text { Breitung })}{\alpha_{p}(\text { Breitung })} \cdot 100 \%
$$

Extrapolations of the thermal expansion coefficients from the low temperature measurements of Christensen ${ }^{5}$ and Drotning ${ }^{2}$ to $7600 \mathrm{~K}$ show good agreement throughout the temperature range. Deviations of recommended values from those determined from measurements by Drotning range from $-1.4 \%$ at the melting point to $-2.5 \%$ at $7600 \mathrm{~K}$. Christensen's values deviate from those of Breitung and Reil by $0.2 \%$ at the melting temperature and by $0.4 \%$ at $7600 \mathrm{~K}$. Figure 4.3 .2 shows that all deviations are well within the uncertainty limits given by Breitung and Reil. 


\section{REFERENCES}

1. W. Breitung and K. O. Reil, The Density and Compressibility of Liquid (U,Pu)-Mixed Oxide, Nuclear Science and Engineering 105, 205-217 (1990).

2. W. D. Drotning, Thermal Expansion of Molten Uranium Dioxide, Proceedings of the 8th Symp. On Thermophysical Properties, Gaithersburg, Maryland, June 15-18, 1981, National Bureau of Standard (1981).

3. J. K. Fink, M. G. Chasanov, and L. Leibowitz, Thermophysical Properties of Uranium Dioxide, J. Nucl. Mater. 102 17-25 (1981).

4. J. K. Fink, M. G. Chasanov, and L. Leibowitz, Properties for Reactor Safety Analysis, ANLCEN-RSD-80-3, Argonne National Laboratory Report (April, 1981).

5. J. A. Christensen, Thermal Expansion and Change in Volume of Uranium Dioxide on Melting, J. Am. Ceram. Soc. 46, 607-608 (1963).

6. J. H. Harding, D. G. Martin, and P. E. Potter, Thermophysical and Thermochemical Properties of Fast Reactor Materials, " Commission of European Communities Report EUR 12402 (1989). 
Table 4.3.1 Density and Volumetric Thermal Expansion Coefficient for Liquid $\mathrm{UO}_{2}$

\begin{tabular}{|c|c|c|}
\hline $\begin{array}{c}\text { Temperature } \\
\mathbf{K}\end{array}$ & $\begin{array}{l}\text { Density } \\
\mathrm{Mg} \mathrm{m}^{-3}\end{array}$ & $\begin{array}{l}\text { Thermal Expansion } \\
\qquad \alpha_{\mathrm{p}} \times 10^{5}, \mathrm{~K}^{-1}\end{array}$ \\
\hline $\begin{array}{l}3120 \\
3200 \\
3300 \\
3400 \\
3500\end{array}$ & $\begin{array}{l}8.86 \\
8.79 \\
8.69 \\
8.60 \\
8.51 \\
\end{array}$ & $\begin{array}{l}10.48 \\
10.57 \\
10.68 \\
10.80 \\
10.91 \\
\end{array}$ \\
\hline $\begin{array}{l}3600 \\
3700 \\
3800 \\
3900 \\
4000\end{array}$ & $\begin{array}{l}8.41 \\
8.32 \\
8.23 \\
8.14 \\
8.04\end{array}$ & $\begin{array}{l}11.03 \\
11.16 \\
11.28 \\
11.41 \\
11.54\end{array}$ \\
\hline $\begin{array}{l}4100 \\
4200 \\
4300 \\
4400 \\
4500\end{array}$ & $\begin{array}{l}7.95 \\
7.86 \\
7.76 \\
7.67 \\
7.58\end{array}$ & $\begin{array}{l}11.68 \\
11.82 \\
11.96 \\
12.10 \\
12.25\end{array}$ \\
\hline $\begin{array}{l}4600 \\
4700 \\
4800 \\
4900 \\
5000\end{array}$ & $\begin{array}{l}7.49 \\
7.39 \\
7.30 \\
7.21 \\
7.11\end{array}$ & $\begin{array}{l}12.40 \\
12.56 \\
12.72 \\
12.88 \\
13.05\end{array}$ \\
\hline $\begin{array}{l}5100 \\
5200 \\
5300 \\
5400 \\
5500\end{array}$ & $\begin{array}{l}7.02 \\
6.93 \\
6.84 \\
6.74 \\
6.65\end{array}$ & $\begin{array}{l}13.22 \\
13.40 \\
13.58 \\
13.77 \\
13.96\end{array}$ \\
\hline $\begin{array}{l}5600 \\
5700 \\
5800 \\
5900 \\
6000\end{array}$ & $\begin{array}{l}6.56 \\
6.46 \\
6.37 \\
6.28 \\
6.19\end{array}$ & $\begin{array}{l}14.16 \\
14.36 \\
14.57 \\
14.79 \\
15.01\end{array}$ \\
\hline $\begin{array}{l}6100 \\
6200 \\
6300 \\
6400 \\
6500\end{array}$ & $\begin{array}{l}6.09 \\
6.00 \\
5.91 \\
5.81 \\
5.72\end{array}$ & $\begin{array}{l}15.24 \\
15.47 \\
15.72 \\
15.97 \\
16.23\end{array}$ \\
\hline $\begin{array}{l}6600 \\
6700 \\
6800 \\
6900 \\
7000\end{array}$ & $\begin{array}{l}5.63 \\
5.54 \\
5.44 \\
5.35 \\
5.26\end{array}$ & $\begin{array}{l}16.50 \\
16.77 \\
17.06 \\
17.35 \\
17.66\end{array}$ \\
\hline $\begin{array}{l}7100 \\
7200 \\
7300 \\
7400 \\
7500 \\
7600\end{array}$ & $\begin{array}{l}5.16 \\
5.07 \\
4.98 \\
4.89 \\
4.79 \\
4.70\end{array}$ & $\begin{array}{l}17.98 \\
18.31 \\
18.65 \\
19.00 \\
19.37 \\
19.75\end{array}$ \\
\hline
\end{tabular}


Figure 4.3.1 Coefficient of Thermal Expansion for Liquid $\mathrm{UO}_{2}$

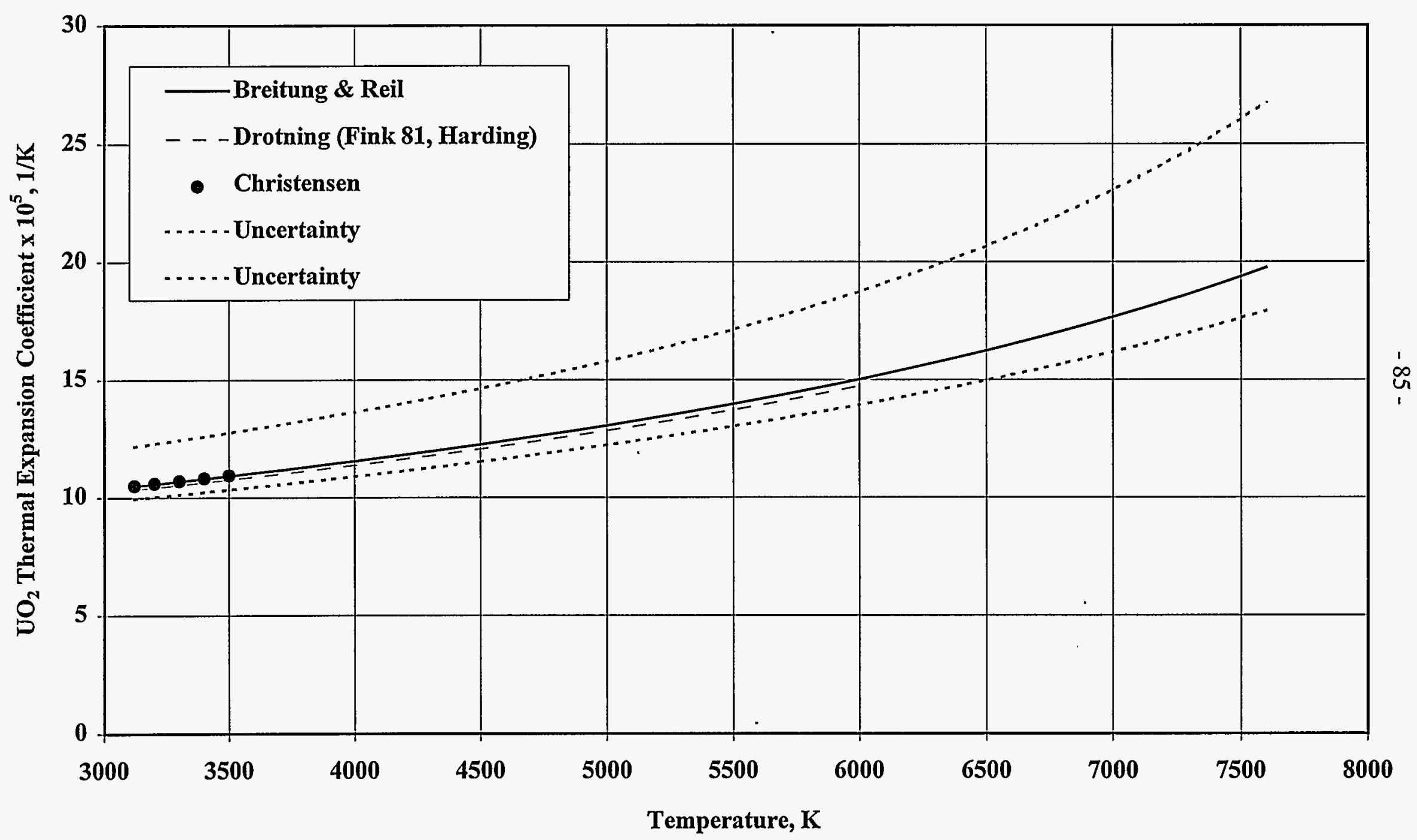




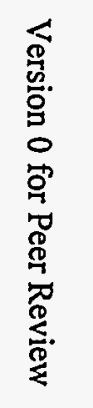

Thermal Expansion Coefficient Deviations, \%

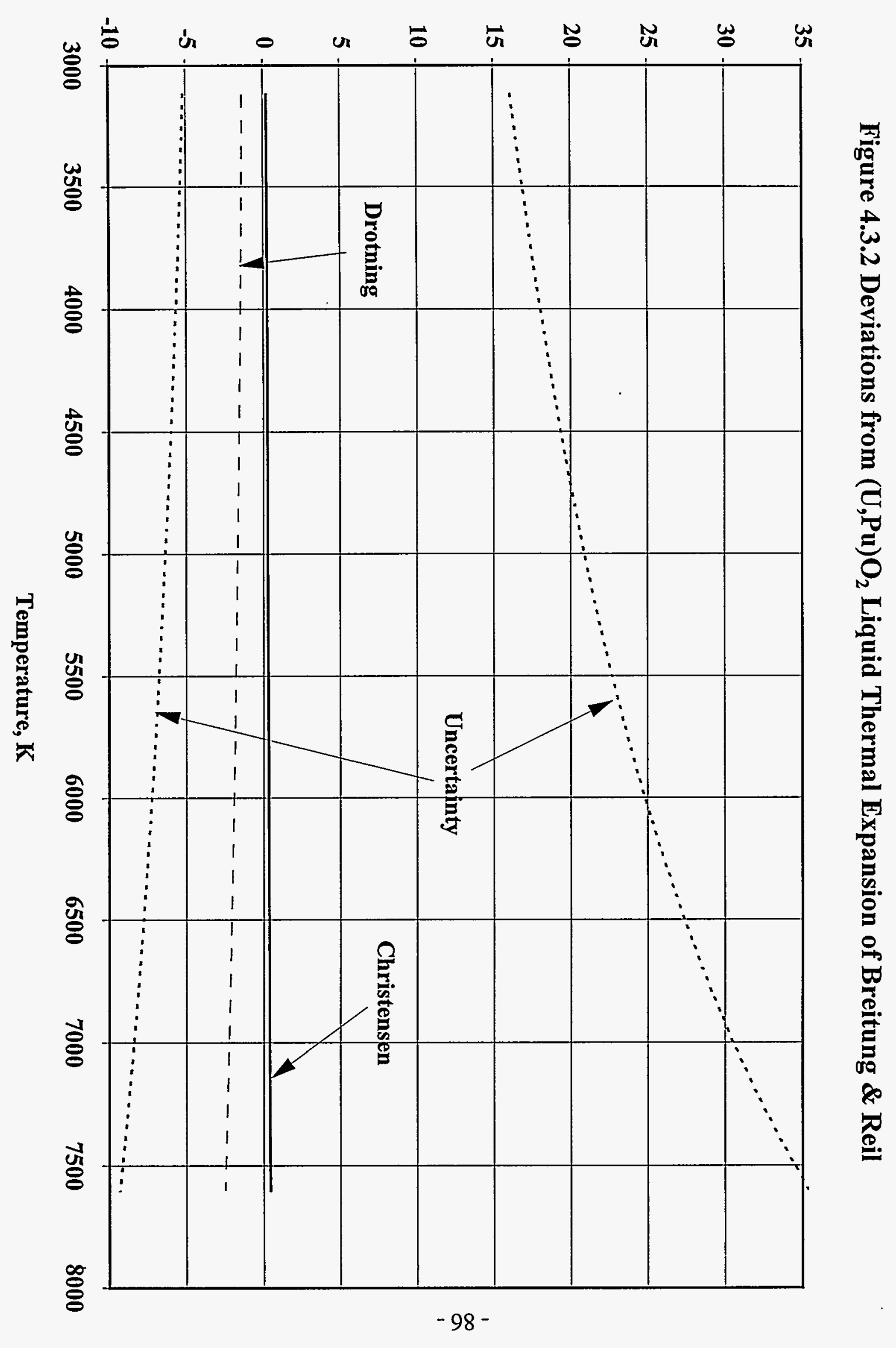




\subsection{DENSITY OF LIQUID UO}

\section{Recommended Equation}

The recommended equation for the density of liquid uranium dioxide is based on the in-pile effective equation-of-state measurements of the vapor pressure, density, and isothermal compressibility of liquid $(\mathrm{U}, \mathrm{Pu}) \mathrm{O}_{2}$ by Breitung and Reil. ${ }^{1}$ Measurements of density as a function of enthalpy and as a function of temperature were obtained from the melting point ( $3120 \mathrm{~K}$ ) to $7600 \mathrm{~K}$. The equation of Breitung and Reil for the density of $\mathrm{UO}_{2}$ and $(\mathrm{U}, \mathrm{Pu}) \mathrm{O}_{2}$ for mole fractions of $\mathrm{Pu} \leq 0.25$ is in good agreement with the equation for the density of $\mathrm{UO}_{2}$ from experiments by Drotning, ${ }^{2}$ which had been recommended in the 1981 assessment by Fink et al. ${ }^{3,4}$

The recommended equation for the density of $\mathrm{UO}_{2}$ as a function of temperature is

$$
\rho=8.860-9.285 \times 10^{-4}(T-3120)
$$

where density $(\rho)$ is in $\mathrm{Mg} / \mathrm{m}^{3}$ and temperature $(T)$ is in $\mathrm{K}$. Values for the density and the instantaneous thermal expansion coefficient of $\mathrm{UO}_{2}$ are given in Table 4.4.1. Figure 4.4.1 shows the recommended values for the density of $\mathrm{UO}_{2}$, the uncertainties determined by Breitung and Reil, ${ }^{1}$ and the $\mathrm{UO}_{2}$ density data of Drotning ${ }^{2}$ and of Christensen. ${ }^{5}$

\section{Uncertainties}

Breitung and Reil determined experimental uncertainties from the uncertainty in the fuel mass $(\delta \mathrm{m} / \mathrm{m}=10 \%)$, the uncertainty in the test volume $(\delta \mathrm{V} / \mathrm{V}=2.5 \%)$, and the uncertainty in the fuel enthalpy $(\delta h / h=6 \%)$. From these uncertainties, they obtained upper and lower limiting values in addition to the most probable reference values. Their uncertainty bands correspond to uncertainties in the coefficients in Eq. (1) given by

$$
\rho=(8.860 \pm 0.120)+\left[-9.285\left(\begin{array}{l}
+0.036 \\
-0.135
\end{array}\right)\right] \times 10^{-4}(T-3120)
$$

The upper and lower uncertainty limits calculated from Eq. (2) are shown in Figure 4.4.1. They correspond to uncertainties of

$\pm 1.4 \%$ at $3120 \mathrm{~K}$

$+1.6 \%$ and $-2 \%$ at $3500 \mathrm{~K}$; 
$+2.2 \%$ and $-4 \%$ at $4500 \mathrm{~K}$;

$+3 \%$ and $-6.3 \%$ at $5400 \mathrm{~K}$;

$+4.2 \%$ and $-10 \%$ at $6500 \mathrm{~K}$;

$+6 \%$ and $-15.4 \%$ at $7600 \mathrm{~K}$.

Discussion of the Recommended Equation

Measurements and Assessments - Three experiments have provided data on the density and thermal expansion of liquid $\mathrm{UO}_{2}$. Breitung and Reil ${ }^{1}$ determined the density of $\mathrm{UO}_{2}$ and $(\mathrm{U}, \mathrm{Pu}) \mathrm{O}_{2}$ from the melting point to $7600 \mathrm{~K}$ from measurements of the pressure rise of a sealed capsule during a transient in-pile pulse. Their vapor pressure measurements using ultrapure $\mathrm{UO}_{2}$, reactor grade $\mathrm{UO}_{2}$, and reactor grade $(\mathrm{U}, \mathrm{Pu}) \mathrm{O}_{2}$ showed no significant difference for the vapor pressures of all three fuel types. Drotning ${ }^{2}$ determined the density of $\mathrm{UO}_{2}$ with $\mathrm{O} / \mathrm{M}$ ratios ranging from 2.01 to 2.04 as a function of temperature using gamma-ray attenuation measurements. Christensen measured the thermal expansion of solid and liquid $\mathrm{UO}_{2}$ and the volume change on melting using gamma radiographs to determine the sample dimensions.

$\mathrm{UO}_{2}$ liquid densities at the melting point measured by Drotning ranged from 8.779 to 8.939 $\mathrm{Mg} / \mathrm{m}^{3}$ with an average of $8.860 \mathrm{Mg} / \mathrm{m}^{3}$ and a deviation of $\pm 0.061 \mathrm{Mg} / \mathrm{m}^{3}$ or $0.7 \%$. His equation for the density of $\mathrm{UO}_{2}$ in $\mathrm{Mg} / \mathrm{m}^{3}$ from 3120 to $3250 \mathrm{~K}$ is

$$
\rho=(8.860 \pm 0.06)-(9.16 \pm 0.43) \times 10^{-4}(T-3120)
$$

where temperature is in $\mathrm{K}$. This equation was recommended in the 1981 assessment by Fink et al. ${ }^{3,4}$

The change of density of $\mathrm{UO}_{2}$ at the melting point measured by Christensen was $9.6 \%$. In the liquid range, he measured densities from the melting point (which he measured as $3073 \mathrm{~K}$ rather than $3120 \mathrm{~K}$ ) to $3373 \mathrm{~K}$. At the melting point, he gave solid and liquid densities of $9.67 \pm 0.13$ $\mathrm{Mg} / \mathrm{m}^{3}$ and $8.74 \pm 0.16 \mathrm{Mg} / \mathrm{m}^{3}$, respectively. His equation for the liquid density of $\mathrm{UO}_{2}$ adjusted to a melting point of $3120 \mathrm{~K}$ is

$$
\rho=8.74-9.18 \times 10^{-4}(T-3120)
$$


where density is in $\mathrm{Mg} / \mathrm{m}^{3}$ and temperature is in $\mathrm{K}$.

In their 1989 review of the data on density of liquid $\mathrm{UO}_{2}$, Harding, Martin, and Potter ${ }^{6}$ used the solid density at the melting point recommended by $\operatorname{Martin}^{7}\left(9.56 \pm 0.04 \mathrm{Mg} / \mathrm{m}^{3}\right)$ and the change in density at melting determined by Christensen (9.6\%) to obtain $8.64 \pm 0.06 \mathrm{Mg} / \mathrm{m}^{3}$ for the liquid density at $3120 \mathrm{~K}$. Because of the higher accuracy of Drotning's liquid density measurements compared with the thermal expansion measurements of Christensen, Harding et al. ${ }^{6}$ based the slope of their density equation on the slope given by Drotning corrected to the different density at the melting point, $3120 \mathrm{~K}$. They recommended the equation

$$
\rho=(8.64 \pm 0.06)-(8.93 \pm 0.42) \times 10^{-4}(T-3120)
$$

for the density of $\mathrm{UO}_{2}$ in $\mathrm{Mg} / \mathrm{m}^{3}$, where temperature is in $\mathrm{K}$. The liquid density at the melting point given by this equation is lower than the lowest density measured by Drotning but is above Christensen's lower uncertainty of $8.58 \mathrm{Mg} / \mathrm{m}^{3}$.

Breitung and Reil set their melting point density of $\mathrm{UO}_{2}$ and $(\mathrm{U}, \mathrm{Pu}) \mathrm{O}_{2}$ to $8.860 \mathrm{Mg} / \mathrm{m}^{3}$, the density of $\mathrm{UO}_{2}$ at the melting point given by Drotning ${ }^{2}$ because of the smaller error in Drotning's measurements $( \pm 0.7 \%)$ than in Christensen's measurements $( \pm 2 \%)$. The densities of Christensen and of Drotning agree within their experimental uncertainties. The uncertainty $\left( \pm 0.120 \mathrm{Mg} / \mathrm{m}^{3}\right)$ given by Breitung and Reil for this parameter in their density equation is large enough to include the melting point density given by Christensen. The liquid density at the melting point recommended by Fink, Chasanov, and Leibowitz ${ }^{3,4}$ was also $8.860 \mathrm{Mg} / \mathrm{m}^{3}$.

Equation Selection - The equation given by Breitung and Reil, Eq. (1), has been recommended because it is a careful analysis of the experimental data with experimental uncertainties for the largest temperature range and is consistent with the measurements of Drotning. Figure 4.4.2 compares the recommended equation of Breitung and Reil with the equations of Drotning, ${ }^{2}$ Christensen, ${ }^{5}$ and Harding et al. ${ }^{6}$ and the experimental data of Drotning and of Christensen. In Figure 4.4.2, the data of Christensen has been corrected for his temperature offset at the melting point. Figure 4.4 .2 shows that the slope of the density equation recommended by Breitung and Reil is also consistent with that of Christensen. However, the equation of Harding 
et al. is consistently lower than that of Breitung and Reil in this temperature region due to the melting point density selected by Harding et al. Because the solid density data of Christensen has been shown, by Martin's analysis ${ }^{7}$ of the thermal expansion of solid $\mathrm{UO}_{2}$, to be inconsistent with later more accurate measurements of Hutchings, ${ }^{8}$ there is some question with regard to the reliability of his determination of the change of density on melting. Because the liquid densities at the melting point determined by Drotning and by Christensen are consistent within their error limits and the uncertainties for Drotning's data are less than those for Christensen's, the melting point density of Drotning is preferred to using the density change on melting given by Christensen and the solid density at the melting point given by Martin. ${ }^{7}$

Deviations from Recommended Equation - Percent deviations of the densities given by the equations of Drotning, ${ }^{2}$ Christensen, ${ }^{5}$ and Harding et al. ${ }^{6}$ from the recommended values given by the equation of Breitung and Reil are shown in Figure 4.4.3. Percent deviations in Figure 4.4.3 are defined as

$$
\operatorname{Deviation}(\%)=\frac{\rho(E q)-\rho(\text { Breitung })}{\rho(\text { Breitung })} \cdot 100 \%
$$

The uncertainties given by Breitung and Reil are included in Figure 4.4.3, expressed as percents, for comparison with the deviations. Figure 4.4.3 shows that all the equations are within the uncertainties of Breitung and Reil except for the equation of Harding et al. for the temperature range $3120 \mathrm{~K}$ through $3700 \mathrm{~K}$. Absolute values of the percent deviations for the equation of Harding et al. decrease from a maximum deviation of $-2.5 \%$ at the melting point to $-1.3 \%$ at $7600 \mathrm{~K}$. Percent deviations for the density equation of Christensen show little variation with temperature. They range from $-1.4 \%$ at $3120 \mathrm{~K}$ to $-1.6 \%$ at $7600 \mathrm{~K}$. The smallest deviations occur for Drotning's equation, which gives densities within $1 \%$ of those given by Breitung and Reil from the melting, point through $7200 \mathrm{~K}$. At $7600 \mathrm{~K}$, the percent deviation for these equations is $1.2 \%$. Thus, for the entire temperature range of interest in severe accidents, the recommended densities of Breitung and Reil are in good agreement with those given by the equation of Drotning, which was recommended in the 1981 assessment by Fink et al. ${ }^{3,4}$ 


\section{REFERENCES}

1. W. Breitung and K. O. Reil, The Density and Compressibility of Liquid (U,Pu)-Mixed Oxide, Nuclear Science and Engineering 105, 205-217 (1990).

2. W. D. Drotning, Thermal Expansion of Molten Uranium Dioxide, Proceedings of the 8th Symp. On Thermophysical Properties, Gaithersburg, Maryland, June 15-18, 1981, National Bureau of Standard (1981).

3. J. K. Fink, M. G. Chasanov, and L. Leibowitz, Thermophysical Properties of Uranium Dioxide, J. Nucl. Mater. 102 17-25 (1981).

4. J. K. Fink, M. G. Chasanov, and L. Leibowitz, Properties for Reactor Safety Analysis, ANLCEN-RSD-80-3, Argonne National Laboratory Report (April, 1981).

5. J. A. Christensen, Thermal Expansion and Change in Volume of Uranium Dioxide on Melting, J. Am. Ceram. Soc. 46, 607-608 (1963).

6. J. H. Harding, D. G. Martin, and P. E. Potter, Thermophysical and Thermochemical Properties of Fast Reactor Materials, " Commission of European Communities Report EUR 12402 (1989).

7. D. G. Martin, The Thermal Expansion of Solid $\mathrm{UO}_{2}$ and (U,Pu) Mixed Oxides - A Review and Recommendations, J. Nucl. Mater. 152 94-101 (1988).

8. M. T. Hutchings, High-Temperature Studies of $\mathrm{UO}_{2}$ and $\mathrm{ThO}_{2}$ Using Neutron Scattering Techniques, J. Chem. Soc. Faraday Trans. II 83, 1083-1103 (1987). 
Table 4.4.1 Density of Liquid $\mathrm{UO}_{2}$

\begin{tabular}{|c|c|}
\hline $\begin{array}{c}\text { Temperature } \\
\mathbf{K}\end{array}$ & $\begin{array}{l}\text { Density } \\
\mathrm{Mg} \mathrm{m}^{-3}\end{array}$ \\
\hline $\begin{array}{l}3120 \\
3200 \\
3300 \\
3400 \\
3500\end{array}$ & $\begin{array}{l}8.86 \\
8.79 \\
8.69 \\
8.60 \\
8.51\end{array}$ \\
\hline $\begin{array}{l}3600 \\
3700 \\
3800 \\
3900 \\
4000\end{array}$ & $\begin{array}{l}8.41 \\
8.32 \\
8.23 \\
8.14 \\
8.04\end{array}$ \\
\hline $\begin{array}{l}4100 \\
4200 \\
4300 \\
4400 \\
4500\end{array}$ & $\begin{array}{l}7.95 \\
7.86 \\
7.76 \\
7.67 \\
7.58\end{array}$ \\
\hline $\begin{array}{l}4600 \\
4700 \\
4800 \\
4900 \\
5000\end{array}$ & $\begin{array}{l}7.49 \\
7.39 \\
7.30 \\
7.21 \\
7.11\end{array}$ \\
\hline $\begin{array}{l}5100 \\
5200 \\
5300 \\
5400 \\
5500\end{array}$ & $\begin{array}{l}7.02 \\
6.93 \\
6.84 \\
6.74 \\
6.65\end{array}$ \\
\hline $\begin{array}{l}5600 \\
5700 \\
5800 \\
5900 \\
6000\end{array}$ & $\begin{array}{l}6.56 \\
6.46 \\
6.37 \\
6.28 \\
6.19\end{array}$ \\
\hline $\begin{array}{l}6100 \\
6200 \\
6300 \\
6400 \\
6500\end{array}$ & $\begin{array}{l}6.09 \\
6.00 \\
5.91 \\
5.81 \\
5.72\end{array}$ \\
\hline $\begin{array}{l}6600 \\
6700 \\
6800 \\
6900 \\
7000\end{array}$ & $\begin{array}{l}5.63 \\
5.54 \\
5.44 \\
5.35 \\
5.26\end{array}$ \\
\hline $\begin{array}{l}7100 \\
7200 \\
7300 \\
7400 \\
7500 \\
7600\end{array}$ & $\begin{array}{l}5.16 \\
5.07 \\
4.98 \\
4.89 \\
4.79 \\
4.70\end{array}$ \\
\hline
\end{tabular}




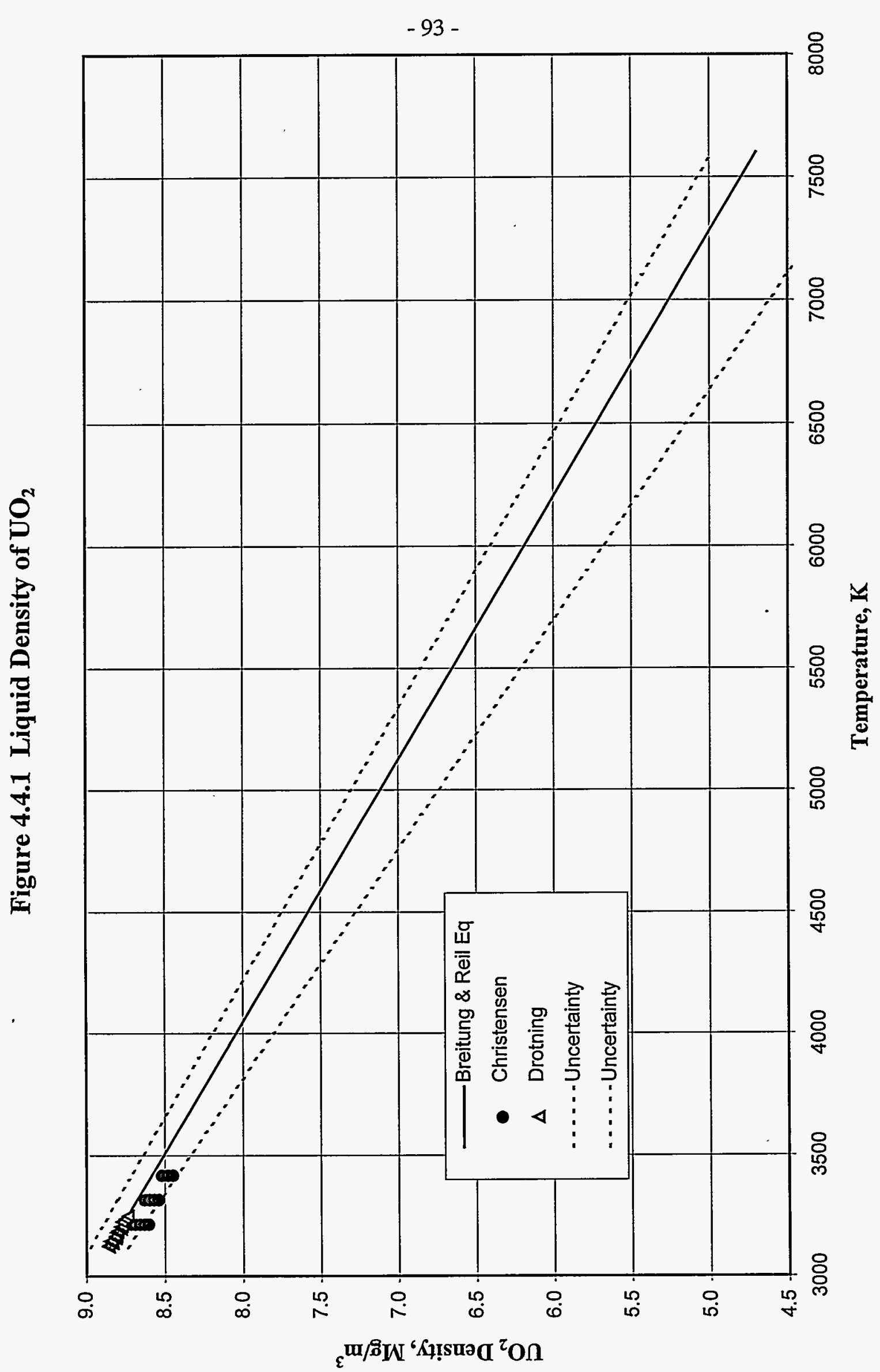

竞 
Figure 4.4.2 Liquid Density of $\mathrm{UO}_{2}$

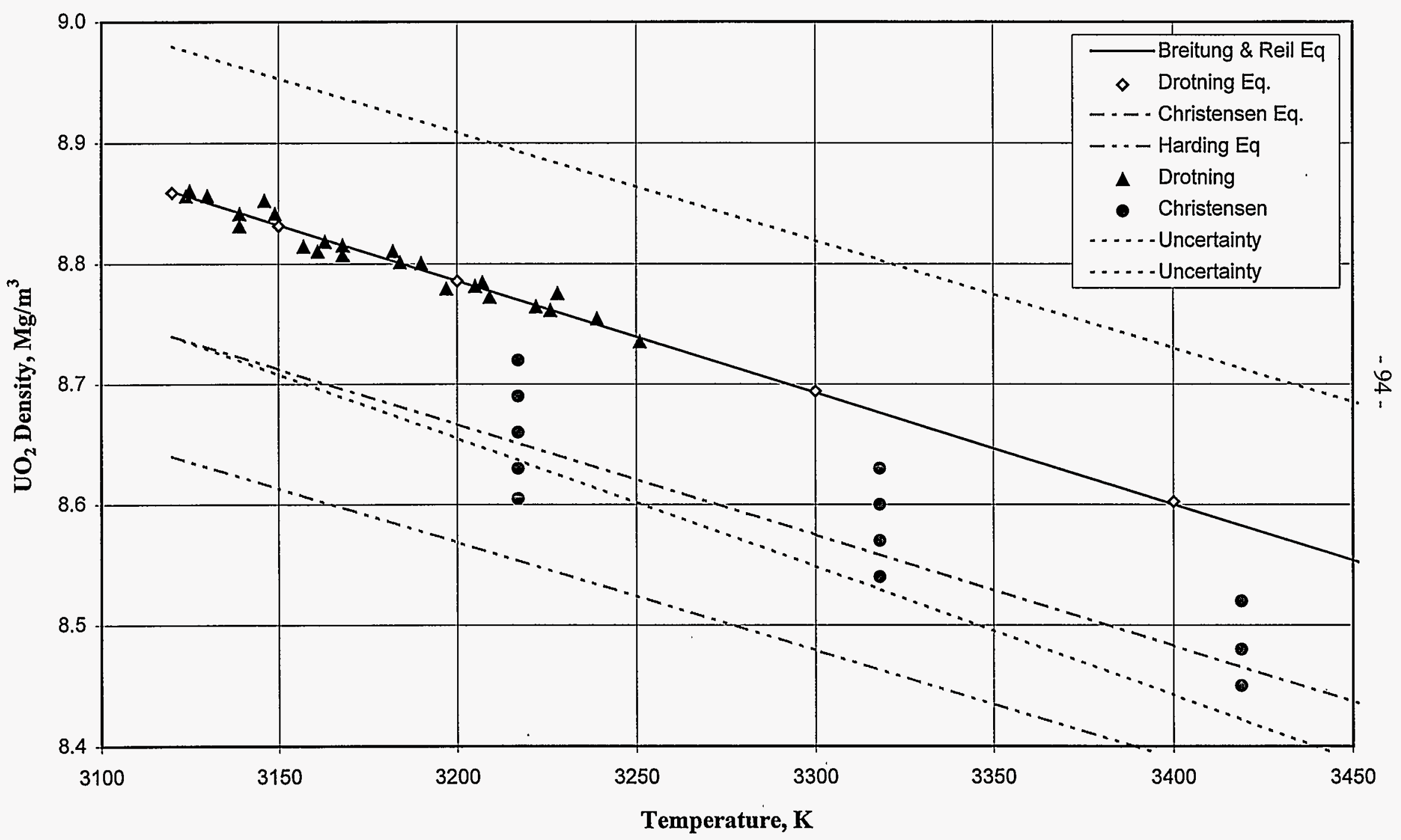


Figure 4.4.3 Deviations from (U,Pu) $\mathrm{O}_{2}$ Liquid Density Eq. of Breitung \& Reil

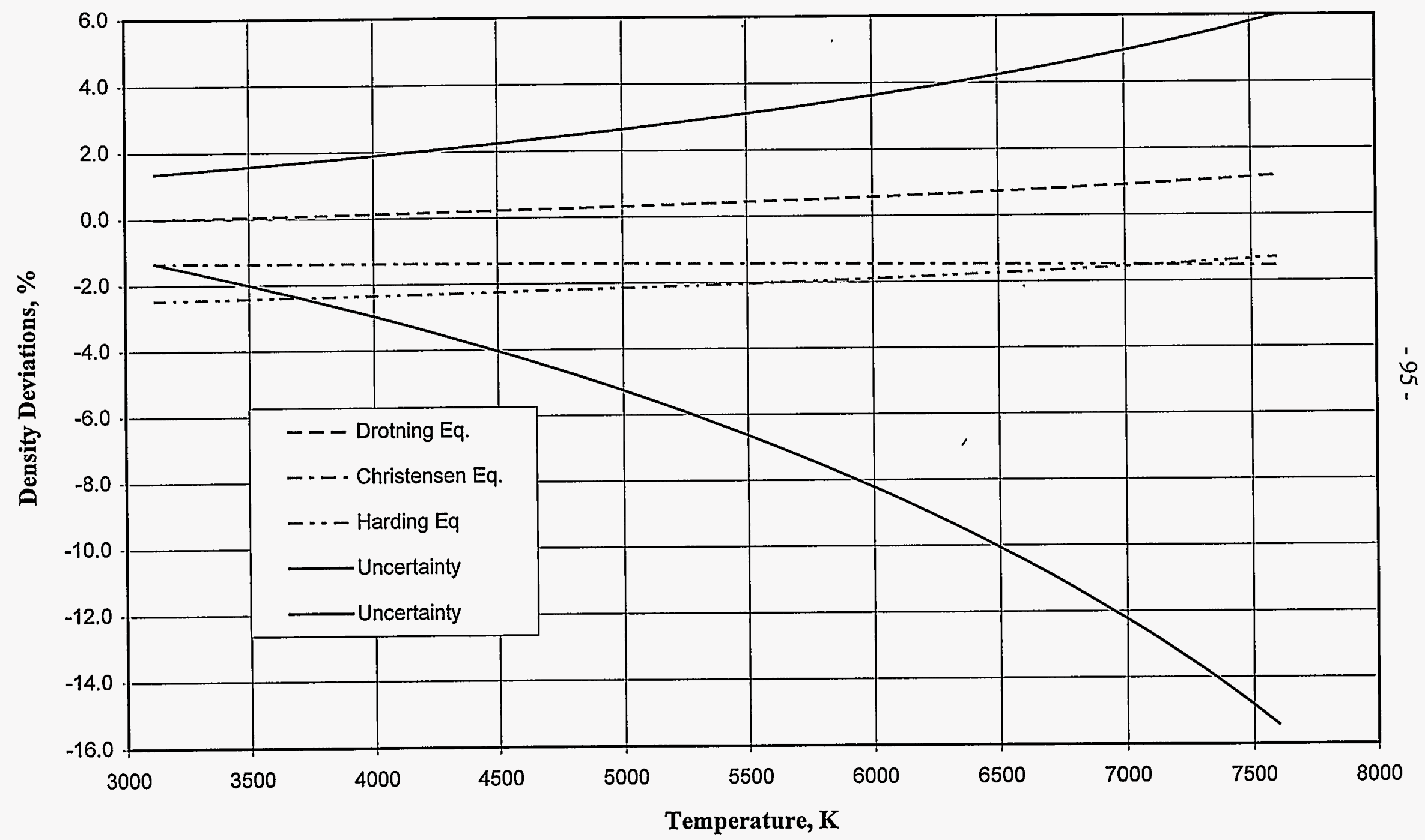




\subsection{DENSITY AND THERMAL EXPANSION RELATIONS}

The thermal-expansion coefficient $\left(\alpha_{\mathrm{p}}\right)$ is a thermodynamic quantity defined as

$$
\alpha_{\mathrm{P}}=\frac{1}{\mathrm{~V}}\left(\frac{\partial \mathrm{V}}{\partial \mathrm{T}}\right)
$$

where $\mathrm{P}, \mathrm{V}$, and $\mathrm{T}$ are, respectively, pressure, volume, and temperature. We will refer to $\alpha_{\mathrm{P}}$ as the instantaneous volumetric thermal-expansion coefficient. For simplicity, the subscript $\mathrm{P}$ has been eliminated from the thermal-expansion coefficients in the following discussion with the understanding that constant pressure is implied in all the following equations.

The mean volumetric thermal-expansion coefficient is defined as

$$
\bar{\alpha}=\frac{1}{V_{0}}\left(\frac{V-V_{0}}{T-T_{0}}\right)
$$

where $\mathrm{V}$ and $\mathrm{V}_{\mathrm{o}}$ are the volumes at temperatures $\mathrm{T}$ and $\mathrm{T}_{\mathrm{o}}$ respectively.

Because many measurements of thermal expansion involve measurement of a length change, it is common to find tabulations of the fractional (or percent) change in length,

$$
\frac{\Delta \mathrm{L}}{\mathrm{L}_{\mathrm{o}}}=\left(\frac{\mathrm{L}-\mathrm{L}_{\mathrm{o}}}{\mathrm{L}_{\mathrm{o}}}\right)
$$

where $L$ and $L_{o}$ are respectively the sample lengths at temperatures $T$ and $T_{0}$.

The instantaneous linear thermal-expansion coefficient is

$$
\alpha_{\ell}=\frac{1}{\mathrm{~L}}\left(\frac{\partial \mathrm{L}}{\partial \mathrm{T}}\right)
$$

The mean linear thermal-expansion coefficient is:

$$
\bar{\alpha}_{\mathrm{f}}=\frac{1}{\mathrm{~L}_{\mathrm{o}}}\left(\frac{\mathrm{L}-\mathrm{L}_{\mathrm{o}}}{\mathrm{T}-\mathrm{T}_{\mathrm{o}}}\right)=\frac{1}{\Delta \mathrm{T}}\left(\frac{\mathrm{L}}{\mathrm{L}_{\mathrm{o}}}-1\right)
$$


The instantaneous volumetric thermal-expansion coefficient is just three times the instantaneous linear thermal-expansion coefficient; i.e., $\alpha=3 \alpha_{\ell}$. The same relation does not hold for the mean thermal-expansion coefficients, as the following considerations show. The mean volumetric thermal-expansion coefficient may be written as:

$$
\bar{\alpha}=\frac{1}{\Delta \mathrm{T}}\left(\frac{\mathrm{V}}{\mathrm{V}_{\mathrm{o}}}-1\right)
$$

Since $V=L^{3}$ the definition of the mean linear thermal-expansion coefficient in Eq. (5) gives

$$
\frac{\mathrm{V}}{\mathrm{V}_{0}}=\left(1+\bar{\alpha}_{\ell} \Delta \mathrm{T}\right)^{3}
$$

When this is substituted in Eq. (6) and expanded, the relationship between the mean volumetric and mean linear coefficient is:

$$
\bar{\alpha}=3 \bar{\alpha}_{\ell}+3 \Delta \mathrm{T} \bar{\alpha}_{\ell}^{2}+\Delta \mathrm{T}^{2} \bar{\alpha}_{\ell}^{3}
$$

The error introduced by taking only the first term in this equation will generally be small in many applications. For example for $\Delta \mathrm{T}=1000$ and $\bar{\alpha}_{\ell}=1 \times 10^{-5}$, only a $1 \%$ error will be introduced by ignoring the last two terms.

The relation between linear thermal expansion and density is

$$
\frac{\Delta \rho}{\rho_{0}}=\frac{1-\left(1+\Delta \mathrm{L}_{\mathrm{o}}\right)^{3}}{\left(1+\Delta \mathrm{L} / \mathrm{L}_{\mathrm{o}}\right)^{3}}
$$

where $\Delta \rho=\rho-\rho_{0}$ is the difference between densities at temperatures $T$ and $T_{0}$.

Equation (9) can be derived from the definition of density

$$
\rho=\frac{m}{V}=\frac{m}{V_{0}\left(1+\frac{\Delta V}{V_{0}}\right)}
$$


giving

$$
\frac{\Delta \rho}{\rho_{0}}=\frac{\frac{-\Delta V}{V_{0}}}{\left(1+\frac{\Delta V}{V_{0}}\right)}
$$

and the relation between fractional change in volume and fractional change in length

$$
1+\frac{\Delta V}{V_{0}}=\left(1+\frac{\Delta L}{L_{0}}\right)^{3}
$$




\section{SURFACE TENSION AND SURFACE ENERGY OF URANIUM DIOXIDE}

\section{Summary and Recommendation}

Surface Tension of Liquid $\mathrm{UO}_{2}$ - In 1987, Hall, Mortimer, and Mortimer ${ }^{1}$ reported results of a critical review of available data on the surface tension of liquid $\mathrm{UO}_{2}$ and on the surface energy of solid $\mathrm{UO}_{2}$. Because no new data have been reported since this review, the results of this critical review are recommended. The recommended surface tension of liquid $\mathrm{UO}_{2}$ at the melting point is the average of measurements by Schins, ${ }^{2}$ Christensen, ${ }^{3}$ and Bates ${ }^{4}$ with a temperature dependence based on an equation derived by Nikopoulos and Schulz: ${ }^{5}$

$$
\gamma_{L V}=0.513-0.19 \times 10^{-3}(T-3120)
$$

where the surface tension, $\gamma_{\mathrm{LV}}$, is in $\mathrm{J} \mathrm{m}^{-2}$ and temperature, $\mathrm{T}$, is in $\mathrm{K}$.

Surface Energy of Solid $\mathrm{UO}_{2}$ - From review of the multi-phase equilibrium measurements of the surface energy of $\mathrm{UO}_{2}$, Hall et al. ${ }^{1}$ concluded that from 273 to $3120 \mathrm{~K}$ the surface energy $\left(\gamma_{\mathrm{SV}}\right)$ in $\mathrm{J} \mathrm{m}^{-2}$ of solid $\mathrm{UO}_{2.00}$ probably lies between two lines defined as follows:

Line 1:

$$
\gamma_{S V}=1.5-2.82 \times 10^{-4}(T-273)
$$

Line 2:

$$
\gamma_{S V}=0.20
$$

with the mean line between these given by:

$$
\gamma_{S V}=0.85-1.40 \times 10^{-4}(T-273)
$$

where temperature, $\mathrm{T}$, is in $\mathrm{K}$. 
Hall et al. ${ }^{1}$ gave the dependence of the solid surface energy on stoichiometry as:

$$
\left(\gamma_{S V}\right)_{x}-\gamma_{S V}=6.8 x \quad(0 \leq x \leq 0.05 ; 0<T<2170 K)
$$

where $\left(\gamma_{s v}\right)_{x}$ is the surface energy of $\mathrm{UO}_{2 \pm x}$ in $\mathrm{J} \mathrm{m}^{-2}$.

Hall et al. ${ }^{\prime}$ concluded that the effective surface energy for pores in $\mathrm{UO}_{2}, \gamma_{\mathrm{P}}$, is different from $\gamma_{\text {sv. }}$ It is given by:

$$
\gamma_{P}=0.41 \gamma_{S V}
$$

\section{Uncertainties}

Surface Tension of Liquid $\mathrm{UO}_{2}$ - The standard error in the average of four measurements ${ }^{2-4}$ of the surface tension of liquid $\mathrm{UO}_{2}$ at the melting point is $\pm 0.085 \mathrm{~J} \mathrm{~m}^{-2}$, which is an uncertainty of approximately $\pm 17 \%$.

Surface Energy of Solid $\mathrm{UO}_{2}$ - Because experimental estimates of the surface energy of solid $\mathrm{UO}_{2}$ in the temperature range of 1773 to $2173 \mathrm{~K}$ from multi-phase equilibration techniques are uncertain up to $\pm 70 \%$ and the sign of the temperature dependence is not unambiguously determined, Hall et al. gave the uncertainty in Eq. (4) as $\pm 70 \%$. Although the uncertainty in the dependence on stoichiometry is $\pm 15 \%$, the $\mathrm{UO}_{2 \pm x}$ surface energy uncertainty is $> \pm 70 \%$ because of the $\mathrm{UO}_{2}$ surface energy uncertainty.

Table 5.1 Measurements of the Surface Tension of Liquid $\mathrm{UO}_{2}$ at the Melting Point

\begin{tabular}{||c|l|l|c||}
\hline \hline Surface Tension, $\mathrm{J} \mathrm{m}^{-2}$ & \multicolumn{1}{|c|}{ Method } & Experimenter & Reference \\
\hline \hline $0.615 \pm 0.180$ & liquid drop measurements & Schins & 2 \\
\hline $0.441 \pm 0.210$ & liquid meniscus shape measurements & Bates & 4 \\
\hline $0.445 \pm 0.210$ & droplet photographs & Christensen & 3 \\
\hline $0.550 . \pm 0.210$ & droplet photographs & Christensen & 3 \\
\hline $0.420^{*}$ & shape of frozen menisci & Chasanov & 6 \\
\hline
\end{tabular}

*Not included in the determination of the recommended surface tension. 


\section{Discussion}

Surface Tension of Liquid $\mathrm{UO}_{2}$ - The measurements of the surface tension of liquid $\mathrm{UO}_{2}$ at the melting point are given in Table 5.1. The value given by Chasanov has no estimate of uncertainty and has not been included in the assessment by Hall. ${ }^{1}$ Therefore, the recommended value for the surface tension at the melting point, $0.513 \pm 0.085 \mathrm{~J} \mathrm{~m}^{-2}$, is the average of the surface tensions given in the first four rows of Table 5.1. Nikolopoulos and Schulz ${ }^{5}$ calculated the surface tension of liquid $\mathrm{UO}_{2}$ at three temperatures near the melting point using a theory for ionic liquids developed by Furth. ${ }^{7}$ Their calculated values at 3125,3175 and $3225 \mathrm{~K}$ are respectively 0.521 , 0.514 , and $0.502 \mathrm{~J} \mathrm{~m}^{-2}$. These values are consistent with the average experimental value of the measurements by Schins, Bates, and Christensen. The value obtained by Chasanov ${ }^{6}$ is low relative to this calculation. Inclusion of the value, $0.420 \mathrm{~J} \mathrm{~m}^{-2}$, given by Chasanov in the average would give $0.494 \mathrm{~J} \mathrm{~m}^{-2}$ for the surface tension at the melting point. This value, recommended by Fink, Leibowitz, and Chasanov, ${ }^{8}$ is low relative to the calculation of Nikopoulos and Schulz. ${ }^{5}$

Nikopoulos and Schulz ${ }^{5}$ used their calculations to estimate the temperature dependence of the surface tension of liquid $\mathrm{UO}_{2}$ near the melting point as $\mathrm{d} \gamma_{\mathrm{SV}} / \mathrm{dT}=-0.19 \times 10^{-3} \mathrm{~J} \mathrm{~m}^{-2}$. Combining this result and the average experimental value at the melting point, $0.513 \pm 0.085 \mathrm{~J} \mathrm{~m}^{-2}$, gives the recommended equation for the surface tension of liquid $\mathrm{UO}_{2}$, Eq. (1). This equation, recommended by Hall et al., ${ }^{1}$ is also recommended in the assessment by Harding et al. ${ }^{9}$

Surface Energy of Solid $\mathrm{UO}_{2}$ - The experimental data have been most recently reviewed by Hall et al. ${ }^{1}$ The variations between the published data are much larger than the published error bars. The large variations in the data have been attributed to stoichiometry variations and to errors in the measurements of the angles (contact angle, grain boundary groove angle, and dihedral angle) from which the surface energy is calculated. Hall et al. ${ }^{1}$ commented that the error in the dihedral angle dominates the uncertainty.

Surface energies obtained from multi-phase equilibration studies have been reported by Hodkin and Nicholas ${ }^{10}\left(\mathrm{Cu}\right.$ on $\left.\mathrm{UO}_{2}\right)$, by Nikolopoulos, Nazare and Thummler ${ }^{11}\left(\mathrm{Ni}\right.$ on $\left.\mathrm{UO}_{2}\right)$, and by Bratton and $\mathrm{Beck}^{12}\left(\mathrm{Ni}\right.$ on $\left.\mathrm{UO}_{2}\right)$. Hodkin and Nicholas ${ }^{13}$ used sessile drop measurements of $\mathrm{Cu}$ Th alloys on $\mathrm{UO}_{2 \pm \mathrm{x}}$ to study the effect of stoichiometry. Published data from these studies, shown in Figure 5.1, illustrate the large variation in the available data. Figure 5.1 includes the two 
bounding lines and the mean line defined by Hall et al. ${ }^{1}$ (Hall Line 1, Hall Line 2, and Hall Mean), which are given in Eqs. (2-4), as well as estimates at the melting point. Eberhart ${ }^{14}$ used the surface tension of liquid $\mathrm{UO}_{2}$ to estimate the solid surface energy at the melting point as $0.56 \pm 0.09 \mathrm{~J} \mathrm{~m}^{-2}$. Deshpande, Desai, and Solomon ${ }^{15}$ report the surface tension at the melting point as $0.805 \pm 0.06 \mathrm{~J}$ $\mathrm{m}^{-2}$ based on an estimate made by Skapski. ${ }^{16}$ Hall et al. commented that both estimation methods are more appropriate for metals than for $\mathrm{UO}_{2}$ and, in the absence of a theoretical critique, used an average of the two values $\left(0.68 \pm 0.06 \mathrm{~J} \mathrm{~m}^{-2}\right)$ in their assessment. Hertzian indentation studies reported by Matzke et al. ${ }^{17-19}$ gave surface energies at room temperature as a function of O:M ratio. Their published values have been included in Figure 5.1.

Hall et al. ${ }^{1}$ have analyzed the various individual parameters that go into the calculations for the surface energies and tried to estimate best values of each. This analysis has the effect of smoothing out each parameter. Figure 5.2 shows the surface energies published by Hodkin and Nicholas, Nikolopoulos et al., Bratton and Beck, and Matzke et al., and the recalculated values obtained by Hall et al. Note that this re-analysis by Hall et al. has reversed the slope of the data of Nikolopoulos et al. and increased the magnitude of the slope of the data by Hodkin and Nicholas. Hall et al. stated that indentation results tend to be high because there is often plastic deformation rather than the elastic behavior assumed in the model. Indentation measurements on $\mathrm{ThO}_{2}$ showed that the surface energy was reduced by $35 \%$ if the sample had been preheated so that the oxygen becomes mobile. ${ }^{17}$ Assuming a similar effect in $\mathrm{UO}_{2}$ would reduce the surface energy from $1.8 \pm$ $0.3 \mathrm{~J} \mathrm{~m}^{-2}$ to $1.2 \pm 0.3 \mathrm{~J} \mathrm{~m}^{-2}$. In their re-analysis, Hall et al. applied this correction to the indentation data, as shown in Figure 5.2.

The re-analyzed data given by Hall et al. with estimated error bars are shown in Figure 5.3. They commented that the mean value they assumed for the surface energy at the melting point could be in considerable error and the room temperature surface energy for stoichiometric $\mathrm{UO}_{2}$ is very dependent on the assumed $35 \%$ correction for relaxation. They stated that their analysis supports the conclusion made by Fink et al. ${ }^{8}$ that, in view of the scatter in the measurements, there is no clear indication of the temperature dependence within the solid phase. However, their analysis indicates that the surface energy of $\mathrm{UO}_{2.00}$ is likely to lie in a wedge defined by the two lines given in Eq. (2) and Eq. (3) and shown as dashed lines in Figure 5.3. Since some of the data, both before and after 
re-analysis, lie outside this wedge, this recommendation has been made with great reserve. The best values would be expected to lie in the band between these two lines. The mean line in this band is given by Eq. (4) and is shown as a solid line in Figure 5.3.

Hall et al. also assessed the available data on the variation of surface energy with stoichiometry to obtain Eq. (5). For $x>0.05$, the dependence is more pronounced than given by Eq. (5).

The ratio of the grain boundary energy to surface energy on the free surface is a function of the grain boundary groove angle only and is therefore better known than the grain boundary energy. Hall et al. define this ratio as

$$
\frac{\gamma_{G B}}{\gamma_{S V}}=0.58 \pm 0.05
$$

where $\gamma_{G B}$ is the grain boundary energy and $\gamma_{S V}$ is the surface energy. This relation is assumed by Hall et al. ${ }^{\prime}$ to be correct over the entire temperature range of solid $\mathrm{UO}_{2}$. Because the error in the surface energy is so large, $\pm 70 \%$, the uncertainty in the grain boundary energy calculated from this relation is also large.

Hall et al. discussed pore geometry and defined an empirical surface energy of pores, $\gamma_{P}$, which they related to the grain boundary surface energy $\gamma_{\mathrm{GB}}$ by

$$
\frac{\gamma_{G B}}{\gamma_{P}}=1.40 \pm 0.02
$$

Substitution of Eq. (7) into Eq. (8) gives the relation of the surface energy of pores and the surface energy of $\mathrm{UO}_{2}$ given in Eq. (6).

Further experimental measurements are needed to determine more accurate values of these quantities. To reduce the uncertainty in the surface tension of liquid $\mathrm{UO}_{2}$,-measurements are needed under controlled conditions. To obtain better data for the solid surface energy using the multi-phase 
equilibration technique, methods must be developed for greater accuracy in the measurements of the angles, which now have errors on the order of $3^{\circ}$. Surface energy values accurate to $\pm 10 \%$ require that the dihedral angle must be reproducible to $0.05^{\circ}$. 


\section{REFERENCES}

1. R. O. A. Hall, M. J. Mortimer, and D. A. Mortimer, Surface Energy Measurements on $\mathrm{UO}_{2}$, A Critical Review, J. Nucl. Mater. 148, 237-256 (1987); see also A. Critical Review of the Surface Energy of $\mathrm{UO}_{2}$, J. Less-Common Metals 121, 341-345 (1986); and R. O. A. Hall and M. J. Mortimer, Effect of Changes in Stoichiometry on the Surface Energy of $\mathrm{UO}_{2}$, J. Nucl. Mater. 137, 77-85 (1985).

2. H. Schins, On the Surface Tension of Liquid $\mathrm{UO}_{2}$, J. Nucl. Mater. 78, 215-216 (1978).

3. J. A. Christensen, Battelle-Northwest Laboratory Report, Richland, WA, BNWL-SA588884-A (1966).

4. J. L. Bates, C. E. McNeilly and J. J. Rasmussen, Material Science Research 5, 11 (1971); see also Battelle-Northwest Laboratory Report BNWL-SA-3579 (1970).

5. O. Nikolopoulos and B. Schulz, Density, Thermal Expansion of Stainless Steel and Interfacial Properties of $\mathrm{UO}_{2}$ - Stainless Steel Above $1690 \mathrm{~K}$, J. Nucl. Mater. 82, 172-178 (1979).

6. M. G. Chasanov, L. Leibowitz, and S. D. Gabelnick, J. Nucl. Mater. 49, 129 (1974).

7. R. Furth, Proc. Cambr. Phil. Soc. 37, 252 (1941) as referenced by O. Nikolopoulos and B. Schulz, J. Nucl. Mater. 82, 172-178 (1979).

8. J. K. Fink, M. G. Chasanov, and L. Leibowitz, Thermodynamic Properties of Uranium Dioxide, Argonne National Laboratory Report ANL-CEN-RSD-80-3 (1981).

9. J. H. Harding, D. G. Martin, and P. E. Potter, Thermophysical and Thermochemical Properties of Fast Reactor Materials, Commission of the European Communities Report EUR 12402 EN (1989).

10. E. N. Hodkin and M. G. Nicholas, The Surface and Interfacial Energies of Stoichiometric Uranium Dioxide, J. Nucl. Mater. 47, 23 (1973).

11. P. Nikolopoulos, S. Nazare, and F. Thummler, Surface Grain Boundary and Interfacial Energies in $\mathrm{UO}_{2}$ and $\mathrm{UO}_{2}-\mathrm{Ni}$, J. Nucl. Mater. 71, 89-94 (1977); see also Comments on "Surface Grain Boundary and Interfacial Energies in $\mathrm{UO}_{2}$ and $\mathrm{UO}_{2}-\mathrm{Ni}$," J. Nucl. Mater. 78, 213-214 (1978).

12. R. J. Bratton and C. W. Beck, Surface Energy of Uranium Dioxide, J. Am. Ceram. Soc. 54, 379-381 (1971). 
13. E. N. Hodkin and M. G. Nicholas, Surface and Interfacial Properties of Non-Stoichiometric Uranium Dioxide, J. Nucl. Mater. 67, 171-180 (1977); see also Comments on "Surface Grain Boundary and Interfacial Energies in $\mathrm{UO}_{2}$ and $\mathrm{UO}_{2}-\mathrm{Ni}$ " by P. Nikolopoulos et al., J. Nucl. Mater. 74, 178 (1978);

14. J. G. Eberhart, J. Nucl. Mater. 25, 103 (1968).

15. M. S. Deshpande, P. D. Desai, and A. Solomon, High Temp. Sci. 17303 (1984).

16. A. S. Skapski, Acta Metall. 4576 (1956), as referenced by R. O. A. Hall, M. J. Mortimer, and D. A. Mortimer, J. Nucl. Mater. 148, 237-256 (1987).

17. H. Matzke, T. Inoue, and R. Warren, The Surface Energy of $\mathrm{UO}_{2}$ as Determined by Hertzian Indentation, J. Nucl. Mater. 91, 205-220 (1980).

18. H. Matzke, J. Mater. Sci. 15, 739 (1980).

19. H. Matzke, The Fracture Surface energy of $\left(U_{0.8} P u_{0.2}\right) O_{2}$, J. Nucl. Mater. 113, 273-275 (1983). 


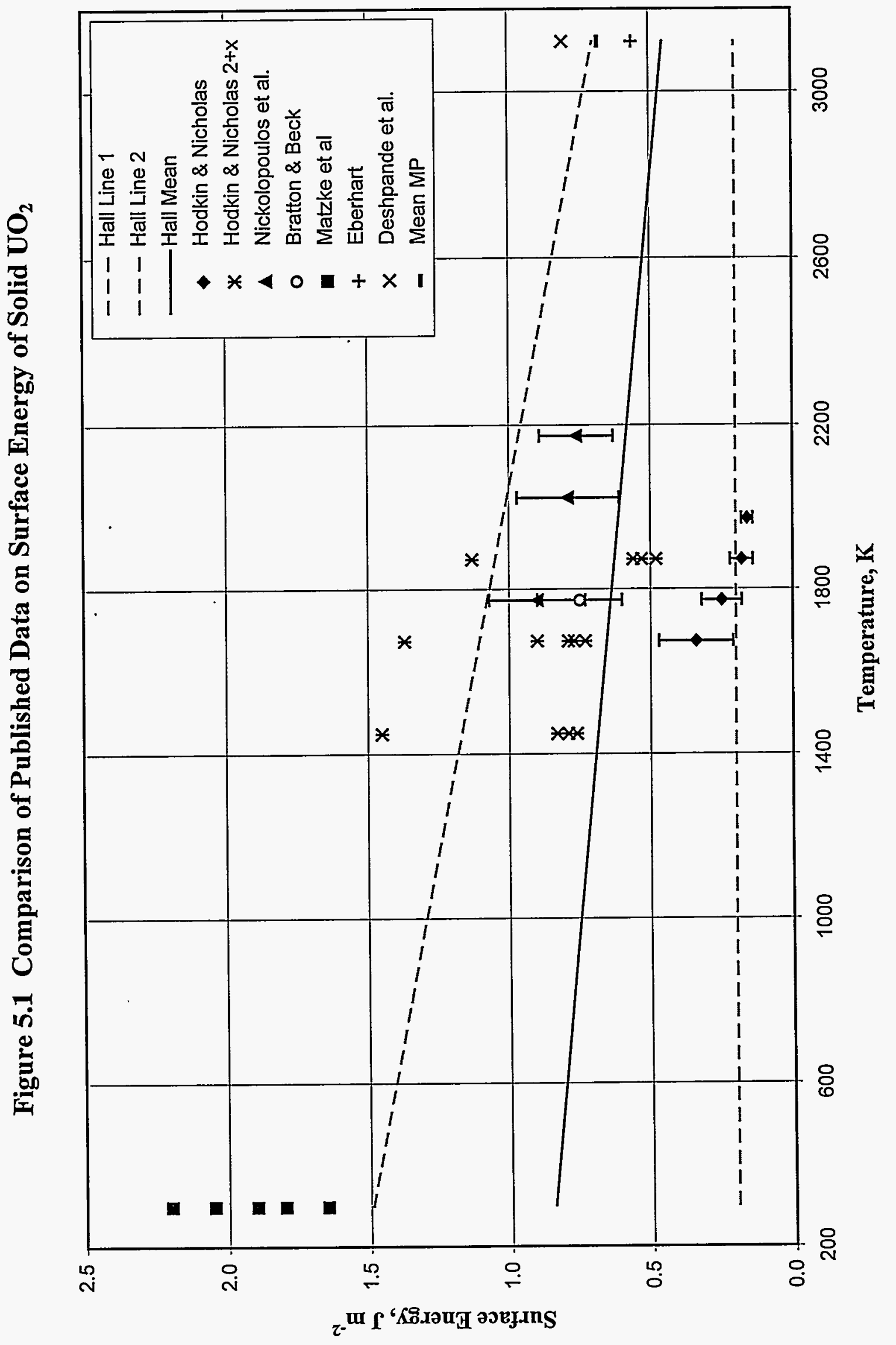

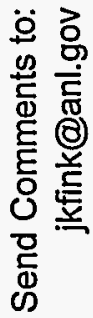


Figure 5.2 Corrections by Hall et al. to $\mathrm{UO}_{2}$ Surface Energy Data

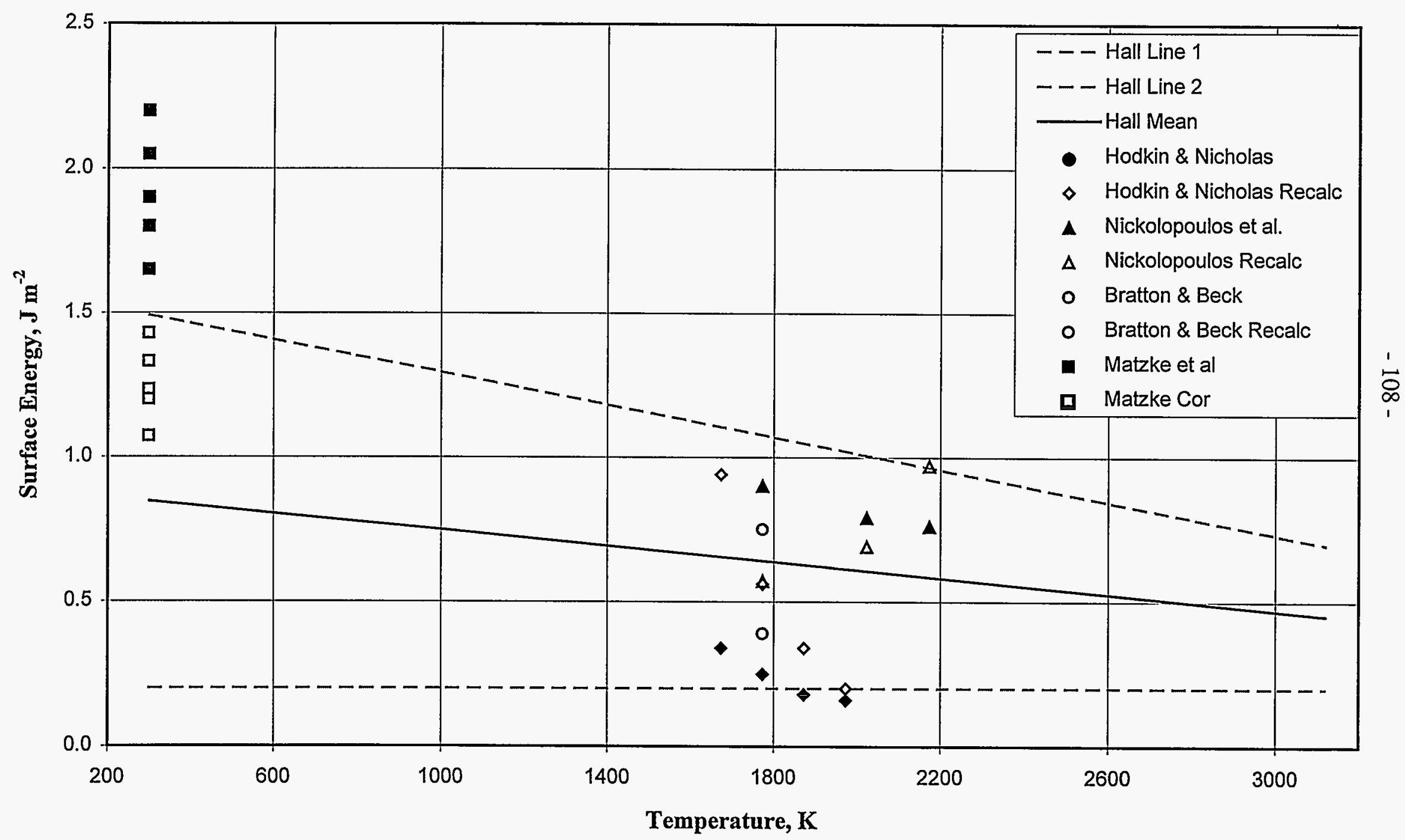


Figure 5.3 Surface Energy of Solid $\mathrm{UO}_{2}$ of Hall et al. and Corrected Data

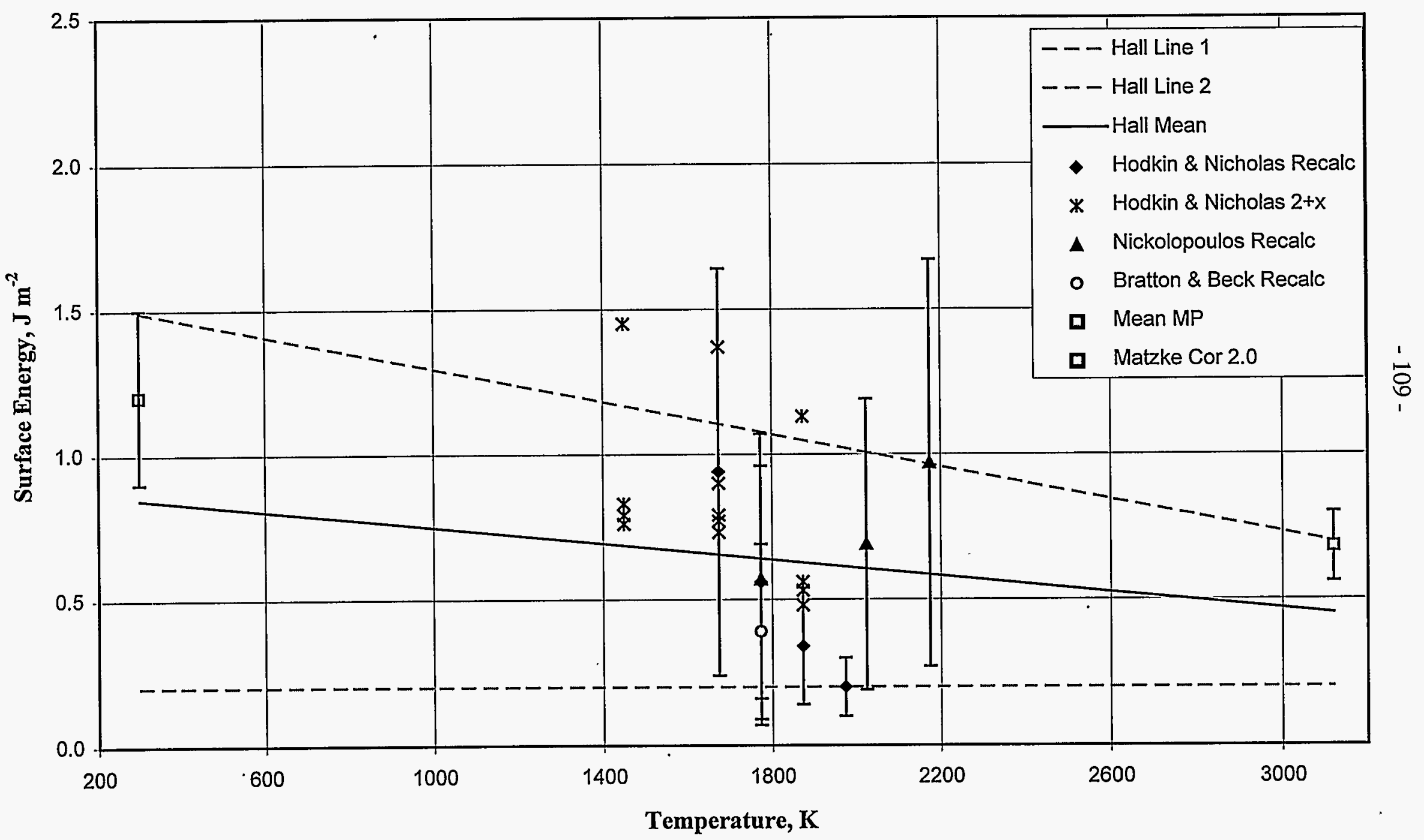

Send Comments to: 


$$
\log _{10} P=-\frac{31284}{T}+7.616
$$

The vapor pressure of $\mathrm{UO}_{2}(\mathrm{~g})$ calculated using the equation of Ackermann et al. ${ }^{2}$ and the total vapor pressure over $\mathrm{UO}_{2}(\mathrm{~s})$ calculated using the equation of Tetenbaum and Hunt ${ }^{4}$ are tabulated as a function of temperature in Table 6.2 and shown with estimated uncertainties in Figure 6.2.

\section{Uncertainties}

The estimated uncertainties in total vapor pressure over liquid $\mathrm{UO}_{2}$ calculated from Eq. (1) range from $-40 \% /+60 \%$ at $3120 \mathrm{~K}$ to $-45 \% /+80 \%$ at $6000 \mathrm{~K}$. From 3120 to $6000 \mathrm{~K}$, the negative uncertainties are assumed to decrease linearly: $\Delta P / P(\%)=-\left[34.58+1.7 \times 10^{-3} T\right]$. The positive uncertainties are assumed to increase linearly from $+60 \%$ at $3120 \mathrm{~K}$ to $+80 \%$ at $4500 \mathrm{~K}$ : $\Delta P / P(\%)=14.78+0.0145 T$. Above $4500 \mathrm{~K}$, the positive uncertainties are assumed constant $(+80 \%)$. The uncertainties in the pressure of $\mathrm{UO}_{2}(\mathrm{~g})$ over solid $\mathrm{UO}_{2}$ calculated from Eq. (2) and in the total vapor pressure over solid $\mathrm{UO}_{2}$ calculated using Eq. (3) are estimated as $-40 \% /+60 \%$ from 1700 to $3120 \mathrm{~K}$.

\section{Stoichiometry}

Uranium dioxide can exist over a wide range of compositions (hypostoichiometric to hyperstoichiometric with respect to oxygen), which are temperature dependent. The total vapor pressure depends on the oxygen-to-uranium ratio of the condensed phase, so that the total vapor pressure over $\mathrm{UO}_{2 \pm \mathrm{x}}$ will depend on the value of $\mathrm{x}$. The vaporization of $\mathrm{UO}_{2}$ is not congruent because the $\mathrm{O}: \mathrm{U}$ ratio in the gas phase is greater than in the condensed phase. The total vapor pressure above solid and liquid $\mathrm{UO}_{2}$ includes contributions from $\mathrm{UO}_{2}(\mathrm{~g}), \mathrm{UO}(\mathrm{g}), \mathrm{UO}_{3}(\mathrm{~g}), \mathrm{U}(\mathrm{g})$, $\mathrm{O}(\mathrm{g})$, and $\mathrm{UO}(\mathrm{g})$.

\section{Discussion: Vapor Pressure over Liquid $\mathrm{UO}_{2}$}

Breitung and Reil ${ }^{1}$ have recently reviewed the experimental measurements of the total vapor pressure of liquid $\mathrm{UO}_{2}$. The data used in their assessment are summarized in Table 6.3. They included both pressure-temperature measurements and pressure-enthalpy measurements in their assessment. 
Pressure-Temperature Measurements - The transpiration measurements of Reedy and Chasanov ${ }^{5}$ were weighted high in the assessment of Breitung and Reil ${ }^{1}$ for the following reasons: (1) they are the only measurements on both solid and liquid $\mathrm{UO}_{2}$, (2) the technique produces true equilibrium data, and (3) the experimental uncertainties are very small $( \pm 10 \%$ in pressure; $\pm 1 \%$ in temperature). In these experiments, the $\mathrm{UO}_{2}$ was contained in tungsten, which limited the temperature range $(2615-3390 \mathrm{~K})$. At 2615 and $2860 \mathrm{~K}$, the O:U ratio of the condensed phase was 1.98. At $3390 \mathrm{~K}$, the O:U ratio of the liquid was 1.94 .

The laser-heated vapor pressure measurements listed in Table 6.3 may be divided into two groups: (1) measurements performed far from thermodynamic equilibrium ${ }^{6-13}$ and (2) measurements close to thermodynamic equilibrium. ${ }^{14,15}$ Measurements far from thermodynamic equilibrium consist of experiments in which the fuel vapor expands into a vacuum or a rare gas environment. Such experiments require a theoretical model to convert properties of the expanding nonequilibrium plasma into saturation vapor pressures. The large scatter in the data from different experiments of this type is indicative of the difficulty of obtaining saturation vapor pressure data from these nonequilibrium measurements. Measurements close to equilibrium use a boiling point technique that determines the temperature at which a laser-generated $\mathrm{UO}_{2}$ vapor cloud begins to expand against a xenon cover gas of a given pressure. At this temperature, the $\mathrm{UO}_{2}$ vapor pressure is assumed to be equal to the gas pressure. The xenon gas atoms initially confine the laser-generated vapor cloud so that evaporation proceeds close to thermodynamic equilibrium. The recent boiling-point experiments by Bober and Singer ${ }^{15}$ included corrections for optical absorption (by the vapor cloud) of thermal radiation emitted from the liquid surface. Breitung and Reil concluded that the recent measurements by Bober and Singer are the most reliable saturation vapor pressure data for liquid $\mathrm{UO}_{2}$ from the laser experiments.

In-Reactor Experiments - The first in-reactor measurements of vapor pressure as a function of adiabatic fuel enthalpy by Reil ${ }^{16}$ determined upper and lower bounds for the vapor pressure. Later calculations showed that these values were overly conservative. ${ }^{1}$ Benson ${ }^{17}$ measured the isobaric expansion of a $25-\mu \mathrm{m}$-thick layer of $\mathrm{UO}_{2}$ powder confined by two movable pistons as it was heated to a certain internal energy in one microsecond. Results of this experiment were inconsistent with the expansion of a single-component liquid-vapor system. An unknown source of pressure, such as 
water vapor, adsorbed by the fine $\mathrm{UO}_{2}$ powder is believed to have contributed to the measured pressure. Fission heating was used in the eight Commissariat a l'Energie Atomique (CEA) experiments by Limon et al. ${ }^{18}$ to heat a thin solid $\mathrm{UO}_{2}$ disk to boiling under constant argon pressure. The boiling point was determined by the sudden increase in pressure. The average energy deposited in the $\mathrm{UO}_{2}$ was assumed to be equal to the fuel enthalpy in the boiling zone. This assumption led to deviations of only a few percent in six high-enthalpy tests but the actual enthalpy in the boiling zone may have been on the order of $10 \%$ higher for the two low-enthalpy tests. ${ }^{1}$

Breitung and Reil ${ }^{1}$ measured the saturation vapor pressure of pure $\mathrm{UO}_{2.01}$, reactor grade $\mathrm{UO}_{2.08}$, and reactor grade $\left(\mathrm{U}_{0.77} \mathrm{Pu}_{0.23}\right) \mathrm{O}_{2.09}$ as a function of enthalpy for enthalpies from 2000 to $3700 \mathrm{~kJ} \mathrm{~kg}^{-1}$. Their six effective equation-of-state experiments at the annular core research reactor at Sandia National Laboratories determined the saturation vapor pressure as a function of enthalpy at conditions that are very close to those of the disassembly phase of a core disruptive accident. These experiments gave very reproducible results. They found that under these conditions

(1) the fuel saturation vapor pressure for fuel containing uranium-plutonium mixed oxide was essentially identical to that of pure $\mathrm{UO}_{2}$;

(2) fuel impurities from fabrication did not noticeably contribute to the pressure;

(3) stoichiometry variations have no strong influence on the saturation vapor pressure for $\mathrm{UO}_{2.01}$, and $\mathrm{UO}_{2.08}$

(4) replacement of uranium by plutonium in concentrations equivalent to mixed oxide fuel, e.g., $\left(\mathrm{U}_{0.77} \mathrm{Pu}_{0.23}\right) \mathrm{O}_{2.09}$, does not significantly affect the measured vapor pressure.

From the data obtained in these six experiments, Breitung and Reil developed an equation for the vapor pressure for all three fuels:

$$
\log _{10} P(z)=-9.7652+8.0934 \times 10^{-3} z-2.0515 \times 10^{-6} z^{2}+1.9013 \times 10^{-10} z^{3}
$$

where $z=h-h_{298}$ is the enthalpy increment in $\mathrm{kJ} \mathrm{kg}^{-1}$ and $P$ is the saturation pressure in MPa. This equation fits their data for all three fuel types within their experimental uncertainties of $\pm 0.5 \mathrm{MPa}$ in pressure and $\pm 3 \%$ in enthalpy. Breitung and Reil ${ }^{1}$ converted their pressure-enthalpy equation to 
a pressure-temperature equation, Eq. (1), using Fischer's ${ }^{20}$ theoretical prediction for the saturation pressure as a function of internal energy of liquid $\mathrm{UO}_{2}$ and the melting point enthalpy given by Fink et al. ${ }^{21}(1398.6 \mathrm{~kJ} / \mathrm{kg})$. Their equation for pressure as a function of temperature, Eq. (1), is slightly different from an earlier equation given by Breitung and Reil ${ }^{22,23}$ (which was recommended by Harding et al. $^{24}$ ) because different equations were used to convert from pressure-enthalpy to pressure-temperature. Breitung and Reil ${ }^{1}$ stated that the main uncertainty in the conversion is the choice of equation for the heat capacity. The large variations in the available equations for the heat capacity of liquid $\mathrm{UO}_{2}$ are shown in Figure 6.3. The data in Figure 6.3 are those determined by Ronchi et al. ${ }^{25}$ from their cooling curve experiments. In the analysis of these experiments, Ronchi et al. assumed a constant thermal conductivity of $2.5 \mathrm{~W} \mathrm{~m}^{-1} \mathrm{~K}^{-1}$. The solid line is the fit by Ronchi et al. ${ }^{25}$ to their data. The dashed line labeled " $\mathrm{H}+\mathrm{Cp}$ Fit Fink" is a combined fit to the enthalpy data $^{26,27}$ and the heat capacity data of Ronchi et al. ${ }^{25}$ from 3100 to $4500 \mathrm{~K}$. The line labeled "Rand et al." is the constant heat capacity obtained from the linear fit by Rand et al. ${ }^{28}$ to the enthalpy data. ${ }^{26,27}$ The heat capacities of Fischer ${ }^{20}$ were preferred by Breitung and Reil to the equation they used previously (labeled "Breitung and Reil KfK 3939") because the model used by Fischer was anchored at experimental results for the vapor pressure and density of liquid $\mathrm{UO}_{2}$. Figure 6.1.3 shows that values from both equations used by Breitung and Reil are high relative to the values given by Ronchi et al. ${ }^{25}$ Harding et al. ${ }^{24}$ have pointed out that the heat capacity may be varied without significant effect on the vapor pressure at a given temperature. They stated that a $20 \%$ variation in heat capacity at $6000 \mathrm{~K}$ gives a $30 \%$ change in the vapor pressure.

Comparison of Recommended Equation with Data - In Figure 6.4, the recommended equation of Breitung and Reil for the total vapor pressure over liquid $\mathrm{UO}_{2}$ is compared with the most recent and reliable vapor pressure data from each experimental method, with the equation formulated by the 1978 IAEA International Working Group on Fast Reactors (IWGFR), ${ }^{29}$ and with vapor pressures calculated by Green and Leibowitz. ${ }^{3}$ The IWGFR equation was based on a review of the data available in 1978 and was recommended for use up to $5000 \mathrm{~K}$. The vapor pressures and vapor compositions above uranium dioxide calculated by Green and Leibowitz ${ }^{3}$ are based on a statisticalmechanical calculation of the thermodynamic functions of the individual vapor species using molecular energy levels from spectroscopic data and an oxygen potential model. Experimental data 
included in Figure 6.4 are: transpiration data of Reedy and Chasanov, ${ }^{5}$ the boiling-point data of Bober and Singer, ${ }^{15}$ data from the most recent laser-heating vaporization experiments of Ohse et al., ${ }^{12,13}$ and data from the in-pile experiments of Limon et al. ${ }^{18}$ The equation recommended by Limon et al. to best describe their data has also been included. Breitung and Reil's earlier vapor pressure equation that was obtained by using a different heat capacity ${ }^{22,23}$ to convert their data has been included in Figure 6.4 to show the effect of differences in choice of heat capacity on the final vapor pressure equation. It is labeled "Breitung KfK3939." Figure 6.4 shows that at high temperatures, it gives lower pressures than the recommended equation of Breitung and Reil. Therefore, the recommended equation is in better agreement with the high-temperature data of Limon et al.

The IWGFR equation is consistent with the total pressures calculated by Green and Leibowitz ${ }^{3}$ and with the early laser-vaporization data, which were higher than the 1980 data of Ohse et al. ${ }^{12}$. The datum at $4220 \mathrm{~K}$ from the 1980 measurements of Ohse et al. ${ }^{12}$ is a factor of 3.3 higher than the vapor pressure at $4220 \mathrm{~K}$ calculated using the recommended equation of Breitung and Reil. ${ }^{1}$ At $4000 \mathrm{~K}$, vapor pressures obtained from the IWGFR equation and calculations by Green and Leibowitz ${ }^{3}$ are, respectively, factors of 2.1 and 1.6 higher than the vapor pressure calculated with the equation of Breitung and Reil. ${ }^{1}$ The recommended equation of Breitung and Reil is in good agreement with the vapor pressures determined from laser-vaporization experiments in 1985 by Ohse et al., ${ }^{13}$ with the low-temperature data of Reedy and Chasanov, ${ }^{5}$ with the high-temperature data of Limon et al., ${ }^{18}$ and with the data of Bober and Singer. ${ }^{15}$ It is a good representation of all equilibrium in-pile and out-of-pile data.

Breitung and Reil ${ }^{1}$ noted that if the two low-temperature CEA data points of Limon et al. ${ }^{18}$ are disregarded, all in-pile results are located close to an almost linear extension of the transpiration data of Reedy and Chasanov ${ }^{5}$ and the laser boiling point data of Bober and Singer. ${ }^{15}$ All these methods provide conditions very close to equilibrium vaporization so that the slope of the line connecting these data should give the heat of vaporization. They attributed the steeper slopes obtained from the earlier laser-vaporization experiments (as characterized by the 1980 data of Ohse et al.) to the use of nonequilibrium pressure models to reduce the data and/or to the neglect of jkfink@anl.gov 
optical absorption of thermal surface radiation in the vapor cloud. Application of the Clausius Clapeyron equation to their vapor pressure equation gives an effective heat of vaporization:

$$
\Delta H_{\text {vap }}=516382-22.946 T
$$

where $\Delta H_{v a p}$ is in $\mathrm{J} \mathrm{mol}^{-1}$ and $\mathrm{T}$ in $\mathrm{K}$ ranges from 3120 to $8000 \mathrm{~K}$. The heat of vaporization at the normal boiling point $(3815.1 \mathrm{~K})$ is $413.5 \mathrm{~kJ} \mathrm{~mol}^{-1}$.

\section{Discussion: Vapor Pressure over Solid $\mathrm{UO}_{2}$}

Although the total vapor pressure above solid $\mathrm{UO}_{2}$ includes contributions from $\mathrm{UO}_{2}(\mathrm{~g})$, $\mathrm{UO}(\mathrm{g}), \mathrm{UO}_{3}(\mathrm{~g}), \mathrm{U}(\mathrm{g}), \mathrm{O}(\mathrm{g})$, and $\mathrm{UO}(\mathrm{g})$, the greatest contribution is from $\mathrm{UO}_{2}(\mathrm{~g})$. Ackermann et al. ${ }^{2}$ measured the vapor pressure of $\mathrm{UO}_{2}(\mathrm{~g})$ above solid $\mathrm{UO}_{2}$ from 1800 to $2600 \mathrm{~K}$ and commented that $\mathrm{UO}_{2}(\mathrm{~g})$ comprises $94 \%$ of the total pressure at $2150 \mathrm{~K}$. Tetenbaum and Hunt ${ }^{4}$ determined the total vapor pressure above $\mathrm{UO}_{2-\mathrm{x}}$ in the temperature range 2080 to $2705 \mathrm{~K}$. Green and Leibowitz ${ }^{3}$ used models for the partial Gibbs free energy of oxygen above $\mathrm{UO}_{2}$ to determine the contributions of the various vapor species above hypostoichioeteric uranium dioxide for $\mathrm{UO}_{2.00}$ through $\mathrm{UO}_{1.90}$.

Measurements of the total vapor pressure above solid $\mathrm{UO}_{2}$ by Knudson effusion, ${ }^{30-33}$ Langmuir surface evaporation, ${ }^{35}$ and transpiration ${ }^{4,36}$ methods and have been reviewed by Ackermann et al. ${ }^{2}$ and compared with measurements of the vapor pressure due to $\mathrm{UO}_{2}(\mathrm{~g})$ determined from mass-spectrometric measurements by Pattoret et al. ${ }^{37}$ and by Ackermann et al. ${ }^{2}$ They found reasonable agreement between the different measurements. Table 6.4 shows the vapor pressures at $2150 \mathrm{~K}$ determined from the experiments included in the assessment by Ackermann et al. ${ }^{2}$ Ackermann et al. corrected the data of Alexander et al. ${ }^{36}$ for a systematic error. Consequently, the vapor pressure attributed to Alexander et al. in Table 6.4. (which is from the table of Ackermann et $\mathrm{al}^{2}$ ) differs from the value given in the original paper by Alexander et al. ${ }^{36}$ The average of the values, excluding the value from the 1979 mass spectroscopy measurements by Ackermann et al., ${ }^{2}$ is $1.38 \times 10^{-7} \mathrm{MPa}$. This is in good agreement with the vapor pressure of $\mathrm{UO}_{2}(\mathrm{~g})\left(1.32 \times 10^{-7} \mathrm{MPa}\right)$ determined by Ackermann et al. in 1979.

The recommended equation for the vapor pressure of $\mathrm{UO}_{2}(\mathrm{~g})$ over $\mathrm{UO}_{2}$, Eq. (2), is from the 1979 measurements and assessment of Ackermann et al. ${ }^{2}$ It is in reasonable agreement with other data and was derived with considerations for consistency with the thermodynamic functions for solid 
$\mathrm{UO}_{2}$ and the enthalpy of sublimation from the solid. It is consistent with a heat capacity that has a phase transition at $2670 \mathrm{~K}$. In Figure 6.5 , this recommended equation of Ackermann et al. ${ }^{2}$ for the vapor pressure of $\mathrm{UO}_{2}(\mathrm{~g})$ over solid $\mathrm{UO}_{2}$ is compared with vapor pressure equations and data from earlier measurements and with the vapor pressure of $\mathrm{UO}_{2}(\mathrm{~g})$ and the total vapor pressure over $\mathrm{UO}_{2.00}$ calculated by Green and Leibowitz. ${ }^{3}$ In the legend for Figure 6.5, the notation " $\mathrm{UO}_{2}$ " has been included to distinguish measurements or calculations of the pressure due to the vapor species $\mathrm{UO}_{2}(\mathrm{~g})$ from the total vapor pressure over $\mathrm{UO}_{2}$. Below $2450 \mathrm{~K}$, the 1956 low-temperature data of Ackermann et al. ${ }^{30}$ and the equation of Tetenbaum and Hunt ${ }^{4}$ are in excellent agreement with the recommended equation of Ackermann et al. ${ }^{2}$ Above $2615 \mathrm{~K}$, the equation of Tetenbaum and Hunt for the total vapor pressure over $\mathrm{UO}_{2}$ gives higher vapor pressures than the equation of Ackermann et al. for the vapor pressure of $\mathrm{UO}_{2}(\mathrm{~g})$. Two data from transpiration measurements of the total vapor pressure over $\mathrm{UO}_{1.98}$ by Reedy and Chasanov ${ }^{5}$ have been included in Figure 6.5. These are the only vapor pressure measurements over uranium dioxide in both the liquid and solid phases. The Reedy and Chasanov datum at $2615 \mathrm{~K}$ is in good agreement with the equation of Ackermann et al. but their datum at $2860 \mathrm{~K}$ is higher than values from both the equation of Ackermann et al. and the equation of Tetenbaum and Hunt. Total vapor pressures over $\mathrm{UO}_{2}$ measured by Ohse et al. ${ }^{32}$ are in good agreement with the equation of Ackermann et al. at low temperatures but are higher at high temperatures. Above $2500 \mathrm{~K}$, the data of Ohse et al. approach total pressures calculated by Green and Leibowitz. The contribution to the total vapor pressure from $\mathrm{UO}_{2}(\mathrm{~g})$ calculated by Green and Leibowitz is in good agreement with the equation of Ackermann et al. ${ }^{2}$ above $2600 \mathrm{~K}$. However, the total vapor pressure over $\mathrm{UO}_{2}$ calculated by Green and Leibowitz is consistently higher than the $\mathrm{UO}_{2}(\mathrm{~g})$ pressure given by the equation of Ackermann et al. The difference between these values increases with temperature. The contribution to the total vapor pressure from $\mathrm{UO}_{2}(\mathrm{~g})$ calculated by Green and Leibowitz descreases with increasing temperature. It is $70 \%$ at $2100 \mathrm{~K}, 54 \%$ at $2500 \mathrm{~K}$, and only $37 \%$ at $3100 \mathrm{~K}$. These comparisons indicate that the equation for the vapor pressure of $\mathrm{UO}_{2}(\mathrm{~g})$ over solid $\mathrm{UO}_{2}$ is a reasonable approximation of the total vapor pressure over solid $\mathrm{UO}_{2}$ up to $2600 \mathrm{~K}$ but not at higher temperatures. At higher temperatures, extrapolation of the equation of Tetenbaum and Hunt [Eq. (3)] is a better approximation to the total vapor pressure over solid $\mathrm{UO}_{2}$. 
The logarithm to the base 10 of the vapor pressures determined from a number of vapor pressure equations near the solid/liquid phase boundary are compared in Figure 6.6. Equations included in Figure 6.6 are: the 1978 IWGFR equation ${ }^{29}$ for the vapor pressure over liquid $\mathrm{UO}_{2}$, the equation of Breitung and Reil ${ }^{2}$ for the vapor pressure over liquid $\mathrm{UO}_{2}$, the equation of Ackermann et al. for the vapor pressure of $\mathrm{UO}_{2}(\mathrm{~g})$ over solid $\mathrm{UO}_{2}$, the equation of Tetenbaum and Hunt ${ }^{4}$ for the total vapor pressure over solid $\mathrm{UO}_{2}$, and a modified equation of Tetenbaum and Hunt. ${ }^{21}$ The equation of Tetenbaum and Hunt was modified by Fink, Leibowitz, and Chasanov ${ }^{21}$ for continuity at the solid/liquid interface with the IWGFR equation ${ }^{29}$ for the vapor pressure over liquid urania. The logarithms of the total vapor pressures over $\mathrm{UO}_{2}$ calculated by Green and Leibowitz ${ }^{3}$ are also shown in Figure 6.6. The total vapor pressure data of Reedy and Chasanov ${ }^{5}$ that spans this temperature range and the 1985 liquid vapor pressure data of Ohse et al. ${ }^{13}$ have also been included in the figure. Harding et al. ${ }^{24}$ have recommended the equation of Ackermann et al. ${ }^{2}$ as an approximation to the total vapor pressure over solid $\mathrm{UO}_{2}$ up to the melting point. However, Figure 6 shows that extrapolation of the equation of Ackermann et al. to the melting point gives vapor pressures that are lower than the experimental data and $47 \%$ lower than the liquid vapor pressures at the melting point calculated from the equation of Breitung and Reil. Extrapolation of the equation of Tetenbaum and Hunt ${ }^{4}$ into the liquid region gives vapor pressures that are consistent with the vapor pressures over the liquid determined in 1985 by Ohse et al. ${ }^{13}$ but the vapor pressure at the melting point calculated with this extrapolated equation is $17 \%$ lower than that calculated using the equation of Breitung and Reil. The modified equation of Tetenbaum and $\mathrm{Hunt}^{21}$ is consistent with the IWGFR equation and with the data of Reedy and Chasanov but the vapor pressure at the melting point calculated with this modified equation is $19 \%$ higher than the vapor pressure calculated with the equation of Breitung and Reil. Thus, the deviations from the equation of Breitung and Reil by the original equation of Tetenbaum and $\mathrm{Hunt}^{4}$ and the modified equation of Tetenbaum and $\mathrm{Hunt}^{21}$ are similar in magnitude but opposite in sign. The original equation of Tetenbaum and $\mathrm{Hunt}^{4}$ is preferred to the modified equation of Tetenbaum and $\mathrm{Hunt}^{21}$ because the original equation of Tetenbaum and Hunt was based on experimental data and it agrees better with the low-temperature vapor pressure data over solid $\mathrm{UO}_{2}$ and with the equation of Ackermann et al. below $2450 \mathrm{~K}$. 


\section{REFERENCES}

1. W. Breitung, and K. O. Reil, Vapor Pressure Measurements on Liquid Uranium Oxide and $(U, P u)$ Mixed Oxide, Nucl. Sci. Eng. 101, 26-40 (1989).

2. R. J. Ackermann, E. G. Rauh, and M. H. Rand, A Re-Determination and Re-Assessment of the Thermodynamics of Sublimation of Uranium Dioxide, Symp. on Thermodynamics of Nuclear Materials Julich 1979, Vol.1, IAEA, pp.11-27, Vienna (1980).

3. D. W. Green and L. Leibowitz, Vapor Pressures and Vapor Compositions in Equilibrium with Hypostoichiometric Uranium Dioxide at High Temperatures, Argonne National Laboratory Report ANL-CEN-RSD-81-1 (June 1981); also J. Nucl. Mater. 105, 94 (1982).

4. M. Tetenbaum and P. D. Hunt, Total Pressure of Uranium-Bearing Species over OxygenDeficient Urania, J. Nucl. Mater. 34, 86-91 (1970).

5. G. T. Reedy and M. G. Chasanov, Total Pressure of Uranium-Bearing Species over Molten Urania, J. Nucl. Mater. 42 341-344 (1972).

6. M. Bober, H. U. Karow, and K. Schretzmann, Evaporation Experiments to Determine the Vapor Pressure of UO2 Fuel (3000 -5000 K), IAEA Symp. on Thermodynamics of Nuclear Materials, Vol. 1, 295 (1975); Nucl. Technol. 26, 237 (1975).

7. M. Bober, W. Breitung, H. U. Karow, and K. Schretzmann, Evaporation Studies of Liquid Oxide Fuel at Very High Temperatures Using Laser Beam Heating, KFK-2366, Kernforschungszentrum Karlsruhe (1976).

8. R. W. Ohse, P. G. Berrie, H. G. Bogensberger, and E. A. Fischer, Thermodyn. Nucl. Mater. 1, 307 (1975).

9. J. F. Babelot, G. D. Brumme; P. R. Kinsman, and R. W. Ohse, Atomwirtsch. Atomtech., 12, 387 (1977), as referenced by W. Breitung, and K. O. Reil,, Nucl. Sci. Eng. 101, 26-40 (1989).

10. H. C. Tsai, A. Convington, and D. R. Olander, Laser Vaporization of $\mathrm{UO}_{2}$, in Materials and Molecular Research Division Annual Report LBL-6016, Lawrence Berkeley Laboratory, University of California, Berkeley (1976).

11. M. Bober, W. Breitung, and H. U. Karow, Thermodynamic Calculation and Experimental Determination of the Equation of State of Oxide Fuels up to $5000 \mathrm{~K}$, KFK-2689, Kernforschungszentrum Karlsruhe (1978). 
12. R. W. Ohse, J. F. Babelot, A. Frezzotti, K. A. Long, and J. Magill, Equation of State of Uranium Oxide: Mach-disk Investigation of Transient Laser-induced Vaporization of $\mathrm{UO}_{2}$ up to $5000 \mathrm{~K}$, High Temp.-High Pressures 12, 537 (1980).

13. R. W. Ohse, J. F. Babelot, C. Cercignani, J. P. Hiernaut, M. Hoch, G. J. Hyland, and J. Magill, J. Nucl. Mater. 130, 165 (1985).

14. M. Bober and M. Trapp, Bestimmung des Dampfdrucks von flussigem Uranoxid mittels Laseraufheizung, Kernforschungszentrum Karlsruhe (unpublished), as referenced by W. Breitung, and K. O. Reil,, Nucl. Sci. Eng. 101, $26-40$ (1989).

15. M. Bober and J. Singer, Nucl. Vapor Pressure Determination of Liquid UO $\mathrm{U}_{2}$ Using a Boiling Point Technique, Nucl. Sci. Eng. 97, 344-352 (1987).

16. K. O. Reil, Effective Equation of State Measurements on Uranium Dioxide, Dissertation, University of New Mexico (May 1977), as referenced by W. Breitung, and K. O. Reil, Nucl. Sci. Eng. 101, 26-40 (1989).

17. D. A. Benson, Application of Pulsed Electron Beam Vaporization to Studies of $\mathrm{UO}_{2}$, SAND77-0429, Sandia National Laboratories (1977).

18. R. Limon, G. Sutren, P. Combetter, and F. Barbry, Equation of State of Non-Irradiated UO, Proc. ENA/ANS Topical Meeting on Reactor Safety Aspects of Fuel Behavior, Sun Valley, Idaho, August 2-6, 1981, Vol. 2, pp. 2-576 to 2-583, CEA-CONF-5816, American Nuclear Society (1981).

19. S. A. Wright, D. H. Worledge, G. L. Cano, P. K. Mast, and F. Briscoe, Fuel-Disruption Experiments Under High-Ramp-Rate Heating Conditions, SAND81-0413, Sandia National Laboratories (Oct. 1983).

20. E. A. Fischer, Evaluation of the Urania Equation of State Based on Recent Vapour Pressure Measurements, KfK- 4084 Kernforschungszentrum Karlsruhe (Sept. 1987).

21. J. K. Fink, M. G. Chasanov, and L. Leibowitz, Thermodynamic Properties of Uranium Dioxide, J. Nucl. Mater. 102, 17-25 (1981); see also Thermophysical Properties of Uranium Dioxide, ANL-CEN-RSD-80-3, Argonne National Laboratory (April 1981).

22. W. Breitung and K. O. Reil, In-Pile Vapor Pressure Measurements on $\mathrm{UO}_{2}$ and $(\mathrm{U}, \mathrm{Pu}) \mathrm{O}_{2}$ from 5000 to $8000 \mathrm{~K}$, Proc. of Conf. on Science and Technology of Fast Reactor Safety, Guernsey, U. K., May 12-16, 1986, p. 501.

23. W. Breitung and K. O. Reil, In-Pile Vapor Pressure Measurements on $\mathrm{UO}_{2}$ and $(\mathrm{U}, \mathrm{Pu}) \mathrm{O}_{2}$, KfK-3939 Kernforschungszentrum Karlsruhe (Aug. 1985). 
24. J. H. Harding, D. G. Martin, and P. E. Potter, Thermophysical and Thermochemical Properties of Fast Reactor Materials, Commission of the European Communities Report EUR 12402 EN (1989).

25. C. Ronchi, J. P. Hiernaut, R. Selfslag, and G. J. Hyland, Laboratory Measurement of the Heat Capacity of Urania up to 8000 K: I. Experiment, Nucl. Sci. Eng. 113, 1-19 (1993).

26. L. Leibowitz, M. G. Chasanov, L. W. Mishler, and D. F. Fischer, Enthalpy of Liquid Uranium Dioxide to 3500 K, J. Nucl. Mater. 39 115-116 (1971).

27. R. A. Hein and P. N. Flagella, Enthalpy Measurements of $\mathrm{UO}_{2}$ and Tungsten to $3260 \mathrm{~K}$, General Electric Report GEMP-578 (February 16, 1968).

28. M. H. Rand, R. J. Ackermann, F. Gronvold, F. L. Oetting, and A. Pattoret, The Thermodynamic Properties of the Urania Phase, Rev. Int. Hautes Temp. Refract. 15, 355365 (1978).

29. International Working Group on Fast Reactors, Specialists' Meeting on Equations of State of Materials of Relevance to the Analysis of Hypothetical Fast Breeder Reactor Accidents, Harwell, U. K., June 19-23, 1978, IWGFR/26, IAEA (1978).

30. R. J. Ackermann, P. W. Giles, R. H. Thorn, J. Chem. Phys. 25, 1089 (1956).

31. V. E. Ivanov, A. A. Kruglykh, V. S. Pavlov, G. P. Kovtin, and V. M. Amonenko, Proc. Symp. On Thermodynamics of Nuclear Materials, Vienna, 1962, IAEA, p. 735, Vienna (1962).

32. R. W. Ohse, J. Chem. Phys. 44, 1375 (1966).

33. Y. A. Gorban, L. V. Pavlinov, and V. N. Vykov, At. Ehnerg. 22, 465 (1955), as referenced by R. J. Ackermann, E. G. Rauh, and M. H. Rand, A Re-Determination and Re-Assessment of the Thermodynamics of Sublimation of Uranium Dioxide, Proc. Symp. on Thermodynamics of Nuclear Materials, Julich, 1979, Vol.1, IAEA, pp.11-27, Vienna (1980).

34. R. J. Ackermann, E. G. Rauh, and M. S. Chandrasekhariah, J. Phys. Chem. 73, 762 (1969).

35. N. M. Voronov, A. S. Danilin, I. T. Kovalev, Symp. on Thermodynamics of Nuclear Materials Vienna 1962, IAEA, p. 789, Vienna (1962). 
36. C. A. Alexander, J. S. Ogden, and G. C. Cunningham, Battelle Memorial Institute Report BMI-1789 (Jan. 1967), as referenced by R. J. Ackermann, E. G. Rauh, and M. H. Rand, A Re-Determination and Re-Assessment of the Thermodynamics of Sublimation of Uranium Dioxide, Proc. Symp. on Thermodynamics of Nuclear Materials, Julich, 1979, Vol. 1, IAEA, pp. 11-27, Vienna (1980).

37. A. Pattoret, J. Drowart, and J. Smoes, Proc. Symp. Thermodynamics of Nuclear Materials, Vienna 1967, IAEA, p. 613, Vienna (1968). 
Table 6.1 Total Vapor Pressure Over Liquid $\mathrm{UO}_{2}$

\begin{tabular}{|c|c|c|}
\hline Temperature, K & Pressure, MPa & Pressure, atm \\
\hline 3120 & 0.00469 & 0.0463 \\
\hline 3200 & 0.00720 & 0.0711 \\
\hline 3300 & 0.0119 & 0.118 \\
\hline 3400 & 0.0191 & 0.188 \\
\hline 3500 & 0.0297 & 0.293 \\
\hline 3600 & 0.0450 & 0.444 \\
\hline 3700 & 0.0664 & 0.656 \\
\hline 3800 & 0.0960 & 0.948 \\
\hline 3900 & 0.136 & 1.34 \\
\hline 4000 & 0.189 & 1.86 \\
\hline 4100 & 0.257 & 2.54 \\
\hline 4200 & 0.346 & 3.41 \\
\hline 4300 & 0.457 & 4.51 \\
\hline 4400 & 0.595 & 5.87 \\
\hline 4500 & 0.765 & 7.55 \\
\hline 4600 & 0.972 & 9.60 \\
\hline 4700 & 1.22 & 12.1 \\
\hline 4800 & 1.52 & 15.0 \\
\hline 4900 & 1.87 & 18.4 \\
\hline 5000 & 2.28 & 22.5 \\
\hline 5100 & 2.75 & 27.1 \\
\hline 5200 & 3.29 & 32.5 \\
\hline 5300 & 3.91 & 38.6 \\
\hline 5400 & 4.62 & 45.6 \\
\hline 5500 & 5.41 & 53.4 \\
\hline 5600 & 6.30 & 62.2 \\
\hline 5700 & 7.29 & 71.9 \\
\hline 5800 & 8.38 & 82.7 \\
\hline 5900 & 9.58 & 94.6 \\
\hline 6000 & 10.91 & 107.6 \\
\hline
\end{tabular}


Table 6.2 Vapor Pressure Over Solid $\mathrm{UO}_{2}$ Calculated from Equations of Áckermann et al. and of Tetenbaum and Hunt

\begin{tabular}{|c|c|c|}
\hline $\begin{array}{c}\text { Temperature } \\
\text { K }\end{array}$ & $\begin{array}{c}\text { UO } \text { Pressure }_{\mathbf{M P a}} \\
\text { (Ackermann et al.) }\end{array}$ & $\begin{array}{c}\text { Total Pressure } \\
\text { MPa }\end{array}$ \\
\hline 1800 & $2.05 \times 10^{-10}$ & - \\
1900 & $1.67 \times 10^{-09}$ & - \\
2000 & $1.10 \times 10^{-08}$ & $9.42 \times 10^{-09}$ \\
\hline 2100 & $5.98 \times 10^{-08}$ & $5.23 \times 10^{-08}$ \\
2200 & $2.77 \times 10^{-07}$ & $2.49 \times 10^{-07}$ \\
2300 & $1.12 \times 10^{-06}$ & $1.03 \times 10^{-06}$ \\
2400 & $3.96 \times 10^{-06}$ & $3.81 \times 10^{-06}$ \\
2500 & $1.26 \times 10^{-05}$ & $1.27 \times 10^{-05}$ \\
\hline 2600 & $3.62 \times 10^{-05}$ & $3.83 \times 10^{-05}$ \\
2700 & $9.54 \times 10^{-05}$ & $1.07 \times 10^{-04}$ \\
2800 & $2.31 \times 10^{-04}$ & $2.77 \times 10^{-04}$ \\
2900 & $5.22 \times 10^{-04}$ & $6.74 \times 10^{-04}$ \\
3000 & $1.10 \times 10^{-03}$ & $1.54 \times 10^{-03}$ \\
\hline 3100 & $2.17 \times 10^{-03}$ & $3.34 \times 10^{-03}$ \\
\hline
\end{tabular}


Table 6.3 Vapor Pressure Measurements Over Liquid $\mathrm{UO}_{2}$

\begin{tabular}{|c|c|c|c|}
\hline Experimenter & Method & Year & Reference \\
\hline & Out-of-Pile Experiments & & \\
\hline Reedy \& Chasanov & Transpiration & 1972 & 5 \\
\hline Bober et al. & $\begin{array}{l}\text { Laser-heating, expansion into } \\
\text { vacuum }\end{array}$ & $\begin{array}{l}1975 \\
1976 \\
\end{array}$ & 6,7 \\
\hline Ohse et al. & Laser-heating, vacuum & $\begin{array}{l}1975 \\
1977\end{array}$ & 8,9 \\
\hline Tsai et al. & Laser-heating, vacuum & 1976 & 10 \\
\hline $\begin{array}{l}\text { Bober, Breitung, \& } \\
\text { Karow }\end{array}$ & Laser-heating, vaporization & 1978 & 11 \\
\hline Ohse et al. & Laser-heating, evaporation & 1980 & 12 \\
\hline Ohse et al. & Laser-heating, evaporation & 1985 & 13 \\
\hline Bober \& Trapp & Laser-heating in xenon & 1984 & 14 \\
\hline \multirow[t]{2}{*}{ Bober \& Singer } & $\begin{array}{l}\text { Laser-heating in xenon, } \\
\text { Boiling point method. }\end{array}$ & 1987 & 15 \\
\hline & In-Pile Experiments & & \\
\hline Reil & Adiabatic enthalpy vs pressure & 1977 & 16 \\
\hline Benson & Isobaric expansion & 1977 & 17 \\
\hline Limon et al. & $\mathrm{UO}_{2}$ Fission-heated in argon & 1981 & 18 \\
\hline Wright et al. & In-pile fuel disruptive exp'ts & 1983 & 19 \\
\hline Breitung \& Reil & $\begin{array}{l}\text { Effective equation of state } \\
\text { technique }\end{array}$ & $\begin{array}{l}1985- \\
1989\end{array}$ & 1 \\
\hline
\end{tabular}


Table 6.4 Measurements of the Vapor Pressure of $\mathrm{UO}_{2}$ at $2150 \mathrm{~K}$

\begin{tabular}{|c|l|c|l|c|}
\hline $\begin{array}{c}\text { Vapor Pressure } \\
\text { at } \\
\mathbf{2 1 5 0} \mathbf{K}, \mathbf{1 0} \mathbf{7} \mathbf{M P a}\end{array}$ & \multicolumn{1}{|c|}{ Experimenter } & Year & \multicolumn{1}{|c|}{ Method } & $\begin{array}{c}\text { Temperature } \\
\text { Range, K }\end{array}$ \\
\hline 1.23 & Ackermann et al. [30] & 1956 & mass effusion & $1758-2378$ \\
\hline 1.94 & Ivanov et al. [31] & 1962 & mass effusion & $1930-2160$ \\
\hline 0.58 & Voronov et al. [35] & 1962 & Langmuir & $1723-2573$ \\
\hline 1.34 & Ohse [32] & 1966 & mass effusion & $2200-2800$ \\
\hline 0.93 & Alexander et al. [36] & 1967 & transpiration & $2090-2900$ \\
\hline 2.00 & Gorban et al. [33] & 1967 & mass effusion & $1873-2573$ \\
\hline 1.83 & Pattoret et al. [37] & 1968 & mass spectroscopy & $1890-2420$. \\
\hline 1.18 & Tetenbaum \& Hunt [4] & 1970 & transpiration & $2080-2705$ \\
\hline 1.32. & Ackermann et al. [2] & 1979 & mass spectroscopy & $1813-2463$ \\
\hline
\end{tabular}


Figure 6.1 Total Vapor Pressure Over Liquid $\mathrm{UO}_{2}$

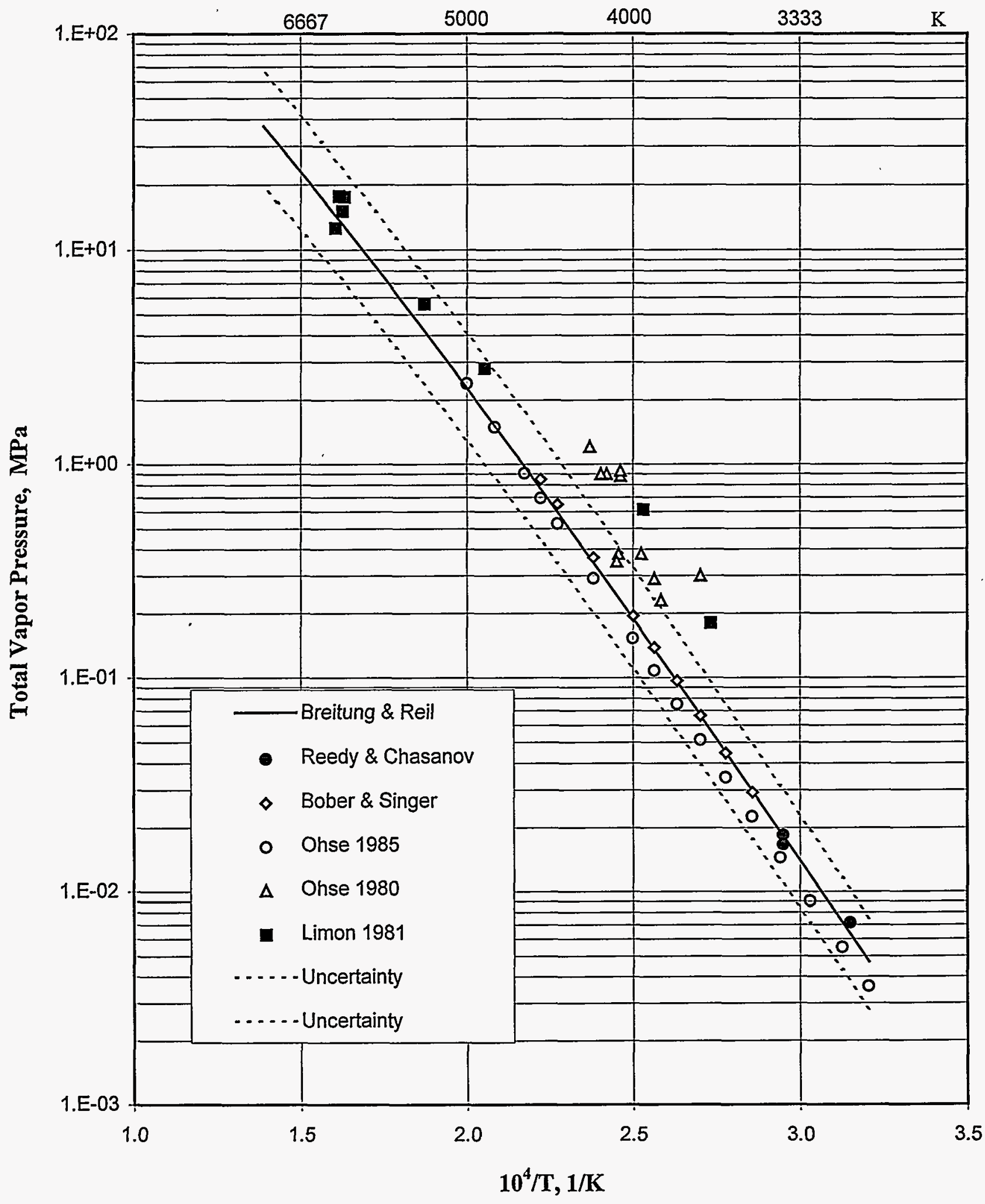


Figure 6.2 Vapor Pressure Over Solid $\mathrm{UO}_{2}$

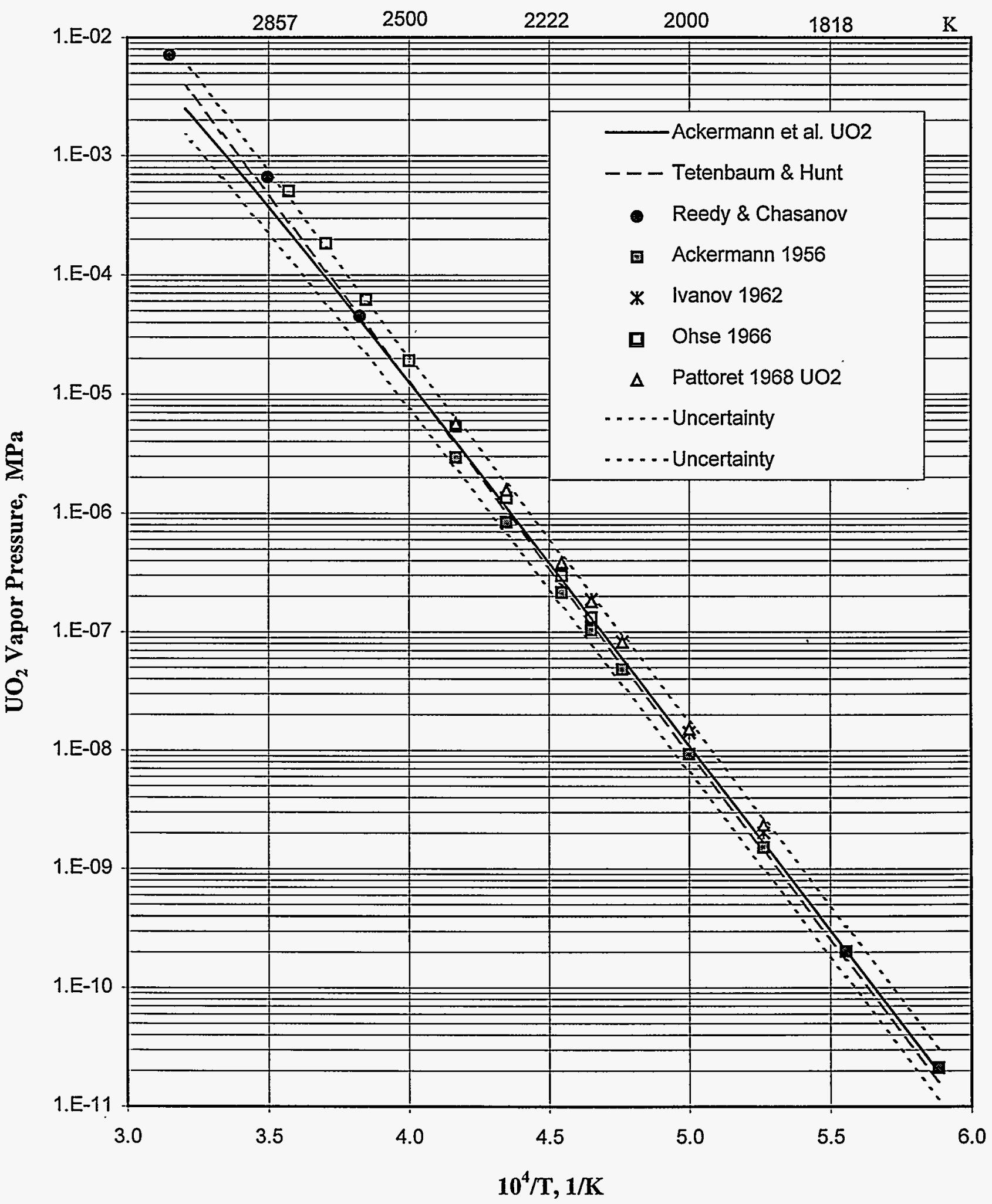

Send Comments to: 


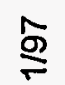

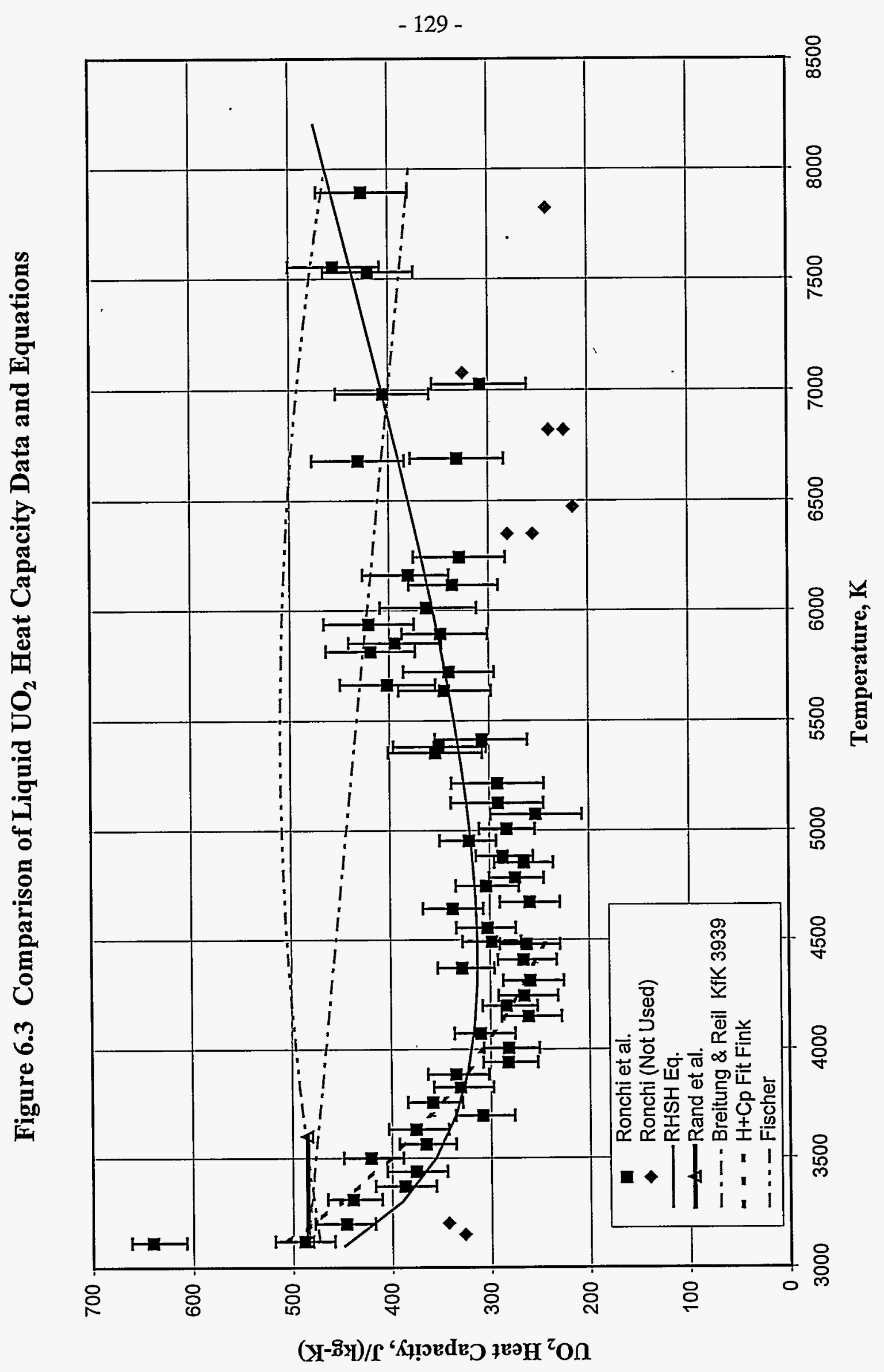

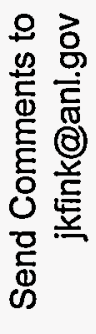


Figure 6.4 Total Vapor Pressure Over Liquid $\mathrm{UO}_{2}$

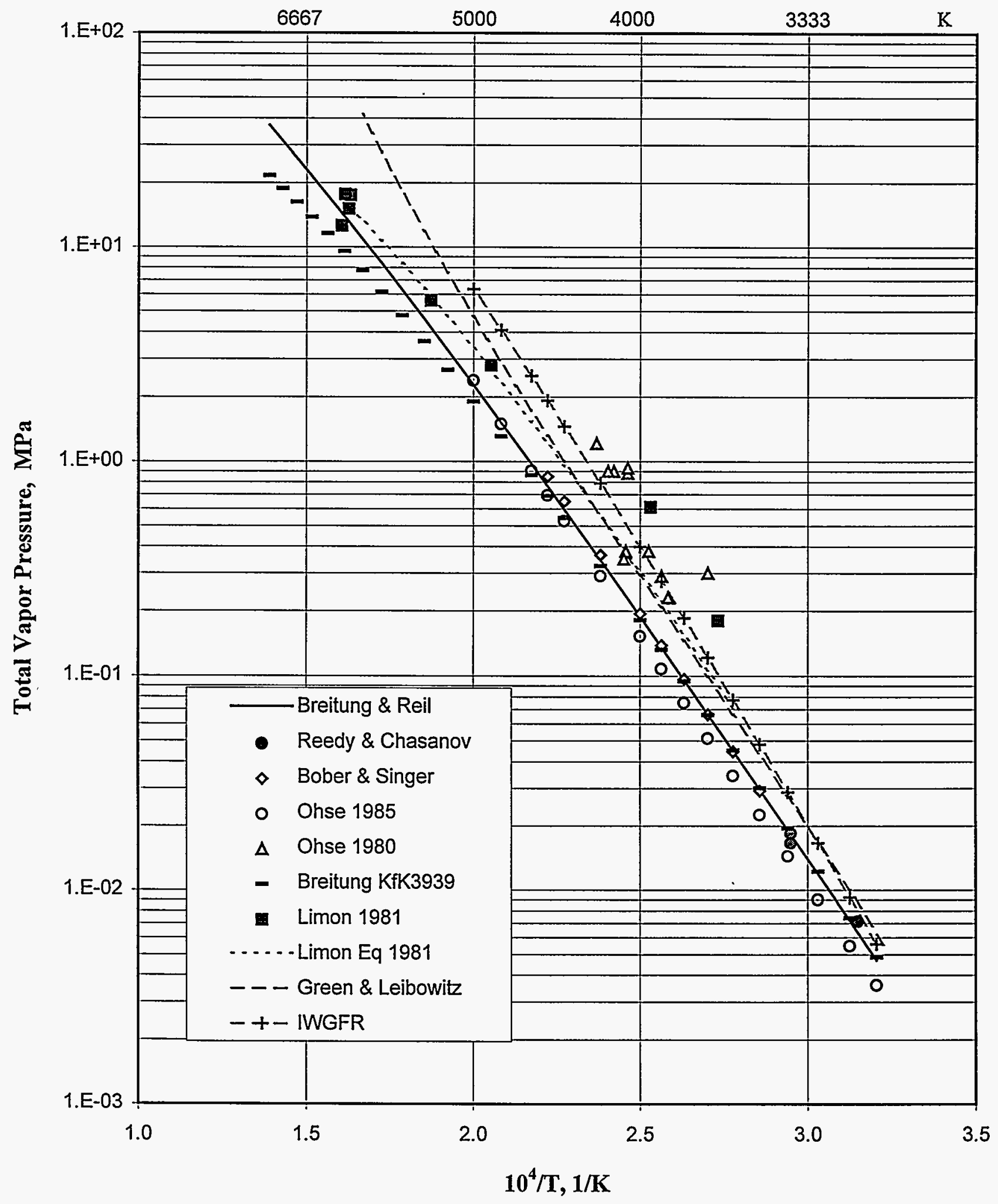

Send Comments to: jkfink@anl.gov 
Figure 6.5 Vapor Pressure Over Solid $\mathrm{UO}_{2}$

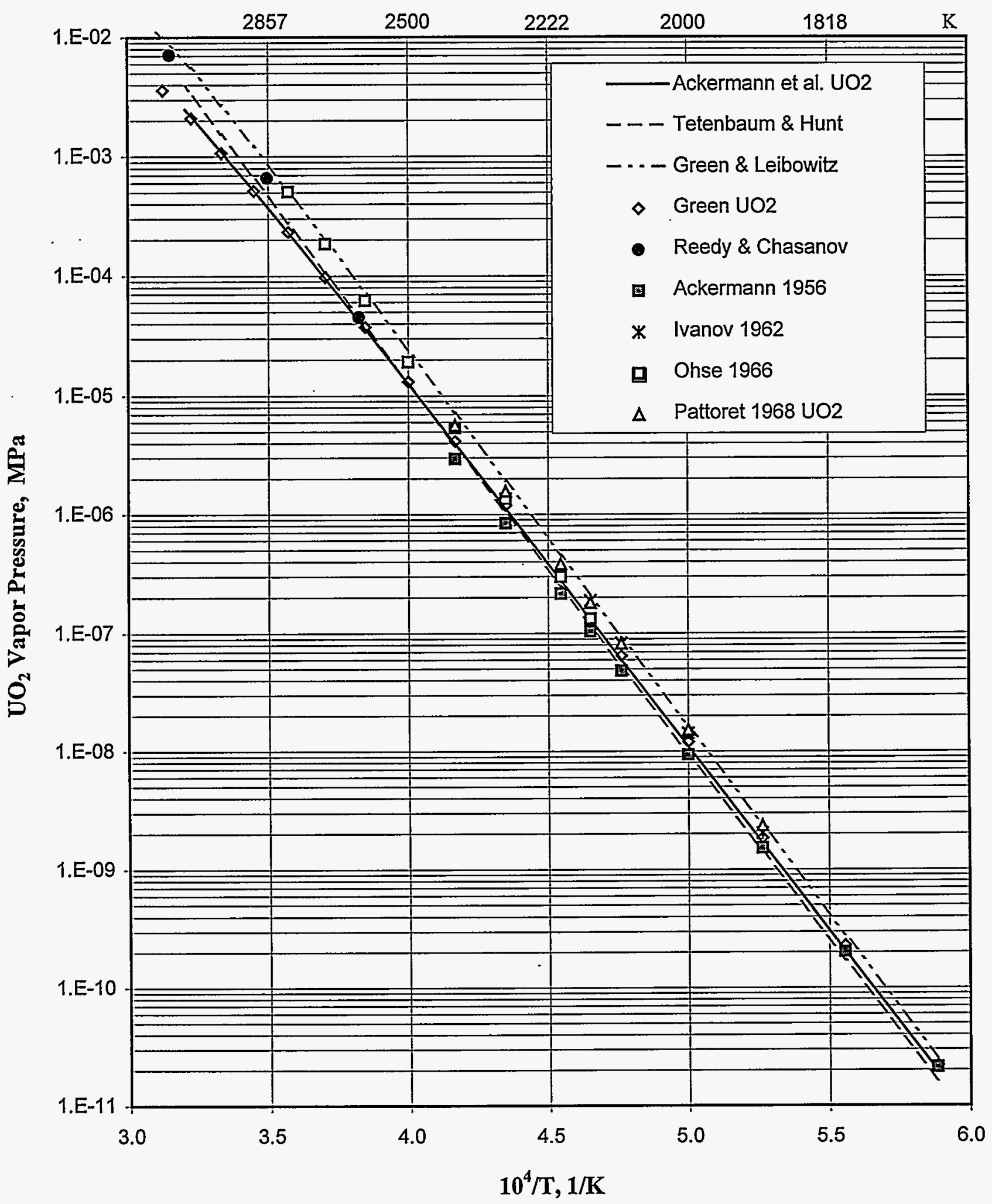

Send Comments to: 
Figure 6.6 Vapor Pressure Over $\mathrm{UO}_{2}$ at Solid/Liquid Interface

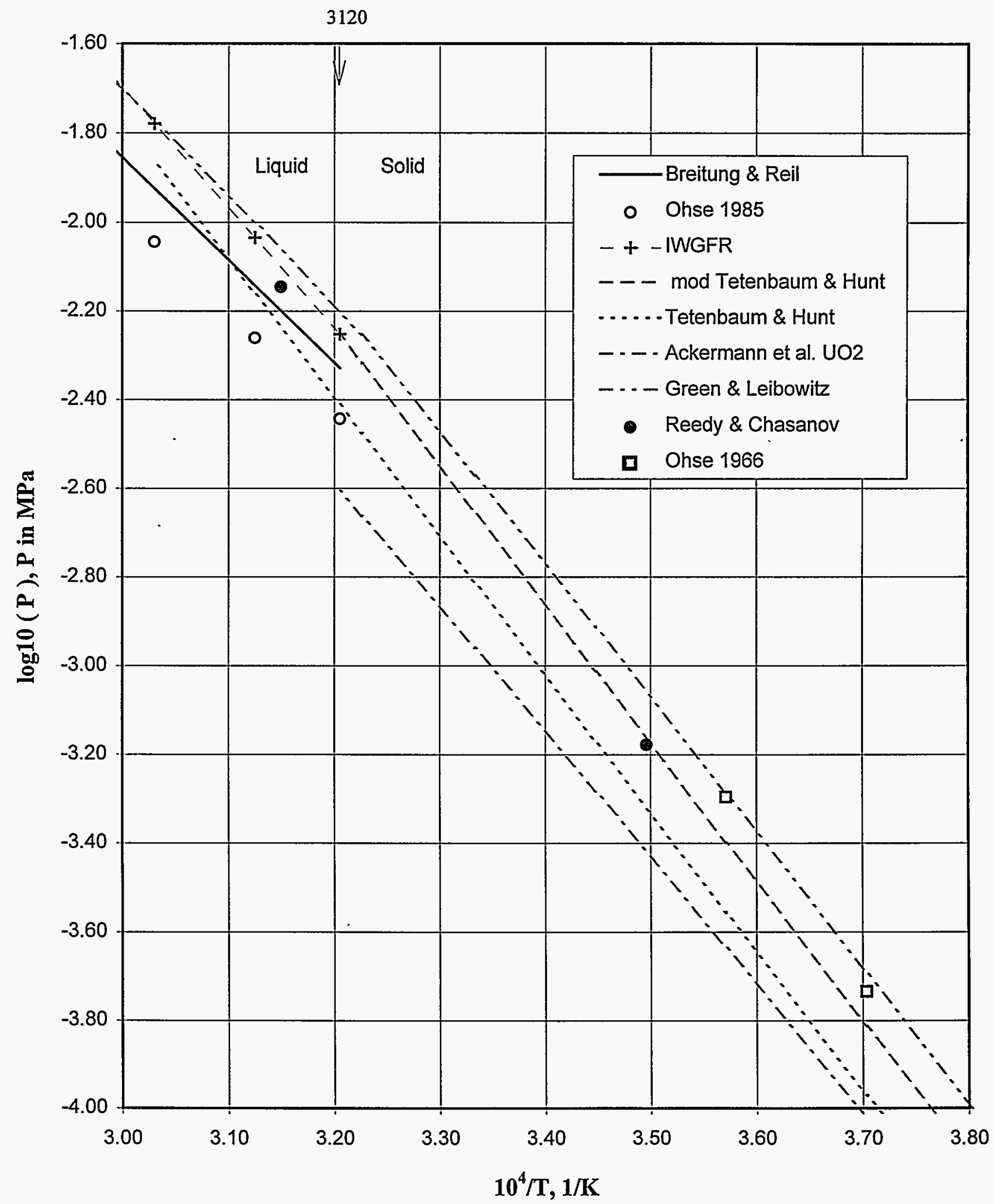




\section{TRANSPORT PROPERTIES}

\section{THERMAL CONDUCTIVITY AND DIFFUSIVITY OF URANIUM DIOXIDE \\ 7.1 THERMAL CONDUCTIVITY OF SOLID UO ${ }_{2}$ \\ Summary and Recommended Equation}

The recommended equation for the thermal conductivity of fully dense solid $\mathrm{UO}_{2}$ is from Harding and Martin ${ }^{1}$ who have carefully considered the theoretical aspects related to the thermal conductivity of fully dense $\mathrm{UO}_{2}$ to obtain a physically based equation for the temperature range of $773 \mathrm{~K}$ to the melting point, $3120 \mathrm{~K}$. This equation was selected because it is the best equation available from a theoretical aspect, it is in good agreement with earlier equations that are based on statistical fits to the experimental data, and it is consistent with in-reactor measurements of the integral to melting. Although this equation is recommended only for the temperature range for which it was derived ( 773 to $3120 \mathrm{~K}$ ), it is in good agreement with other equations that fit the experimental data below $773 \mathrm{~K}$. The recommended equation of Harding and Martin for the thermal conductivity, $k$, in $\mathrm{W} \mathrm{m}^{-1} \mathrm{~K}^{-1}$ is:

$$
k=\left(0.0375+2.165 \times 10^{-4} T\right)^{-1}+\frac{4.715 \times 10^{9}}{T^{2}} \exp \left(\frac{-16361}{T}\right)
$$

where the temperature, $T$, is in $\mathrm{K}$. The first term in this equation represents the contribution from phonons. The second term represents the small polaron contribution. Values of the thermal conductivity for fully dense solid $\mathrm{UO}_{2}$ calculated from Eq. (1) are tabulated as a function of temperature in Table 7.1.1 and shown graphically in Figure 7.1.1. Figure 7.1.1 also includes uncertainty bands.

\section{Uncertainties}

Harding and Martin ${ }^{1}$ estimate the uncertainties in thermal conductivities calculated with their equation as $7 \%$ from 773 to $1800 \mathrm{~K}$ increasing to $15 \%$ at $3120 \mathrm{~K}$. The increase in uncertainty from $7 \%$ at $1800 \mathrm{~K}$ to $15 \%$ at $3120 \mathrm{~K}$, shown in Figure 7.1.1, is assumed to be linear in accord with the equation: $\%$ Uncertainty $=-3.9+0.0061 \mathrm{~T}$, where $\mathrm{T}$ is the temperature in $\mathrm{K}$. 


\section{Discussion of Recommendation}

In 1982, Martin ${ }^{2}$ reviewed the equations of Washington, ${ }^{3}$ Brandt and Neuer, ${ }^{4}$ Ainscough, ${ }^{5}$ and Killeen ${ }^{6}$ with respect to the experimental data, the integral to melting, and the physical models. Martin ${ }^{2}$ pointed out that the MATPRO ${ }^{7}$ equation, although used extensively, is not physically based. Therefore, it was not recommended. Martin included the polynomial equation of Ainscough, which has no physical basis, in his assessment because it represents the best fit to the low-temperature data and was significant in the development of the physically-based equation given by Killeen. Since the review by Martin, Fink et al. ${ }^{8,9}$ reviewed the available thermal conductivity and thermal diffusivity data, converted the diffusivity data to conductivities and fit the combined data to a two term equation to account for the phase transition at $2670 \mathrm{~K}$ that appears in heat capacity data but not in either thermal diffusivity or density data. Differences between the physically based equations of Washington, ${ }^{3}$ Brandt and Neuer, ${ }^{4}$ Killeen, ${ }^{6}$ and Fink et al ${ }^{8,9}$ arise from differences in the physical processes included in the equations used to represent the thermal conductivity and differences in the data sets included in the fits.

Washington's equation ${ }^{3}$ for thermal conductivity in $\mathrm{W} \mathrm{m}^{-1} \mathrm{~K}^{-1}$ and $\mathrm{T}$ in $\mathrm{K}$ is:

$$
k=\left(0.035+2.25 \times 10^{-4} T\right)^{-1}+83.0 \times 10^{-12} T^{3}
$$

The first term of Washington's equation is the contribution due to phonons. The form of the second term is consistent with a contribution due to radiation implying that the increase in thermal conductivity at high temperatures arises from thermal radiation rather than electronic excitation. The limitations of Washington's equation are: the form of this second term and the minimum conductivity which is about $8 \%$ higher than most experiments but within the experimental uncertainty. Washington included integral-to-melting data in his fitting procedure to ensure good agreement with the available in-reactor data.

The equation given by Brandt and Neuer ${ }^{4}$ is: 


$$
\begin{aligned}
k= & \left(0.0439+2.16 \times 10^{-4} T\right)^{-1}+11.2 \times 10^{-2} T \exp \left(-\frac{1.18}{k_{B} T}\right) \\
& -4.18 \times 10^{5} \exp \left(-\frac{3.29}{k_{B} T}\right)
\end{aligned}
$$

where $k_{B}$ is the Boltzmann constant $\left(8.6144 \times 10^{-5} \mathrm{eV} \mathrm{K}^{-1}\right)$, $\mathrm{T}$ is in $\mathrm{K}$, and thermal conductivity is in $\mathrm{W} \mathrm{m}^{-1} \mathrm{~K}^{-1}$. The first term in Eq. (3) gives the phonon contribution, the second term gives the contribution from electronic conduction, and the third term gives the decrease in conduction due to dislocations at high temperature. Martin ${ }^{2}$ commented that this equation appears to be overly complicated and gives low values for the integral-to-melting. At low temperatures, thermal conductivities calculated with the equation of Brandt and $\mathrm{Neuer}^{4}$ are slightly lower than the mean experimental values but are consistent with both the Round Robin experimental data ${ }^{10}$ (based on $\mathrm{UO}_{2}$ with $\mathrm{O} / \mathrm{M}$ in the range of $2.002-2.007$ ) and with the more recent low-temperature data of Weilbacher. ${ }^{11,12}$

The Ainscough equation ${ }^{5}$ is a polynomial fit given by:

$$
k=9.851-8.803 \times 10^{-3} T+3.301 \times 10^{-6} T^{2}-3.727 \times 10^{-10} T^{3}
$$

where $T$ is in $K$ and thermal conductivity is in $W \mathrm{~m}^{-1} \mathrm{~K}^{-1}$. Although the equation given by Ainscough represents the best fit to the low-temperature data, it deviates at high temperatures and gives low integral-to-melting values of $6.3 \mathrm{~kW} / \mathrm{m}$ for $95 \%$ dense fuel and $6.8 \mathrm{~kW} / \mathrm{m}$ for $100 \%$ dense fuel.

Killeen's equation ${ }^{6}$ is:

$$
k=\left(0.0375+2.165 \times 10^{-4} T\right)^{-1}+3.861 \times 10^{-3} T \exp \left(\frac{-1.07}{k_{B} T}\right)
$$

where $k_{B}$ is the Boltzmann constant $\left(8.6144 \times 10^{-5} \mathrm{eV} \mathrm{K}^{-1}\right)$, $\mathrm{T}$ is in $\mathrm{K}$, and thermal conductivity is in $\mathrm{W} \mathrm{m}^{-1} \mathrm{~K}^{-1}$. The first term in Killeen's equation is the phonon contribution. The parameters were chosen to give a best fit to Ainscough's low-temperature thermal conductivities. The second term represents thermal transport by electronic charge carriers with both electrons and holes contributing 
to the conduction. The form is a modified Wiedemann-Franz relationship for intrinsic semiconductors. Killeen's physically based equation is a good representation of the low-temperature data and gives good integral-to-melting values but gives high thermal conductivities at high temperatures.

The equations of Fink et al. are:

For $\mathrm{T} \leq 2670 \mathrm{~K}$,

$$
k=\left(6.8337 \times 10^{-2}+1.6693 \times 10^{-4} T+3.1886 \times 10^{-8} T^{2}\right)^{-1}+1.2783 \times 10^{-1} T \exp \left(\frac{-1.1608}{k_{B} T}\right)
$$

For $\mathrm{T} \geq 2670 \mathrm{~K}$,

$$
k=4.1486-2.2673 \times 10^{-4} T
$$

where $k_{B}$ is the Boltzmann constant $\left(8.6144 \times 10^{-5} \mathrm{eV} \mathrm{K}^{-1}\right)$, $\mathrm{T}$ is in $\mathrm{K}$, and thermal conductivity is in $\mathrm{W} \mathrm{m}^{-1} \mathrm{~K}^{-1}$. The first term in Eq.(6) gives the phonon contribution. The second term, which gives the electronic contribution, has the same form as that of Killeen. The discontinuity at $2670 \mathrm{~K}$ arises from conversion of the thermal diffusivity measurements of Weilbacher ${ }^{11,12}$ and Bates ${ }^{10}$ to thermal conductivity. As pointed out by Harding et al., ${ }^{13}$ there is currently no basis for a discontinuity in thermal conductivity at the Bredig transition but there is only one experimental thermal conductivity datum above $2670 \mathrm{~K}$ (at $2777 \mathrm{~K}$ by Stora et al. ${ }^{14}$ ). Although this equation gives a better overall fit to the experimental data than that of Brandt and Neuer, like the equation of Brandt and Neuer, it gives a low integral-to-melting value.

Hyland ${ }^{15}$ has published a detailed critique and recommendation for the thermal conductivity of $\mathrm{UO}_{2}$ that discusses the lattice, radiation, and electronic contributions to the thermal conductivity and the errors in the theories and the experimental data. However, he gives no equation to represent the thermal conductivity for the entire temperature range. Hyland comments that the electronic contribution is from small polarons and is not well represented by the intrinsic semiconductor contribution used by Killeen. Hyland assumed that at temperatures above $2000 \mathrm{~K}$, the lattice contribution to the thermal conductivity was constant and equal to the value at $2000 \mathrm{~K}$ where the total thermal conductivity reaches a minimum value. This was based on Schmidt's ${ }^{16}$ comment that as temperatures increase, the phonon component decreases as the mean free path between scattering jkfink@anl.gov 
events decreases. Schmidt estimated that by $2323 \mathrm{~K}$ the mean free path had fallen to values equal to the inter-ionic separation. Since smaller mean free paths have no physical meaning, Schmidt recommended that above $2323 \mathrm{~K}$ the phonon lattice contribution should be a constant equal to the value at $2323 \mathrm{~K}$. Hyland calculated the electrical contribution due to small polarons using the electrical conductivity data of Killeen ${ }^{17}$ to obtain the temperature dependence. The radiation contribution was included to account for the increase in thermal conductivity at high temperatures.

The first term of the equation of Harding and Martin, Eq. (1), is identical with that given by Killeen, which gives a good fit to the low-temperature thermal conductivity data. Because Schmidt's determination of the mean-free path was based on extrapolated elastic constants, his calculation was repeated by Harding and Martin using recent elastic constant measurements. ${ }^{18}$ They concluded that the mean free path is always greater than the inner-ionic spacing, suggesting that the phonon contribution given by the first term of Killeen's equation could be used at all temperatures up to the melting point. They commented that there is no experimental evidence indicating whether the phonon contribution reaches a minimum and remains a constant or continues to decrease until the melting point. $\mathrm{ThO}_{2}$ thermal conductivity, which has no electronic contribution at high temperatures, shows a monotonic decrease up to $2800 \mathrm{~K}$. However, this is still far from the $3640 \mathrm{~K}$ melting point of $\mathrm{ThO}_{2}$. The second term of the equation of Harding and Martin is the contribution due to small polarons. It has been calculated from the activation energy for the formation of electron-hole pairs and the electrical conductivity using data related to the hole mobility from Dudney et al. ${ }^{19}$ and from the recommendations by Hampton et al. ${ }^{20}$ and the high-temperature electrical conductivity data of Bates..$^{21}$ This term has a different temperature dependence than the small polaron contribution given by Hyland and gives higher values. The integral to melting for $95 \%$ theoretically dense $\mathrm{UO}_{2}$ was calculated by Harding and Martin assuming a porosity correction factor of (1-2.5 $\mathrm{p}$ ) where $\mathrm{p}$ is the porosity. They obtained $6.8 \mathrm{~kW} \mathrm{~m}^{-1}$ for the integral to melting, which is the value recommended by Marchandise. ${ }^{22}$

\section{Comparison with Recommendation}

The recommended equation of Harding and Martin $^{1}$ [Eq. (1)] is compared in Figure 7.1.2 with curves from the calculation of Hyland, ${ }^{15}$ and equations of Killeen, ${ }^{6}$ Fink et al., ${ }^{8,9}$ Brandt and Neuer, ${ }^{4}$ Washington, ${ }^{3}$ Ainscough, ${ }^{5}$ and MATPRO. ${ }^{7}$ Below $600 \mathrm{~K}$, it is consistent with the equation 
of Killeen, which is high relative to the equation of Ainscough. However, the equations of Ainscough, Brandt and Neuer, Washington, Killeen, and Harding and Martin are recommended only from 773 to $3120 \mathrm{~K}$, so the differences below $600 \mathrm{~K}$ are not surprising. Above the solid-solid phase transition at $2670 \mathrm{~K}$, the equation of Harding and Martin is consistent with values given by the equation of Brandt and Neuer which fit the high-temperature data of Weilbacher. Thus, at high temperatures, the equation of Harding and Martin gives lower values than the equation of Killeen and slightly higher values than calculated by Hyland. Figure 7.1.3 shows percent deviations of the calculation by Hyland and the equations of Killeen, Fink et al., Brandt and Neuer, Washington, Ainscough, and MATPRO from the recommended equation of Harding and Martin. These deviations are defined by:

$$
\operatorname{Deviation}(\%)=\frac{k(\text { Other })-k(\text { Recommended })}{k(\text { Recommended })} \cdot 100 \%
$$

From 1000 to $2800 \mathrm{~K}$, percent deviations are greatest for the MATPRO equation. The unusual deviations near $2670 \mathrm{~K}$ in the values from the equations of Fink et al. are due to the inclusion of a discontinuity at the solid-solid phase transition and the use of a linear equation above that transition.

Above $2670 \mathrm{~K}$, the only experimental data available are the thermal diffusivity measurements of Weilbacher ${ }^{11,12}$ and Bates ${ }^{10}$ and a single datum from the thermal conductivity measurements of Stora et al. ${ }^{14}$ Since Brandt and Neuer ${ }^{4}$ fit these data, new equations have been determined for the heat capacity ${ }^{23}$ and density ${ }^{24}$ of $\mathrm{UO}_{2}$. The heat capacity equations ${ }^{23}$ are consistent with the experimental data that confirm a solid-solid phase transition at $2670 \mathrm{~K}$. At high temperatures, the density equation ${ }^{24}$ has been based on the recent high-temperature data from Hutchings. 25'o compare these high-temperature diffusivity measurements with the recommended equation of Harding and Martin, the thermal diffusivity data of Weilbacher and Bates have been converted to thermal conductivity using these new equations for density and heat capacity and the relation:

$$
k=\delta C_{P} \rho
$$

where $\delta$ is the thermal diffusivity, $C_{P}$ is the heat capacity, and $\rho$ is the density. In Figure 7.1.4, the equation of Harding and Martin is compared with the thermal conductivities obtained from the data 
of Weilbacher and of Bates and the thermal conductivity values of Stora et al. Uncertainty bands based on the uncertainty recommendations of Harding and Martin have been included in the figure. The thermal conductivities of Stora et al. and all the thermal conductivities from the thermal diffusivities of Weilbacher except for the datum of Weilbacher at $3023 \mathrm{~K}$ are within the $15 \%$ uncertainty. However, conductivities calculated from the thermal diffusivities of Bates are lower than the $15 \%$ uncertainty. The recent measurements of Weilbacher are considered more reliable than the older high-temperature measurements of Bates.

\section{Effect of Porosity}

The recommended equation of Harding and Martin is for fully dense stoichiometric $\mathrm{UO}_{2}$. Although the effect of porosity on thermal conductivity of $\mathrm{UO}_{2}$ has been studied experimentally, a large spread exists in the experimental results. This is due to differences in the shape and orientation of the porosity depending on the history of the fuel. The influence of porosity on the thermal conductivity of irradiated $\mathrm{UO}_{2}$ has been determined by Bakker et al. ${ }^{26}$ using the finite element method which considers the effects of shape, orientation, and distribution of the pores in the fuel. They found good agreement between their calculations and the analytical equations derived by Schulz, ${ }^{27}$ which approximate the shape of the pores by ellipsoids and assume that the pores are randomly positioned. Schulz used general relationships for the thermal conductivity of two-phase materials to obtain equations for thermal conductivity of porous materials. These equations require data on the structure (dispersion or penetration), the porosity $(\mathrm{P})$ and whether it is open or closed, the shape of the pores, the orientation of the pores, and the thermal conductivity of the pure phases. Equations recommended by Schulz for the thermal conductivity for closed and open porosity are: Closed Porosity:

$$
\begin{gathered}
k=k_{0}(1-P)^{X} \\
X=\frac{1-\cos ^{2} \alpha}{1-F}+\frac{\cos ^{2} \alpha}{2 F}
\end{gathered}
$$


Open Porosity:

$$
(1-P)\left(k_{0}-k\right)\left[\frac{2\left(1-\cos ^{2} \alpha\right)}{k_{0}+k}+\frac{\cos ^{2} a p h a}{k}\right]=P\left(2-\cos ^{2} \alpha\right)
$$

where $\mathrm{k}$ is the thermal conductivity of the porous material, $\mathrm{k}_{0}$ is the thermal conductivity of the theoretically dense material, $\mathrm{P}$ is the porosity, and $\mathrm{F}$ and $\cos ^{2} \alpha$ are shape and orientation factors for the pores. In general, the pores are treated as three-dimensional ellipsoids which leads to complex integrals for the shape and orientation factors as given by Bakker et al. ${ }^{26}$ The complexity of these equations of Schulz limit their usefulness.

A number of simpler equations have been suggested based on measurements on unirradiated fuel. A modified Loeb relation has been recommended by a number of analysts including Washington and by Brandt and Neuer. The modified Loeb relation is:

$$
k=k_{0}(1-\alpha P)
$$

where $\mathrm{k}_{0}$ is the thermal conductivity of fully dense fuel and $\mathrm{P}$ is the fractional porosity. Washington recommended $\alpha=2.5$; Brandt and Neuer proposes that $\alpha$ is a linear function of temperature given by $\alpha=2.6-0.5 \times 10^{-5} \mathrm{~T}$, where $\mathrm{T}$ in ${ }^{\circ} \mathrm{C}$. The porosity correction proposed in MATPRO is the Maxwell-Eucken equation:

$$
k=k_{0} \frac{1-P}{1+\beta P}
$$

where $\mathrm{k}_{0}$ is the thermal conductivity of fully dense fuel and $\mathrm{P}$ is the fractional porosity. The factor $\beta$ is a linear function of temperature, $\mathrm{T}$ in $\mathrm{K}$ :

$$
\beta=\beta_{0}+\beta_{1} T
$$

Mean values given in MATPRO for $\beta_{0}$ and $\beta_{1}$ are: 6.5 and -0.00469 , respectively. Martin ${ }^{2}$ recommended a modified Loeb relation with $\alpha=2.5$ for fractional porosity values less than 0.1 . For higher porosities, Martin recommended a Maxwell-Euken relationship with $\beta=2$. 
Harding et al. ${ }^{13}$ commented that the Loeb equation and the Maxwell-Euken equation may be replaced to an acceptable accuracy with the single equation:

$$
k=k_{0}(1-P)^{2.5}
$$

where $P$ is the fractional porosity. However, this equation as well as Eqs. (14) and (15) have the defect that the correction factors are means of values that have been determined from measurements on fuels from different laboratories that have possible differences in manufacturing that could result in genuine differences in pore structure in the different fuels. In addition, no consideration has been made for irradiated fuel which has different pore structures from unirradiated materials. Consequently, Harding et al. recommended an equation, based on the work of J. R. Mathews, which accounts for the pore structure by splitting the porosity into a number of components. Their equation for the thermal conductivity of fuel containing porosity is:

$$
k=k_{0}\left(1-P_{1}\right)\left(1-P_{2}-P_{3}\right)^{2.5}\left(1-P_{4}-P_{5}\right)^{3.5}
$$

where $\mathrm{k}_{0}$ is the conductivity for theoretically dense fuel and the various $\mathrm{P}$ 's refer to volume fractions of different types of pore:

$$
\begin{aligned}
& \mathrm{P}_{1}=\text { large spherical pores, } \\
& \mathrm{P}_{2}=\text { small spherical manufacturing pores, } \\
& \mathrm{P}_{3}=\text { small spherical intragranular gas bubbles or pores, } \\
& \mathrm{P}_{4}=\text { lenticular grain face bubbles or pores, and } \\
& \mathrm{P}_{5}=\text { toroidal grain edge bubbles or pores. }
\end{aligned}
$$

In these definitions, large (small) refer to pores greater than (less than) $5 \mu \mathrm{m}$ in diameter. The first term $\left(1-\mathrm{P}_{1}\right)$ comes from measurements on $\mathrm{UO}_{2}$ containing large, spherical pores that were deliberately introduced in the sample. The 2.5 exponent is based on the experimental evidence that led to Eq. (17). The higher power of 3.5 for the third bracket is a recognition that the aspect ratios of lenticular and toroidal pores are higher than those associated with small spherical pores. Because this equation has more physical basis than the simpler Loeb and Maxwell-Euken equations and also Eq. (17) and does not have the complexity of Schulz's analytical expressions, it is recommended. 


\section{REFERENCES}

1. J. H. Harding and D. G. Martin, A Recommendation for the Thermal Conductivity of $\mathrm{UO}_{2}$, J. Nucl. Mater. 166, 223-226 (1989).

2. D. G. Martin, A Re-Appraisal of the Thermal Conductivity of $\mathrm{UO}_{2}$ and Mixed (U,Pu) Oxide Fuels, J. Nucl. Mater. 110, 73-94 (1982).

3. A. B. G. Washington, Preferred Values for the Thermal Conductivity of Sintered Ceramic Fuel for Fast Reactor Use, UKAEA Report TRG Report 2236 (D) (1973).

4. R. Brandt and G. Neuer, Thermal Conductivity and Thermal Radiation Properties of $\mathrm{UO}_{2}$, J. Non-Equilib. Thermodyn. 1, 3-23 (1976).

5. J. B. Ainscough, Springfields Nuclear Power Development Laboratories, unpublished work (1972) as referenced by M. Martin in J. Nucl. Mater. 110, 73-94 (1982).

6. J. G. Killeen, Berkeley Nuclear Laboratories, unpublished work (1980) as shown by M. Martin in J. Nucl. Mater. 110, 73-94 (1982).

7. J. K. Horhorst, editor, SCADAP/RELAP5/MOD2 Code Manual Vol. 4: MATPRO - a library of materials properties for light-water-reactor accident analysis, EG\&G Idaho Report NUREG/CR-5273 (1990).

8. J. K. Fink, M. G. Chasanov, and L. Leibowitz, Thermal Conductivity and Thermal Diffusivity of Solid $\mathrm{UO}_{2}$, Argonne National Laboratory Report ANL-CEN-RSD-81-3 (June 1981).

9. J. K. Fink, M. G. Chasanov, and L. Leibowitz, Thermophysical Properties of Uranium Dioxide, J. Nucl. Mater. 102, 17-25 (1981); also as ANL Report ANL-CEN-RSD-80-3, Argonne National Laboratory (April 1981).

10. J. L. Bates, High-Temperature Thermal Conductivity of 'Round Robin' Uranium Dioxide, Battelle Memorial Institute Pacific Northwest Laboratories, Richland, Washington (July 1970).

11. J. C. Weilbacher, Measurement of Thermal Diffusivity of Mixed Uranium Plutonium Oxides, CEA Report CEA-R-4572, Centre d'Etudes Nucléairs de Fontenay-aux Roses, France (1974).

12. J. C. Weilbacher, Diffusivité Thermique de l'Oxyde d'Uranium et de l'Oxyde de Thorium à Haute Temperature, High Temp.-High Pressures 4, 431-438 (1972). 
13. J. H. Harding, D. G. Martin, and P. E. Potter, Thermophysical and Thermochemical Properties of Fast Reactor Materials, Commission of the European Communities Report EUR 12402 EN (1989).

14. J. C. Stora, B. de Bernardy de Sigoyer, R. Delmas, P. Deschamps, B. Lavaud, and C. Ringot, Conductibilite Thermique de l'UO ${ }_{2}$ Fritté dans les Conditions d'Utilisation en Pile, CEA Report CEA-R-2586, Centre d'Etudes Nucléaires de Saclay, France (1964).

15. G. J. Hyland, Thermal Conductivity of Solid $\mathrm{UO}_{2}:$ Critique and Recommendation, J. Nucl. Mater. 113, 125-132 (1983).

16. H. E. Schmidt, Some Considerations on the Thermal Conductivivty of Stoichiometric Uranium Dioxide at High Temperatures, J. Nucl. Mater 39, 234-237 (1971)

17. J. C. Killeen, The Effect of Niobium Oxide Additions on the Electrical Conductivity of $\mathrm{UO}_{2}$, J. Nucl. Mater 88, 185-192 (1980).

18. D. G. Martin, The Elastic Constants of Polycrystalline UO2 and (U,Pu) Mixed Oxides: A Review and Recommendations, High Temp.-High Pressures 21, 13-24 (1989).

19. N. J. Dudney, R. L. Coble, and H. L. Tuller, electrical Conductivity of Pure and YttriaDoped Uranium Dioxide, Am. Ceram. Soc. 64, 627-631 (1981).

20. R. N. Hampton, G. A. Saunders, A. M. Stoneham and J. H. Harding, The Electrical Impedance of Single-Crystal Urania at Elevated Temperatures, J. Nucl. Mater 154, 245-252 (1988).

21. J. L. Bates, Electrical Conductivity of $\mathrm{UO}_{2}$, Pacific Northwest Laboratory Report BNWL296 Pt. 2 (November 1967).

22. H. Marchandise, Conductibilite Thermique du Dioxyde d'Uranium, Commission of the European Communities Report EUR4568f (November 1970).

23. J. K. Fink, Enthalpy and Heat Capacity of the Actinide Oxides, Int. J. Thermophys. 3(2), 165-200 (1982).

24. D. G. Martin, The Thermal Expansion of solid $\mathrm{UO}_{2}$ and (U,Pu) Mixed Oxides - A Review and Recommendations, J. Nucl. Mater. 152 94-101 (1988).

25. M. T. Hutchings, High-Temperature Studies of $\mathrm{UO}_{2}$ and $\mathrm{ThO}_{2}$ using Neutron Scattering Techniques, J. Chem. Soc. Faraday Trans. II 83, 1083-1103 (1987). 
26. K. Bakker, H. Kwast, and E. H. P. Cordfunke, Determination of a Porosity Correction Factor for the Thermal Conductivity of Irradiated $\mathrm{UO}_{2}$ Fuel by Means of the Finite Element Method, J. Nucl. Mater. 226 128-143 (1995).

27. B. Schulz, Thermal Conductivity of Porous and Highly Porous Materials, High Temp.-High Pressure 13, 649-660 (1981)and KFK 1988 (1974). 
Table 7.1.1 Recommended Thermal Conductivity of Theoretically Dense $\mathrm{UO}_{2}$

\begin{tabular}{|c|c|}
\hline $\begin{array}{c}\text { Temperature } \\
\mathbf{K}\end{array}$ & $\begin{array}{c}\text { Thermal Conductivity } \\
\mathbf{W ~ m}^{-1} \mathrm{~K}^{-1}\end{array}$ \\
\hline $\begin{array}{l}298.15 \\
300 \\
400 \\
500\end{array}$ & $\begin{array}{l}9.80 \\
9.76 \\
8.06 \\
6.86 \\
\end{array}$ \\
\hline $\begin{array}{c}600 \\
700 \\
800 \\
900 \\
1000 \\
\end{array}$ & $\begin{array}{l}5.97 \\
5.29 \\
4.75 \\
4.30 \\
3.94 \\
\end{array}$ \\
\hline $\begin{array}{l}1100 \\
1200 \\
1300 \\
1400 \\
1500 \\
\end{array}$ & $\begin{array}{l}3.63 \\
3.37 \\
3.14 \\
2.96 \\
2.80 \\
\end{array}$ \\
\hline $\begin{array}{l}1600 \\
1700 \\
1800 \\
1900 \\
2000 \\
2000 \\
\end{array}$ & $\begin{array}{l}2.67 \\
2.57 \\
2.50 \\
2.46 \\
2.45 \\
2.45 \\
\end{array}$ \\
\hline $\begin{array}{l}2100 \\
2200 \\
2300 \\
2400 \\
2500 \\
\end{array}$ & $\begin{array}{l}2.47 \\
2.52 \\
2.59 \\
2.69 \\
2.81 \\
\end{array}$ \\
\hline $\begin{array}{l}2600 \\
2670 \\
2700 \\
2800 \\
2900 \\
3000 \\
\end{array}$ & $\begin{array}{l}2.95 \\
3.06 \\
3.11 \\
3.29 \\
3.49 \\
3.69 \\
\end{array}$ \\
\hline $\begin{array}{l}3100 \\
3120 \\
\end{array}$ & $\begin{array}{l}3.91 \\
3.95 \\
\end{array}$ \\
\hline
\end{tabular}




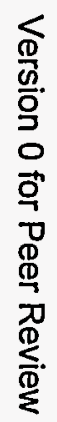

$\mathrm{UO}_{2}$ Thermal Conductivity, W/(m K)

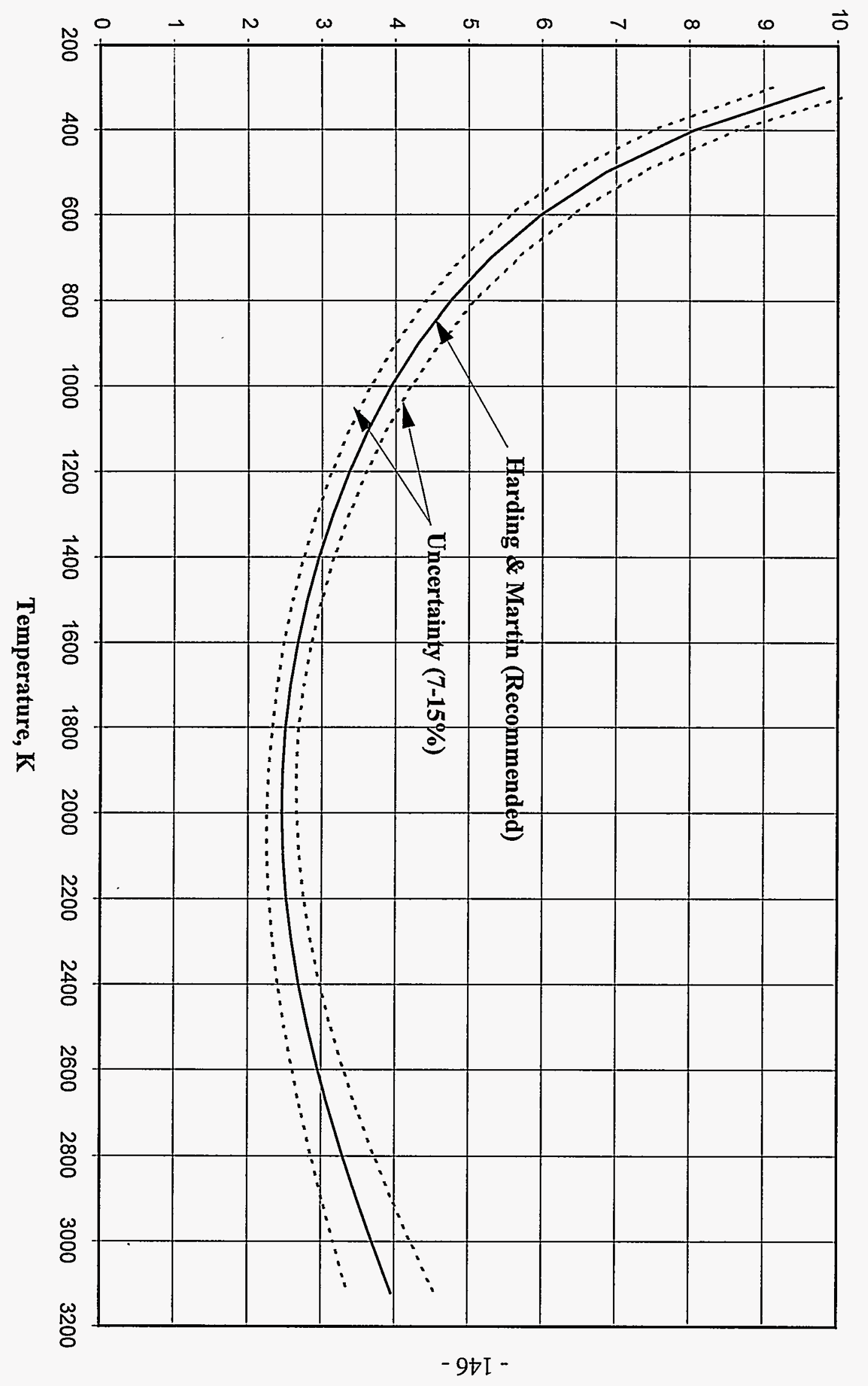

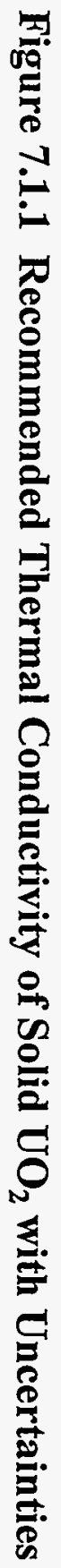

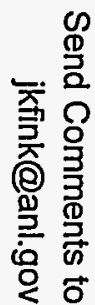


Figure 7.1.2 Comparison of Equations for the Thermal Conductivity of Solid $\mathrm{UO}_{2}$

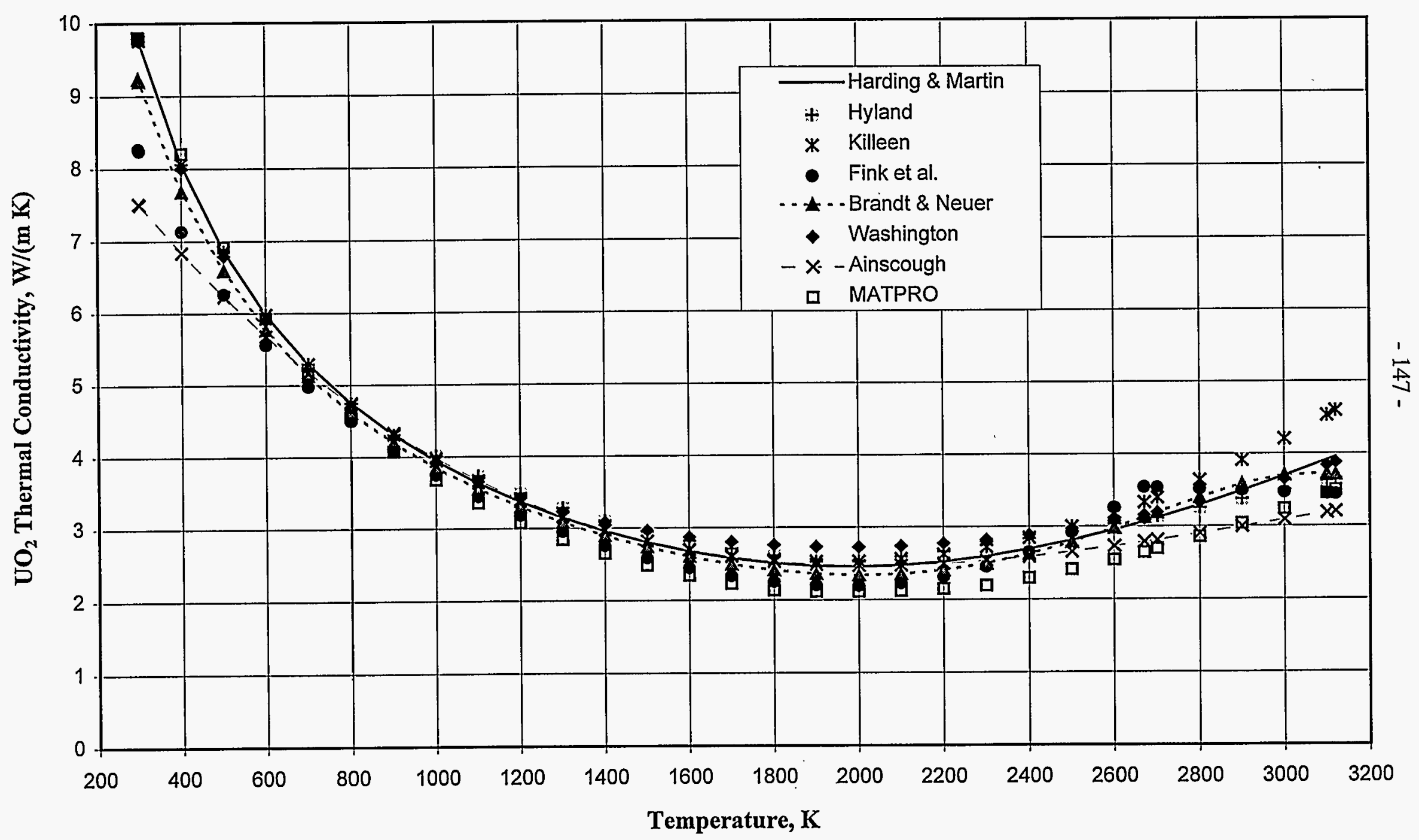

Send Comments to 
Figure 7.1.3 Deviations from $\mathrm{UO}_{2}$ Thermal Conductivity Eq. of Harding \& Martin

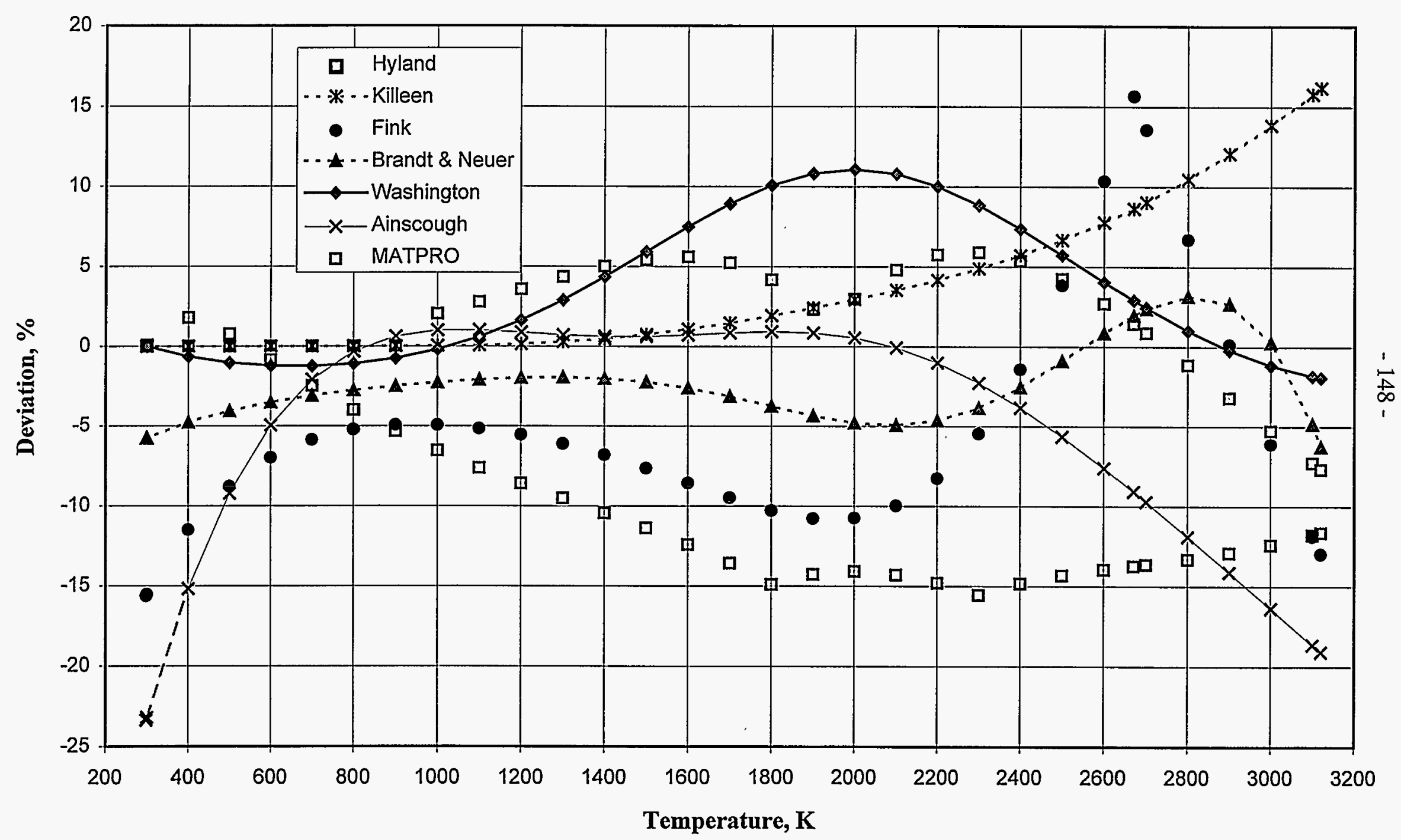




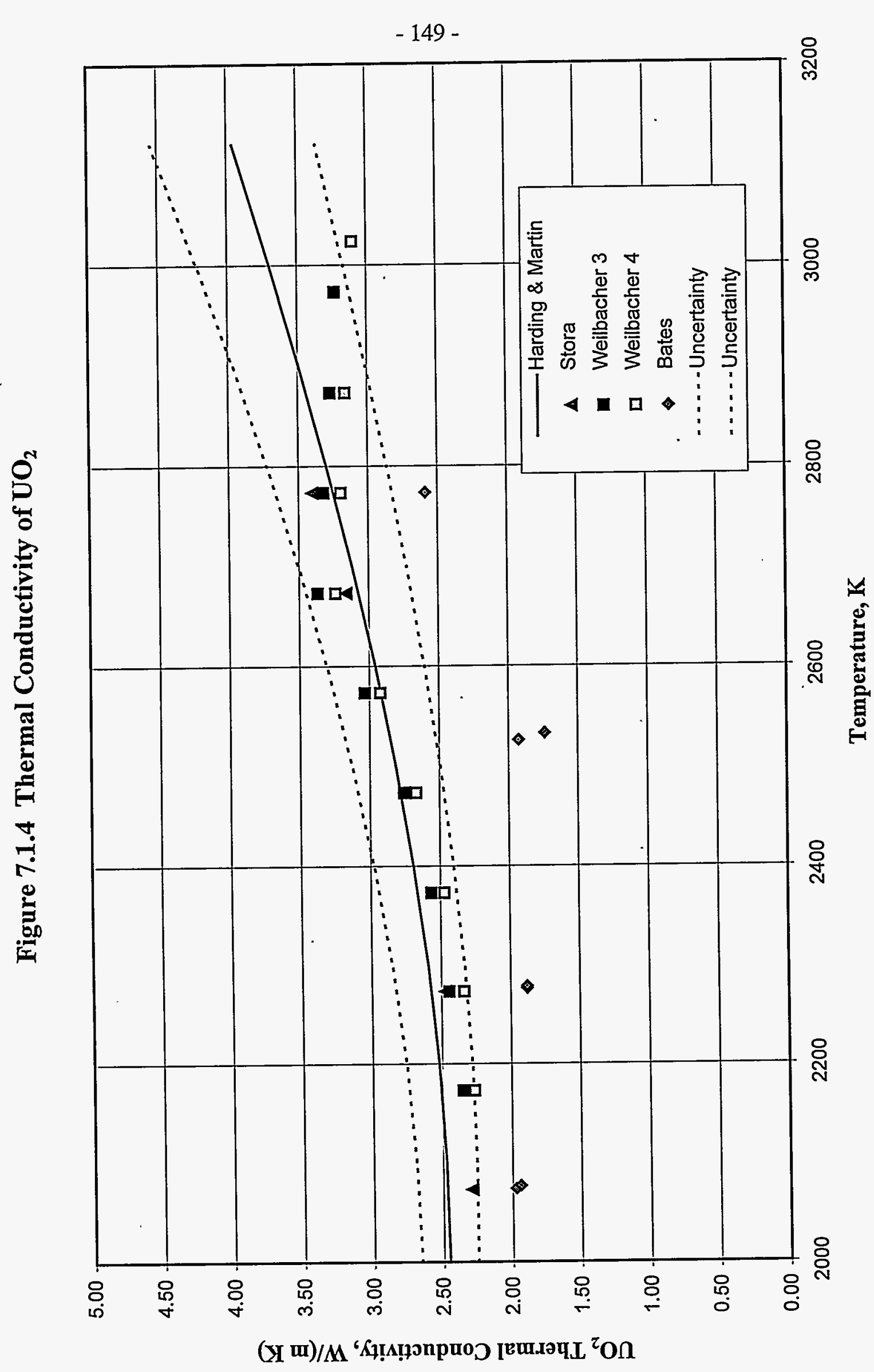

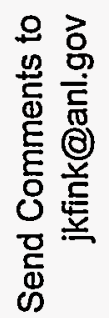

: 


\subsection{THERMAL CONDUCTIVITY AND DIFFUSIVITY OF LIQUID UO \\ Preliminary Recommendation}

Based on an initial review of the limited data ${ }^{1-4}$ on the thermal conductivity and thermal diffusivity of liquid $\mathrm{UO}_{2}$, the liquid thermal conductivity is in the range of 2.5 to $3.6 \mathrm{~W} \mathrm{~m}^{-1} \mathrm{~K}^{-1}$. Liquid thermal diffusivities range from $6 \times 10^{-7}$ to $11 \times 10^{-7} \mathrm{~m}^{2} \mathrm{~s}^{-1}$.

\section{Experiments}

The available data on the thermal conductivity $(\mathrm{k})$ and thermal diffusivity $(\alpha)$ of liquid $\mathrm{UO}_{2}$ are summarized in Table 7.2.1. Measurements of thermal diffusivity were made by Kim et al. ${ }^{1}$ and by Otter and Damien. ${ }^{2}$ Tasman et al. ${ }^{3,4}$ measured thermal conductivity. The measurements by Kim et al. and by Otter and Damien were based on standard methods for obtaining the thermal diffusivity.

Kim et al. ${ }^{1}$ used a modulated electron beam technique to measure the thermal diffusivity of $\mathrm{UO}_{2}$ in the temperature range of 3187 to $3310 \mathrm{~K}$. A thin $\mathrm{UO}_{2}$ sample clad in tungsten was heated by two electron beams. The top beam was modulated sinusoidally and the difference in phase between the top and bottom temperatures was measured. The thermal diffusivity was determined from the phase changes. Measurements were made on two thicknesses of $\mathrm{UO}_{2}(0.813$ and 1.219 $\mathrm{mm}$ ) and three modulated frequencies: $0.25 \mathrm{~Hz}\left(\pi / 2 \mathrm{rad} \mathrm{s}^{-1}\right), 0.50 \mathrm{~Hz}\left(\pi \mathrm{rad} \mathrm{s}^{-1}\right)$, and $0.75 \mathrm{~Hz}(3 \pi / 2$ $\mathrm{rad} \mathrm{s}^{-1}$ ). The tungsten above and below the $\mathrm{UO}_{2}$ layer was 1.397 and $1.016 \mathrm{~mm}$ thick. In the reanalysis ${ }^{5}$ of the data of Kim et al., ${ }^{1}$ an error was found in the original analysis by Kim et al. ${ }^{1}$ The reanalysis included (1) the ideal calculation done by Kim et al., (2) an ideal model using a threedimensional unsteady-state heat transfer code that assumed infinite slabs with no sidewalls, and (3) the real case accounting for heat transfer in the tungsten sidewalls using a transient 3-dimensional unsteady-state heat transfer code. No radiative heat transfer within the liquid was modeled based on the comment of Bober ${ }^{7}$ that radiative heat transfer in the liquid would be small and could not account for the increase in thermal conductivity of the liquid. The heat transfer analysis using ideal and real models of the $\mathrm{UO}_{2}$ in the tungsten cell showed that if the thermal conductivity was low, then the ideal model was not a good approximation because wall conductivity becomes important as the conductivity of the liquid layer decreases. As shown in Table 7.2.1, a statistically significant difference was found between the thermal conductivities of the thick and thin layers. Although tungsten contamination of the samples could affect the conductivity, it would have a greater effect 
Table 7.2.1. Thermal Conductivity of Liquid $\mathrm{UO}_{2}$ from Measurements of Thermal Diffusivity and Thermal Conductivity

\begin{tabular}{|c|c|c|c|}
\hline Experiment & Kim et al. [1] & Otter \& Damien [2] & Tasman et al. [3,4] \\
\hline Property Measured & Thermal Diffusivity & Thermal Diffusivity & Thermal Conductivity \\
\hline Method & Periodic Heat Flow & Laser Flash & $\begin{array}{l}\text { Laser Heating - Melt \& } \\
\text { Ablate } \mathrm{UO}_{2} \text { self- } \\
\text { contained sample }\end{array}$ \\
\hline Sample & $\begin{array}{c}\mathrm{UO}_{2} \text { in tungsten } \\
3 \text {-layers; } \mathrm{UO}_{2} \text { layer: } \\
0.8 \mathrm{~mm}, 1.2 \mathrm{~mm}\end{array}$ & $\begin{array}{c}\mathrm{UO}_{2} \text { in tungsten } \\
3 \text {-layers; } \\
\mathrm{UO}_{2} \text { layer: } 0.7 \mathrm{~mm}\end{array}$ & $\begin{array}{l}\mathrm{UO}_{2} 6 \mathrm{~mm} \text { diam disc } \\
\text { partially molten; } \\
\text { molten layer: } 0.2 \mathrm{~mm}\end{array}$ \\
\hline $\mathrm{k}$ reported, $\mathrm{W} \mathrm{m}^{-1} \mathrm{~K}^{-1}$ & 11 & 8.5 & $2.0-2.4 ;$ mean $2.2[3]$ \\
\hline $\begin{array}{l}\text { Re-evaluated 3-dim. } \\
\text { transient heat transfer } \\
\text { model }[5] \mathrm{k} \\
\mathrm{W} \mathrm{\textrm {m } ^ { - 1 }} \mathrm{K}^{-1}\end{array}$ & $\begin{array}{c}5.5(\text { mean }) \\
4.8 \text { (thin } 0.8 \mathrm{~mm} \text { ) } \\
6.2 \text { (thick } 1.2 \mathrm{~mm} \text { ) }\end{array}$ & 6.7 & 4.5 \\
\hline $\begin{array}{l}\text { Corrected 3-dim } \\
\text { transient heat transfer } \\
\text { calculation [5] using } \\
\text { Cp of Ronchi et al. [6] } \\
\mathrm{k}, \mathrm{W} \mathrm{m} \mathrm{m}^{-1} \mathrm{~K}^{-1}\end{array}$ & $\begin{array}{l}3.9 \text { (thin) } \\
5.1 \text { (thick) }\end{array}$ & 5.8 & 3.3 \\
\hline 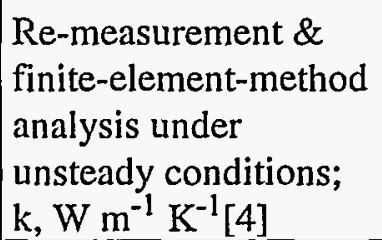 & & & $2.5[4]$ \\
\hline
\end{tabular}

in the thin cell than in the thick cell and give the larger conductivity for the thin cell. Lack of good contact between the tungsten and the liquid could also affect the experimental results. The difference between the thin and thick cell results is analogous to differences observed in diffusivity measurements of materials in which radiation is important and cannot be neglected. ${ }^{8,9}$ The main uncertainties in this experiment are effects from radiative heat transfer in the liquid and effects from changes in the $\mathrm{O} / \mathrm{M}$ ratio in the $\mathrm{UO}_{2}$ due to tungsten contamination in the liquid $\mathrm{UO}_{2}$ sample.

Otter and Damien ${ }^{2}$ measured the thermal diffusivity of a $0.7-\mathrm{mm}$ layer of liquid $\mathrm{UO}_{2}$ encased in tungsten using a laser flash method in the temperature range of 3133 to $3273 \mathrm{~K}$. Although this 
method is well established, analysis of the data becomes more complex at high temperatures with liquids encased in metal cells because of the necessity of including thermal losses to the environment and the need for properties such as heat capacity, density, and thermal conductivity of the metal containment. ${ }^{10}$ The reanalysis ${ }^{5}$ of their experiment gave lower thermal conductivities than those originally reported by Otter and Damien. Insufficient information is available regarding their experiment and heat losses to determine if the differences are due to different treatment of heat losses in the reanalyzed three-dimensional transient heat transfer calculation. Radiation within the sample was not included in the reanalysis. If radiative heat transfer was significant in the experiments of Kim et al., it would also affect the experiment of Otter and Damien. In addition, errors from tungsten contamination of the sample cannot be ruled out.

Tasman et al. ${ }^{3}$ determined the thermal conductivity of liquid $\mathrm{UO}_{2}$ from a steady-state finite element analysis of the heat transfer in a partially molten, self-contained sample. $\mathrm{A} \mathrm{UO}_{2}$ disc $(6 \mathrm{~mm}$ in diameter by 1.2 - to 3-mm thick) was heated in an argon atmosphere at 4 bar ( $0.4 \mathrm{MPa})$ using three continuous-wave $\mathrm{CO}_{2}$ laser beams. One laser beam was focused on a $4 \mathrm{~mm}$ diameter area on the bottom of the disc; two laser beams were focused on area $2 \mathrm{~mm}$ in diameter on the top of the disc. The sample was heated with only the bottom beam until it reached $1800^{\circ} \mathrm{C}(2073 \mathrm{~K})$. Then the upper beams were turned on and a molten pool was formed on the top of the sample. Temperatures were measured with optical pyrometers and a fast scanning device. During heating, only the bottom temperature was measured. The peak top temperature was $3200^{\circ} \mathrm{C}(3473 \mathrm{~K})$. Because of extensive vaporization of the sample, the top of the sample could be heated for only 4-5 sec. When heated longer, extensive evaporation created a deep pit in the top center of the sample and part of the ejected material was deposited in crystalline form along the center crater edge. Even on short (5-sec) exposures, recondensed crystals were found. Sample loss from evaporation was limited to less than $2 \mathrm{mg}(0.5 \%)$ if the exposure to the upper beams was limited to $5 \mathrm{sec}$. However, it is not clear how much sample mass was redistributed by vaporization and condensation on cooler parts of the sample during the $5 \mathrm{sec}$ exposure to the upper beam. Significant vaporization of $\mathrm{UO}_{2}$ began at $2300^{\circ} \mathrm{C}$ $(2573 \mathrm{~K})$, which is well below the melting point, $3120 \mathrm{~K}$. Tasman et al. ${ }^{3}$ stated that the largest uncertainty in their experiment was the temperature measurement and temperature profile of the top and bottom faces. Because these profiles are critical input in the analysis of the experiment, there 
is significant uncertainty in the calculated results. The precision of the experiment is limited by the presence of very high radiai temperature gradients and axial asymmetries. However, the error is bounded by the depth of the molten layer, which was determined after solidification from examination of cross sections of the sample. The reliability of visual observation of the liquid depth was questioned ${ }^{5}$ based on (1) low melting points (2661 and $2699 \mathrm{~K}$ ) obtained by early investigators ${ }^{11}$ from the appearance of residues and (2) the observed ${ }^{12}$ softening and plasticity of $\mathrm{UO}_{2}$ above about $2500 \mathrm{~K}$ where the Frenkel oxygen lattice disorder increases as the phase transition is approached. Above $2670 \mathrm{~K}$, the creep rate also increases significantly, ${ }^{12}, 13$ so $\mathrm{UO}_{2}$ readily deforms to the shape of its container. Ronchi ${ }^{14}$ commented that in the short duration of the experiment of Tasman et al. $(\sim 10 \mathrm{sec})$, the grain growth is approximately $10 \mu \mathrm{m}$ at $2700 \mathrm{~K}^{13}$ and is estimated to be only 5 times larger at $3050 \mathrm{~K}$. He, therefore, concluded that the solid grains are still recognizable at temperatures near the melt front so that the liquid phase is readily distinguished. The reanalysis of this experiment by Fink and Leibowitz ${ }^{5}$ indicated that the assumption of steady state conditions made by Tasman et al. ${ }^{3}$ makes a significant difference in the resulting thermal conductivity.

Tasman ${ }^{4}$ repeated his experiment using a rapid 2D temperature-scanning device and included unsteady transport in the 2D finite-element method (f.e.m.) analysis. His correction was less than that reported by Fink and Leibowitz. ${ }^{5}$ He claimed that perturbations that cannot be accounted for in his analysis would lead to lower values in the thermal conductivity. ${ }^{14}$ He concluded that the thermal conductivity of liquid $\mathrm{UO}_{2}$ is $2.5 \pm 1 \mathrm{~W} \mathrm{~m}^{-1} \mathrm{~K}^{-1}$, which is lower than the thermal conductivity of the solid at the melting point given by Harding and $\operatorname{Martin}^{15}\left(3.95 \mathrm{~W} \mathrm{~m}^{-1} \mathrm{~K}^{-1}\right)$ and by Hyland ${ }^{16}\left(3.65 \mathrm{~W} \mathrm{~m}^{-1} \mathrm{~K}^{-1}\right)$. The thermal conductivity equation for solid $\mathrm{UO}_{2}$ of Harding and Martin includes a phonon lattice contribution and an electronic contribution from small polarons, whereas Hyland also included a radiation contribution. At the melting point, the electronic contribution calculated by Harding and Martin is $2.56 \mathrm{~W} \mathrm{~m}^{-1} \mathrm{~K}^{-1}$, which is slightly higher than the value for the thermal conductivity of the liquid obtained by Tasman. The electronic, radiation, and lattice contributions to the solid thermal conductivity at the melting point determined by Hyland are $1.55 \mathrm{~W} \mathrm{~m}^{-1} \mathrm{~K}^{-1}, 0.2 \mathrm{~W} \mathrm{~m}^{-1} \mathrm{~K}^{-1}$, and $2.1 \mathrm{~W} \mathrm{~m}^{-1} \mathrm{~K}^{-1}$, respectively. The radiative contribution calculated by Hyland was $0.48 \mathrm{~W} \mathrm{~m}^{-1} \mathrm{~K}^{-1}$, but he assumed a $50 \%$ uncertainty because this value was 
higher than needed for good agreement with experimental total thermal conductivities. Differences in the lattice and electronic contributions to the thermal conductivity of the solid in these two calculations are related to the different data used in the models. Because of these differences, no conclusions with regard to the reliability of the measurement of Tasman can be made from comparison with contributions to the solid thermal conductivity at the melting point.

\section{Discussion}

Ronchi et al. ${ }^{6}$ determined the heat capacity of liquid $\mathrm{UO}_{2}$ from the melting point to $8000 \mathrm{~K}$ by heating sintered 0.5 - to $1-\mathrm{mm}$ diameter microspheres by four tetrahedrally oriented laser beams in an inert autoclave at pressures up to 1000 bar. The samples were suspended by a tungsten needle during pulses of a few milliseconds duration. The heat capacity was calculated numerically from the energy input, the sample temperature during and after laser pulse heating, the energy loss rates, the cooling mechanisms (radiation and convection), and the heat transport within the sample. The accuracy of the calculation depended on the symmetry (of the temperature field from the lasers and the sample shape) and the accuracy of the physical properties (density and thermal conductivity) used in the heat transport analysis. In the calculations, Ronchi et al. ${ }^{6}$ used $2.5 \mathrm{~W} \mathrm{~m}^{-1} \mathrm{~K}^{-1}$ for the thermal conductivity of liquid $\mathrm{UO}_{2}$. However, they commented that selection of a higher value for the thermal conductivity of the liquid would result in a lower heat capacity. The thermal conductivity values in the next-to-the-last row of Table 7.2.1 are the values of thermal conductivity from the reanalysis of Fink and Leibowitz ${ }^{5}$ adjusted for the heat capacities of Ronchi et al. Although the new heat capacity values reduce the thermal conductivities calculated by Fink and Leibowitz, ${ }^{5}$ the calculated thermal conductivities are not as low as the value reported by Tasman. ${ }^{4}$ However, the corrected value calculated for the experiment of Tasman et al. ${ }^{3}$ is within the original uncertainty given by Tasman et al. ${ }^{3,4}$

Because the heat capacities obtained by Ronchi et al. ${ }^{6}$ are a function of the value selected for the thermal conductivity and are consistent with the value reported by $\operatorname{Tasman}^{4}$ and all other data in Table 7.2.1 are from thermal diffusivity measurements, thermal diffusivities should be compared instead of thermal conductivities. The temperature at which the thermal conductivity of liquid $\mathrm{UO}_{2}$ was remeasured by Tasman ${ }^{4}$ has not been reported by Ronchi et al. ${ }^{6,14}$ In their analysis of their heat capacity data, Ronchi et al. ${ }^{13}$ assumed that the liquid thermal conductivity is constant at 2.5 
$\mathrm{Wm}^{-1} \mathrm{~K}^{-1}$ for the liquid temperature range $(3120-8000 \mathrm{~K})$. It is not clear if their observed variation in heat capacity with temperature is real or is due, in part, to this assumption of constant thermal conductivity. In any case, the thermal diffusivity calculated using the heat capacities $\left(\mathrm{C}_{\mathrm{P}}\right)$ of Ronchi et al. ${ }^{6,13}$ and constant thermal conductivity $(\mathrm{k})$ of $2.5 \mathrm{~W} \mathrm{~m}^{-1} \mathrm{~K}^{-1}$ is consistent with the analytical treatment of the heat capacity data of Ronchi et al. ${ }^{6,13}$ The liquid $\mathrm{UO}_{2}$ densities $(\rho)$ of Breitung and Reil, ${ }^{17}$ which agree with the values of Drotning, ${ }^{18}$ have been used in the conversion to thermal diffusivity $(\alpha)$ via the relationship

$$
\alpha=\frac{k}{C_{P} \rho}
$$

Thermal diffusivities from the most recent measurements of $\operatorname{Tasman}^{4}$ and the thermal diffusivity experiments of Otter and Damien ${ }^{2}$ and Kim et al. ${ }^{1}$ are given in Table 7.2.2.

Ronchi ${ }^{14}$ commented that diffusivity in crystals decreases with temperature due to increased anharmonic vibrations caused by defects, impurities, and lattice strains. Below $2500 \mathrm{~K}$, the behavior of the thermal diffusivity of $\mathrm{UO}_{2}$ is in accord with this crystalline behavior. As the $\lambda$ phase transition at $2670 \mathrm{~K}$ is approached, the number of phonon scattering centers increases. Above the $\lambda$ phase transition, the concentration of Frenkel pairs in the oxygen sublattice approaches $0.2,{ }^{13}$ so the lattice has a very high degree of disorder similar to an amorphous or glassy material. Ronchi ${ }^{14}$ commented that materials that have both crystalline and glassy forms (e.g., $\mathrm{SiO}_{2}$ ) have a different temperature dependence for the thermal diffusivity in the two forms (decreasing for the crystal; increasing for the glassy phase). ${ }^{14}$ In metals and alloys that undergo order/disorder $\lambda$ transitions, the slope of thermal diffusivity, changes at the $\lambda$ transition from decreasing to increasing. If no transition exists, the reversal of slope normally occurs at the melting point and is often accompanied by a discontinuity in thermal diffusivity upon melting. For materials with a premelting order/disorder transition, the thermal diffusivity typically increases continuously across the melting point. ${ }^{14}$ In Figure 7.2.1, the thermal diffusivities of liquid $\mathrm{UO}_{2}$ from the measurements of Kim et al., ${ }^{1}$ Otter and Damien, ${ }^{2}$ and Tasman ${ }^{4}$ are compared with thermal diffusivities of solid $\mathrm{UO}_{2}$ near the melting point. The solid values are from thermal diffusivity measurements by Weilbacher ${ }^{19,20}$ and the thermal conductivity equations of Harding and Martin ${ }^{15}$ and of Hyland. ${ }^{16}$ The thermal 
Table 7.2.2 Thermal Diffusivity of Liquid $\mathrm{UO}_{2}$ from Measurements of Thermal Diffusivity and. Thermal Conductivity

\begin{tabular}{|c|c|c|c|}
\hline Experiment & Kim et al. [1] & $\begin{array}{c}\text { Otter \& Damien } \\
{[2]} \\
\end{array}$ & Tasman et al. $[3,4]$ \\
\hline Property Measured & Thermal Diffusivity & Thermal Diffusivity & Thermal Conductivity \\
\hline Method & Periodic Heat Flow & Laser Flash & $\begin{array}{l}\text { Laser Heating - Melt } \\
\& \text { Ablate } \mathrm{UO}_{2} \text { self- } \\
\text { contained sample }\end{array}$ \\
\hline Sample & $\begin{array}{c}\mathrm{UO}_{2} \text { in tungsten } \\
3 \text {-layers; } \mathrm{UO}_{2} \text { layer: } \\
0.8 \mathrm{~mm}, 1.2 \mathrm{~mm} \\
\end{array}$ & $\begin{array}{c}\mathrm{UO}_{2} \text { in tungsten } \\
3 \text {-layers; } \\
\mathrm{UO}_{2} \text { layer: } 0.7 \mathrm{~mm} \\
\end{array}$ & $\begin{array}{c}\mathrm{UO}_{2} 6 \mathrm{~mm} \text { diam disc } \\
\text { partially molten; } \\
\text { molten layer: } 0.2 \mathrm{~mm}\end{array}$ \\
\hline Reported $\alpha, \mathrm{m}^{2} \mathrm{~s}^{-1}$ & $\begin{array}{c}19 \times 10^{-7}-33 \times 10^{-7} \\
*\end{array}$ & $16 \times 10^{-7}-25 \times 10^{-7}$ & - \\
\hline $\begin{array}{l}\text { Re-evaluated 3-dim. } \\
\text { transient heat transfer } \\
\text { model [5] }\end{array}$ & $\begin{array}{r}11 \times 10^{-7} \text { (thin) } \\
15 \times 10^{-7} \text { (thick) }\end{array}$ & $16 \times 10^{-7}$ & \\
\hline $\begin{array}{l}\text { Re-measurement \& } \\
\text { f.e.m. analysis under } \\
\text { unsteady conditions; } \\
\alpha, \mathrm{m}^{2} \mathrm{~s}^{-1}[4]\end{array}$ & & & $6 \times 10^{-7}-8 \times 10^{-7}$ \\
\hline
\end{tabular}

* In the assessment by Fink and Leibowitz, an error was found in the original analysis that indicated that these values reported by Kim et al. are high by about a factor of two.

conductivities were converted to thermal diffusivities using Eq. (1) and the heat capacities from the assessment by Fink ${ }^{21}$ and the densities from the assessment of Martin. ${ }^{22}$ Thermal diffusivities calculated from the thermal conductivity of Tasman ${ }^{4}$ are between the solid values of Martin and of Hyland. Based on the behavior of other materials with premelting transitions, Ronchi ${ }^{14}$ concluded that the thermal diffusivity obtained from the thermal conductivity measurement of Tasman is the most consistent with the thermal diffusivities of solid $\mathrm{UO}_{2}$.

If the $\lambda$ transition at $2670 \mathrm{~K}$ results in sufficient disorder for the thermal diffusivity to follow glassy behavior, then internal radiation, which is important for glassy materials, must also be 
considered for $\mathrm{UO}_{2}$ above this transition. In his critical analysis of the thermal conductivity of solid $\mathrm{UO}_{2}$, Hyland ${ }^{16}$ included a contribution from radiation. At the melting point, $0.48 \mathrm{~W} \mathrm{~m}^{-1} \mathrm{~K}^{-1}$ is the radiative contribution to the thermal conductivity of solid $\mathrm{UO}_{2}$ calculated by Hyland ${ }^{16}$ using the method given by Browning ${ }^{23}$ and the optical property data for solid $\mathrm{UO}_{2}$ measured by Bober et al. ${ }^{7}$ This result for the solid and the statistically significant difference between the thermal diffusivities of the thin and thick $\mathrm{UO}_{2}$ layers, which is indicative of internal radiation, ${ }^{8,9}$ imply that the radiative contribution should also be considered for the liquid. The radiative contribution to the thermal conductivity for an optically thick sample is

$$
k_{r}=\frac{16 n^{2} \sigma T^{3}}{3 \kappa_{R}}
$$

where $\mathrm{n}$ is the refractive index $\left(1.72 \text { for liquid } \mathrm{UO}_{2}\right)^{7}, \mathrm{~K}_{\mathrm{R}}$ is the Rosseland absorption coefficient, and $\sigma$ is the Stephan-Boltzmann constant. Following Hyland, ${ }^{16}$ the value of $\kappa_{R}$ was obtained from Figure 4 of Browning, ${ }^{23}$ which includes the contributions beyond the absorption edge of the material. For the liquid at the melting point, the radiative contribution to the thermal conductivity in the optically thick limit is $0.28 \mathrm{~W} \mathrm{~m}^{-1} \mathrm{~K}^{-1}$. This corresponds to corrections to the thermal diffusivity of $0.7 \times 10^{-7}$ to $0.9 \times 10^{-7} \mathrm{~m}^{2} \mathrm{~s}^{-1}$ between 3120 and $3400 \mathrm{~K}$, assuming constant thermal conductivity and thermal diffusivity variations with temperature in accord with changes in density and heat capacity. In Figure 7.2.2, the curve labeled "Tasman + Radiation" includes the optically thick radiative contribution to the thermal conductivity of Tasman. If the assumption is made that the difference in thermal diffusivities between the thick and thin layers of $\mathrm{UO}_{2}$ in the experiment of Kim et al. arises from failure to include the radiative term in the analysis, and the radiative contribution scales according to the thickness of the $\mathrm{UO}_{2}$ layer, the experimental thermal diffusivity of a $0.2 \mathrm{~mm}$ thickness of $\mathrm{UO}_{2}$ (thickness of the molten layer in the experiment of Tasman ${ }^{3}$ ) can be estimated. For the temperatures of 3250 and $3277 \mathrm{~K}$, this estimate gives thermal diffusivities in the range of 5.8 $\times 10^{-7} \mathrm{~m}^{2} \mathrm{~s}^{-1}$ and $6.7 \times 10^{-7} \mathrm{~m}^{2} \mathrm{~s}^{-1}$. These values, shown in Figure 7.2.2, are slightly lower than the values calculated from the thermal conductivity of $\operatorname{Tasman}^{4}$ using the heat capacities of Ronchi et al. $^{6}$ and densities of Breitung and Reil. ${ }^{17}$ This scaled correction is larger than the calculated 
radiative contribution due to an optically thick layer. Figure 7.2.2 includes the positive uncertainty of Tasman and a corresponding negative uncertainty $(-40 \%)$ in the thermal diffusivities from the 0.813-mm layer measurements of Kim et al. These uncertainty bands overlap.

\section{Conclusion}

From these comparisons, it is reasonable to assume that $2.5 \mathrm{~W} \mathrm{~m}^{-1} \mathrm{~K}^{-1}$ (the new value reported by Tasman ${ }^{4}$ ) represents a lower limit of the thermal conductivity of liquid $\mathrm{UO}_{2}$. An upper limit of $3.6 \mathrm{~W} \mathrm{~m}^{-1} \mathrm{~K}^{-1}$ is consistent with the error limit given by Tasman and with the lower value obtained from the experiments of Kim et al. with the optically thick radiative contribution ( $0.3 \mathrm{~W}$ $\mathrm{m}^{-1} \mathrm{~K}^{-1}$ ) subtracted. Clearly, the data of Kim et al. must be reanalyzed with radiative contributions for the thickness of the $\mathrm{UO}_{2}$ layers included. Although the data of Kim et al. show systematic differences between the thick and thin layers of $\mathrm{UO}_{2}$ and the data of Otter and Damien appear to be high, these measurements are consistent in that they show little variation in thermal diffusivity with temperature. However, thermal diffusivities calculated using the constant thermal conductivity of $\operatorname{Tasman}^{4}$ and the heat capacities of Ronchi et al. ${ }^{6}$ show significant increases with temperature. From the experiments of Ronchi et al. ${ }^{6}$ it is unclear how much of the temperature variation in $C_{P}$ arises from the change in thermal conductivity with temperature. (Thermal conductivity was assumed to be constant in their analysis). Ronchi ${ }^{14}$ states that glassy ceramics show a slight increase in the thermal diffusivity with temperature and the thermal diffusivity usually increases continuously across the melting point. Because no information is available with respect to the recent thermal conductivity measurements of Tasman, ${ }^{4,14}$ the temperature of the measurement is uncertain. If the thermal diffusivity was assumed to be constant, the thermal conductivity data of Tasman and the heat capacity of Ronchi et al. at $3473 \mathrm{~K}$ would give $8.2 \mathrm{~m}^{2} \mathrm{~s}^{-1}$ for the thermal diffusivity of liquid $\mathrm{UO}_{2}$. At the melting point, this would correspond to a thermal conductivity of $3.2 \mathrm{~W} \mathrm{~m}^{-1} \mathrm{~K}^{-1}$. This is within the range of recommended values.

\section{Uncertainty}

The uncertainty in the thermal conductivity and thermal diffusivity of liquid $\mathrm{UO}_{2}$ is approximately $40 \%$, the uncertainty given by Tasman et al. ${ }^{3,4}$ 


\section{REFERENCES}

1. C. S. Kim, R. A. Haley, J. Fischer, M. G. Chasanov, and L. Leibowitz, Measurement of Thermal Diffusivity of Molten $\mathrm{UO}_{2}$, Proc. Seventh Symp. On Thermophysical Properties, A. Cezairliyan, Ed., ASME, New York, p. 338-343 (1977).

2. C. Otter and D. Damien, Mesure de la Diffusivité Thermique de $\mathrm{UO}_{2}$ Fondu, High Temp.High Pressures 16, 1-6 (1984).

3. H. A. Tasman, D. Pel, J. Richter, and H. E. Schmidt, Measurement of the Thermal Conductivity of Liquid $\mathrm{UO}_{2}$, High Temp.-High Pressures 15, 419-431 (1983).

4. H. A. Tasman, Thermal Conductivity of Liquid $\mathrm{UO}_{2}$, Commission of the European Communities Joint Research Centre Annual Report TUAR88, Karlsruhe, Germany (1988); as referenced by C. Ronchi in On the Thermal Conductivity and Diffusivity of Solid and Liquid Uranium Dioxide, J. Phys. Condens. Matter 6, L561-L567 (1994).

5. J. K. Fink and L. Leibowitz, An Analysis of Measurements of the Thermal Conductivity of Liquid Urania, High Temp.- High Pressures 17, 17-26 (1985).

6. C. Ronchi, J. P. Hiernaut, R. Selfslag, and G. J. Hyland, Laboratory Measurement of the Heat Capacity of Urania up to $8000 \mathrm{~K}$ : I. Experiment, Nuclear Science and Engineering 113, 1-19 (1993).

7. M. Bober, J. Singer, and K. Wagner, Determination of the Optical Constants of Liquid UO from Reflectivity Measurements, Proc. Eighth Symp. On Thermophysical Properties, J. V. Sengers, Ed., ASME, New York, Vol. II, p. 234-244 (1981).

8. K. C. Mills, and W. A. Wakeham, Effect of Radiation on Thermal Transport Measurements, High Temp.-High Pressures 17, 343-348 (1985).

9. S. Fischer, and E. Obermeier, Influence of Radiative Heat Transfer on the Effective Thermal Conductivity of Liquids: Experimental and Theoretical Investigation, High Temp.-High Pressures 17, 699-705 (1985).

10. C. Otter and J. Vandevelde, Contribution à l'Etude du Probleme de Thermocinétique lie à la Mesure de la Diffusivité Thermique des Materiaux Liquides a Haute Temperature par la Méthode $d u<<$ Flash Laser $>>$, Rev. Int. Hautes Temp. Refract. 19, 41-53 (1982).

11. R. J. Ackermann, The High Temperature, High Vacuum Vaporization and Thermodynamic Properties of Uranium Dioxide, Argonne National Laboratory Report ANL-5482 (1955). 
12. M. T. Hutchings, High-Temperature Studies of $\mathrm{UO}_{2}$ and $\mathrm{ThO}_{2}$ Using Neutron Scattering Techniques, J. Chem. Soc., Faraday Trans. II 83, 1083-1103 (1987).

13. C. Ronchi and G. J. Hyland, Analysis of Recent Measurements of the Heat Capacity of Uranium Dioxide, J. of Alloys and Compounds 213/214 159-168 (1994).

14. C. Ronchi, On the Thermal Conductivity and Diffusivity of Solid and Liquid Uranium Dioxide, J. Phys. Condens. Matter 6, L561-L567 (1994).

15. J. H. Harding and D. G. Martin, A Recommendation for the Thermal Conductivity of $\mathrm{UO}_{2}$, J. Nucl. Mater. 166, 223-226 (1989).

16. G. J. Hyland, Thermal Conductivity of Solid $\mathrm{UO}_{2}:$ Critique and Recommendation, J. Nucl. Mater. 113, 125-132 (1983).

17. W. Breitung and K. O. Reil, The Density and Compressibility of Liquid (U,Pu)-Mixed Oxide, Nucl. Sci. and Eng. 105, 205-217 (1990).

18. W. D. Drotning, Thermal Expansion of Molten Uranium Dioxide, Proceedings of the Eighth Symp. Thermophysical Properties, Gaithersburg, Maryland, June 15-18, 1981, J. V. Sengers, Ed., ASME, New York, Vol. II, pp 245-249 (1981).

19. J. C. Weilbacher, Measurement of Thermal Diffusivity of Mixed Uranium Plutonium Oxides, CEA Report CEA-R-4572, Centre d'Etudes Nucleairs de Fontenay-aux Roses, France (1974).

20. J. C. Weilbacher, Diffusivité Thermique de l'Oxyde d'Uraium et de l'Oxyde de Thorium à Haute Temperature, High Temp.-High Pressures 4, 431-438 (1972).

21. J. K. Fink, Enthalpy and Heat Capacity of the Actinide Oxides, Int. J. Thermophys. 3(2), 165-200 (1982).

22. D. G. Martin, The Thermal Expansion of Solid $\mathrm{UO}_{2}$ and $(U, P u)$ Mixed Oxides - A Review and Recommendations, J. Nucl. Mater. 152 94-101 (1988).

23. P. Browning, On the Relative Importance of the Electronic and Radiative Contributions to the Thermal Conductivity of Uranium Dioxide, J. Nucl. Mater. 92 33-38 (1982). 
Figure 7.2.1 $\mathrm{UO}_{2}$ Thermal Diffusivity

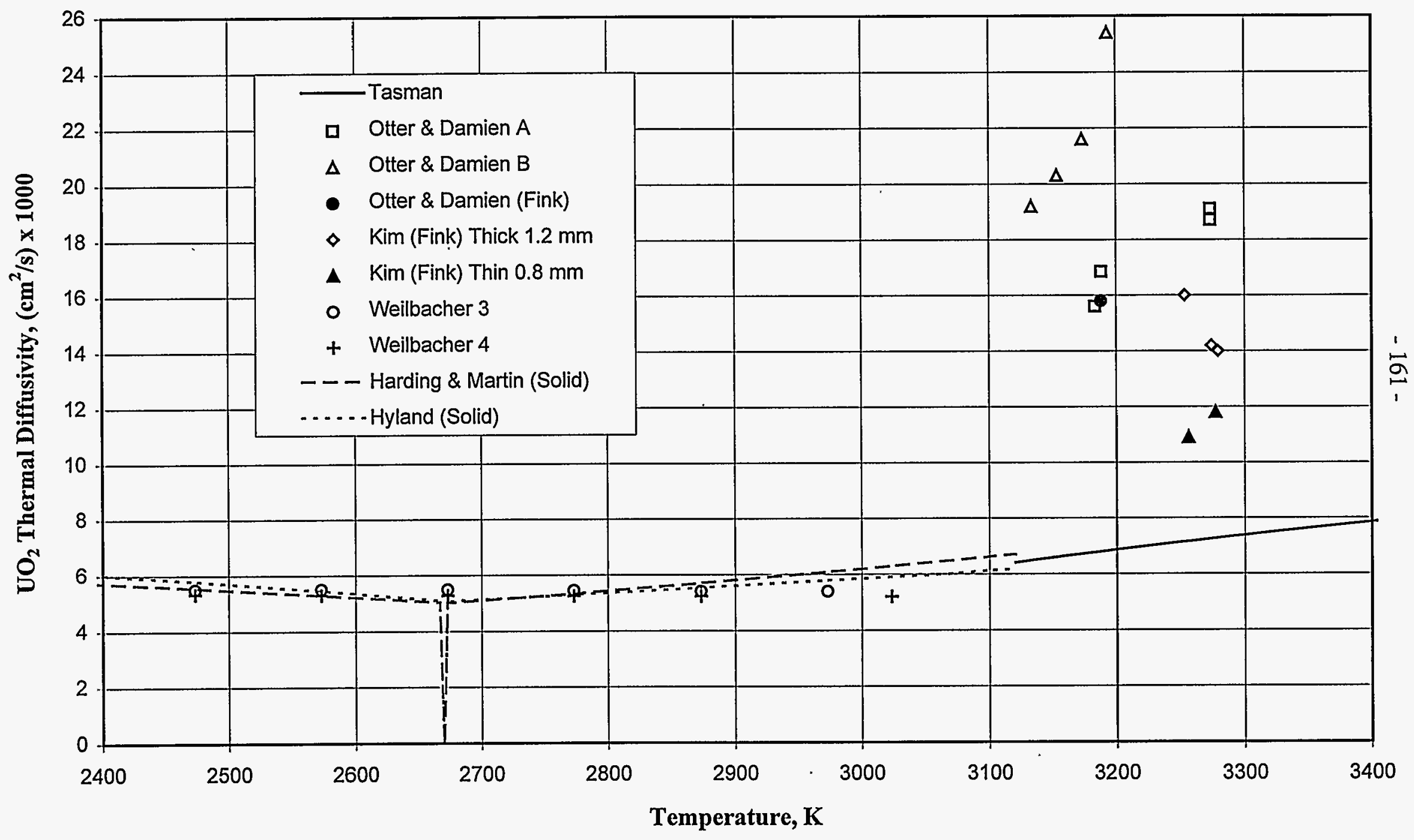


Figure 7.2.2 $\mathrm{UO}_{2}$ Thermal Diffusivity

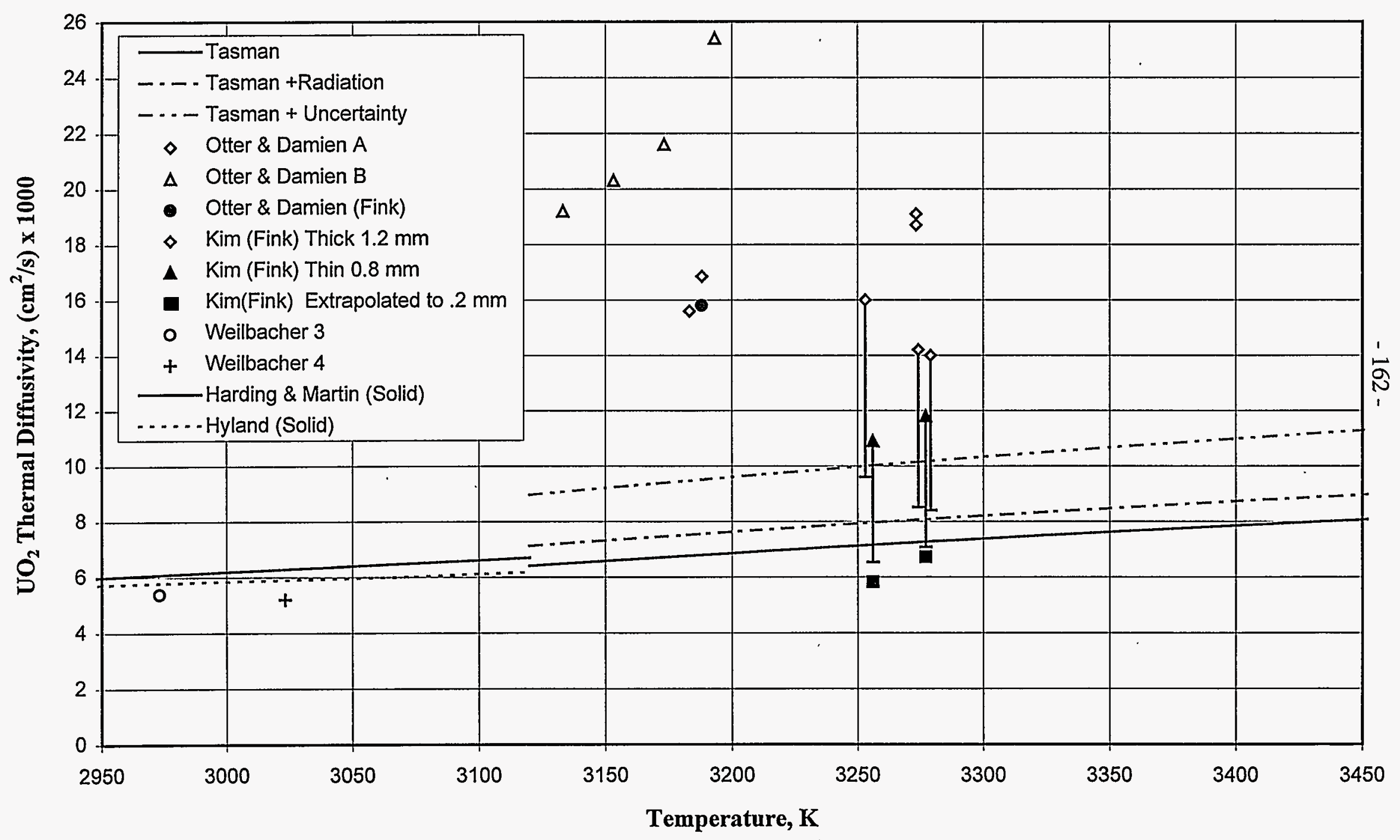




\section{VISCOSITY OF LIQUID URANIUM DIOXIDE}

\section{Summary and Recommendation}

Viscosities of liquid uranium dioxide have been measured in the temperature range of 3143 to $3303 \mathrm{~K}$ by Woodley, ${ }^{1}$ at the melting point $\left(3120 \mathrm{~K}\right.$ ) by Palinski, ${ }^{2}$ and from 3083 to $3328 \mathrm{~K}$ by Tsai and Olander. ${ }^{3}$ The recommended equation is that of Woodley because of the greater precision of his data and the agreement between Woodley and Palinski. The Woodley equation is

$$
\eta=0.988 \exp \left(\frac{4620}{T}\right)
$$

where the kinematic viscosity, $\eta$, is in centipoise ( $\mathrm{mPa} \mathrm{s}$ ) and $\mathrm{T}$ is in $\mathrm{K}$. Recommended values are given in Table 8.1 as a function of temperature and graphed in Figure 8.1. The data of Woodley, ${ }^{1}$ Palinski, ${ }^{2}$ and Tsai and Olander ${ }^{3}$ as well as estimated uncertainties have been included in Figure 8.1.

\section{Uncertainties}

The uncertainty in the available data is difficult to estimate because of the lack of hightemperature viscosity standards. For the temperature range of 3120 to $3400 \mathrm{~K}$, the error is estimated as $\pm 25 \%$. The uncertainty of extrapolated viscosities in the temperature range of 3400 to $4000 \mathrm{~K}$ is estimated as $\pm 50 \%$.

\section{Discussion}

Figure 8.2 shows the viscosity data of Woodley, ${ }^{1}$ Tsai and Olander, ${ }^{3}$ and Palinski. ${ }^{2}$ Tsai and Olander made measurements on two different samples. Their viscosities are higher than the values of Woodley and of Palinski and lack the precision of the data of Woodley. In addition, the Tsai and Olander data for the second sample are consistently higher than for the first sample, indicating a possible systematic error. Tsai and Olander gave the melting point of $\mathrm{UO}_{2}$ as $3073 \mathrm{~K}$ (not $3120 \mathrm{~K}$ ) so that their lowest temperature datum, $9.2 \mathrm{cP}(\mathrm{mPa} \mathrm{s})$ at $3083 \mathrm{~K}$, is at a temperature that they consider to be completely liquid. They commented that their low melting point may be due to temperature measurement errors, change in stoichiometry of their samples, or contamination of their melt by the tungsten crucible. Figure 8.2 shows that Woodley's two series of measurements on the same encapsulated sample are in good agreement and in reasonable agreement with the datum of Palinski. The viscosity of $\mathrm{UO}_{2.003}$ at the melting point measured by Palinski ${ }^{2}$ is $4.6 \mathrm{cP}(4.6 \mathrm{mPa} \mathrm{s})$ 
which is within $7 \%$ of the value $(4.3 \mathrm{cP})$ obtained with Eq. (1), given by Woodley. Thus, the equation based on the Woodley data is preferred. This equation has also been recommended in the assessment by Harding, Martin, and Potter. ${ }^{4}$

The viscosity of $\mathrm{UO}_{2}$ was also measured by Nelson et al. ${ }^{5}$ at $3028 \mathrm{~K}$ and at $3068 \mathrm{~K}$, which they believed was just above the melting point. Their viscosity values at these temperatures are 46 $\mathrm{cP}$ and $36 \mathrm{cP}$, respectively, which are about a factor of 10 above the viscosity at $3120 \mathrm{~K}$ calculated with Eq. (1). The temperatures and viscosities obtained by Nelson et al. ${ }^{4}$ suggest that these measurements were made below the melting point of $\mathrm{UO}_{2}$. Thus, these data have not been included in this analysis. 


\section{REFERENCES}

1. R. E. Woodley, The Viscosity of Molten Uranium Dioxide, J. Nucl. Mater. 50, 103-106 (1974).

2. R. Palinski, Core Melts - Measurement of Some Thermophysical Properties of Liquid Reactor Materials at High Temperatures, Commission of European Communities Joint Reșearch Centre, Ispra Establishment, Italy Report EUR 7002 EN (1980).

3. H. C. Tsai and D. R. Olander, The Viscosity of Molten Uranium Dioxide, J. Nucl. Mater. 44, 83-86 (1972).

4. J. H. Harding, D. G. Martin, and P. E. Potter, Thermophysical and Thermochemical Properties of Fast Reactor Materials, Commission of the European Communities Report EUR 12402 EN (1989).

5. R. P. Nelson, J. J. Rasmussen, and O. D. Slagle, Properties of Molten Fast-Reactor Oxide Fuels, pp. 2-4 to 2.26 of Battelle-Northwest Laboratory Report BNWL-1279 (February 1970); this study is also briefly described by J. L. Bates, C. E. McNeilly and J. J. Rasmussen, Materials Research 5, 11 (1971). 
Table 8.1 Viscosity of Liquid Uranium Dioxide

\begin{tabular}{|c|c|}
\hline $\begin{array}{c}\text { Temperature } \\
\text { K }\end{array}$ & $\begin{array}{c}\text { Viscosity } \\
\text { mPa s }\end{array}$ \\
\hline 3120 & 4.34 \\
3150 & 4.28 \\
3200 & 4.19 \\
3250 & 4.09 \\
3300 & 4.01 \\
3350 & 3.92 \\
\hline 3400 & 3.84 \\
3450 & 3.77 \\
3500 & 3.70 \\
3550 & 3.63 \\
3600 & 3.57 \\
3650 & 3.50 \\
3700 & 3.44 \\
\hline 3750 & 3.39 \\
3800 & 3.33 \\
3850 & 3.28 \\
3900 & 3.23 \\
3950 & 3.18 \\
4000 & 3.14 \\
\hline
\end{tabular}

Viscosities at temperatures $\geq 3400 \mathrm{~K}$ are extrapolated. 
黑

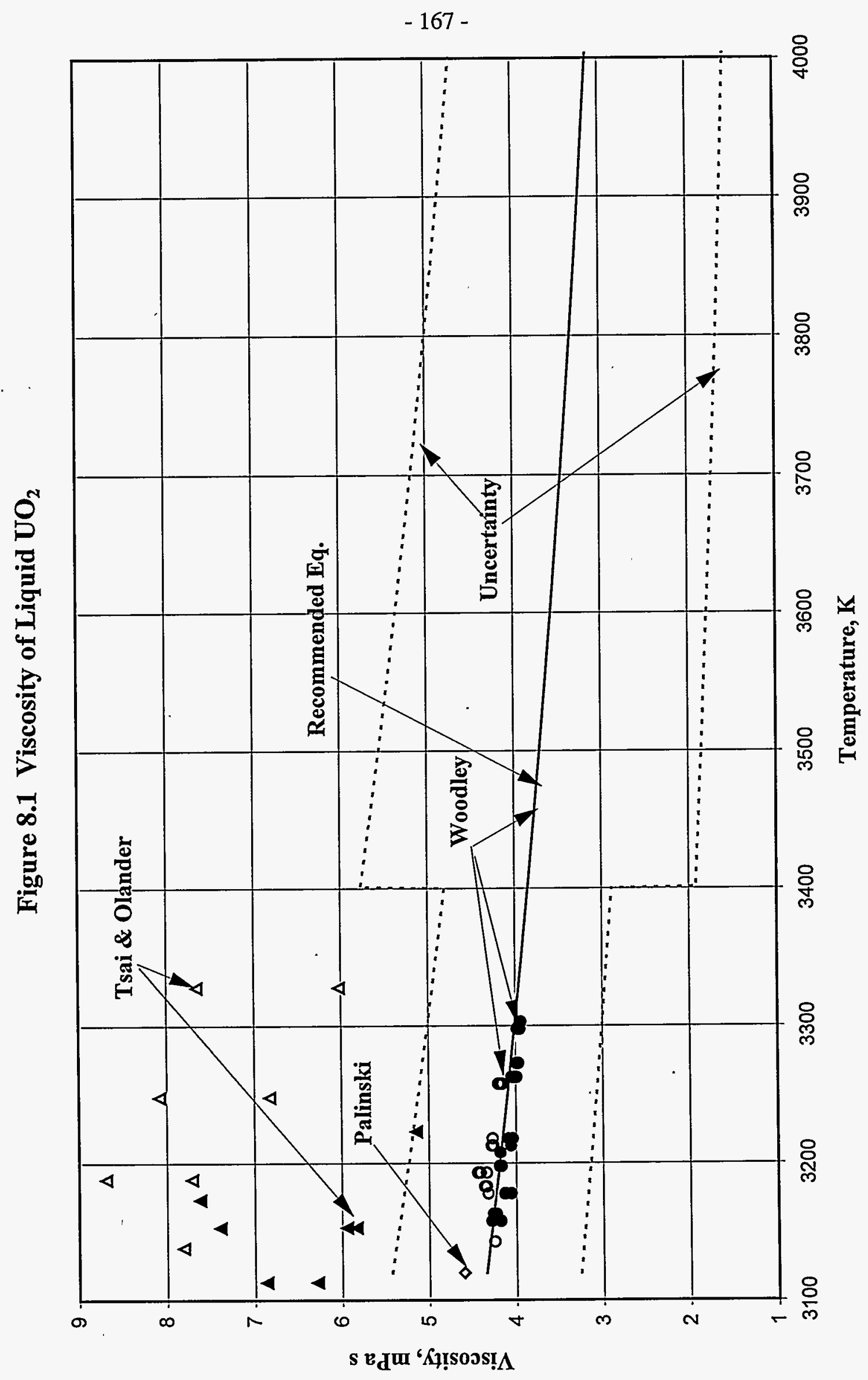

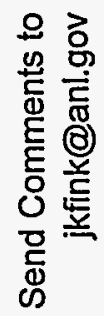




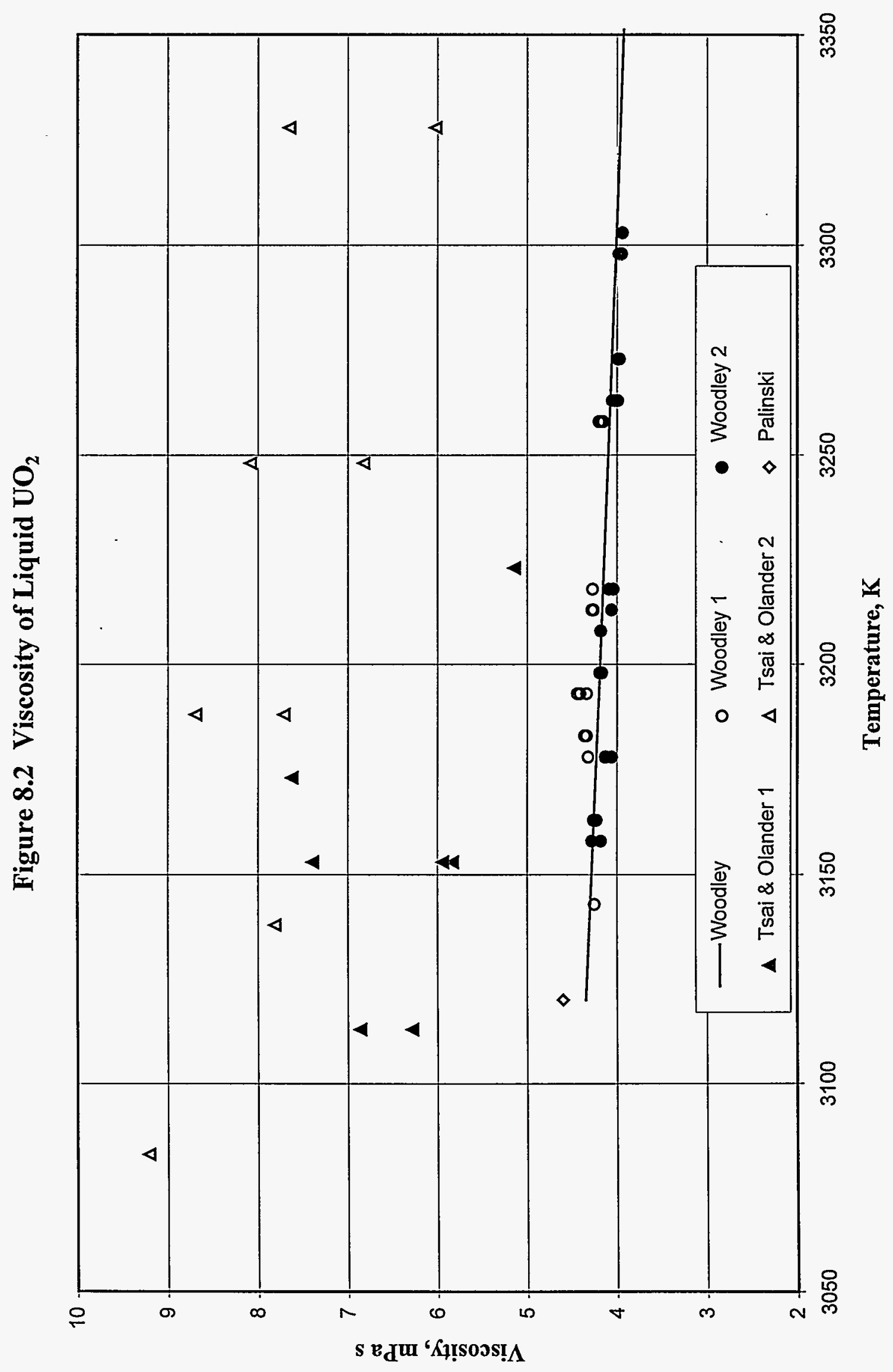

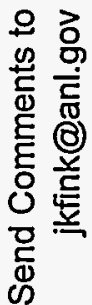

要

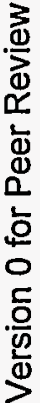




\section{EMISSIVITY AND OPTICAL CONSTANTS OF URANIUM DIOXIDE}

\section{Summary of Recommendations}

Emissivity - The experiments of Bober et al. ${ }^{1-6}$ for the emissivity, reflectivity, and optical constants of $\mathrm{UO}_{2}$ in the solid and liquid phases provide the most reliable data for these properties. Bober, Karow, and Mueller ${ }^{3}$ commented that, within the limits of experimental error, their data for solid $\mathrm{UO}_{2}$ agree with earlier emissivity measurements by Cabannes et al., ${ }^{7}$ Held and Wilder, ${ }^{8}$ and Schoenes. ${ }^{9}$ The data in the range of $1000 \mathrm{~K}$ to the melting temperature $(3120 \mathrm{~K})$ indicate that the emissivity of both sintered and premelted solid $\mathrm{UO}_{2}$ varies little with temperature and is only a weak function of wavelength. Thus, the constant total hemispherical emissivity $\left(\epsilon^{\mathrm{h}}\right)$ that was suggested by Gentry ${ }^{10}$ and also by Harding et $a{ }^{11}{ }^{11}$ is recommended:

$$
\epsilon^{h}=0.85 \pm 0.05
$$

The equation given by Bober, Karow, and Muller ${ }^{3}$ for the normal spectral emissivity of premelted solid $\mathrm{UO}_{2}$ at the wavelength of $630 \mathrm{~nm}$ is recommended for wavelengths in the visible range:

For $1000 \mathrm{~K} \leq T \leq 3120 \mathrm{~K}$ and $400 \mathrm{~nm} \leq \lambda \leq 700 \mathrm{~nm}$,

$$
\epsilon(\lambda=630 \mathrm{~nm})=0.836+4.321 \times 10^{-6}(T-3120)
$$

where $T$ is in $\mathrm{K}$. Values from this equation are given in Table 9.1 and shown in Figure 9.1.

The emissivity of liquid $\mathrm{UO}_{2}$ is a function of both wavelength and temperature. For wavelengths in the visible range, however, the normal spectral emissivity of liquid $\mathrm{UO}_{2}$ is approximately independent of wavelength. The recommended values as a function of temperature for this wavelength range are those calculated from an equation for a wavelength of $630 \mathrm{~nm}$ determined by Fink et al. ${ }^{12}$ :

For $3120 \mathrm{~K} \leq T \leq 6000 \mathrm{~K}$ and $400 \mathrm{~nm} \leq \lambda \leq 700 \mathrm{~nm}$,

$$
\epsilon(\lambda=630 \mathrm{~nm})=1-0.16096 \exp \left[-3.7897 \times 10^{-4} \Delta T-3.2718 \times 10^{-7}(\Delta T)^{2}\right]
$$

where $\Delta T=T-3120 \mathrm{~K}$. Normal spectral emissivities calculated with this equation are tabulated in Table 9.2 and are included in Figure 9.1. Although Eq. (3) was derived to fit the data of Bober, Karow, and Muller 3 at a wavelength of $630 \mathrm{~nm}$, it also gives a good fit to more recent data ${ }^{1,2}$ at 
wavelengths of $548,514.5,647$, and $752.5 \mathrm{~nm}$. However, the behavior of the emissivity in the infrared region differs considerably from Eq. (3). Bober et al. ${ }^{3,6}$ found that the normal spectral emissivity at a wavelength of $10600 \mathrm{~nm}$ falls from 0.85 at $3120 \mathrm{~K}$ to 0.64 at $3670 \mathrm{~K}$ and to 0.4 at $4000 \mathrm{~K}$. Further emissivity measurements of liquid $\mathrm{UO}_{2}$ are needed in the infrared and far infrared region to confirm these results.

Optical Constants - Provisional recommendations are available from measurements by Bober, Singer, and Wagner. ${ }^{1,2}$ They determined the optical constants for liquid $\mathrm{UO}_{2}$ from 3100 to $3600 \mathrm{~K}$ and for single-crystal $\mathrm{UO}_{2}$ at room temperature from reflectivity measurements in the spectral range of 450 to $750 \mathrm{~nm}$. Their room temperature index of refraction values confirm the values of Ackermann et al. ${ }^{13}$ The average values for the index of refraction (n) and absorption coefficient (k) of $\mathrm{UO}_{2}$ at room temperature and in the liquid region are

For $\mathrm{T}=300 \mathrm{~K}$,

$$
\mathrm{n}=2.2 ; \mathrm{k}=0.7
$$

For $3100<\mathrm{T} \leq 3600 \mathrm{~K}$,

$$
\mathrm{n}=1.7 ; \mathrm{k}=0.8
$$

\section{$\underline{\text { Uncertainties }}$}

The uncertainty in the total hemispherical emissivity is $\pm 0.05 .^{10,11}$ Experimental uncertainties given by Karow and Bober ${ }^{6}$ for the normal spectral emissivity of premelted solid $\mathrm{UO}_{2}$ at the wavelength of $630 \mathrm{~nm}$ increase from $\sim 1 \%$ at $1500 \mathrm{~K}$ to $2 \%$ at $3000 \mathrm{~K}$. In the liquid region, their uncertainties are 2.5 to $3 \%$. Uncertainties of $+3 \% /-10 \%$ are suggested ${ }^{12}$ for extrapolation of Eq. (2) above $4200 \mathrm{~K}$. Large scatter in the reflectivity data from which the optical constants are derived lead to uncertainties in the refractive index (n) of $\pm 10 \%$ and in the absorption constant $(\mathrm{k})$ of $\pm 20 \%$.

Discussion

Emissivity of Solid $\mathrm{UO}_{2}$ - Data of Bober et al. ${ }^{1-6}$ provide normal spectral emissivities of solid and molten $\mathrm{UO}_{2}$ from 1000 to $4200 \mathrm{~K}$ and optical constants of molten $\mathrm{UO}_{2}$ from 3000 to $4000 \mathrm{~K}$. These are the most recent and reliable data and cover the largest temperature range. The normal spectral emissivities at a wavelength of $630 \mathrm{~nm}$ determined by Bober et al. ${ }^{3,6}$ are in reasonable jkfink@anl.gov 
agreement with normal spectral emissivities of Cabannes et al. ${ }^{7}$ at a wavelength of $650 \mathrm{~nm}$, and of Held and Wilder ${ }^{8}$ at wavelengths of 656 and $700 \mathrm{~nm}$ but disagree with earlier data of Claudson ${ }^{14,15}$ and of Ehlert and Margrave, ${ }^{15,16}$ as shown in Figure 9.1. The data of Claudson, ${ }^{14,15}$ which show a decrease in the emissivity in the temperature range of 1000 to $2000 \mathrm{~K}$, have been rejected in reviews by Fink et al., ${ }^{12}$ Gentry, ${ }^{10,11}$ and Harding et al. ${ }^{11}$ Cabannes et al. ${ }^{7}$ have suggested that the decrease with temperature observed by Claudson ${ }^{14,15}$ was due to errors in the experimental technique. Unlike the data of Held and Wilder, ${ }^{8}$ which decrease with temperature above $2000 \mathrm{~K}$, the data of Bober et al. ${ }^{3,}$ ${ }^{6}$ show little temperature dependence and no decrease with temperature above $2000 \mathrm{~K}$.

Bober, Karow, and $\mathrm{Muller}^{3}$ found that the normal spectral emissivity of sintered $\mathrm{UO}_{2}$ at a wavelength of $630 \mathrm{~nm}$ is slightly higher than that for premelted $\mathrm{UO}_{2}$. From 1000 to $3120 \mathrm{~K}$, they obtained an emissivity of 0.87 for sintered $\mathrm{UO}_{2}$ and recommended Eq. (1) to represent the emissivity of premelted $\mathrm{UO}_{2}$. Their data are supported by the measurements of Babelot et al., ${ }^{17}$ who obtained an emissivity of 0.84 at a wavelength of $650 \mathrm{~nm}$ at the melting point, $3120 \mathrm{~K}$.

Cabannes et al. ${ }^{7}$ determined emissivities at 300,1200 , and $1600 \mathrm{~K}$ for wavelengths ranging from $500 \mathrm{~nm}$ to the infrared region $(10000 \mathrm{~nm})$. They found little variation in emissivity with wavelength or temperature. From these data, they obtained total emissivities of $0.86,0.90$, and 0.90 at 300,1200 and $1600 \mathrm{~K}$, respectively. These total emissivities are consistent with the recommendation of Gentry ${ }^{10,11}$ for a total emissivity of $0.85 \pm 0.05$. The temperature-dependent total emissivity for solid $\mathrm{UO}_{2}$ determined by Mason ${ }^{18}$ is given in MATPRO: ${ }^{19}$

$$
\epsilon=0.7856+1.5263 \times 10^{-5} \mathrm{~T}
$$

Total emissivities calculated with Eq. (6) increase from 0.79 at $300 \mathrm{~K}$ to 0.80 at $1000 \mathrm{~K}$ and 0.83 at $3120 \mathrm{~K}$. These emissivities are consistently lower than the value given by Gentry. ${ }^{10,11}$ However, above $700 \mathrm{~K}$, they are within the uncertainty for the total emissivity recommended by Gentry.

Emissivity of Liquid $\mathrm{UO}_{2}$ - Bober, Karow, and $\mathrm{Muller}^{3}$ fit their data for the normal spectral emissivity of liquid $\mathrm{UO}_{2}$ at a wavelength of $630 \mathrm{~nm}$ to a quartic equation:

$$
\begin{aligned}
\epsilon(\lambda=630 \mathrm{~nm})= & 0.843+1.4465 \times 10^{-4} \Delta T+1.6497 \times 10^{-7} \Delta T^{2} \\
& -1.3136 \times 10^{-10} \Delta T^{3}+2.899 \times 10^{-14} \Delta T^{4}
\end{aligned}
$$


where $\Delta T=T-3120 \mathrm{~K}$, and $T$ is in $\mathrm{K}$. Although Eq. (7) represents the experimental data of Bober, Karow, and Muller, ${ }^{3}$ this equation should not be used to extrapolate beyond $4200 \mathrm{~K}$ because it goes through an inflection point at $4831 \mathrm{~K}$ followed by an increasing slope that results in values greater than unity for temperatures above $5668 \mathrm{~K}$. Consequently, Fink et al. ${ }^{12}$ fit the data of Bober, Karow, and Muller $^{3}$ to an equation with a functional form appropriate for extrapolation beyond the range of experimental data without introducing unphysical behavior. That equation is the recommended equation, Eq. (3). In the temperature range of experimental data, Eq. (3) reproduces the values given by Eq. (7) to within $0.14 \%$. Equation (3) also provides a good fit to liquid emissivity data for other wavelengths in the visible range $(\lambda=459,514.5,647$, and $752.5 \mathrm{~nm})$.

The normal spectral emissivity of liquid $\mathrm{UO}_{2}$ at wavelengths in the far infrared range shows an entirely different temperature behavior from that at wavelengths in the visible range. Data of Karow and Bober ${ }^{3,6}$ show that for $\lambda=10600 \mathrm{~nm}$ the normal spectral emissivity of liquid $\mathrm{UO}_{2}$ falls from 0.85 at $3120 \mathrm{~K}$ to 0.64 at $3670 \mathrm{~K}$ and to 0.4 at $4000 \mathrm{~K}$. Further data are required at wavelengths in the infrared region to confirm these results and determine total emissivities for the liquid.

Optical Constants - Optical constants of single-crystal $\mathrm{UO}_{2}$ were determined at $300 \mathrm{~K}$ by Bober et al. ${ }^{1,2,4}$ for comparison with values obtained by Ackermann et al. ${ }^{13}$ Ackermann et al. determined the index of refraction at room temperature in the ultraviolet region (at the wavelength of $260 \mathrm{~nm}$ ) and in the visible range (at wavelengths from 450 to $800 \mathrm{~nm}$ ). Figure 9.2 shows refraction indexes obtained from these measurements at wavelengths in the visible range. Room temperature values obtained from measurements by Ackermann et al. are consistently higher than those given by Bober et al. but these data are usually within the estimated $10 \%$ experimental uncertainty. The average of the values for the room temperature index of refraction from the data of Bober et al. ${ }^{1}$ is 2.24. The average index of refraction from the values of Ackermann et al. ${ }^{13}$ is 2.45. These averages are within the $10 \%$ uncertainty given by Bober et al. ${ }^{1,2}$ They are both higher than the room temperature index of refraction at a wavelength of $260 \mathrm{~nm}$ given by Ackermann et al. (1.95). Figure 9.2 shows that they are also consistently higher than values for liquid $\mathrm{UO}_{2}$ at wavelengths in the visible spectrum. Absorption coefficients for $\mathrm{UO}_{2}$ at room temperature, determined by Bober et al., decreased from 0.84 at a wavelngth of $458 \mathrm{~nm}$ to 0.60 at a wavelength 
of $752.5 \mathrm{~nm}$ with an average value of 0.7 .

Bober, Singer, and Wagner, ${ }^{1}$ determined the optical constants for liquid $\mathrm{UO}_{2}$ from reflectivity measurements with polarized light in the temperature range of 3000 to $4000 \mathrm{~K}$ at four visible wavelengths $(458,514.5,647$, and $752.5 \mathrm{~nm})$ and at three angles of incidence $\left(45^{\circ}, 58^{\circ}\right.$, and $\left.71^{\circ}\right)$. Reflectivities measured as a function of temperature and wavelength showed considerable scatter with angle of incidence. Optical constants were calculated from the reflectivities at each temperature and wavelength for each of the three possible pairs of measurement angles $\left(45^{\circ}\right.$ and $58^{\circ}$, $45^{\circ}$ and $71^{\circ}, 58^{\circ}$ and $71^{\circ}$ ). Then these three sets of values were averaged to obtain optical constants for each wavelength and temperature. Figures 9.3 and 9.4 show, respectively, the average refractive index and average absorption coefficient for liquid $\mathrm{UO}_{2}$ for four visible wavelengths as a function of temperature. Both optical constants decrease with increasing temperature. Based on these data, Bober et al. ${ }^{1,2}$ proposed average values for the refractive index and absorption coefficient for wavelengths in the visible range and temperatures from 3100 to $3600 \mathrm{~K}$. Their average values are $\mathrm{n}=1.7$ and $\mathrm{k}=0.8$.

From the scatter in their reflectance data, Bober et al. ${ }^{1.2}$ estimated the uncertainty in the refractive index, $\mathrm{n}$, as $\pm 10 \%$ and the uncertainty in the absorption coefficient, $\mathrm{k}$, as $\pm 20 \%$. Bober et al. ' commented that the accuracy of the absorption coefficient, $\mathrm{k}$, is influenced more by measurement errors than that of the refractive index, $n$. The equations used to calculate the optical constants are based on the assumption of an ideal optically smooth surface, which is difficult to attain. Scatter in the experimental data was attributed to imperfections of the reflecting surface, variations in the angle of incidence arising from oscillations of the liquid surface, and the formation of a meniscus. With increased temperature, surface disturbances from vaporization and gas bursts added to the difficulty of the measurements. The increased difficulty is apparent in the decreased consistency in the reflectance data above $3500 \mathrm{~K}$. 


\section{REFERENCES}

1. M. Bober, J. Singer, and K. Wagner, Determination of the Optical Constants of Liquid UO from Reflectivity Measurements, Proc. Eighth Symp. on Thermophysical Properties, Gaithersburg, MD, 1981, Vol II, pp. 234-244, ASME (1982).

2. M. Bober, J. Singer, and K. Wagner, Bestimmung der Optischen Konstanten von Geschmolzenen Kernbrennstoffen, J Nucl. Mater. 124, 120-128 (1984).

3. M. Bober, H. U. Karow, and K. Muller, Study of the Spectral Reflectivity and Emisssivity of Liquid Ceramics, High Temp. - High Pressures 12, 161-168 (1980).

4. M. Bober, Spectral Reflectivity and Emissivity of Solid and Liquid $\mathrm{UO}_{2}$ as a Function of Wavelength, Angle of Incidence, and Polarization, High Temp. - High Pressures 12, 297-306 (1980).

5. M. Bober and H. U. Karow, Measurements of Spectral Emissivity of $\mathrm{UO}_{2}$ Above the Melting Point, Proc. Seventh Symp. on Thermophysical Properties, Gaithersburg, MD, 1977, pp. 344-350, ASME (1978).

6. H. U. Karow, and M. Bober, Experimental Investigations into the Spectral Relectivities and Emissivities of Liquid $\mathrm{UO}_{2}, \mathrm{UC}, \mathrm{ThO}_{2}$, and $\mathrm{Nd}_{2} \mathrm{O}_{3}$, Thermodynamics of Nuclear Materials 1979 Vol I, Proc. Symp. Julich, 1979, pp. 155-169, IAEA (1980).

7. F. Cabannes, J. P. Stora, and J. Tsakiris, Facteurs de Reflexion et d'Emission de $\mathrm{UO}_{2}$ a Haute Temperature, C. R. Acad. Sc. Paris, 264B, 45-48 (1967).

8. P. C. Held and D. R. Wilder, High-Temperature Hemispherical Spectral Emittance of Uranium Oxides at 0.65 and $0.70 \mu \mathrm{m}$, J. Am. Ceramic Society 52, 152-185 (1969).

9. J. Schoenes, Optical Properties and Electronic Structure of $\mathrm{UO}_{2}$, J. Appl. Phys. 49 14631465 (1978).

10. P. J. Gentry, Report ND-P-6887 (W) (1981), as referenced by J. H. Harding, D. G. Martin, and P. E. Potter, Thermophysical and Thermochemical Properties of Fast Reactor Materials, Commission of the European Communities Report EUR 12402 EN (1989).

11. J. H. Harding, D. G. Martin, and P. E. Potter, Thermophysical and Thermochemical Properties of Fast Reactor Materials, Commission of the European Communities Report EUR 12402 EN (1989).

12. J. K. Fink, M. G. Chasanov, and L. Leibowitz, Transport Properties of Uranium Dioxide, ANL-CEN-RSD-80-4, Argonne National Laboratory (April 1981). 
13. R. J. Ackermann, R. J. Thorn, and G. H. Winslow, Visible and Ultraviolet Absorption Properties of Uranium Dioxide Films, J. Opt. Soc. Am. 49, 1107 (1959).

14. T. T. Claudson, Emissivity Data for Uranium Dioxide, Report AW-55414 (Nov. 1958), as referenced in Uranium Dioxide Properties and Nuclear Applications, J. Belle, Ed.,. pp. 196197, US AEC (1961)

15. J. Belle, Ed., Uranium Dioxide Properties and Nuclear Applications, pp. 196-197, US AEC (1961)

16. T. C. Ehlert and J. L. Margrave, Melting Point and Spectral Emissivity of Uranium Dioxide, J. Am. Ceram. Soc. 41, 330 (1958), as referenced in Uranium Dioxide Properties and Nuclear Applications, J. Belle, Ed., pp. 196-197, USAEC (1961).

17. J. F. Babelot, G. D. Brunne, P. R. Kinsman, and R. W. Ohse, Atomwirt-Atomtech 22, (No. 7-8), 387 (1977).

18. R. E. Mason, Fuel Emissivity, CDAP-TR-78-039, Idaho Engineering Laboratory (1978).

19. J. K. Hohorst, Ed., SCADAP/RELAP5/MOD2 Code Manual, Vol. 4: MATPRO- a Library of Materials Properties for Light-Water-Reactor Accident Analysis, NUREG/CR-5273 (1990). 
Table 9.1 Normal Spectral Emissivity of Premelted $\mathrm{UO}_{2}$ at $\lambda=630 \mathrm{~nm}$

\begin{tabular}{|c|c|}
\hline Temperature, $\mathbf{K}$ & Emissivity $(\lambda=\mathbf{6 3 0} \mathbf{~ n m})$ \\
\hline 300 & 0.82 \\
\hline 500 & 0.82 \\
\hline 1000 & 0.83 \\
\hline 1500 & 0.83 \\
\hline 2000 & 0.83 \\
\hline 2500 & 0.83 \\
\hline 3000 & 0.84 \\
\hline $3120(\mathrm{~s})$ & 0.84 \\
\hline
\end{tabular}

Table 9.2 Normal Spectral Emissivity of Liquid $\mathrm{UO}_{2}$ at $\lambda=630 \mathrm{~nm}$

\begin{tabular}{|c|c|}
\hline Temperature, K & Emissivity $(\lambda=630 \mathbf{n m})$ \\
\hline 3120 & 0.84 \\
\hline 3500 & 0.87 \\
\hline 4000 & 0.91 \\
\hline 4500 & $(0.95)^{*}$ \\
\hline 5000 & $(0.98)^{*}$ \\
\hline 5500 & $(0.99)^{*}$ \\
\hline 6000 & $(0.99)^{*}$ \\
\hline
\end{tabular}

* Extrapolated beyond the range of experimental data 
Figure 9.1 $\mathrm{UO}_{2}$ Emissivity

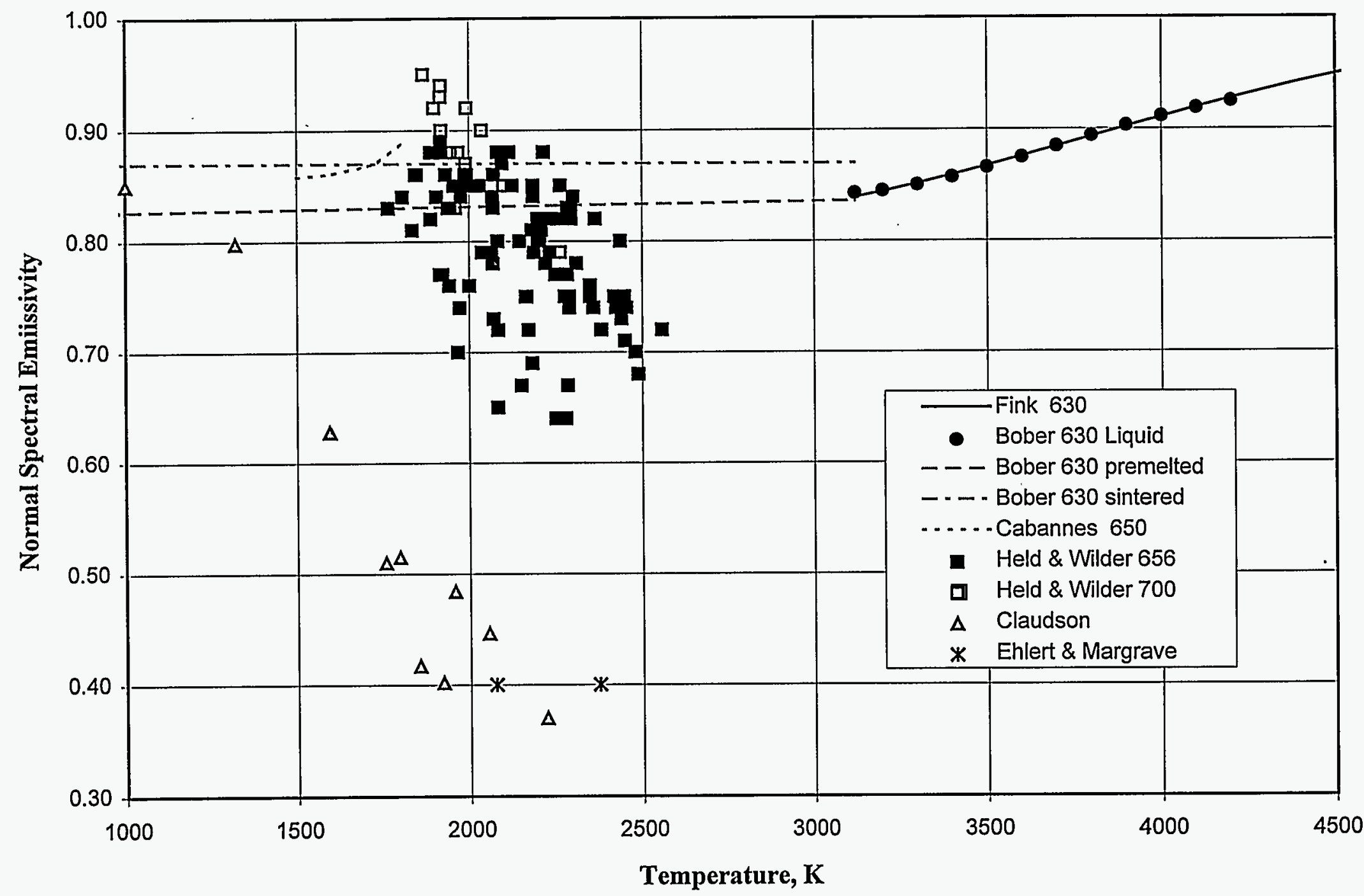



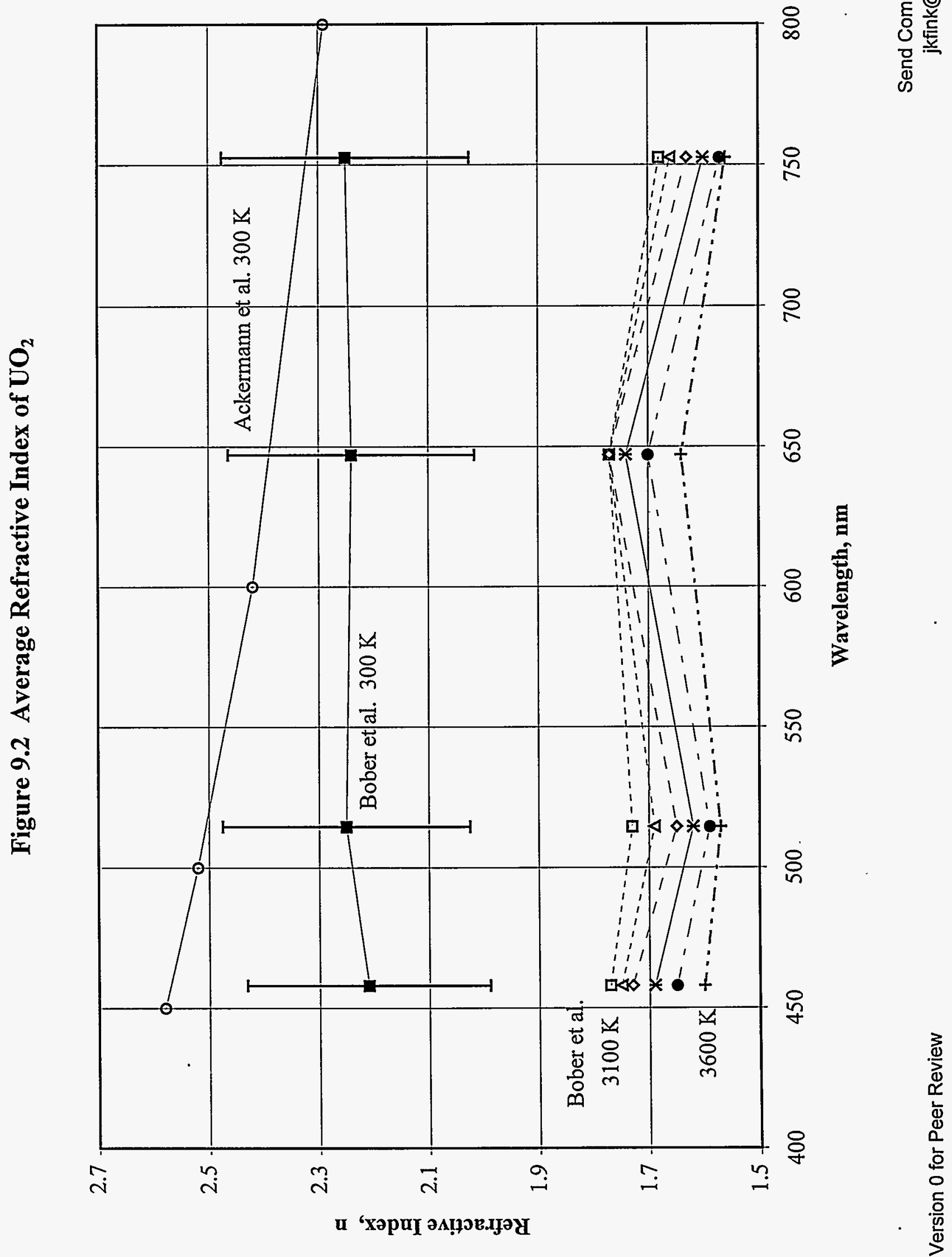


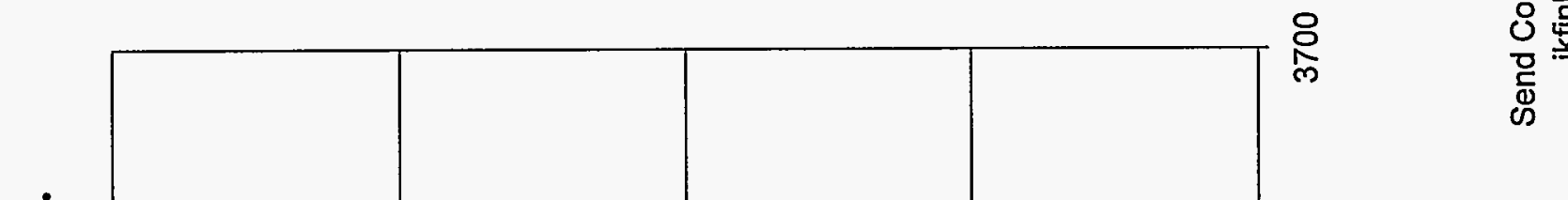

8

율

옹

声

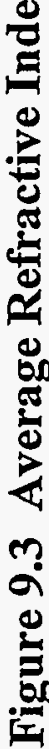

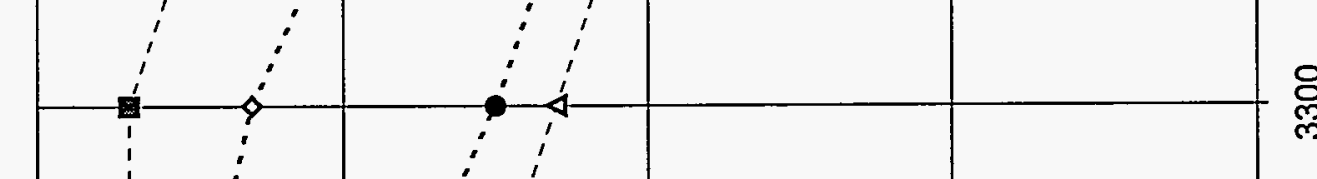

ल 


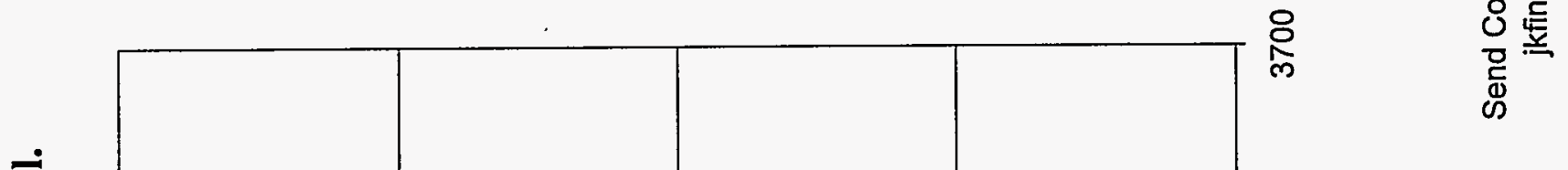

용

을

लำ

융

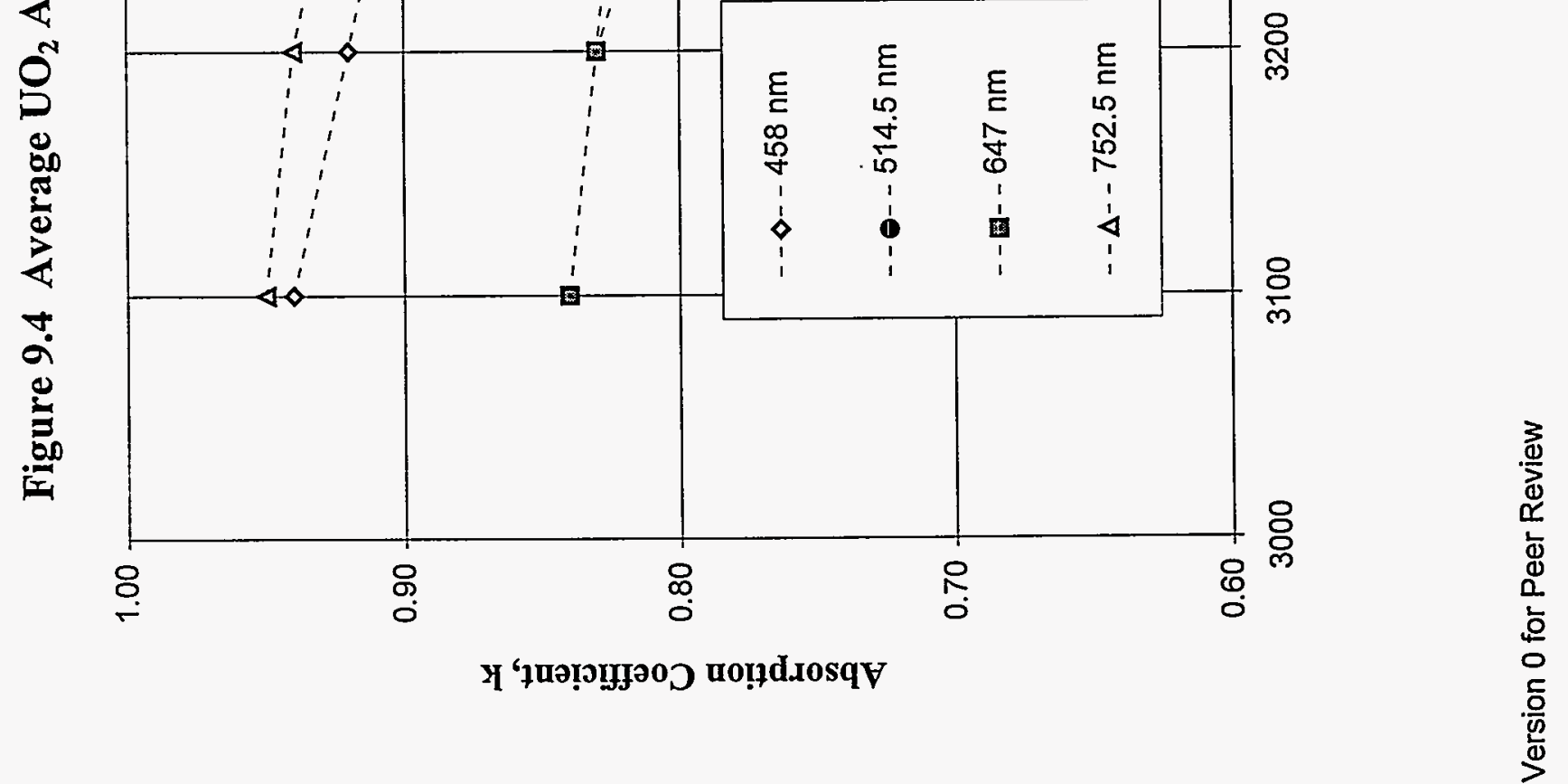




\section{ACKNOWLEDGMENTS}

The technical critique of the new heat capacity and thermal conductivity measurements on liquid $\mathrm{UO}_{2}$ by Theodore $\mathrm{H}$. Bauer provided insights for the assessment of the data from these experiments. His helpful comments on the experiment methodology, data assessments, and the combined fit of the liquid $\mathrm{UO}_{2}$ enthalpy and heat capacity data are greatly appreciated. Tanju Sofu and Hubert Ley have put information contained in this report in the International Nuclear Safety Center on the World Wide Web for world access. Their technical expertise enabled the equations, text, and graphs to be available in the same form in the database and report with no retyping. Throughout this program, John M. Kramer has provided assistance and support. Report preparation was performed by Elsie Brown. These efforts are gratefully acknowledged. 